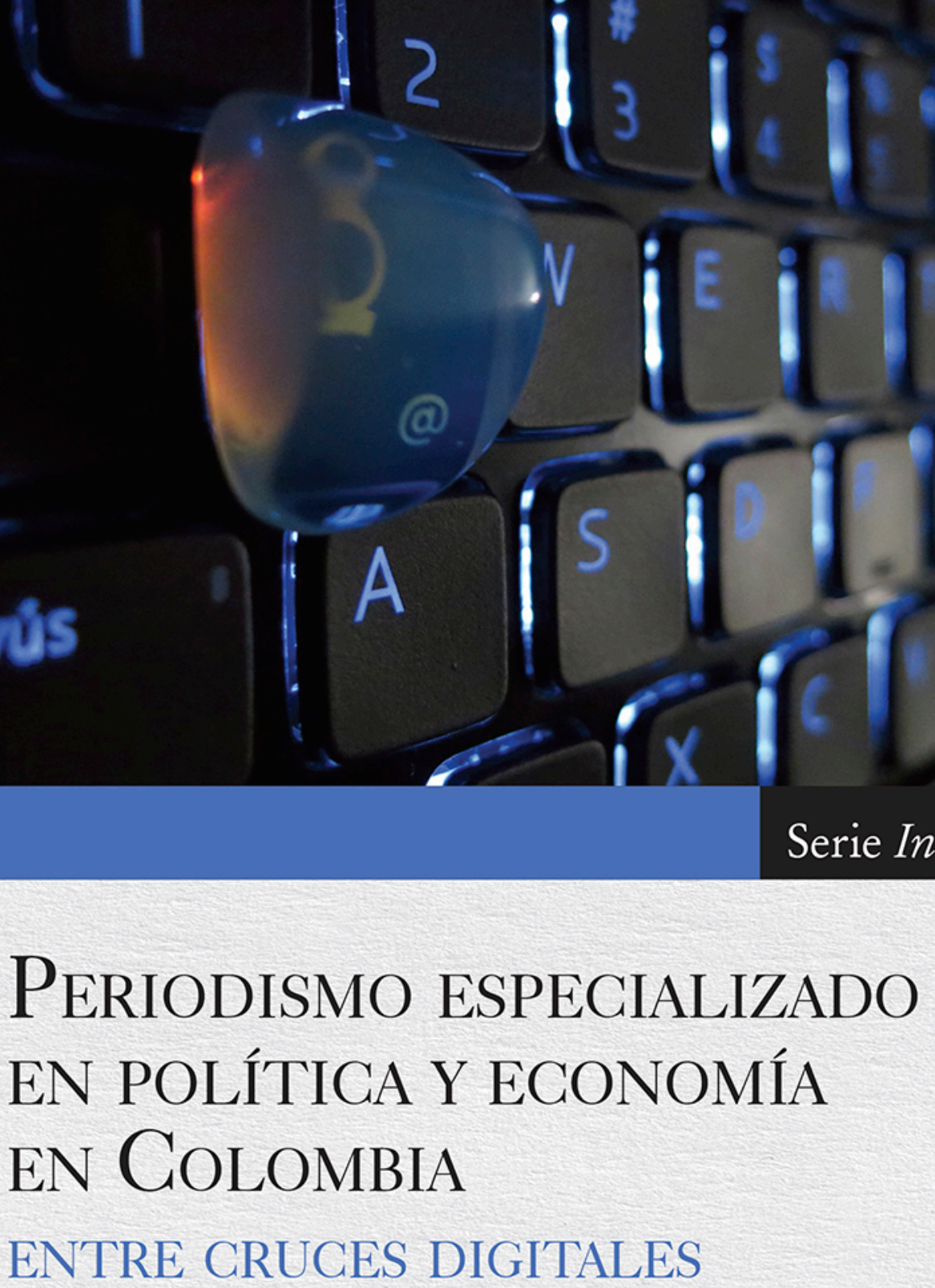

César Augusto Rodríguez Charry Investigador principal

Jorge A. Salazar Manrique Co-investigador 


\section{PERIODISMO ESPECIALIZADO EN POLÍTICA Y ECONOMÍA EN COLOMBIA ENTRE CRUCES DIGITALES}

CÉSAR AUGUSTO RODRÍGUEZ CHARRY Investigador principal

JORGE A. SALAZAR MANRIQUE

Co-investigador

进 UNIVERSIDAD

Bogotá. Colombia 2016 
Rodríguez Charry, César Augusto

Periodismo especializado en política y economía en Colombia entre cruces digitales / César Augusto Rodríguez Charry, Jorge A. Salazar Manrique - Bogotá: Universidad Sergio Arboleda, 2016.

$212 \mathrm{p}$.

ISBN: 978-958-59490-8-9

1. PERIODISMO POLÍTICO - INNOVAGIONES TEGNOLÓGICAS - COLOMBIA 2. PERIODISMO EGONÓMICO - INNOVACIONES TEGNOLOGICAS - COLOMBIA I. Salazar Manrique, Jorge A.

070.449 ed. 21

\section{PERIODISMO ESPECIALIZADO EN POLÍTICA Y ECONOMÍA EN COLOMBIA ENTRE CRUCES DIGITALES}

ISBN: 978-958-59490-8-9 Digital

(C) César Augusto Rodríguez Charry. Investigador principal

(C) Jorge A. Salazar Manrique. Co-investigador

Edición: febrero de 2016

Prohibida la reproducción o cita impresa o electrónica total o parcial de esta obra, sin autorización expresa y por escrito de la Universidad Sergio Arboleda. Las opiniones expresadas en esta obra son responsabilidad de los autores.

Calle 74 No. 14-14

Teléfono: (571) 3257500 ext. 2131/2260

www.usergioarboleda.edu.co

Bogotá, D.C.

Directora de Publicaciones Científicas:

Yadira Caballero Quintero

yadira.caballero@usa.edu.co

Edición realizada por:

Yadira Caballero Quintero

Carlos Andrés Caho Rodríguez

Director del Fondo de Publicaciones:

Jaime Arturo Barahona Caicedo

jaime.barahona@usa.edu.co

Diseño carátula y diagramación: Maruja Esther Flórez Jiménez

Impresión: Digiprint

Bogotá, D.C. 


\title{
AGRADEGIMIENTOS
}

\author{
Existirá un momento, no lejos, cuando un nativo digital \\ se sorprenda al saber que el medio que lee en la red, \\ tiene o tuvo su contraparte en un impreso.
}

as reflexiones que acá se presentan son el resul-
dado de poco más de un año de labor en diversos escenarios, principalmente medios de comunicación de diferentes partes de la geografía colombiana. En cada uno de estos espacios y medios, nos encontramos siempre con la más correcta y cordial actitud, sin excepción, de todos los periodistas - algunos de ellos no periodistas- que conformaron la muestra de la investigación; lo que da cuenta de su calidez y valor humano en tanto que profesionales de la comunicación. El habernos dejado entrar a sus sitios de trabajo y observar de primera mano cómo lo hacían fue de gran valor para la investigación, así como la disposición en el momento de romper sus apretadas agendas, con largas entrevistas y charlas informales. Así mismo este acercamiento no hubiera sido posible sin el aval de las directivas de estos medios.

Todos los periodistas, casi 50, y sus respectivos medios de comunicación se referencian al final de esta publicación. Este estudio también se benefició de la estudiante de Licenciatura en Ciencias Sociales de la Universidad Distrital Francisco José de Caldas, Nohora Lorena Vásquez Coronado, quien fungió como asistente y proveyó puntos de inflexión y reflexión sobre el estado del periodismo en Colombia.

No podemos dejar de mencionar a la Dirección de Investigación e Innovación de la Universidad Sergio 
Arboleda, por su cooperación en temas de la logística necesaria para eldesarrollo de la investigación, así como a la dirección de Posgrado en Comunicación de la misma universidad, en cabeza del Doctor en Comunicación Jorge Arturo Salazar Manrique quien se desempeñó también como coinvestigador. El texto que acá se propone está elaborado con las voces de los periodistas y las constantes reflexiones y descubrimientos en contraste con la teoría.

César Augusto Rodríguez Charry Bogotá, 2014 


\section{PRESENTACIÓN}

T a práctica profesional del Periodismo ha ido desa-

Urrollando nuevos campos de actuación.

La irrupción social de las Tecnologías de la Información y Comunicación (TICs) demanda igualmente un ejercicio informativo exigente, en tanto sugiere un lenguaje más preciso, y porque no, de mayor asertividad.

Las prácticas cualificadas del Periodismo en las diferentes actuaciones profesionales cada vez son más apetecidas, y por eso las conexiones entre antecedentes y secuencias de los hechos, así como los protagonistas, proponen un trabajo exigente de búsqueda de la información.

Los temas de la política y la economía anidan buena parte de la agenda pública y son centrales cuando se quiere indagar sobre la actualidad nacional e internacional, una necesaria forma de entender el papel referencial de los medios y su incidencia en el conocimiento de los perceptores de la Comunicación.

Esa presencia de contenidos mediados por las tecnologías y los intereses de quienes las operan, no deja de ser una forma provocativa de abordar el análisis de los contenidos que atraviesan la actualidad mediada.

El trabajo que ahora se publica, resultado de un rastreo de investigación sobre el Periodismo especializado en $P_{0}$ lítica y Economía en Colombia entre cruces digitales proyecta una observación sobre las prácticas profesionales y cómo éstas inciden en el quehacer profesional.

Un Periodismo con capacidad de ser más incisivo y por eso apropiado a los requerimientos de la sociedad en 
razón de informaciones con monto documental que permitan la comprensión del fenómeno y su contexto, ya representan un cambio y a la vez un desafío para las próximas generaciones de comunicadores periodistas.

Esta apuesta por un Periodismo especializado de mayor factura a partir de la práctica experimental de los medios en línea y las narrativas convergentes no deja de ser igualmente un desafío al momento de conocer las verdaderas condiciones profesionales con las cuales se desarrolla la actividad en nuestro país.

Y esa fue precisamente la premisa sobre la cual se planteó ésta investigación que a más de indagar sobre las rutinas y los usos de las tecnologías, hizo énfasis en los contenidos y los abordajes específicos de los temas políticos y económicos.

El quehacer periodístico no deja de ser una de las profesiones en las cuales la sociedad pone sus ojos, y por eso la dinámica política y las implicaciones económicas de las decisiones de Estado y éstas en la política hacen parte de los cambios entre las fuerzas del poder local, nacional e internacional, y ahí el Periodismo como escribano del acontecer juega papel trascendental.

Pero además los sucesos relatados para lenguajes multimedia en el entorno digital, igualmente plantean nuevas experiencias de la pericia periodística. La estructura de la información, las consulta a las fuentes y el papel de estas en la información plantea una estructura de contenido (titulación-desarrollo-cierre) diferente.

Este trabajo de investigación que se presenta hace un recorrido descriptivo por algunos de los temas resultado de la indagación sistemática y visita de reconocimiento a los espacios donde laboran los periodistas teniendo como telón el nuevo mundo de las tecnologías y los retos profesionales que le corresponden a los periodistas de cara a la interactividad; también se hace un análisis sobre el trabajo del profesional especializado en espacios de convergencia y divergencia a la vez; incluye una mirada a los retos que plantea la cultura digital y los roles que le corresponde atender al periodista en ese ambiente de intercambio cultural, y por último con base en los testimonios de un centenar de periodistas en el país y en la observación de los consejos de redacción se hace una análisis de las rutinas y pericias que hacen parte del nuevo rol de los periodistas en los ambientes digitales. 
Un trabajo de referencia útil para comprender las dinámicas, el estado y las perspectivas del trabajo periodístico en medio de las opciones que conlleva el uso y destinación de los contenidos periodísticos especializados a las audiencias mediante el uso de los lenguajes digitales en sus diferentes formatos.

Pero también una postura documentada de la Especialización en Periodismo Político y Económico de la Universidad Sergio Arboleda frente a los desafíos actuales de la interactividad que provocada el uso social de las tecnologías con responsabilidad frente a las audiencias teniendo como interés identificar esos desafíos en los nuevos roles del Periodismo.

Jorge A. Salazar Manrique, Ph.D.

Director

Especialización en Periodismo Político y Económico

Universidad Sergio Arboleda 



\section{GONTENIDO}

INTRODUGGIÓN

Sobre el periodismo especializado ……………………………………….......19

Periodismo y el factor tecnológico ....................................................................21

La interactividad como parte del factor tecnológico ........................................2. 25

Incertidumbres de los entrecruces entre periodismo y tecnología .................28

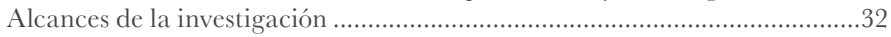

¿Qué entendemos por entornos digitales? ......................................................37

\section{Capítulo 1}

\section{GONVERGENGIAS Y DIVERGENGIAS DE LOS PERIODISTAS}

POLÍTICOS Y ECONÓMICOS.

Eje digital: tejiendo lo digital con práctica periodística .

Política y economía vs. Deportes. ¿Qué importa más?; una fábrica de arepas,

entre la viralidad y la banalidad.

La pequeña fracción del periodismo político y económico....................... 40

Percepción de la ubicación del periodismo político en las regiones........ 44

Especificidad de la ubicación del periodismo económico en la red....... 46

Influencia del periodismo especializado en política y economía sobre la

opinión pública en los entornos digitales.

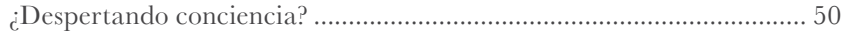

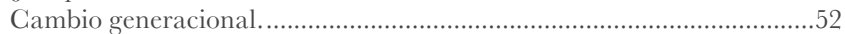

Efectos de los entornos digitales sobre los productos periodísticos..................53

La interactividad llega a los consejos de redacción. ................................ 56

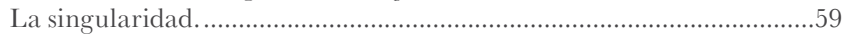

¿Cambios en la redacción de las notas? .................................................... 60

Desniveles en las convergencias. ................................................................61

Los canales de interacción que prefiere la audiencia: de la carta al correo

electrónico, del correo al tuit y del teléfono fijo al museo.......................................63

Efectos de los entornos digitales en las relaciones jerárquicas. Los de la web piden

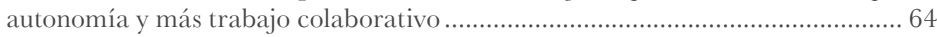

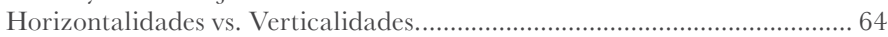

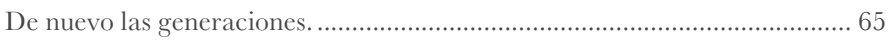

¿Qué hay sobre las relaciones con las fuentes?................................................67

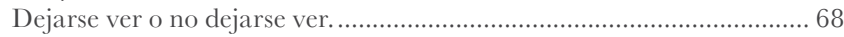

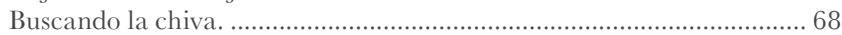

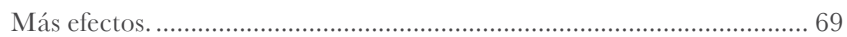

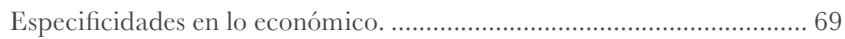

Sobre la creatividad en los formatos o narrativas........................................... 69

Innovar sí, pero en temas de alto consumo.................................................70

"Lo hemos planteado". .............................................................................

En la experimentación..................................................................................

Periodistas polivalientes o polivalentes...............................................72

Más allá de las herramientas..............................................................73

Efecto e interacciones de los nativos digitales como competencia...................74

Eje ético: periodista político y económico en la red...................................................74 


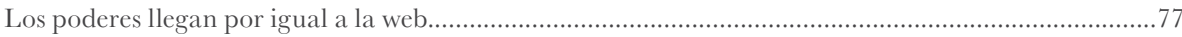

La independencia informativa: una cuestión de estructuras. ............................................................77

El balance lo pueden lograr las audiencias activas........................................................................ 80

Papel del periodismo político y económico frente a los ciudadanos en los entornos digitales. Entre la

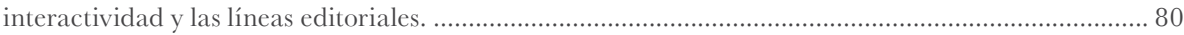

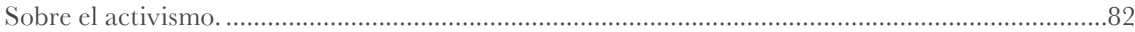

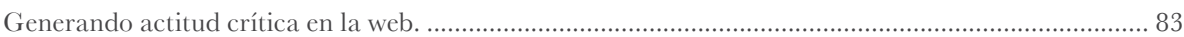

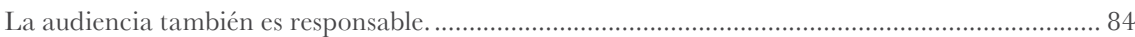

Respondemos a las necesidades de la audiencia/no hacemos periodismo para la gente................ 85

Actitud crítica hasta para abrir una publicación en papel......................................................... 86

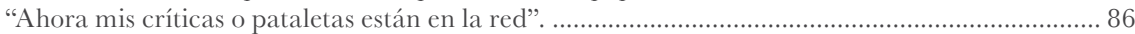

Independencia informativa frente a los intereses políticos y económicos............................................. 88

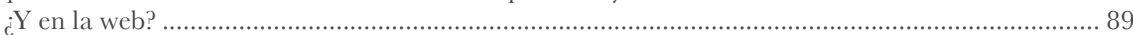

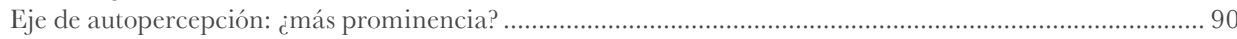

Entornos digitales y la prominencia del periodista político o económico. ..........................................90

La imagen del periodista político se ha modificado con la llegada de la tecnología, y la tecnología llegó

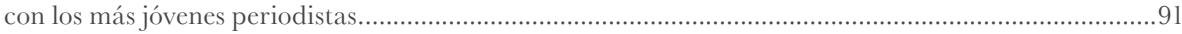

Efectos de los entornos digitales sobre el trabajo investigativo. ............................................................92

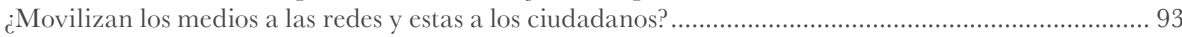

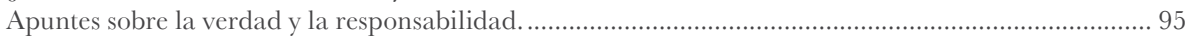

Implicaciones del uso de los entornos digitales en la imagen del periodismo político y económico. .......97

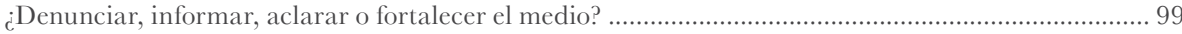

\section{Capítulo 2}

\section{GONVERGENGIAS Y DIVERGENGIAS EDITORES WEB DE LOS MEDIOS}

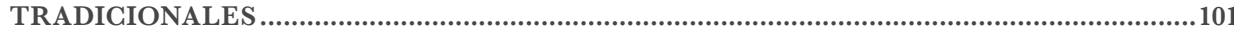

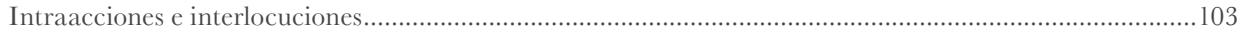

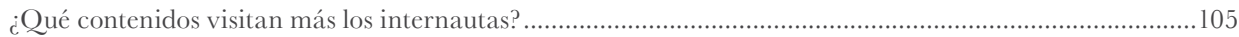

El supuesto imperativo para los periodistas de ser creativos en Internet....................................................108

Relación del periodista especializado en política y economía con los ciudadanos ................................... 113

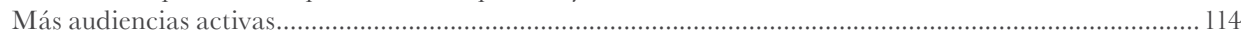

De la movilización ciudadana y el lugar del periodismo político y económico allí ................................. 117

Independencia informativa, la mediación de los intereses políticos y económicos en la labor periodística 117

Efectos de los Entornos Digitales sobre la prominencia del periodista y el periodismo político

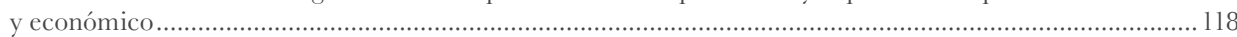

\section{Capítulo 3}

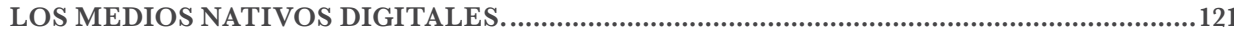

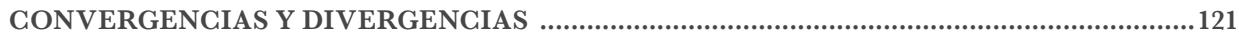

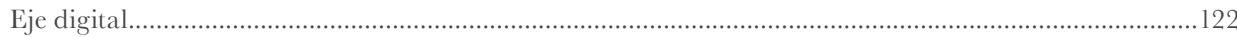

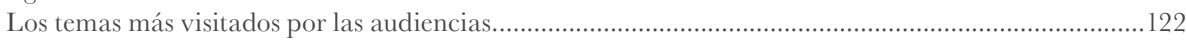

Ubicación del periodismo político y económico en los entornos digitales............................................124

Estado de la creatividad en los entornos digitales. ..........................................................................126

Herramientas o aplicaciones: ¿cambian la forma de conseguir la información? .................................127

Efectos de los entornos digitales en la búsqueda de la información y en la relación con las fuentes.....129

Papel y función del editor web/redes sociales frente a los periodistas. ...............................................130

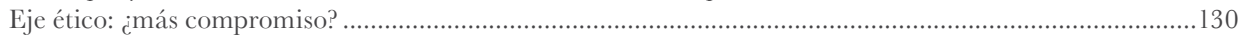

Relación del periodista especializado en política y economía con los ciudadanos en los Entornos

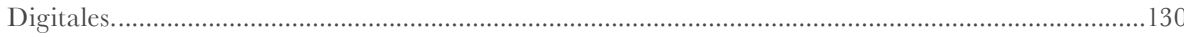

De la independencia informativa en la mediación digital política y económica.................................133

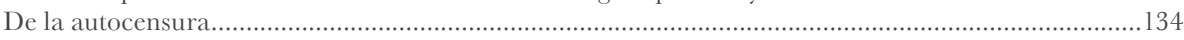

Del control social a los periodistas por los oligopolios económicos y políticos.....................................135

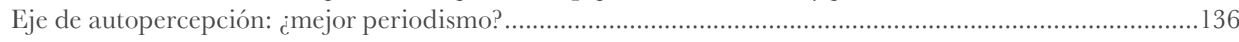

Adaptación de los periodistas a las transformaciones que proponen los entornos digitales. .................136 
¿Altera la corriente participativa la potente agenda mediática?

¿Cómo marca la opinión pública las informaciones políticas a través de los entornos digitales de las noticias que aparecen en la web?

¿En qué medida el periodismo político y económico que usa plataformas digitales moviliza la participación ciudadana?.

\section{Capítulo 4}

GARACTERIZACIÓN DE LOS COMMUNITY MANAGER Y EDITORES WEB

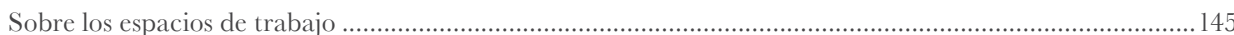

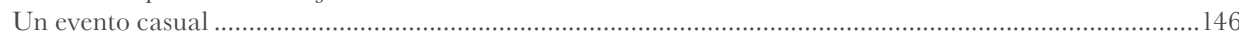

\section{Capítulo 5}

LOS GONSEJOS DE REDAGGIÓN ...........................................................................149

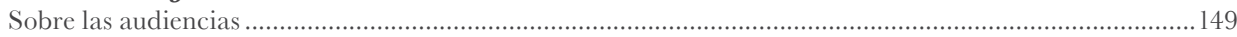

Observaciones etnográficas de los consejos de redacción ............................................................................150

Orden de presentación de los temas y nivel de participación de los periodistas especializados

en política y economía.

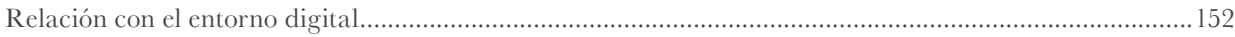

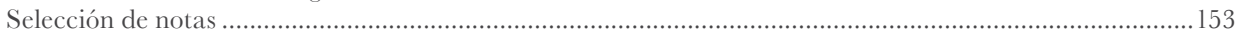

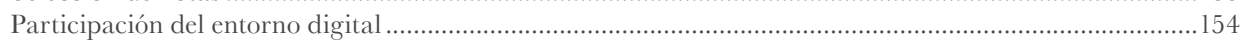

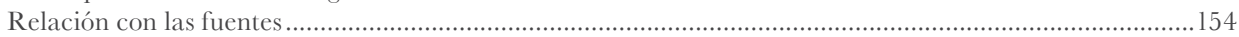

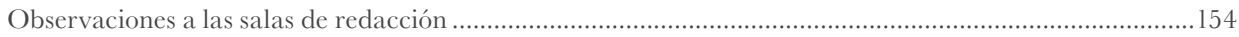

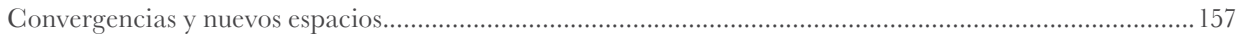

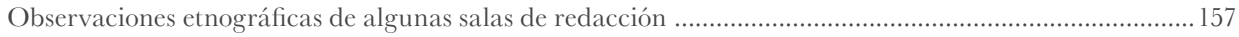

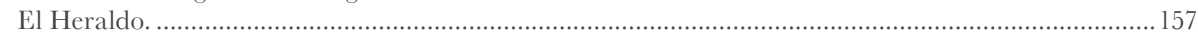

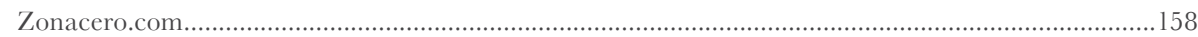

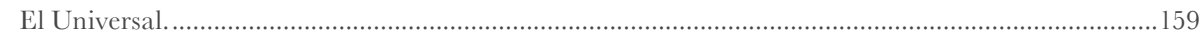

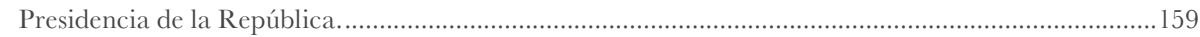

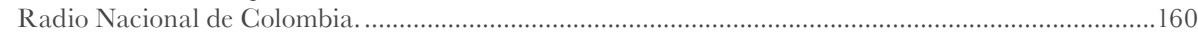

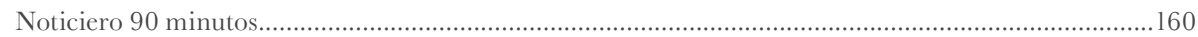

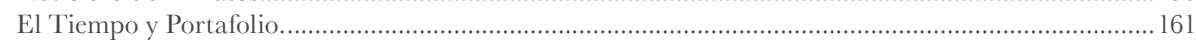

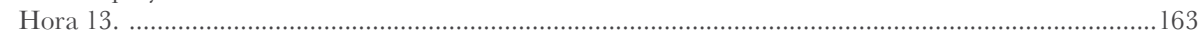

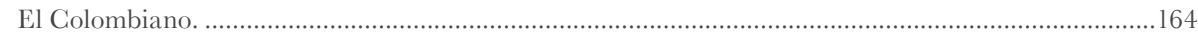

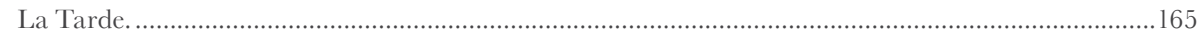

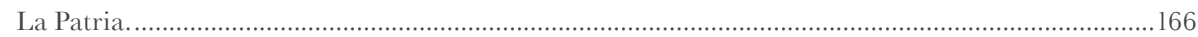

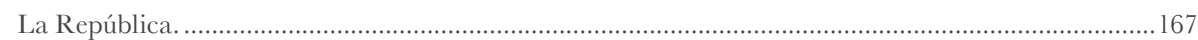

\section{Capítulo 6}

GARENGIAS DE LOS PERIODISTAS ESPEGIALIZADOS EN POLÍTIGA Y EGONOMÍA....169

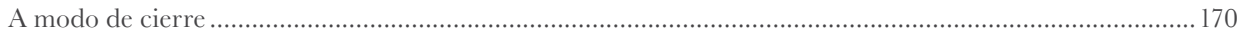

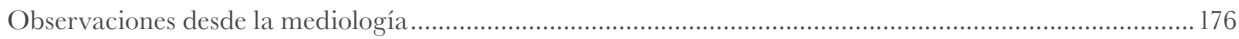

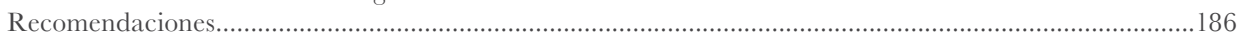

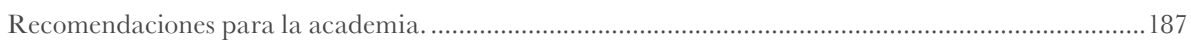

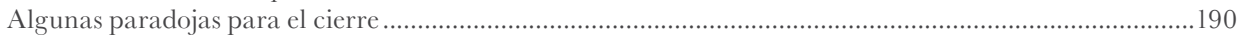

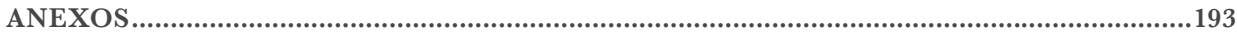

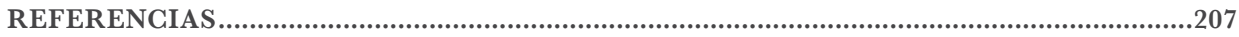





\section{INTRODUGGIÓN}

$\Psi_{\text {cualquier fuente ha requerido tradicionalmente }}^{\text {acer periodismo profesional y especializado para }}$ de mucho estudio y práctica. La especialización de los medios de comunicación benefició al periodismo de manera directa. Luego del éxito de los medios de comunicación, la tendencia a especializarse ya era un hecho en los años sesenta cuando aparecieron los canales de televisión temáticos, las emisoras de radio y revistas dedicadas a ciertos públicos y músicas.

La especialización de los periodistas en temáticas y fuentes ha cobrado importancia, tanto por el interés de los públicos como de los mismos medios de comunicación. Medios impresos y audiovisuales de deportes, de farándula, de cocina, de historia, entre muchos, se han multiplicado en todo el mundo demostrando una fragmentación de las audiencias y abriendo nuevos mercados; lo que demanda la elaboración de informaciones más profundas y confiables por canales más complejos y dinámicos gracias al uso de las nuevas tecnologías ubicando al periodismo en un nuevo contexto, en un nuevo estado, el digital.

Sin embargo, el requerimiento de información especializada en algunas ocasiones supera las iniciativas de los mismos medios. En otras oportunidades lo que se nota es una falta de motivación por parte de las audiencias por ciertos temas y una carencia de estrategias para hacer interesar a los públicos en determinados asuntos. Así lo manifiestan en primer lugar los periodistas económicos y luego los periodistas políticos, tanto de los medios tradicionales como de los nativos digitales. 
En términos generales esta lógica de la especialización obedece a varios factores sociales, históricos, tecnológicos y económicos. A nivel estructural, los propósitos de la industrialización de la información donde, como lo decía Horkheimer y Adorno (1967) en su Dialéctica de la Ilustración; había algo previsto para cada uno con el fin de que nadie pudiera escapar del sistema, dan cuenta de que la producción en masa, no solo es la homogeneización de los contenidos y la estandarización de estos, sino también su especialización para llegarle de manera más directa a los consumidores, para su clasificación y organización. Bezunartea et al. (1988) bajo la misma lógica, afirman que esta es un postura típicamente empresarial y del funcionamiento contemporáneo de las economías que para ser rentables ofrecen productos diferenciados a públicos que quieren diferenciarse. En ese sentido, la especialización obedecería también a que como lo afirman los autores de la Diálectica de la Ilustración (1967) cada individuo dentro de este sistema está en la obligación de comportarse de acuerdo a su propio level.

Desde este razonamiento la idea sería que, en el caso de los contenidos periodísticos especializados, la realidad quede retratada de la manera más fiel posible de acuerdo con un nicho temático. La tradición de la teoría crítica tenderá a analizar y en muchos de los casos a desvalorizar el ejercicio no solo del periodismo especializado, sino del periodismo en general, de sus prácticas y de los compromisos con la sociedad. Por otro lado, desde las propuestas de los programas de periodismo especializado, este hecho se lo ve no solo como un factor positivo, sino que necesario, pues la técnica no siempre está a favor de la razón instrumental (Lévy, 2007).

Si bien los resultados que encontramos en la investigación se enfocan en el mejoramiento de la enseñanza de un periodismo especializado, no podemos olvidar la evaluación y crítica que podrán ir más allá de los planteos de algo creado "para cada uno" o de la estandarización de la producción de la cultura, de los poderes sobre las libertades y la información (Marcuse, 1954).

Más allá de estos supuestos teóricos, buscar la especialización también corresponde a una realidad social del sistema político, constituyéndose en una pieza importante de los sistemas democráticos (Mattelart, A., Delcourt \& Mattelart, M., 1984), donde la cultura y la información deben circular de manera equilibrada para todos, y donde todos deben tener acceso a un abanico de medios, posibilidades y temas. 
La llamada revolución digital, entendida como el conjunto de nuevas técnicas implantadas en etapa de la codificación binaria aplicadas en todos los campos del hacer y el saber, con particular énfasis en la comunicación, llega a todas las etapas de los procesos de producción industrial y cultural: búsqueda, investigación, almacenamiento, tratamiento y distribución. Cada nueva tecnología entendida como revolución, propicia la aparición de una nueva esfera o mediásfera que influye en todos los aspectos de la vida. Así como la imprenta o la televisión generaron la aparición de la grafósfera y la videósfera (respectivamente) (Debray, 2000), la revolución digital ha creado una hiperesfera (Merzeau, 1998) alrededor de la cual los antiguos productores de cultura y contenidos se inclinan a estabilizar sus dinámicas de producción.

En este contexto complejo de interacciones entre la evolución de las condiciones de la producción de contenidos, la aplicación de dicha tendencia generalizada y la respuesta a las necesidades sociales y democráticas, se hallan los periodistas.

En ese sentido la mediología, disciplina en formación, habla de las interacciones entre la materia organizada $(\mathrm{MO})$ y la organización materializada $(\mathrm{OM})$. En el primer grupo está la tecnología en su estado actual acumulativo; su uso tiene incidencia sobre lo social y sobre la cultura. A fin de descubrir las relaciones entre los dos sistemas, a partir de investigaciones en campos determinados, se construyen referentes espacio-temporales: las mediásferas. Se parte de presupuestos de la mediología como los que expone F. Renucci (citada por Merzeau 1998), según los cuales: las lógicas de usos modifican las técnicas de comunicación, el transporte de la información transforma el contenido de los mensajes y la tradición cultural interviene en las innovaciones.

Conforme con el concepto propuesto por Régis Debray y que ya definimos en los primeros apartes de este texto, una mediásfera se determina por la estabilidad de la temporalidad, "por las tendencias, los puntos de ruptura, las fronteras, los desequilibrios, las resistencias y los regresos" (Merzeau, 1998, p. 32)

Así el lograr incorporar a la enseñanza y al ejercicio del periodismo los beneficios de la especialización parece significar una meta tan alta dentro del compromiso que adquiere este periodismo para con la sociedad. 
El periodismo especializado es una consecuencia histórica y tecnológica y una necesidad social y política que puede favorecer a la sociedad y a la profesión del periodista. En Colombia a pesar de la demanda de los públicos por temas especializados, la tradición ha sido que esta especialización esté endilgada principalmente a la praxis, pues no han existido escuelas especializadas. Solo en los últimos años han surgido especializaciones en algunas de las ramas del saber periodístico (periodismo deportivo, político, de datos, etc.).

En España, por ejemplo, la inquietud académica por un periodismo especializado comienza a mediados de los años ochenta del siglo pasado (Borrat, 1993). La inquietud quedó inicialmente registrada en un estudio que desarrollaron los profesores Pedro Orive y Concha Fagoaga (1974) donde se encontró que el $65 \%$ de un grupo de encuestados, consideró que el periodismo del futuro iba a ser especializado. En ese momento los autores definieron el periodismo especializado como aquel que se ajustaba a los intereses y necesidades de las audiencias, acomodando los lenguajes a su nivel proporcionando así una interpretación del mundo lo más ajustada a los lectores.

Otros investigadores como Javier Fernández del Moral y Estévez se han ocupado del tema, tratando de construir los soportes de una teoría que dé sustento a la enseñanza y a la práctica de un periodismo especializado, encontrando que: existe una carencia de bases profesionales que le indiquen a los periodistas cómo informar desde su área. A este propósito los autores se esfuerzan por definir el periodismo especializado como:

La estructura informativa que penetra y analiza la realidad de una determinada área de la actualidad a través de las distintas especialidades del saber; profundiza en sus motivaciones; las coloca en un contexto amplio, que ofrezca una visión global al destinatario y elabora un mensaje periodístico que acomode el código al nivel propio de la audiencia, atendiendo sus intereses y necesidades (Fernández \& Estévez, 1996, p. 100).

Otro de los problemas es el referido al término "especialización". En Colombia la praxis del periodismo especializado en política y economía ha tendido a ser pensada solo desde el tipo de fuente que se cubre o quizá desde las técnicas de recolección de datos; un verdadero periodismo especializado necesitaría construirse como tal como lo afirma Fernández y Estévez (1996) en una disciplina dentro del corpus de las ciencias sociales de la información y cuya función sería crear las bases para la especialización del conocimiento. 
Siguiendo a Fernández et al., (1996) creemos que un periodismo especializado no debe cerrarse a comprender y transmitir otras realidades, sino que es justamente saber comunicar un pensamiento de manera sistémica desde su perspectiva. Esta aseveración coincide con algunas de las respuestas obtenidas de los periodistas políticos y económicos consultados sobre la autopercepción: "todo tiene política” (Leyton, 15 de mayo de 2013, comunicación personal). "la economía está en todas partes" (Tovar, 5 de diciembre de 2012, comunicación personal). Más allá de una apreciación que puede parecer totalizadora, esta es significativa en cuanto a que la política y la economía no solo pueden ser fuentes, sino sobre todo puntos de vista.

En el campo de la enseñanza, este debe ser uno de los derroteros a seguir. Dicha postura sistémica y de profundización la debemos ahora pensar en la web. Así mismo desde las compañías que venden las nuevas tecnologías hasta los medios de comunicación y la producción de las noticias, no se puede desconocer que la constante presión del sistema global a inducir a los públicos a que se vuelquen sobre la red, ha generado múltiples interacciones que tienen que ver con la aparición de un nuevo escenario para la competencia del medio para el mercadeo de productos y para la famosa fidelización de los lectores, a costa muchas veces de la calidad de los productos periodísticos, pero también de la participación de nuevos géneros o de la variación estética de los productos periodísticos.

Por otra parte, la existencia y consolidación de un periodismo especializado requiere de un público especializado, que no solo hay que interesarlo, sino además erigirlo. Ante la gran diversidad de informaciones que circula en la red y a la que está teniendo acceso las nuevas generaciones, el periodismo especializado debe saber llegar y construir un público. Por ello seguimos a Montserrat Quesada (2001), cuando afirma que un periodista profesional "es capaz de traducir a un lenguaje divulgativo y fácilmente comprensible para todos, la cada vez mayor complejidad política, económica, cultural, demográfica, social y humana que caracteriza a las sociedades modernas" (p. 126).

El periodismo especializado se debate entre proponer un lenguaje justamente "especializado" que pudiera disminuir el espectro de consumo y un lenguaje accesible a una mayor cantidad de personas para lograr una incidencia social. 
Es así como nos surgió la pregunta de cómo estaría ese periodismo que se dice especializado en política y economía en Colombia. ¿Cuál es el estado de este periodismo en los medios comerciales tradicionales y en los medios llamados nativos digitales?, ¿quiénes son los periodistas que lo están haciendo?, ¿qué ventajas, carencias y restricciones encuentran los periodistas para desarrollar su trabajo?, y por último, ¿qué impacto han tenido los llamados entornos digitales ${ }^{1}$ en este escenario?

En el trasfondo aparecen interrogantes como: ¿este periodismo especializado en Colombia obedece a algunas lógicas de producción posindustrial?, ¿se están construyendo públicos interesados en el tema?, ¿cuál es el aporte de Internet y su interactividad al posicionamiento del periodismo especializado?, y ¿si todo es política y la economía está en todas partes, cómo hacérselo ver a los públicos en los espacios digitales?

La historia de Colombia ha estado agitada por temas de política. El momento en que se ejecutó esta investigación no estuvo exento de estos agitados contextos; se desarrolló durante el tercer y cuarto año de mandato del presidente Juan Manuel Santos, en medio de levantamientos de orden público en el campo y la ciudad que se derivaron principalmente de los efectos de la entrada en vigencia del tratado de libre comercio (TLG) con Estados Unidos y de las expectativas de los efectos del TLC con Europa; así mismo en medio de las críticas por el manejo de la minería, reforma a la justicia, a la educación, escándalos políticos de todos los órdenes, reconfiguración del paramilitarismo en las "Bacrim" o bandas criminales y los preacuerdos y acuerdos para la instalación de las mesas de negociación con las Fuerzas Armadas Revolucionarias de Colombia-Ejército del Pueblo (Farc-EP) en La Habana. Mientras que en el contexto global los levantamientos en Egipto continuaban y los enfrentamientos entre rebeldes sirios y el gobierno estaban a la orden del día de los titulares de las páginas internacionales, junto con la preocupación en Europa por el debilitamiento del euro y los efectos posteriores a la llamada Primavera Árabe.

Definimos para nuestra investigación como entornos digitales el ambiente en constante construcción y mutación que implica la aparición de la Internet apoyada por la información binaria y la virtualización de los contenidos, el diseño de portales, el surgimiento de redes sociales, la telefonía celular, las numerosas aplicaciones y los desarrolladores de contenidos. 


\section{Sobre el periodismo especializado}

El periodismo político y económico verdaderamente especializado es muy escaso en los medios de comunicación en Colombia. En las condiciones actuales, donde las compañías de comunicación ponen el oficio al servicio de la inmediatez y de la producción casi industrializada de las noticias, el buen desarrollo de este tipo de periodismo se ve impedido, tal y como nos lo manifestaron varios periodistas en entrevistas que examinaremos más adelante. Esta autopercepción coincide con otras investigaciones sobre las rutinas periodísticas. Acosta (2013) siguiendo a Tuchman (1983) afirma que "los reporteros se obligan con los pedidos de la empresa informativa: todos los días deben entregar notas rutinarias, cumpliendo con los plazos de entrega, con las cuotas de espacio, y con información cierta” (p. 67). Más adelante citando un trabajo de 1987 de Villafañe, Bustamante y Prado en España asegura que:

[...] los modos de racionalización del proceso productivo adoptados por los grandes medios de información analizados tienden a ceñirse continuamente a las demandas y necesidades del poder; son, fundamentalmente, la información sobre el poder mismo. Y ello, según lo observado, con tanta fuerza en los medios públicos como en los privados (Acosta, 2013, p. 70)

Así se da cuenta de que las salas de redacción de los medios tradicionales siguen con los modelos de la era tipográfica y de la fábrica, de lo que se infiere el rezago en cuanto a los nuevos entornos digitales.

Ahora bien, existen algunas contradicciones al interior de la definición de "especializado". Esta condición, ¿depende del tipo de medio en el que se labora? (Diarios económicos, noticieros de temas políticos). ¿Del tipo de fuente? (Independientemente de si el medio trata temas generales). ¿O del periodista que redacta o hace la nota? Cuando preguntamos a los periodistas por quiénes serían en Colombia los verdaderos periodistas especializados en política, en la lista no surgieron más de diez nombres, algunos de ellos "no periodistas", más bien politólogos, columnistas, entrevistadores en temas de política o directores de medios, que por su posición se dedican más a gestionar el medio y no tanto a desarrollar trabajo periodístico de base.

Tentar una definición, a propósito de esta investigación, sobre lo que consideramos o esperamos que sea un periodismo especializado tiene que ver con la academia y sus logros en la enseñanza de un periodismo especializado, pero también con la práctica. Para Muñoz (1997) 
[...] estudia la producción de mensajes informativos que divulgan las distintas especialidades del saber humano, de manera comprensible e interesante, al mayor número posible de personas, con el fin de dotar de sentido a la realidad, a través de los medios de comunicación (p. 41).

En los medios conocidos como "nativos digitales" la posibilidad de llegar a la definición de lo que podría ser especializado parece estar más cercana de la realidad. Los periodistas de estos medios manifiestan tener mayores posibilidades de erigir y fortalecer un periodismo especializado pues se les facilita la investigación, contrastación y búsqueda de fuentes, entre otras potencialidades. Muchos de estos medios son subvencionados, lo que daría ciertas libertades y holguras de tiempo. "El buen periodismo siempre ha estado subvencionado: los mercados nunca han proporcionado todas las noticias que la democracia precisa. El modo más obvio es la subvención pública indirecta" (Anderson, Bell \& Shirky, 2013, p. 8).

Un gran número de periodistas de los grandes medios se ha formado en la dictadura de la inmediatez y la producción masiva de contenidos, lo cual es contrario a las condiciones necesarias para la producción de un periodismo serio y duro. Por otra parte, nos encontramos con que cumplir los requerimientos académicos y de conocimiento de teorías económicas o de aspectos sobre el funcionamiento del Estado, da al periodista la confianza y el respaldo para llevar al buen análisis los hechos noticiosos. Un periodista que se diga especializado tiene las facultades y obligaciones de estudiar la información (Fernández et al., 2004).

Como si fuera poco, los medios tradicionales no están otorgando suficiente tiempo y espacios de trabajo para que los periodistas exploren - en grupo o individualmente- un periodismo especializado en los entornos digitales, quizá porque:

Los medios tradicionales tienden a conservar los métodos de trabajo y las jerarquías incluso cuando los antiguos modelos de negocio se derrumban e, incluso, cuando las nuevas oportunidades no encajan en esos viejos patrones. En numerosas entrevistas con miembros de la prensa tradicional orientados a lo digital, surgió el problema de cómo sus esfuerzos se vieron frustrados por el Sistema (Anderson et al., 2013, p. 7).

Nos surge aquí la inquietud respecto a cómo podemos entonces entender el periodismo especializado a la luz de ciertas realidades y tensiones entre el medio, los periodistas, las audiencias y el entorno digital. 


\section{Periodismo y el factor tecnológico}

Periodismo y entornos digitales son una simbiosis hoy imposible de desconocer y que particularmente en los últimos años, luego de la casi total adopción de lo digital, ha suscitado al interior de la profesión nutridos debates desde los teóricos de la academia, desde la enseñanza hasta la praxis. El nuevo ecosistema ha tomado por sorpresa tanto a los medios de comunicación como a las mismas universidades, que solo en años recientes, han conseguido modificar de manera significativa los programas de pregrado o han logrado posicionar posgrados con acento digital.

Esta situación de retraso es natural en todos los procesos históricos del periodismo y en general, se presenta bien sea por desconfianza de los nuevos soportes, por desconocimiento de los mismos o porque no se ha podido encontrar el sentido de esa correspondencia regulada entre los dos. A partir de esta posición y en el gran ecosistema del periodismo, se "sugiere que se pueda buscar una lógica de los mensajes (= lo simbólico) en una lógica del medio (= la técnica)" (Debray, 2000, p. 66), que es para donde finalmente parecen decantarse las producciones culturales y periodísticas del futuro.

El pensar un factor cultural como lo es el periodismo y sus relaciones con el factor técnico, como lo es la web, motiva desde el primer momento un sinnúmero de preguntas; pues no se trata simplemente de colocar al servicio y beneficio de una profesión una serie de espacios virtuales y de instancias técnicas. Los debates han ido más allá, pues la profesión u oficio del periodismo siempre ha estado en los debates por su calidad, por su compromiso con la sociedad y la ciudadanía y por la transparencia, el rigor a la verdad y la independencia informativa, entre otros aspectos. La responsabilidad del registro, manejo y difusión de la información por parte de los periodistas y medios de comunicación compete a todas las capas de la sociedad. Así es como nuevos interrogantes aparecen con los nuevos contextos que involucran esta vez a la profesión como tal, a los periodistas, a los medios de comunicación, grandes o pequeños, y a la misma ciudadanía como prosumidora o receptora.

La investigación desarrollada aquí desea conocer principalmente cuál es el estado actual en Colombia del periodismo y de los periodistas especializados en política y economía, en los entornos digitales a fin de detectar las necesidades que estos presentan, sus logros o virtudes para llevarlos 
posteriormente a los programas de formación especializada. Esta tarea no se puede hacer ignorando a los medios de comunicación y a los ciudadanos.

Entre los múltiples enfoques posibles para tratar el tema de la interacción entre la tecnología y el periodismo en la nueva mediásfera, hemos querido privilegiar el mediológico. La mediología nos permite combinar aspectos históricos, sociológicos, y aun de análisis semiótico, desde una posición más bien desideologizada para comprender mejor ese estado actual del periodismo.

Es así como la web la comprendemos como una tecnología de memoria en plena instauración, alrededor de la cual se equilibran las mentalidades colectivas, entendidas estas últimas como: tendencias históricas de la sociedad relativamente homogeneizadas y homogeneizadoras que actúan y deciden sobre la misma sociedad y sobre el uso que se le dé a la tecnología. En ese sentido no debemos separar el desarrollo de la tecnología del desarrollo del ser humano.

[...] no solo las técnicas son imaginadas, fabricadas y reinterpretadas en el uso por los hombres, sino que es incluso el uso intensivo de los útiles que constituye la humanidad en tanto que tal (conjuntamente con el lenguaje y las instituciones sociales complejas) (Lévy, 2007, p. 5).

Todo factor cultural requiere de un factor técnico (Debray, 2000). El periodismo desde el primer momento requirió del papel, la máquina de escribir, la rotativa y la filmadora, y de medios y espacios de transporte y difusión de los millones de signos: el telégrafo, el ferrocarril, el télex, las salas de cine; todos ellos formaban parte de un periodismo diríamos tradicional. La llegada de Internet revolucionó las técnicas de registro y difusión y también varió las rutinas del periodismo. En muchos sentidos el periodismo sigue siendo el mismo, sus valores no presentan cambios sustanciales, según muchos periodistas entrevistados, pero estos, y otros, reconocen al mismo tiempo la incidencia ya instalada en muchos medios, de los ambientes digitales. Esta perspectiva de hacer relacionar los entornos digitales (factor técnico) con el periodismo (factor cultural) corresponde a un enfoque mediológico. ${ }^{2}$

La mediología es una disciplina de origen francés que desea encontrar los entrecruces propiciados por las mediaciones tecnológicas en la cultura a lo largo de la historia. El método tiene por eje "la conexión controlada de la historia noble de las creencias y las instituciones con la historia prosaica de las herramientas y las máquinas" (Debray, 1995, p. 11). 
La investigadora española Concha Edo afirmaba en 2009 que "en este paisaje informativo de principios de siglo el periodismo es más necesario que nunca, pero al ritmo que avanza la tecnología es muy difícil hacer un vaticinio firme sobre lo que pueda ocurrir dentro de unos años" (p. 10). Pasados cinco años de esta observación, la incertidumbre y el carácter experimental de los medios en línea siguen presentes, aunque ya hay ciertas prácticas y escenarios instaurados.

Colombia y sus medios de comunicación siguen muy de cerca las tendencias de la mentalidad occidental en cuanto al uso de la web. Algunas experimentaciones ya están en marcha y la evaluación de sus resultados al interior de los medios propone rutas a seguir. El preguntarse por la sinergia entre la técnica y el periodismo también se alimenta de un posible desfase entre dos ritmos de evolución; por un lado el de las rutinas y prácticas periodísticas que durante el siglo XX marcaron claros patrones y procedimientos para hacer periodismo, fruto en ese momento de la Revolución Industrial; y por otro, la adopción que esas mismas prácticas heredadas deben hacer de los nuevos ambientes de la revolución digital.

Si un periodista quisiera hoy hacer su trabajo de manera tradicional, generando su agenda propia sin tener en cuenta las demandas de las audiencias o visitando siempre las fuentes físicas de la noticia, chocaría con las audiencias y con las mismas fuentes. Para equilibrar este desfase en las organizaciones de periodismo tradicional, será menester una verdadera renovación o convergencia a riesgo de perder audiencias y mercados, como lo afirman los autores de Periodismo postindustrial: adaptación al presente: "si esperan mantener o incluso aumentar su relevancia tendrán que aprovechar los nuevos métodos de trabajo y procesos que ofrece el medio digital" (Anderson et al., 2013, p. 12). Así es que nuestra pregunta básica intersistema ${ }^{3}$ es: ¿qué efecto tienen hoy los llamados entornos digitales en el quehacer del periodismo especializado en política y economía en Colombia?

La convergencia como necesidad y condición y la interactividad como posibilidad, son dos de los grandes asientos en los que se sustenta la realidad

\footnotetext{
Relaciones de interacción intersistemas desde la mediología, son aquellas que se producen o se construyen entre sistemas, universos diferentes pero próximos, como el realizado por Walter Benjamin en La obra de arte en la época de su reproductibilidad técnica (véase Debray, 2000, p. 113).
} 
del nuevo entorno, luego de la aparición de la Internet. Los otros como hipertextualidad, multimedialidad e inmediatez, a nuestro modo de ver están en el nivel más del mensaje, de la mecánica del soporte y de las necesidades de la información.

Hacer periodismo en los entornos digitales no es "colgar" información en la red o conseguir que el editor web (EW) o el community manager (CM) lo haga. Junto con la esperada retroalimentación de los lectores con el medio, y de los lectores entre ellos; el periodista y el medio de comunicación se enfrentan a la necesidad de ser "convergentes". Hacer convergencia no es tan solo pensar la producción periodística en función de las plataformas que se tienen para su difusión. De ser así se trataría únicamente de una función mecánica regulada por unos manuales de estilo para cada plataforma a partir de una redacción más o menos centralizada. Al definir convergencia en el periodismo podemos sumarnos a esta apreciación:

[...] un proceso multidimensional que, facilitado por la implementación de tecnologías digitales de telecomunicación, afecta al ámbito tecnológico, empresarial, profesional y editorial de los medios de comunicación, propiciando una integración de herramientas, espacios, métodos de trabajo y lenguajes anteriormente disgregados, de forma que los periodistas elaboran sus contenidos que se distribuyen a través de múltiples plataformas, mediante los lenguajes propios de cada una (Salaverria \& Garcia-Aviles, 2008, p. 12).

Como se ve en esta definición, el tema de la convergencia sobrepasa en buena medida la superficialidad referida al uso de diversos soportes y plataformas. La Internet sin quererlo ha demandado que en el caso de la producción periodística, dicha convergencia se piense como un proceso que a nuestro juicio implica las rutinas clásicas del periodista como son la investigación, la producción y redacción de la nota en un género específico, la difusión (que tradicionalmente le competía solo al medio) y por último la interacción con los públicos, tomando nota de sus comentarios o respondiendo a ellos de modo directo o indirecto.

Dentro de este proceso de producción periodística están los ciudadanos participando con las mismas herramientas e iguales plataformas. Para lograr la convergencia de un medio, esta debe concebirse en toda la organización empresarial, desde las directivas hasta los reporteros o social media, así como en todos los soportes y plataformas. Una serie de determinaciones empresariales que miren de manera sistémica al medio de comunicación. 
Scolari (2008) se refería a la polivalencia de los periodistas como condición para su participación en un medio convergente. Existe una desconfianza de los periodistas y de la academia a ver la polivalencia como una esfera positiva del trabajo periodístico, dado que en algún momento puede significar la reducción de puestos de trabajo y el incremento de horas, energía y creatividad por parte de los reporteros y, por ende, una disminución de los gastos de producción a costa de la calidad y especialización de los contenidos.

Por último, la convergencia también compete a las herramientas digitales que pueda usar el periodista en el ejercicio de sus funciones; al tipo de lenguaje que debe emplearse para la red y al dominio de las plataformas para su difusión. Como dice Salaverría (2009):

De nuevo, se advierte una confluencia de líneas, pues elaborar informaciones para los cibermedios obliga a dominar tanto la narrativa escrita como la audiovisual, al tiempo que es preciso enriquecer ambas con las posibilidades hipertextuales e interactivas propias de la red. El lenguaje ciberperiodístico plantea, en fin, una amalgama de códigos que, sin duda, desembocará en el alumbramiento de nuevos géneros y en profundas mutaciones futuras en las formas de elaborar contenidos informativos (p. 11).

¿Están nuestros reporteros haciendo este tipo de periodismo polivalente y multiplataforma?

\section{La interactividad como parte del factor tecnológico}

El otro pilar es la interactividad en Internet y vale la pena que la definamos en pos de nuestra investigación. Entendemos la interactividad como la posibilidad (y la acción) que tiene la audiencia de participar de los contenidos "periodísticos", bien sea de manera pasiva, propositiva o con contenidos concretos como comentarios, textos elaborados, fotos o videos demandados por el medio o entregados por ella de forma espontánea. Para nosotros la interactividad no estaría completa si el medio de comunicación y el grupo de foristas no reconocen, toman, comentan o tienen en cuenta de algún modo esta participación incentivada y facilitada por los entornos digitales.

Así, no se trata solo de un feedback entre los medios tradicionales y la red. Los periodistas revisan los trending topics (TT) de Twitter para medir el clima de las noticias, para evaluar temas y enfoques y para hallar datos o pregun- 
tarle a la audiencia por los mismos. Algunos periodistas leen los comentarios de los foristas y con toda esta información, como si se tratara de otras fuentes, construyen su producto periodístico, lo hacen circular en el medio y luego revisan su impacto o receptividad, respondiendo directa o indirectamente por medio de la agenda general del medio. Sin embargo, pocas veces el medio responde de manera directa a sus lectores y pocas veces se observa una real construcción de cultura política.

La aparición de lo digital en la prensa multiplicó el flujo de información y colocó buena parte de esta a correr a velocidades nunca antes vistas (Debray, 2000). Otra información permanece en los impresos en diferido o en las emisiones exclusivas para el medio tradicional. Los medios de comunicación se han convertido en bibliotecas de la información incluyendo en su estatus, a parte del registro de la actualidad, el de almacenaje de hechos; asignándoles una responsabilidad inmensa con la memoria histórica. Los medios construyen la ilusión de receptores individualizados - gracias al uso de la cuarta pantalla (pantallas de los móviles, tabletas y computadores personales)- que, con el desarrollo de numerosas aplicaciones para los teléfonos inteligentes, dan la posibilidad a los usuarios de producir contenidos y participar en la red desde cualquier parte del mundo, gracias a los sistemas $3 \mathrm{G}$ y $4 \mathrm{G}$.

En 2011 la venta de estos dispositivos móviles superó a la de los ordenadores y para 2013 el comercio de tabletas rebasó en mucho al de los computadores portátiles. En 2014 los teléfonos celulares de grandes pantallas comenzaron a sobrepasar en ventas a las tabletas. Este dinamismo en los soportes hace que las compañías de tecnología y las empresas productoras de contenidos en la web consideren a los tipos usuarios y a sus necesidades particulares.

El periódico despojado de su materialización física y el noticiero de radio o televisión de su ritualización horaria, motivan constantemente la participación de los públicos. "actor, fundamental, y por ello experimenta procesos hasta ahora limitados a los emisores de la información” (Borga, 2013, p. 14)

Los grandes medios, quizá para poder estar a la vanguardia tecnológica, ya han incursionado en algunos de los retos que Silva (citado por Gordillo, Curiel \& Rey, 2011) proponía que se deben aprovechar todos los potenciales tecnológicos como GPS, la realidad aumentada, para asi aumentar la parti- 
cipación de los usuarios. Todo por medio del dispositivo móvil gracias a los cuales los ciudadanos pueden participar desde sus intereses. Estos intereses están en el estar informados, convertirse en consumidores o productores o participar colaborativamente.

La interacción de los usuarios con los medios de comunicación en la red la podemos agrupar en los niveles que proponemos a continuación:

1. Interactiva en el sentido de participación en los contenidos publicados por el medio en su portal o en las cuentas de redes sociales.

2. Interactiva en el sentido de comunicación con el medio o sus periodistas.

3. Interactiva con otros usuarios o "foristas" en los espacios dispuestos por los medios.

4. Interactiva en la conexión del usuario con programas y sistemas inteligentes dispuestos por los medios en la red, como infografías, encuestas o videojuegos.

5. Interactiva por la participación de los usuarios con la creación de contenidos propios, desde frases a contenidos audiovisuales.

La interactividad supone de entrada la aparición del prosumidor: usuario que no solo consume sino que produce información, generando la autocomunicación (Castells, 2009). Dado que la situación tecnológica hace que los códigos digitales sean de uso masivo y estandarizado, los medios de comunicación y el periodismo en la red han podido sacar provecho y se han visto altamente beneficiados para posicionarse gracias al surgimiento del prosumidor. Por otra parte, la interactividad también se enmarca en una revolución espacial y temporal que comprendemos así:

- Desritualización temporal del usuario frente al medio. Puede acceder y participar en cualquier momento.

- Flexibilidad espacial. Poder participar desde cualquier lugar.

Con todo, el colocar la perspectiva técnica en el periodismo, no implica necesariamente desplegar una observación de la influencia de la primera sobre el segundo, y menos aún de partir de un supuesto impacto negativo. Pues como se ha dicho, y siguiendo el enfoque mediológico, el empleo de la tecnología ha sido y es algo innato en el periodismo y a toda actividad social o cultural del hombre. 
Es imposible separar lo humano de su entorno material o de los signos e imágenes a través de los cuales se da sentido a los sujetos y a su mundo. Por ello, no se puede disociar el mundo material - y aún menos su parte artificial - de las ideas con las que los objetos técnicos se conciben y utilizan, ni de los humanos que los inventan, los producen y se sirven de ellos (Lévy, 2007).

De acuerdo con Debray (2000) la Internet no matará la prensa... sin embargo, los embates sobre el ejercicio de la profesión y sobre su modelo clásico se seguirán sintiendo, quizá por factores asociados a la aparición de la Internet y no a ella misma. Así, para conocer en qué estado se encuentran es necesario construir los entrecruces.

Por ejemplo el ejercicio del periodismo y su financiación en Internet. Quién pagará por una prensa en la red, y cómo lograr una independencia informativa, un periodismo profesional sin las tácticas de la publicidad asociadas al producto periodístico como mercancía? Esta inquietud estaba planteada en el interesante texto: periodismo postindustrial de Anderson, C. W., Bell, E., \& Shirky, C. (2013) cuando se afirmaba que: "Hay muchos factores que apuntan a más reducciones de los ingresos publicitarios y muy pocos que sugieran un crecimiento en los próximos años. Aunque la fase más intensa del desplome de ingresos ha terminado" (p. 10).

Otro de los embates tiene que ver con los sistemas de producción y todo lo que ello implica. Desde quienes producen, dónde producen y cómo lo hacen. Así Anderson et al. (2013), recuerdan la definición de Doc Searls 2011 sobre un periodismo postindustrial como aquel que: "ya no se organiza en función de la cercanía a la maquinaria de producción. (la justificación original de la sala de redacción no era organizativa, sino práctica; las personas que producían las palabras tenían que estar cerca de la máquina que reproducía esas palabras, situada a menudo en el sótano)" (p. 12).

\section{Incertidumbres de los entrecruces entre periodismo y tecnología}

Una de las dificultades de investigaciones que comprometen a la tecnología, es la relativa rapidez con que se introducen los cambios en ella, la volatilidad de los mismos, lo que conlleva incertidumbres, experimentaciones y la casi imposibilidad de hallar conclusiones estables que ayuden a inferir las directrices básicas - en este caso, para la enseñanza del periodismo al inte- 
rior de la academia- y que encuentren su realización práctica y más efectiva en el ejercicio de la labor periodística.

La mediología nos facilita salir de este escollo, al menos en parte, pues al explorar los entrecruces entre, en este caso tecnología y ejercicio de un periodismo especializado, logra dar sentido al momento actual -al presente para poderlo hacer dialogar con su reciente pasado- y esclarece y cuenta lo que parece evidente. Por ello la mediología puede entrar en enfrentamiento con un pensamiento científico clásico al estudiar lo evidente, lo que nadie estudiaría por obvio así que: "Cuando el sabio señala la luna, el tonto mira al dedo", la mediología examinará el dedo que señala la Luna.

Si bien podemos crear vectores que proyecten un estado futuro de los efectos de los entornos digitales y el periodismo, particularmente el político y económico, todas estas propuestas podrían quedarse en el plano de la hipótesis. Los efectos aún no son claros o muy determinantes. Ya hemos visto cómo algunas tendencias en contenidos y la forma de presentarlos, tan populares hace unos años al inicio de Facebook, por ejemplo, se han abandonado con rapidez.

Por otra parte, tormentas mediáticas que podrían haber definido una crisis profunda de la comunicación en Internet, como el caso Snowden del 2013 con el que se liberaron informaciones y procedimientos de vigilancia y espionaje global a través de la Internet, y que eran claramente clasificadas de la National Security Agency (NSA) de los Estados Unidos, no pasaron de ser otra noticia más en una ya larga tradición de escándalos precedidos por las revelaciones de WikiLeaks. No sabemos hasta dónde todos estos movimientos podrían llegar a modificar la base de la Internet y la relación entre sus usuarios, que también afectaría al periodismo digital.

Más allá de esas, a veces apocalípticas visiones sobre el futuro de las relaciones entre la sociedad y la tecnología, nos suscribimos a lo que hemos denominado un "estado actual", así este sea inestable y difícil de encauzar en derroteros determinados, donde la única estabilidad parece ser el propio dinamismo y la lógica de producción que llevada a la red, se convierte en una línea infinita de productos que actualizan cada vez más rápido el presente.

Por eso a nuestro marco de observaciones sobre el periodismo especializado en lo político y económico en Colombia, en los entornos digitales lo 
hemos bautizado como: "convergencias y divergencias". Para llegar a esta pareja de conceptos desarrollamos la metodología de preguntarle a los periodistas sobre cuál es su apreciación respecto a la incidencia de los entornos digitales en la labor periodística. Estas apreciaciones se cotejaron en algunos casos con la observación etnográfica no participante en la recolección de datos al interior de los medios de comunicación y durante las jornadas de producción de noticias.

En el ejercicio del periodismo existen muchos "factores humanos" y humanistas que lo intervienen y todos ellos entrecruzados con los escenarios digitales. Aquí quisimos abordar varios de estos factores: el papel del periodismo frente a los ciudadanos; la ubicación del periodismo político y económico respecto a otros tipos de periodismo; sus efectos en la opinión pública y en la relación con las fuentes y la independencia informativa. La apertura del campo de la tecnología digital al periodismo tampoco es un asunto terminado, ni elaborado concretamente para el periodismo.

Nadie se imaginó al principio que Twitter se convirtiera en una de las principales herramientas para la difusión de noticias en Internet; la lógica de la red social, se asemejaba mucho a la lógica del titular y el lead de prensa. Así mismo, una gran cantidad de aplicaciones digitales de uso genérico comenzaron a adoptarse y adaptarse al periodismo. Ahora bien, el acogimiento o no de tecnologías obedece no solo a las posibilidades técnicas del medio, sino a las directrices y políticas empresariales, derivadas a su vez de tendencias tecnológicas y políticas globales.

La apuesta por las tecnologías digitales en el campo del periodismo y en particular de la prensa escrita -tan hija de la primera tecnología del periodismo como lo es la rotativa y el papel-, es una decisión que aún no encuentra una solución económicamente rentable. No es claro cómo sacarle el mejor provecho al medio en el ámbito digital en cuanto a las ventas del producto. Algunos medios lo han logrado, otros no tanto.

Por ejemplo en España y Estados Unidos numerosos medios pasaron por momentos difíciles: despidieron a muchos periodistas. Se habla de hallar el "modelo de negocio". ¿Estaremos ya seguros de que los estándares de la comunicación del siglo XXI, se basan primordialmente en la interacción y el flujo de datos digitales por la web? 
En 2013 el legendario The Washington Post fue comprado por Jeff Bezos, fundador de Amazon. Teniendo en cuenta que Amazon es la mayor tienda por departamentos en la red y que sobrevivió al desplome de la burbuja de Internet, Bezos se constituye según los expertos ${ }^{4}$, en una esperanza para el nuevo modelo del periodismo. ¿Este será el camino que tomen los diarios?

Ramonet (2011) ve un futuro en extremo sombrío para la prensa escrita y allí para el periodismo. Hablando de los impactos de la crisis de la economía y de las tecnologías, afirma que "Por todas estas razones (tecnológicas pero también deontológicas e ideológicas) la prensa diaria de pago se encuentra al borde del precipicio y busca desesperadamente ideas para sobrevivir" (p. 69).

Los resultados de la investigación, acompañados de su discusión, se presentan en seis capítulos que se distribuyen así: en el primer capítulo se exponen las convergencias y divergencias de los periodistas políticos y económicos de los medios tradicionales sobre los tres ejes construidos y al interior de cada uno. Se tratan variables de control como el lugar del periodismo político y económico en Colombia, la influencia sobre la opinión pública, la inmediatez, la creatividad y la independencia informativa.

En el segundo capítulo se presentan las convergencias y divergencias de los Editores Web e los medios tradicionales, donde también se muestra el lugar del periodismo político y económico, manejo de herramientas digitales y relación del medio con los ciudadanos. En el capítulo tres se caracteriza con estos mismos ejes a los medios digitales, examinando las ventajas de este periodismo al tratar temas de política y economía, el compromiso y las relaciones con los ciudadanos.

Para el cuarto capítulo se tratan brevemente aspectos referidos a los CM. En el capítulo cinco se describen los consejos de redacción y la participación de los entornos digitales. Para el sexto y último capítulo se enumeran, a modo de preconclusión, las carencias más recurrentes manifestadas por los periodistas políticos y económicos.

Carl Bernstein dijo que: "Jeff Bezos, me parece exactamente el tipo de elección inventiva e innovadora necesaria para llevar a cabo una renovación de gran periodismo en la escala que muchos de nosotros hemos estado esperando" (citado por Reyes, 2013, párr. 4). 
Con este desarrollo temático se espera dar cuenta del estado actual del periodismo político y económico en Colombia, a fin de generar reflexiones, discusiones, cambios e intercambios de experiencias entre los diferentes medios.

\section{Alcances de la investigación}

La investigación es de tipo cualitativo con un enfoque hermenéutico y se valió de los métodos etnográficos e interpretativos. Se visitaron distintos tipos de medios, se realizaron entrevistas y observaciones etnográficas de las

rutinas de los periodistas. Se generaron criterios de selección e indicadores de clasificación de los discursos de los entrevistados. Los criterios de selección de los medios fueron los siguientes:

Para los medios escritos:

- Los medios de mayor circulación nacional: El Tiempo y El Espectador, de Bogotá. Los medios regionales de mayor circulación: El País, de Cali; El Colombiano, de Medellín; El Heraldo, de Barranquilla; El Universal, de Cartagena; La Patria, de Manizales, y La Tarde, de Pereira.

- Medios más reconocidos especializados en temas de política o economía: Portafolio, perteneciente a El Tiempo, y La República, de Bogotá.

- Medios digitales nacionales y regionales más reconocidos por número de visitas: La Silla Vacía, de Bogotá; Cali Escribe, de Cali; Zonacero, de Barranquilla; Revista Gobierno, de Manizales; Punto de Vista, de Medellín; El Blog del Ministro, de Pereira; y El Turbión, de Bogotá.

- Revistas de circulación nacional centradas en temas de política: Semana.

- Revistas especializadas en temas de economía dirigidas por el periodista Silverio Gómez Carmona: Petróleo y Gas y Fase 4, editadas en Bogotá.

Para los medios audiovisuales:

- Noticieros de televisión, representativos por algunas regiones: Noticiero 90 minutos (Telepacífico), de Cali; noticiero Hora 13 (Teleantioquia), de Medellín. Además, un noticiero afincado en Bogotá y con visión internacional: $\mathcal{N} T \mathcal{N} 24$.

Para radio:

- Emisoras: Caracol Básica y un medio público: Radio Nacional de Colombia. 
No fue fácil determinar los criterios de selección y evaluación del desempeño de los periodistas-redactores, tales como tiempo que llevaban cubriendo la fuente, premios o reconocimientos, cursos de especialización en la fuente, etc., dado que la movilidad de los periodistas entre los medios y, a veces entre las fuentes, es alta. Por otra parte, en cuanto a "periodistas especializados" surgió la pregunta de cómo considerar el término "especializado", tal y como ya lo referimos arriba. Dado que el número de periodistas especializados académicamente o que por medio de su extensa experiencia pudieran ser así considerados, resultaba reducido y a la vez subjetivo, decidimos entrevistar a periodistas con al menos dos años cubriendo las fuentes de economía o política. Así, el único criterio que cobijó a todos fue su experiencia, que va de los dos años a los 25 años. También se entrevistaron periodistas con una base profesional diferente al periodismo como economistas, politólogos y relacionistas internacionales

Así mismo, los CM no siempre eran periodistas, nos encontramos con algunos tienen como carrera la publicidad o el diseño y que incluso aún no estaban graduados y su trabajo en el medio correspondía a sus prácticas profesionales. Sin embargo, los editores y editores web sí fueron todos periodistas.

Incluir a los CM y a los editores web correspondió a una decisión tomada en los primeros meses de la investigación, dado que nos topamos con un sorpresivo desconocimiento por parte de los periodistas del medio impreso o análogo sobre las dinámicas al interior de la web.

Se construyeron tres categorías que llamaremos ejes, los cuales se elaboraron con los elementos que forman parte del fenómeno que hemos venido refiriendo, con un amplio soporte bibliográfico sobre periodismo clásico, opinión pública y periodismo en la red, y con base en observaciones directas y seguimiento durante varios meses a los principales medios en las redes sociales.

Los ejes abarcan estas temáticas: incidencia de los entornos digitales en las rutinas de los periodistas que cubren los temas de política y economía, incidencia de las dinámicas digitales en el compromiso de los periodistas políticos y económicos con la sociedad y la ciudadanía, efecto de lo digital en la transparencia, el rigor, la verdad y la independencia informativa y cambios en la autopercepción de los periodistas especializados en política y economía frente al entorno digital. 
La investigación se plantea, entonces, los siguientes ejes: de autopercepción; de entorno digital; y ético y de responsabilidad; que son comunes para todo tipo de periodistas, sean tradicionales, web o de medios nativos digitales.

Eje de autopercepción: las preguntas buscan detectar cómo perciben los periodistas el estado del periodismo político y económico en los entornos digitales, y el grado de empatía y compatibilidad de los periodistas especializados con los entornos digitales.

Eje de entorno digital: los interrogantes pretenden evidenciar los entrecruces y condicionamientos de los entornos digitales y el criterio que se usa para la elaboración de los productos periodísticos en temas de investigación, creatividad y la relación con las fuentes, entre otros. Las preguntas y observaciones en este eje se elaboraron en armonía con las discusiones en torno al periodismo digital y las rutinas periodísticas.

Eje ético y de responsabilidad: se examinan los pilares del ejercicio del periodismo, que tienen que ver con su responsabilidad frente a la ciudadanía, su compromiso con la verdad, los posibles nuevos vínculos con los entornos digitales, notablemente progresistas, y la influencia del poder. Las preguntas hechas a los periodistas y las observaciones de sus rutinas se hicieron a partir de la teoría clásica del periodismo.

$\mathrm{Al}$ interior de cada eje se construyeron ítems temáticos específicos que corresponden a los resultados de preguntas individuales o grupos de preguntas, y cuya redacción en los resultados y discusión en varias ocasiones se realiza en coautoría con los periodistas en entrevista, lo que ofrece un estilo que puede parecer inicialmente periodístico con descripciones etnográficas, pero que, como hemos dicho, se complementa luego con una interpretación y reflexión.

Es así como la muestra incluye a 27 medios y más de 50 entrevistados distribuidos en siete ciudades de Colombia, principalmente en prensa escrita, medios digitales, canales de televisión y emisoras de radio. Dos grandes variables dividen la muestra: periodistas asignados a la web y periodistas asignados al medio tradicional, también trabajamos con las variables de medio tradicional y medio solo digital.

Como ya dijimos a todos los grupos se le aplicó los mismos ejes. La única diferencia fue que para los GM y EW se empleó una entrevista con menos 
preguntas para enfocarla más en sus rutinas. Las entrevistas a los periodistas políticos y económicos tenían entre cuatro y seis preguntas por cada eje. Primero las referidas al entorno digital, luego a la autopercepción y finalmente a la ética y responsabilidad.

Las respuestas de los entrevistados se llevaron al procesador de textos Word y luego de una relectura se construyeron tablas de matrices en Excel, sobre las que se hicieron los vertimientos de las respuestas textuales más relevantes de los entrevistados y que correspondían a las categorías de intereses de la investigación al interior de cada eje (véase anexo 1). La construcción, pues, de estas categorías dependió en primera instancia de las preguntas y luego de categorías emergentes en las respuestas. La consignación de los discursos en estas tablas permitió la ubicación de los indicadores con los que se elaboraron los apartes de los capítulos alusivos a los resultados de la investigación.

Las observaciones no participantes se desarrollaron con el método tradicional de la etnografía: observación, toma de notas y fotografías casuales no invasivas; y luego de los encuentros: consignación en tablas de las observaciones (véase anexo 2). Para la consignación y descripción de estas observaciones en las tablas fue de vital importancia el método de la antropología visual: el uso de la fotografía como elemento de registros visuales en cuanto a proxemias, disposiciones de grupos e individuos, objetos y ambientes. El registro de contextos, la ubicación del fotógrafo y el tipo de escenas a tomar (Collier \& Collier, 1986).

Con este material semibruto se hicieron algunos cruces entre las variables y también entre ejes procurando unidad temática. A partir de allí, de los discursos de los propios periodistas, se comenzaron a redactar inferencias y, cuando fue posible, preconclusiones al cotejarlas con teorías o investigaciones previas referidas.

Las entrevistas semiestructuradas se nos presentaron como la mejor opción, por ejemplo, frente a una encuesta, dado que nos facilitaban hacer contrapreguntas, profundizar en algunos temas y nos obligaban a estar presentes. Otros métodos como focus-group o cualquier otro que significara reunir a periodistas para un taller o experiencia, se descartaron ante la imposibilidad de reunir a varios periodistas en un momento mismo del día. Por otra parte, la observación no participante hizo posible mantener la discreción; 
además, podía desarrollarse en los mismos contextos en que se daba la entrevista, bien antes o después de esta. La cohesión de los resultados se logra a través de la aplicación de los mismos tres ejes ya citados. En el caso de los consejos de redacción, los resultados se exponen de manera independiente.

Los objetivos de la investigación están enfocados a conocer el estado actual de las rutinas periodísticas de los periodistas especializados en temas de política y economía en Colombia, evidenciando en este ecosistema la relación de tal periodismo con temas específicos como el papel del periodismo político y económico frente a los ciudadanos en los entornos digitales; influencia del periodismo político y económico (PPE) en los entornos digitales (ED) sobre la opinión pública; efectos de los ED en los productos periodísticos, en las relaciones jerárquicas y en la creatividad de los formatos; papel de los ED en la construcción de la actitud crítica; independencia informativa en el medio; y efectos de los ED sobre el trabajo investigativo y sobre la verdad y la responsabilidad.

Muchos aspectos quedan fuera de este análisis como las decisiones empresariales para bajar costos y sobrevivir en los nuevos escenarios, la exploración de los modelos de negocios de los medios, el examen del comportamiento de las audiencias en Internet e, incluso, la tan cuestionada calidad de la información periodística en Colombia ${ }^{5}$. Es decir, la observación de la convergencia en todos sus niveles. Quisimos entonces recopilar los discursos de los periodistas frente a este estado de cosas, y a través de ellos detectar las ventajas, carencias y complejidades de la sinergia entre los entornos digitales y el ejercicio del periodismo.

En la práctica, esto se traduce en observar las rutinas de los periodistas "especializados en política y economía" o por lo menos de aquellos que cubren esas fuentes de manera exclusiva al interior de los medios; asistir a algunos de los consejos de redacción y en realizar entrevistas a los periodistas asignados a la web. En los consejos se aplicaron tablas de observación et-

\footnotetext{
Si bien no era un objetivo inicial y central de la investigación cuestionar la calidad del periodismo político y económico en Colombia, pues no se manejaron herramientas para su evaluación, en el transcurso de la misma indagación fue apareciendo una serie de alertas sobre este aspecto, muchas de ellas manifestadas por los periodistas, otras emergentes en el trabajo de observación etnográfica.
} 
nográfica que aquí aparecen a modo de textos descriptivos e interpretativos. Con Gerard Dereze (2009) reconocemos que:

Recurrimos a la descripción e intentamos hacer escribir una representación lo más fiel posible de lo que ocurrió, de lo que se dijo... A pesar de todos nuestros esfuerzos de objetivación, una descripción no está nunca desprendida de su autor. En efecto, una redacción, la más literal posible, no escapa a la selección de datos, a los atajos o incluso a la pragmática de la escritura (p. 203).

Las respuestas que emitieron los periodistas sobre el estado actual del periodismo especializado en política y economía, no podrán estar desprendidas de interpretaciones y de ciertas contrastaciones con las funciones, a veces ideales del periodismo en democracia. Por este motivo suprimimos la autoría de algunas declaraciones de los periodistas, comprendiendo que las mismas pueden afectar su reputación profesional o personal y el vínculo de estos con sus jefes o compañeros de trabajo. Algunas interpretaciones generales son, entonces, nuestra alternativa en el entendido de que constituyen el resultado de las percepciones de los mismos periodistas. El trabajo en el terreno con los periodistas y medios se divide en tres grandes grupos:

1. Periodistas especializados en política y economía de medios tradicionales.

2. Editores web y $\mathrm{CM}$ de los medios tradicionales.

3. Periodistas pertenecientes a los medios especializados en política o economía, independientes, nativos digitales.

Además se brinda un apartado con las observaciones a los consejos de redacción de algunos medios, estas son complementarias a las observaciones y entrevistas a los periodistas de los medios tradicionales.

\section{¿Qué entendemos por entornos digitales?}

Para resumir, en los entornos digitales consideramos el factor técnico y la relación de este con la labor periodística. En tal sentido, examinamos en los entornos digitales todos los espacios virtuales que se han generado en esta forma de hacer periodismo, comparándolos algunas veces con el llamado periodismo tradicional o de medios análogos.

Qué sucede cuando un medio o un periodista hace una publicación en un portal o en una red social, qué herramientas emplea, qué prácticas in- 
novadoras se están llevando en la web y cuáles son las implicaciones para su trabajo, hasta dónde se compromete el ejercicio profesional, qué ventajas encuentra en el nuevo espacio de trabajo, cómo están las salas de redacción en los temas de interactividad, "trabajo colaborativo" y transmedia, qué limitaciones enfrenta hoy, con qué recursos cuenta, qué espacios se abren para las audiencias y cómo están siendo utilizados por los medios, y finalmente qué puede aportar la academia para la preparación de los periodistas, en especial de los políticos y económicos en estos entornos.

Por lo anterior el presente estudio es principalmente de carácter descriptivo sobre el estado del periodismo político y económico en Colombia en estos entornos. Con todo, se ofrecen elementos y conceptos teóricos básicos en boga para la mejor comprensión del fenómeno, que en otras circunstancias históricas ha basculado el periodismo mundial. 


\section{Capítulo 1}

\section{GONVERGENGIAS Y DIVERGENGIAS DE LOS PERIODISTAS POLÍTICOS Y ECONÓMICOS}

\section{Eje digital: tejiendo lo digital con práctica periodística}

Tndagamos acá aspectos como el lugar que ocupa el

1 periodismo especializado en política y economía en los entornos digitales. La influencia sobre la opinión pública y los productos periodísticos, las relaciones jerárquicas, la relación con las fuentes, la creatividad, los canales de interactividad, entre otros. Todo esto se considera a la luz de los discursos de los periodistas en las entrevistas.

Política y economía vs. Deportes. ¿Qué importa más?; una fábrica de arepas, entre la viralidad y la banalidad.

Cuando se habla de la ubicación del periodismo político y económico, nos referimos al lugar de prominencia que tienen estas áreas respecto a otras al interior del medio y en las lógicas y dinámicas de los espacios digitales. El nivel de prominencia lo detectamos a través de tres momentos:

1. La observación etnográfica de los consejos de redacción.

2. Los discursos de los periodistas de la autopercepción de su trabajo sobre estas fuentes. 
3. Las respuestas de los editores web sobre el lugar del periodismo político frente a otras fuentes.

Se advirtió en los consejos de redacción, que los temas de política y economía no son los más destacados, se pierden en referencias y comentarios sobre deportes, judiciales o farándula, pero adquieren mayor significación al momento de jerarquizar qué noticias aparecerán primero en los portales o en las primeras páginas (sobre este tema, consúltese en el capítulo cinco las observaciones a los consejos de redacción).

La gran mayoría de los periodistas políticos y económicos entrevistados, al preguntárseles por la importancia de sus fuentes con relación a otras, reconocieron que estas no tenían mayor relevancia entre los lectores, a no ser por temas de coyunturas que según manifestaron se movían muy bien en la red, pero que no necesariamente generaban una conciencia en política o economía.

Los ED, quienes conocen las cifras y métricas de los movimientos por temas, admitieron de forma unánime que los contenidos que más se movían eran los de deportes, fútbol, judiciales, farándula e incluso el horóscopo. Así, mientras que la economía se movía por asuntos que tocaban el bolsillo de los ciudadanos, la política lo hacía en temas de debate, de última hora, de discusiones entre figuras.

El Olimpo del periodismo, como se estimaba al periodismo político, parece relativizarse en las redes. Pero antes de concluir sobre este lugar del periodismo, examinemos otros aspectos: ¿cómo consideran los periodistas políticos el sitio que le corresponde al periodismo político y económico respecto a las demás fuentes? ¿Cuál es la realidad de su lugar en Colombia?

\section{La pequeña fracción del periodismo político y económico.}

Los periodistas de los medios comerciales afirman que "todo es política", que "la política está en todas partes" y que "cualquier nota que se haga, se puede enfocar desde lo político". La postura de los periodistas económicos es similar: "la economía está en todas partes", "cualquier persona en cualquier actividad incluye un pensamiento económico". Ahora bien, los periodistas de los medios independientes y nativos digitales sostienen que "el periodismo político es una fracción muy pequeña del periodismo en Colombia" (León, abril de 2013, comunicación personal). Esta apreciación es compartida por 
otros medios digitales especializados en política como Punto de Vista, Revista Gobierno y Cali Escribe.

A pesar de que "lo político" y "lo económico" en apariencia están en todas partes, ello no asegura el interés del grueso de las audiencias. En los medios "nativos digitales" especializados en política y economía se afirma que fueron justamente ellos, en tanto que medios independientes y especializados, los que abrieron esa "fracción pequeña" del periodismo político y económico, ante la falta de un periodismo profundo y de análisis.

Los periodistas de los medios masivos de comunicación tradicionales expresan que entre las limitaciones que tienen, está el tiempo para hacer las notas, la cantidad de temas que pudieran llegar a cubrir y en algunos casos, el espacio para desarrollarlos. Muchas veces la opción que tiene el grupo de periodistas de los medios comerciales es sacar una nota de una rueda de prensa en materia política, de un minuto o 30 segundos al aire, o una cuartilla, y a este trabajo rutinario y cotidiano se le considera "periodismo político". La mayoría de los periodistas asegura que el ejercicio de un real periodismo político y especializado significaría un reportaje o informe en profundidad, con su contexto y trasfondo, alternativa que está al parecer más a la mano de los periodistas de medios nativos digitales.

Existe entonces una situación de base y es la definición de lo que es periodismo especializado en lo político y lo económico más allá de la temática, como ya lo apuntábamos en la introducción. Al observar las dinámicas de trabajo de los periodistas de los medios nativos digitales, se descubrió que dedican más tiempo a las notas, tienen la oportunidad de salir a la calle a contactar las fuentes y en los consejos de redacción se intenta considerar el trasfondo de la información.

Sin embargo, como es natural, la cantidad de notas producidas es menor. Por otra parte, por su misma posición de "independientes", como se autodenominan, tienen como bandera observar el ejercicio de los poderes públicos, más allá de las fuentes o temáticas, contextualizándolo, describiéndolo, explicándolo, conociendo su trasfondo y analizándolo; y aquellos que hacen activismo, en términos de crítica directa y acción ciudadana. En ese sentido, a pesar de que los medios "nativos digitales" no logran un reconocimiento masivo, sí han abierto el debate que en los medios tradicionales parece ocultarse o menoscabarse. 
Muchos periodistas sitúan el momento del desencadenamiento mundial de la importancia de la política en la red, con el desarrollo mediático de la campaña a la presidencia de Barack Obama en los Estados Unidos. La campaña política llevada a cabo en las redes jalonó el interés por esta plataforma en cuestiones más serias y menos banales. Antes en las redes existía un comportamiento del periodismo con respecto a la política como un elemento más; no obstante, esta campaña demostró la fuerza y el potencial de Internet, sobre todo en la participación en las urnas. Eso ocurrió en el 2008.

El tema de lo político "ha tomado más fuerza", afirman en general los periodistas políticos, en el sentido de que se ve su movimiento en los espacios digitales (portales, redes, foros). Si bien la declaración no se dice con mucho ánimo, pues el periodismo político sigue siendo de los menos consumidos por las audiencias en los entornos digitales. En comparación con los medios tradicionales, por ejemplo, algunos de los periodistas afirman que estos "se están utilizando y se utilizarán para la profundización de temas, mientras que en Internet, de manera inmediata, se dan a conocer temas más superficiales y de manera más rápida” (Guevara, 19 de diciembre de 2012, comunicación personal). Empero, algunos periodistas manifiestan idénticas observaciones sobre la lecturabilidad en Internet, en cuanto a que la gente sí está leyendo artículos extensos en la red y no solamente el tuit (Tovar, 5 de diciembre de 2012, comunicación personal).

Acerca de los temas propiamente económicos en la red, el periodista Juan Carlos Leyton (15 de mayo de 2013, comunicación personal) de La Patria, expresa que "los temas de economía han tomado algo de fuerza; el país está de moda. Esta moda viene sobre todo de la relativa fortaleza de la economía, de los TLC, de las posibilidades de inversión”. Sin embargo, al observar el papel del propio medio, La Patria, la importancia aún no es muy relevante.

En general, en los medios nativos digitales se afirma que el movimiento de los temas políticos y económicos en la web, depende mucho de la coyuntura, del impacto y de los elementos de morbo que pueda tener una nota.

Somos muy morbosos, se hablará mucho de corrupción, habrá mucha desinformación (durante la campaña electoral de 2014), que será parte de los recursos para las campañas y se verá en las redes. En medio de todo, mucho de lo que aparezca allí puede convertirse en una buena noticia (Cárdenas, 28 de febrero de 2012, comunicación personal). 
En general, los periodistas de los medios comerciales aseguran que los temas de escándalos en lo económico y de corrupción en el Estado, se mueven mucho en las redes. No obstante, aparte de estos casos, la cantidad de flujo de información que se ve, es muy poca. La gente la lee y la hace circular menos que otro tipo de noticias. La relevancia de lo político y lo económico es menor frente a las otras fuentes. En el caso de lo económico, la web y el diseño digital han posibilitado volver más visual la fuente mediante diseños, dibujos y gráficos. Este es un ejemplo de cómo dinamizar más los asuntos económicos.

Los periodistas especializados en política y economía sostienen que el periodismo político es poco educativo, de escasa profundidad y poco masivo. "Lo que se ve en la red, con relación a otras fuentes, es que son productos más elaborados, pero los temas de política y economía tienden a ser menos creativos" (Escobar, 28 de febrero de 2013, comunicación personal). Los mismos periodistas manifiestan la dificultad para hacer más atractivas a la política y la economía. En ese sentido demandan más creatividad y pistas para hacer su labor más receptiva.

De todos modos, los periodistas de los medios tradicionales, y aunque consideren que "todo es política y todo puede ser economía", se definen más en términos de la fuente que cubren, independientemente del valor que puedan dar al tipo de información que están haciendo circular. Hay sus excepciones, como es natural.

Los editores de varios medios enfrentados a la presión del tiempo, a las horas del cierre o de la emisión del noticiero, revelaron que la producción de noticia se asemeja a una fábrica de arepas, donde lo que importa es tener algún contenido para lanzar o para publicar en el medio tradicional o en la red. Así la evaluación de la importancia de la noticia política o económica medida a través de su frecuencia de aparición en los medios o en la red, se relativiza, más aún cuando, por ejemplo, en la economía lo que más interesa a los públicos es la economía de bolsillo, y en política las coyunturas de relato novelesco, moviéndose como un virus en las redes. Algunos periodistas comentaron que la falta de credibilidad de las instituciones, también afectaba la prominencia de la fuente.

Les preguntamos a los periodistas que si aparte de informar hacían análisis, o editorializaban o comentaban la nota. Este fue el resultado de dicha inquietud: en los medios comerciales, el análisis de la noticia es diferenciado 
de la noticia a secas. Un reducido grupo de periodistas de estos medios tiene el "derecho" de interpretar o analizar los hechos y contextos de la noticia, mientras que el grueso de los reporteros se dedica a la producción serializada de notas informativas.

Pero este grueso de periodistas no solo tiene la capacidad de analizar o interpretar las noticias, sino que debería poder hacerlo. Es un deber frente a su profesión y frente a la ciudadanía, pero el manejo editorial de los grandes medios debe recaer sobre un grupo reducido de periodistas; así está estipulado en la estructura tradicional de los medios en Colombia, donde la figuración "de algunas estrellas del periodismo", es lo que vale a la hora de generar opinión. Esta situación es más evidente en algunos medios comerciales que en otros. En cuanto a este punto recordamos lo que dice del Moral (2004).

Un periodista especializado está en la posibilidad de analizar la noticia y así debe hacerlo. Entonces ¿quién está en la posición de determinar quién es un periodista suficientemente especializado como para que pueda opinar? ¿La academia, el medio, la audiencia? (p. 26).

Los contextos políticos son determinantes aquí. "Ahora que se vienen las elecciones (presidenciales 2014) veremos mucha actividad en la red, mucho manejo editorial de los medios, mucha guerra" (Cárdenas, 28 de febrero de 2012, comunicación personal). Si esto es así, no tenemos bases científicas para comprobarlo, significaría que los periodistas estarían apoyando líneas editoriales ajustadas a intereses.

\section{Percepción de la ubicación del periodismo político en las regiones.}

La percepción de los periodistas de medios nativos digitales en Cali, Medellín o Pereira es que tales ciudades ya están listas para debates políticos a través de la red. Estos periodistas se refieren acá a temas de interés primordialmente local. Así lo expresaron los periodistas de Cali Escribe y de El Blog del Ministro. Al igual que los periodistas del portal La Silla Vacia, este de temas nacionales. Aseguran que el verdadero periodismo político en general y en la red es casi inexistente, y que no se le da el "correcto enfoque". Dicha percepción también la comparte el portal Zonacero. La situación es también confirmada por los noticieros de televisión regionales visitados. 
Para el subdirector del Noticiero 90 Minutos, Guido Correa (1 de marzo de 2013, comunicación personal), "la red está para informar a nivel más básico, en el noticiero (emisión al aire) los temas de política también son escasos". Así lo constatamos el día de nuestras observaciones etnográficas de las rutinas de trabajo de los periodistas: no hubo noticias de política. En el noticiero de Medellín Hora 13, las informaciones políticas también son exiguas. El noticiero tiene la sección: "Comidilla política", que realiza el periodista Fernando Cifuentes, donde se exponen casos de la política regional, pero con un tratamiento más bien masivo y popular. Esta sección no sale todos los días y combina la información relativamente seria con un manejo irónico o gracioso, estrategia de creatividad para llegar a interesar a los públicos.

Así el tratamiento más en profundidad en estos noticieros, puede ser incipiente. Las notas que emiten al aire son las mismas que se cuelgan en la red y los comentarios de los internautas son pocos, teniendo en cuenta la población de estas ciudades y que estos son los noticieros regionales más importantes. Verificamos que las visitas en la web a una edición de la "Comidilla política”, pasada una semana de su publicación, no sobrepasaba las veinte. Tampoco existe una producción exclusiva para la red, como sería el ideal y como lo dictan muchos de los manuales y publicaciones sobre periodismo digital.

En ambos noticieros se reconoce la situación. En Noticiero 90 Minutos se podría solucionar teniendo más personal y en Hora 13 motivando más a la audiencia. Sin embargo los directores, subdirectores y periodistas de estos medios aseguran que han conseguido mover algunos temas gracias a la red y a que el periodismo político ha logrado más presencia, pero admiten que este protagonismo es relativo, pues todos los demás temas también han ganado relevancia en los entornos digitales. Si bien en algunos casos, los periodistas son más optimistas frente al efecto de la Internet sobre el interés por los temas de política y economía, en general confiesan que el interés y el tipo de periodismo que se está haciendo es el mismo.

A continuación tomamos las palabras de un reconocido periodista que cubre las fuentes de política en Palacio, al referirse a la tradición del periodismo político colombiano que se sumerge en la red y compite con la diversificación de las fuentes. Mauricio Orjuela (septiembre de 2012, comunicación personal), periodista de Radio Nacional de Colombia, resume así la situación: 
A pesar de ser el Olimpo del periodismo por el prestigio de sus fuentes y el grado de influencia que puede tener sobre la vida de los ciudadanos, estos son temas que no alcanzan a interesar a la mayoría, estos temas están relegados: otras fuentes como deportes, judiciales o farándula tienen los más altos marcadores. Solo en temas de coyuntura se ve la relevancia de lo político.

Esto se corrobora con el hecho de que las noticias más consumidas sean las de tendencias, farándula, entretenimiento y actos o datos curiosos. Incluso en diarios tan serios y con su propio nicho, como La República, una de las noticias que más se llegó a comentar, compartir y consultar fue la de una mujer joven que, económicamente hablando, se ofrecía en matrimonio al mejor postor.

\section{Especificidad de la ubicación del periodismo económico en la red.}

Los asuntos económicos en la red funcionan bien en términos de la inmediatez derivada de situaciones como las variaciones de la bolsa, alzas o disminuciones del precio de la gasolina o las tasas de interés. Más allá de la inmediatez, los periodistas declaran que temas de "economía de bolsillo" se "mueven bien en las redes".

Según opinan los periodistas especializados y tal como se contrastó con la información proporcionada por los editores web, los temas de economía son los que menos atención reciben de los internautas frente a todos aquellos que puede manejar un medio (véase capítulo 2). Al preguntárseles a los periodistas por los motivos, consignaron los siguientes:

1. La complejidad del tema hace que sea de difícil tratamiento.

2. Falta de capacidad del reportero para hacer interesar a la ciudadanía. Esta capacidad está en la creatividad y los recursos o herramientas digitales o de diseño que se emplean para informar.

3. El tiempo destinado para desarrollar la nota es limitado.

4. Carencia de una educación del ciudadano desde el colegio o el hogar para construir un pensamiento económico.

Los periodistas especializados revelaron sobre este último punto, que existe una relativa confianza de la ciudadanía con relación a los temas de economía; pues piensa que si hay algún problema, habrá alguien que se ocupe de resolverlo. Se supone que son realidades casi inamovibles, regula- 
das por leyes y por determinaciones a alto nivel y de estructura que no están al alcance del ciudadano común.

Los reporteros entrevistados también manifiestan de diversas maneras que "no existe una fuerte tradición del tema económico en el país", a diferencia del político. Esta situación se alía con la baja capacidad de convocación reconocida por los periodistas. Estas son algunas de las circunstancias que llevan a que el periodismo económico ocupe el lugar que tiene.

Con la caída de Interbolsa ${ }^{1}$ se presentó un interés por parte de los grandes inversionistas, pero no en el ciudadano común que no alcanzaba a comprender la envergadura de la noticia. Existen así dos esferas a las cuales les están informando los periodistas económicos: por un lado, a los grupos y ciudadanos especializados y, por otro, al ciudadano de a pie.

\section{Influencia del periodismo especializado en política y economía sobre la opinión pública en los entornos digitales.}

Podemos pensar que con los entornos digitales, ¿aparece la posibilidad de usar y tomar en cuenta un nuevo indicador de las tendencias cualitativas y cuantitativas referidas a la opinión de los ciudadanos? ¿Este nuevo indicador estaría siendo empleado por los medios de comunicación, tal como lo utilizaría el gobernante en la tradición clásica para saber qué hacer y cómo gobernar?

La opinión pública no es un concepto fácil de precisar. Se han propuesto numerosas definiciones desde la política, la sociología, la psicología social, las teorías de la comunicación y el periodismo. Si bien su conceptualización y uso es anterior al periodismo, para plantear los principales elementos de la discusión partiremos de las reflexiones suscitadas a partir del periodismo y de los medios de comunicación. Podríamos así diferenciar las definiciones y reflexiones contemporáneas sobre la opinión pública ubicándonos en los años veinte con la publicación del libro a comienzos del siglo xx de La opinión pública de Lippmann (2003), donde se afirma que incluso nuestras opiniones que creemos muy nuestras son la reconstrucción de lo que otros han narrado y nosotros nos hemos imaginado. Inlcuso y esto para el caso del periodismo

El caso de Interbolsa estuvo en la agenda del periodismo colombiano durante meses en 2013. Se trató de un importante desfalco en una de las agencias de valores más importantes del país; tales desfalcos alcanzaron efectos internacionales. 
es fundamental, ni siquiera los testigos directos son capaces de reconstruir los hechos de manera fiel. Cada uno de nosotros como testigos o reporteros añade elementos de la experiencia personal.

Así Lippmann (2003) muestra que el concepto puede comprender tanto a receptores como a productores; señala además el grado de subjetividad que envuelve a las opiniones de una audiencia y el nivel de relatividad de la verdad de los testigos o de los productores de contenidos. Por otro lado, el entendimiento de las tendencias de esta opinión sigue siendo un terreno extenso, pues:

[...] Si admitimos que no podemos entender plenamente el comportamiento de otras personas hasta que hayamos averiguado lo que creen saber, no tendremos que evaluar la información de la que disponen, sino que para ser justos también deberíamos tener en consideración la mentalidad a través de la cual hayan filtrado dicha información. Esto se debe a que los prototipos aceptados, los patrones existentes y las versiones estandarizadas interceptan su trayecto final hasta la conciencia (Lippmann, 2003 p. 84).

Esta postura, con su toque psicologista, de todas maneras representa un avance en la concepción marxista de la opinión pública, según la cual existiría una opinión dominante que se impone y difunde desde todas las instancias del poder hacia el resto de la clases sociales. La posición marxista parece reavivarse en las redes sociales gracias a las libertades de los foristas frente a la construcción mediática de las informaciones periodísticas de los medios comerciales en las redes sociales.

Algunos conceptos reaparecen, como el de "lucha", encarnada por las clases oprimidas en constante pugna contra los tiranos que normalmente en la actualidad se identifican con los medios masivos comerciales y sus dueños. En ese sentido, lo que mostraba el marxismo a finales del siglo XIX era el hundimiento de las clases beligerantes y la esperanza del cambio por medio de la revolución y que parecen regresar en el campo de debates en Internet. Así mismo, conceptos del marxismo como la alienación, la falsa conciencia y la conciencia feliz (Marcuse, 1954), retornan en el debate de los medios de comunicación, con la esperanza de suplir la pérdida del producto y lograr la participación de los ciudadanos en los sistemas de producción de información. Gracias a las posibilidades que ha otorgado Internet, los teóricos se preguntan si esta constituye, por lo menos en parte, una solución a un problema olvidado. 
En la antigua sociedad de masas, los receptores no podían responder y menos de manera inmediata. Por lo general, allí toda transformación social dependía de la voluntad del poder; los públicos estaban relegados.

Hoy ya no hablamos de masas sino de públicos, de audiencias, muchos de los periodistas entrevistados hablan de "la gente" y muy pocos de la ciudadanía. Pero más allá de esto, en la web parecemos asistir finalmente al debate sobre quiénes son los que fijan el curso de la opinión pública y la agenda de los medios.

Los espacios para las audiencias en las redes sociales, los microblogueos, los foros - propiciados por los medios de comunicación- y sus posibles incidencias en los poderes, forman parte del debate. Pues acá habría libertad de expresión, pero de nuevo esta libertad parece estar ya mediada con antelación.

Las tendencias de la opinión pública en las redes parecen manifestarse desde la viralidad de una noticia; las tendencias en Twitter parecen ser determinantes tanto para los periodistas como para las audiencias. El número de comentarios y de compartidos y, sobre todo las discusiones en los foros, resultan ser de relevancia. Pero toda esta pasión depositada en la red, en algunos casos, sublima la acción efectiva en forma de protestas, salida a las calles y toma de decisiones por parte de la ciudadanía.

Nuestras observaciones y conclusiones se desprenden de las apreciaciones que están teniendo los periodistas especializados en política y economía, en el entendido de que comprenden y manejan el concepto de opinión pública. Dicho interrogante se planteó también en un momento histórico donde las revueltas de la Primavera Árabe, los movimientos mundiales de los indignados, el descalabro económico del euro, el inicio de las conversaciones de paz entre las Farc-EP y el gobierno de Colombia en La Habana y las revoluciones en Siria, estaban en la agenda de los medios y en los comentarios en la red. Los periodistas económicos aseveran que el tema se ha visto beneficiado en términos generales, pues...

la gente busca y profundiza los temas publicados y esto se nota también en otros espacios como foros, reuniones o en los mismos núcleos familiares; la gente hace esfuerzos por entender los temas, sobre todo en aquellos que les conciernen directamente como salarios, créditos o impuestos (Tovar, 5 de diciembre de 2012, comunicación personal). 
Los periodistas no reconocen en la web algún medio de comunicación que lleve el liderazgo nacional en temas de economía, y así mismo admiten que si bien algunos temas generan movimiento en la opinión pública, igual puede ocurrir con la foto de algún paseo; el error de una cantante al interpretar el himno nacional o un desfalco a las arcas de la nación, todo ello produce comentarios. Los periodistas aceptan esta situación y la usan en su beneficio, así, buena parte del periodismo que se hace y que se pone a circular en la red, se lo hace para llamar la atención y ocasionar movimiento, likes, compartidos. "En los entornos digitales, se puede influir de manera determinante y directa en la generación de opinión pública. Para ello se requiere de suscitar atención y dinamismo que se mide por la participación" (Calvas, 5 de octubre de 2012, comunicación personal).

\section{¿Despertando conciencia?}

Los reporteros encuentran que con las redes se ha logrado despertar conciencia, se nota una participación mayoritaria. Algunos contenidos difundidos por Twitter adquieren tanta relevancia que obligan a que los personajes de la economía y de la política nacional los aborden.

La cuestión de despertar la conciencia de la ciudadanía, es un asunto que los periodistas en Colombia, por lo menos los vinculados a los medios comerciales, tratan de un modo más bien superficial. Los poderes al interior del medio pueden llegar a restringirlos. De hecho, así lo manifestaron cuando se les preguntó sobre la independencia informativa del medio y de ellos mismos, como se estudiará más adelante. Muchos de los periodistas nos dijeron que si tuvieran más libertad en ese sentido lo harían, pero se quedan dentro de los límites que les da el medio. Por eso es que los medios llamados independientes parece que toman para sí esta función. Castells (2009) sobre este particular sostiene que:

Los proyectos alternativos y los valores que plantean los actores sociales para reprogramar la sociedad también deben pasar por las redes de comunicación a fin de transformar la conciencia y las opiniones de la gente para desafiar a los poderes existentes. Y solo actuando sobre los discursos globales a través de las redes de comunicación globales pueden influir en las relaciones de poder en las redes globales que estructuran todas las sociedades (p. 85).

$\mathrm{Al}$ escuchar a los periodistas de los medios llamados "independientes" y de los medios comerciales tradicionales, nos encontramos con una práctica 
muy colombiana: ser muy localistas al momento de querer influir sobre la opinión pública. Un discurso global es prácticamente inexistente. Encauzados en los problemas de la política local, frecuentemente se presentan ajenos a los contextos internacionales. El localismo es una característica histórica del periodismo colombiano, las hipótesis sobre esta condición no las podemos desarrollar aquí. Solo podemos decir, a partir de lo observado, que los periodistas de todos los medios visitados, parecen sobreexpuestos al contexto nacional y, muchas veces, con justificación, dada la prominencia de las noticias que aquí se producen.

Así las noticias de tipo político y económico internacional que podrían reforzar una conciencia nacional son escasas, y por lo común asociadas a las ideas de izquierda y tradicionalmente rechazadas. Esto hace del periodismo político y económico en Colombia algo provincial, sin importar su larga y reconocida tradición.

Los medios no han estimulado en las audiencias una conciencia más universal, lo global lo ven en la farándula, el entretenimiento y los deportes, ejes de una economía mundial capitalista.

El sistema que se erigió en los entornos digitales es más bien cerrado. Los personajes salen a dar declaraciones, trinan sobre el tema, los especialistas y la gente del común se refieren a estos temas en las redes, se convierten en Trending Topics (TT) y aparecen artículos en los blogs. Hay un sistema ya construido entre los medios de comunicación, grandes y pequeños, nativos digitales y tradicionales, los grupos de la sociedad colombiana y los comentaristas de los grandes medios, los comentaristas de los blogs y la audiencia en general. Internet y sus redes sociales son un medio paralelo donde se mide el clima de las noticias.

Infortunadamente este sistema también está permeado en buena medida por comentaristas, opinadores y foristas entre quienes priman las groserías y los insultos personales a los actores de la vida pública. Todo este sistema está auspiciado, muchas veces, por el anonimato. Esta situación ya ha sido referenciada en varias investigaciones previas.

Por otra parte, aunque los periodistas no expresan un sentimiento determinante frente a la competencia, sí se nota un interés por posicionar mejor la política y la economía, para que esta no esté supeditada a la coyuntura. 
El periodismo político y económico también se enfrenta a la gran cantidad de fuentes y contenidos que circulan en la red. Ese Olimpo de las fuentes de información al que aludía el periodista Mauricio Orjuela queda disimulado, "la gente expuesta a tantos contenidos parece no tener ya tiempo de ocuparse de leer artículos de profundidad, de análisis que llevarían a la generación crítica y de peso en la opinión pública” (León, abril de 2013, comunicación personal). En medios especializados en política como La Silla Vacía, ocurre que los lectores entran sabiendo qué tipo de contenidos van a encontrar y que estos siempre se elaboran para tener incidencia pública.

Surge entonces una paradoja, pues de todas maneras el medio va a dirigir la opinión pública. Así se trate de un medio independiente o de uno comercial. La ventaja del primero estaría en proveer al lector "otros" elementos callados en el segundo, para que se pueda hacer su propio juicio. Siguiendo a Luhmann (2000) son finalmente los medios los que se encargan de fijar la agenda a los ciudadanos proponiéndoles temas, los cuales están prefijados por intereses; incluso, la solución al tema está sugerida o impuesta. Así la posible crítica y el debate están ya mediados y disminuidos. Ahora bien, los públicos son de igual modo responsables de poderse alimentar de contenidos variados para hacerse su opinión.

\section{Cambio generacional.}

La formación de una opinión pública consolidada en la web, también es un factor generacional.

El cambio generacional determinará el aumento definitivo del poder de los medios digitales sobre la audiencia. Es manifiesto el hecho de que las audiencias de los medios tradicionales e impresos están muriendo, que un joven de 15 a 25 que se informe por la red, difícilmente no va a abrir un diario (Cárdenas, 28 de febrero de 2012, comunicación personal).

Los que tomen las grandes decisiones serán los que estén en Internet, "hoy aún hay quienes toman esas decisiones leyendo solo los medios impresos" (Abrew, 11 de abril de 2013, comunicación personal).

En el transcurso de nuestras observaciones hicimos notar a los editores web algunas de las temáticas que aparecían publicadas por los medios en las redes sociales como Facebook, Instagram y Twitter, ya que estas parecían enfocarse a públicos más jóvenes. Aunque la pregunta surgió al final de la 
investigación, las respuestas de los editores fue que no había una intención directa en este aspecto. Sin embargo, observaciones posteriores confirman el hecho de que la información sí está fragmentada generacionalmente, al menos en cuanto a la riqueza y diversidad de información para públicos jóvenes que publican los grandes medios en las redes sociales.

El cambio generacional es una realidad al interior de los medios. Las observaciones en las salas de redacción nos mostraron con claridad que no había periodistas veteranos manejando redes, salvo en Cali Escribe. Algunos de ellos admitieron su aversión por esta sección y solo la aceptan como un elemento inevitable del cambio, incluso algunos no tienen interés en el uso de Facebook o Twitter, más allá de una necesidad meramente instrumental para su trabajo. Son los más jóvenes los que ocupan el cargo de CM, incluso son los practicantes quienes realizan con entusiasmo esta labor. El cambio generacional en las salas de redacción será ascendente, donde la base son las redes sociales y los portales de los medios.

\section{Efectos de los entornos digitales sobre los productos periodísticos.}

Una de las mayores inquietudes de los entornos digitales son los efectos que suscitan sobre los productos periodísticos y sobre lo que se está haciendo para posicionar mejor el periodismo político o económico.

Para evaluar este ítem detectamos en las entrevistas que de los criterios clásicos de: inmediatez, proximidad, relevancia, prominencia y singularidad, los más perjudicados eran la inmediatez y la singularidad. ¿Cómo se afectan estos criterios al momento de buscar información, seleccionar y redactar una noticia? ¿Qué papel tienen en las llamadas nuevas narrativas? Nos hallamos con que la mayoría de periodistas no conocía o recordaba estos conceptos.

También se registraron algunos cambios en la prominencia y la proximidad, pero en otros niveles. Con todo, lo que más ha cambiado es la inmediatez que interviene principalmente en las rutinas en el momento de investigar y redactar las notas. Siguiendo a Pierre Lévy (2007), tres elementos han sido claves en la llegada de la Internet al intercambio de informaciones: la "velocidad de cálculo, capacidad de memoria [y] rapidez de transmisión" (p. 11). El requerimiento para este tipo de productos es la concreción, muchas veces en detrimento de la exactitud y siempre de la profundidad. Todos los perio- 
distas manifestaron que por la inmediatez habían sido testigos de errores o que ellos mismos los habían cometido. Los temas prominentes y relevantes se estandarizan en la red frente a los banales o superficiales. La inmediatez de la red hace que numerosos temas parezcan importantes cuando no lo son. Lo prominente se disuelve en lo urgente.

Uno puede hacer una noticia para la web, dos o tres párrafos... Como tienes que hacerlo enseguida, no tienes tiempo de investigar, se vuelve una competencia, por la urgencia, y en esas condiciones no lo hago, o no resulta prominente (Clavijo, octubre de 2012, comunicación personal).

Como ya lo anotábamos, la inmediatez, la premura por la demanda de informaciones, el afán por salir primero en la red, la prisa por alimentar el talego sin fondo que es una red social, restringe la investigación, el encontrar otro lado a la información. También limita el proponer informaciones con mayor desarrollo estético y creativo.

La necesidad de estar primero en la web con una noticia, ha colocado a los medios tradicionales impresos que están en la red, en la lógica que ya se manejaba en la radio (Guevara, 19 de diciembre de 2102, comunicación personal). Twitter ya supera la inmediatez de la radio; esto debe ser así ya que quien esté de primero en una línea de tiempo se podrá llevar la mayor cantidad de visitas al portal, donde de seguro estará la noticia más desarrollada. Lo importante, dicen los periodistas web, es hacer que las personas entren al portal y no se queden solamente con el tuit o el lead de Facebook. Este es un hecho que reconocen y promueven muchos manuales de periodismo en la red.

En el océano de datos en el que vivimos, la inmediatez se convierte en uno de los principales valores al que tienen que aspirar todas y cada una de las informaciones que publica un medio en la red. ¿Es esto positivo? (Romero, 2012).

Para elaborar un producto en el marco de la inmediatez se requiere del uso de las mejores tecnologías a disposición de los periodistas y del medio. Estar en el lugar de los hechos enviando tuits minuto a minuto, con fotos o videos cortos, es una de las demandas que se les hace a los comunicadores. Así la producción de este tipo de noticias tiene dos momentos básicos: primero, hacer avances o estar "atentos", como se dice en algunos medios, mediante Twitter, para avisar y mantener informados a los seguidores en las redes y luego de terminado el evento o el hecho, una redacción de un artículo más 
en profundidad. Esta es una dinámica que no tiene fin, pues las redes deben estarse alimentando constantemente, ya que hay usuarios que consumen a todo momento.

Los periodistas del diario económico La República, por ejemplo, pueden de por sí montar las notas en las páginas del periódico, desde lugares remotos, gracias al computador e Internet portátil y al acceso por medio de un programa de edición. Sin embargo, se necesita buen ancho de banda y conectividad, manifiestan. Un microperiodismo, entonces, aparece dentro de los productos periodísticos y está determinado por el factor tiempo dentro de la inmediatez que exigen los jefes. Esta demanda que contradice el buen periodismo, parece dictarla factores económicos frente a la competencia.

Pero parece que los periodistas también creen en el valor de esta inmediatez en la red y según se desprende de las observaciones etnográficas a las rutinas de los periodistas y de sus declaraciones, "lo importante ahora es la figuración del medio, si se informa más tarde la gente no lo verá, a menos que se tenga un valor agregado" (Leyton, 15 de mayo de 2013, comunicación personal). La idea del valor agregado en la red es una propuesta recursiva de muchos de los reporteros entrevistados (Pacheco, 19 de diciembre de 2012, comunicación personal; Gómez, mayo de 2013, comunicación personal). Un valor no solo respecto al medio impreso sino respecto a los demás medios en la red. La red, en este sentido, no parece tener en cuenta la apreciación ya realizada por Kapuściński (2003) cuando decía que:

Esa equivocada identidad entre los medios y el mundo condujo a un equívoco mayor: a medida que su negocio se hacía más grande e importante, los medios empezaron a encerrarse en una vida propia y desvinculada de la realidad. Si antes la prensa tenía por fin reflejar el mundo, ahora los grandes medios se limitan a reflejar su mundo compitiendo entre ellos. Ya no les interesa tanto lo que sucede afuera, sino que los demás medios no se les adelanten, que no publiquen algo que ellos no tienen (p. 27).

Y para Romero (2012), recordando las palabras del profesor Mezo la búsqueda de la inmediatez por encima de todo conduce a una "distorsión de un principio originalmente bueno, que es la primicia", opina (p. 14).

Josu Mezo es profesor de periodismo de la Universidad de Castilla-La Mancha, Ciudad Real, España. La cita corresponde a una serie de comentarios de Mezo sobre el tema. 
"Esta figuración debe tener por tanto un valor agregado que el periodista debe buscar en la noticia que se emite minuto a minuto vía Twitter, por ejemplo desde el Congreso de la República" (Espejo, julio de 2013, comunicación personal). En el caso del diario La República, los editores de Nuevos Medios reciben informaciones de los periodistas y con estos datos se van montando tuits casi en tiempo real (Sánchez, 11 de abril de 2013, comunicación personal). La figuración del medio en las redes forma parte hoy de su posicionamiento, pero lo que se posiciona, al menos por ahora y en el escenario de los negocios, es el medio tradicional (Leyton, 15 de mayo de 2013, comunicación personal).

Los periodistas también manifiestan que en la lógica de la inmediatez se puede llegar al sensacionalismo, a la falta de profundidad o a informar mal. "Hay que hacer el esfuerzo de contarlo primero y de contarlo mejor, eso hace parte del valor agregado" (Leyton, 15 de mayo de 2013, comunicación personal). La lógica de Internet, incrementa la presión del tiempo que ya estaba presente en los medios.

La disponibilidad de tiempo nos permite hablar con más gente, leer más documentos, observar más, pensar más: trabajar en serio. Del otro lado, resolver las cosas en poco tiempo conduce a la superficialidad y la falsedad, desgraciadamente abundantes en nuestra profesión (Kapuściński, 2003, p. 29).

Por otra parte, no podemos desconocer un efecto que ya señalaron otras investigaciones. Enfrentados a las dinámicas de los comentarios en la red, los periodistas han debido ser más cuidadosos y precisos en sus notas. Son muchos los tópicos que se desprenden de los efectos sobre la elaboración de los productos periodísticos, más allá de las nuevas narrativas. En los juegos de la inmediatez y de figurar primero, en varias ocasiones la cantidad de información que circula en un momento determinado, rebasa la capacidad del periodista y del medio para verificar y cubrir esas informaciones, por lo cual los errores resultan comunes.

\section{La interactividad llega a los consejos de redacción.}

Los medios siempre se han medido en función de un público receptor de los mensajes, de la calidad y sobre todo de la cantidad de estos. Con la posibilidad que abrió la web 2.0 y el constante ascenso en el número de públicos receptores al convertirlos en participantes y emisores, surge la necesidad de 
encontrar un nuevo término para definir a este grupo. En el transcurso de esta investigación descubrimos que muchos periodistas hablan de "la gente", algunos se refieren a "público", otros a "audiencias" y los menos a la "ciudadanía". Ninguno de estos conceptos puede dar cuenta real de las posibilidades de interacción, ni siquiera el de "internauta", que parece más un navegador de las redes, buscando o revisando información y que puede ser anónimo o discreto. La idea de público ya es insuficiente a pesar del modelo de información en doble flujo. ¿Entonces qué nombre darle a ese público interactivo?

En términos prácticos lo que ha ocurrido es que estas audiencias ya pueden colocar mensajes para que todos los vean e interactúen entre sí. La producción del mensaje, siguiendo los planteamientos de la mediología, no es exclusiva de un ente en el proceso de la comunicación. En ese sentido, todos pueden enviar mensajes con carácter de noticia. De igual modo todos pueden utilizar el mismo espectro de herramientas para poner a circular su mensaje: textos, imágenes, videos; instrumentos que por efecto de la web están condicionados a tener unas características especiales.

Por ello lo que ha ocurrido en las audiencias, ahora interactivas, es la ampliación de la posibilidad de la mediación, una necesidad sentida desde siempre y que, como lo dice Debray (2000), corresponde a una "cura antropológica" de la especie humana. Así "[...] la mediación es nuestro destino en tanto que especie: la condición mediológica del hombre es ineludible” (p. 182). Así se ha convertido en un paradigma bien aprovechado por las empresas de los medios de comunicación, esa necesidad humana de la mediación que se alcanza hoy en un proceso de hacerse con el medio y participar en él (redes, portales, foros, la web).

Entre más se esté en la red y se tengan más seguidores en Twitter, la función como mediador se incrementa y apoya a la formación y reconocimiento de los sujetos en el mundo. Mucha de la participación que se da, por cuenta de la interactividad, proviene de ese deseo humano. Hacer de mediador es hacer la función de estar en el medio de dos cosas, es convertirse en el poseedor momentáneo y transportador de un mensaje. Función con atributos divinos, tal como ocurre con Hermes o los ángeles.

Desde nuestro enfoque, y en el contexto que nos ocupa, una audiencia interactiva es aquella que funge como mediadora entre, por una parte, el 
mundo y el medio de comunicación y, por otra, las otras audiencias también interactivas, con mensajes moldeados a interés y colocados para todos, esta vez sobre la misma plataforma digital que es la web, lo que les da no solo la posibilidad de participar sino también de ser reconocidas como mediadoras de una ideología, pues los mensajes tienen la intención de volverse microacontecimientos gracias a los cuales su autor puede autoerigirse como constructor de su propio ser. Participar en la red es hacerse visible, así sea con el anonimato, muchas veces de lo que se trata es de sumar, de viralizar, de tratar de convencer y de querer marcar una tendencia; los públicos han aprendido a hacer propaganda.

Más allá de la idealización cristiana de las audiencias individuales interactivas de convertirse ellas mismas en un medio de comunicación (existen tuiteros o blogueros que tienen tantos seguidores como un medio de comunicación modesto), lo que se pudo constatar en las observaciones a los consejos de redacción y en las charlas con los periodistas es que estas audiencias medidas en la web, se las define con un concepto muy similar a lo que se entendía por "la masa" en las teorías de la comunicación de los años sesenta. Un público más o menos grande que siendo heterogéneo se le puede ahora fragmentar por tendencias y donde, a pesar de pocas excepciones y protagonismos, para el medio de comunicación sigue siendo anónimo.

¿Cómo influye esta interactividad en los medios de comunicación? Los editores web y sobre todo los $\mathrm{CM}$ son las dos figuras que se convierten en fruto de este nuevo sistema. Los CM creados en exclusiva para su relación con las audiencias y a la vez ser los mediadores de estos con el medio, eventualmente participan de los consejos de redacción llevando hasta los demás periodistas y editores las tendencias e impresiones de las audiencias referidas a un tema, lo que puede hacer cambiar las agendas del medio. Así lo reconocieron periodistas de La Patria y El Heraldo. Fernando Cifuentes, del noticiero Hora 13 asegura que:

[...] esa va a ser una realidad que va a desbordar a los medios de comunicación. Por ejemplo, el entregar la agenda a la ciudadanía. Los medios no podrán entregar la agenda a la ciudadanía, pero por lo menos tendrán que negociar con ella (15 de abril de 2013, comunicación personal).

No obstante, en temas propiamente políticos y económicos, la posibilidad de la ciudadanía de repercutir en la agenda es incierta, más aún si esta 
va ganando en autonomía. Frente a estas nuevas dinámicas en la red, para los periodistas son ellos quienes toman las últimas decisiones sobre lo que es o no es noticia (Díaz, octubre de 2013, comunicación personal).

Aquí los periodistas observados manifiestan una tensión con los preceptos de un periodismo tradicional: la solución se va por una negociación entre dar curso a las tendencias de la red y evaluar verdaderamente la importancia de la información.

Así, mientras los públicos interactivos se autoedifican como seres participantes de una polis digital mediante sus mensajes y creen convertirse en mediadores reconocidos (algunas veces lo logran) a través de la participación en los foros de los portales o de las redes, para el medio de comunicación, por lo menos el comercial, lo que le suma son likes y seguidores, cifras comercialmente ventajosas.

Un efecto colateral de los públicos interactivos en las redes, es la visibilidad de lo local, a lo cual los medios no han hecho oídos sordos. Paradójicamente la red con su globalidad ha incentivado lo local, ha dado la posibilidad de conocer los agentes que circulan en las regiones y que interesan al ciudadano de esas mismas regiones. Ahora hay muchas más pequeñas fuentes locales informando.

Esto es evidente en los funcionarios públicos que ahora son más visibles. Y [por] otra parte los temas cercanos geográficamente son los que circulan con mayor velocidad y en mayor cantidad. Pero a veces al informar tanto lo local, por lo menos desde los medios regionales, se presenta una desconexión con lo nacional (Rotavista, 16 de mayo de 2013, comunicación personal).

Periodistas de El Heraldo y El Colombiano también aseguraron que gracias a las redes sociales, tanto los públicos como ellos como medio, se enteraban más de lo que ocurría en la región, arraigando temas de cultura e idiosincrasia. En el caso de El Colombiano, esta situación y la posibilidad del periodismo digital motivaron la creación de espacios de reporterismo en los barrios y comunas.

\section{La singularidad.}

La categoría de singularidad se ha visto afectada. Los periodistas web nos afirman que a los ciudadanos en las redes les atrae más lo excepcional, así no tenga incidencia, ni relevancia, ni proximidad. Así podemos notar 
que lo que antes era gancho para medios populares o sensacionalistas, ahora genera movimiento también en medios más serios, tanto en la red como en el medio impreso. Parece que la diversidad de niveles en la red, desde lo serio a lo más banal, permite jugar más con los límites del periodismo, sobre todo para los medios más serios que ensayan maneras de mantenerse vigentes en las antiguas y nuevas audiencias como ya lo apuntábamos en el tema del cambio generacional.

\section{¿Cambios en la redacción de las notas?}

La obsesión de los medios por posicionarse en lo que se conoce como search engine optimization (SEO) u optimización en la búsqueda de contenidos, ha hecho que la redacción de las notas, los titulares y los lead, cambie quizá para bien:

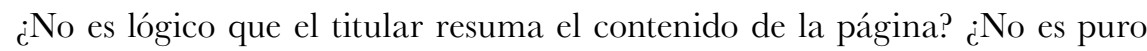
sentido común que un titular contenga todos los elementos fundamentales de la historia? ¿No es lógico que un texto arranque con un resumen que sitúe al lector sobre la totalidad del contenido? ¿No tiene lógica que los elementos destacados vayan en negrita? ¿No es verdad que los lectores valoran las historias originales, las no copiadas? Todas las anteriores preguntas tienen una contestación afirmativa: sí, son lógicas. Si sus textos las cumplen, acaba usted de conseguir un notable alto para los robots y su pensamiento algorítmico (Tascón, 2012, p. 26).

No deja de inquietar que sean, entonces, los algoritmos dispuestos por Google con una lógica del autoaprendizaje, los que "enseñan" a los periodistas a escribir mejor.

De acuerdo con Valle, Gomes, Fernández y García (2012) "la distribución multiplataforma provoca una paulatina hibridación de los géneros periodísticos, homogeneización de la oferta informativa tanto en el contenido, como en la forma". Esto ocurre incluso si se tienen redacciones relativamente autónomas, pues trasladadas al soporte de la red (portal del medio, redes sociales), las noticias de diferente tipo llegan a un grueso heterogéneo de la población del cual se espera más consumo, por lo tanto, muchas veces, las estrategias para lograrlo son estándar, regulando parte de la forma de los contenidos. Esto no es benéfico para un periodismo especializado que puede dejarse llevar por una mainstream. 


\section{Desniveles en las convergencias.}

Entre los medios investigados existen bastantes desniveles en el grado de apropiación y el trabajo en la red que podría afectar los contenidos. Las convergencias digitales operan en diversos niveles y pocos de los medios visitados han logrado verdaderamente dichas convergencias.

Los medios, sobre todo los tradicionales, afirman estar en cambios e innovaciones, en procesos de experimentación, algunos ya con una trayectoria de productos elaborados desde la nueva lógica de producción (El Colombiano, El Tiempo, El País y La República); otros manifiestan haber tocado el tema en los consejos de redacción (La Tarde, Hora 13 y Noticiero 90 Minutos) y otros aseveran estar a punto de implementar los cambios y comenzar a experimentar con nuevos productos (El Heraldo y El Universal). Sin embargo, una inmersión en la red no garantiza innovaciones sustanciales en el trabajo de los periodistas, menos de los tradicionales.

Así como los primeros escritos copiaban las características de la oralidad, los primeros productos en la web han pasado de ser un calco de las hojas impresas diseñadas por ilustradores, a convertirse en espacios con la autonomía propia del soporte; el espíritu de la red es el movimiento, la versatilidad, el color, la interacción, la fluctuación, la renovación, la eficiencia, el minimax, y todas estas características combinadas en posibilidades parecen obligar al periodismo en general a realizar los cambios, afectando los contenidos en cuanto a su presentación y estética. La idea es ser versátiles y que se generen movimiento e interacción. Seguimos la lógica argumentativa de Walter Ong (1987), cercana a la mediología, cuando argumenta que

El cambio de la oralidad a la escritura se registra en muchos géneros de arte verbal, la lírica, la narrativa, el discurso descriptivo, la oratoria (completamente oral hasta la organizada caligráficamente y el discurso público adaptado para televisión), el teatro, las obras filosóficas y científicas, la historiografía y la biografía, por solo mencionar unos cuantos (p. 137).

Lo que quiere resaltar Ong (1987) es que el soporte impone modificaciones a la forma y a veces al contenido. Los cambios se seguirán presentando en el periodismo a medida que se equilibre lo análogo con lo digital, y hasta que este último sea el medio imperante. Uno de los cambios en las narrativas que ya registraron los investigadores es el paso de lo lineal, propio de la escri- 
tura, a lo no lineal, característico del mundo digital. Términos que se usaron primero en los sistemas de edición digital en radio y televisión.

Otra de las transformaciones que observamos al momento en que los periodistas crean la nota para Internet y de acuerdo con instrucciones, más o menos difusas de sus jefes, es la forma como deben introducir la información a las audiencias. Existen literalmente decenas de publicaciones - que no vamos a referir aquí- con recomendaciones sobre cómo redactar y titular para la web. De todas ellas podemos concluir que lo que se busca es hacer aterrizar de otra manera al lector, a las audiencias, sobre la información, la destrucción de la pirámide invertida, el aterrizaje de barriga sobre la cronología de la historia, la punzada constante con la pregunta incisiva y a veces insidiosa.

Aquí el orden de los contenidos permuta, se apela a los conocimientos y a la moral de la audiencia, de tal suerte que algunos elementos que estaban ya predispuestos en un orden en el periodismo clásico, deben ser rescatados y reubicados en la nota. Si estas mudanzas en el caso del paso de lo oral a lo escrito modificaban el orden y la percepción de la historia que se cuenta, en el periodismo, que también es un género narrativo, cambia la percepción de la realidad contada, tal y como estábamos acostumbrados a conocerla.

Aunque como lo declara Ong (1987), estas variaciones no son efecto exclusivo del cambio de soporte; otros aspectos de contexto influyen sobre el producto como "la cambiante organización política, el desarrollo religioso, los intercambios culturales [...]” (p. 137). Quisiéramos tratar este tema en profundidad, pues lo consideramos capital desde nuestra mirada mediológica, pero en aras de los resultados debemos proseguir, no sin apuntar a modo de hipótesis que el periodismo, en un plazo mediano, quizá no sea "el mismo".

Otro movimiento ocurre a la inversa, la conquista de la estética digital sobre el impreso; la relativa autonomía del soporte modifica esta vez las estéticas y formas de lo impreso, tal como ocurrió con El Tiempo, al cambiar sus tradicionales secciones de Bogotá, Nacional o Deportes, por las de Debes Leer, Debes Hacer, etc. En el caso de El País, la estructura del periódico impreso, los nombres de las secciones también cambiaron recientemente: Cali por Entorno, Política por Poder y Judicial o Justicia por Orden. El nuevo modo de organizar las noticias dinamiza y crea conexiones entre temas, uno de los efectos que proponemos de la Internet sobre lo impreso. 


\section{Los canales de interacción que prefiere la audiencia: de la carta al correo electrónico, del correo al tuit y del teléfono fijo al museo}

Las cuentas del medio en Twitter y Facebook son en Colombia las principales vías de interacción de la audiencia, además de otras que siendo más de "la gente" han sido colonizadas por los medios de comunicación como Instagram. Les siguen los espacios habilitados en los foros, muchos de ellos con participación de perfiles falsos para lograr el anonimato. Es así como ocurre un fenómeno curioso: las interacciones de los medios ya no pasan por el mismo medio, sino por soportes y servicios periféricos al propio medio, a pesar de los esfuerzos por redireccionar el flujo hacia los portales. Estos espacios son de gran importancia para los grandes medios impresos, pero en el caso de medios más encaminados a poblaciones populares o regionales, el teléfono fijo sigue siendo protagonista en la interacción de la audiencia.

En los medios digitales, casi toda la interacción se hace digitalmente (entradas y correos electrónicos) y el teléfono resulta ser casi de museo (Puerta, octubre de 2012, comunicación personal). También nos encontramos con periodistas políticos o económicos que no tenían cuentas ni de Facebook ni de Twitter y que se limitaban a redactar sus notas y enviarlas a los servidores o editores. La lectura que pueden hacer de los comentarios a sus propias notas se circunscribe a los foros del portal del medio. La proliferación de dispositivos móviles y el hecho de que quienes están más familiarizados con estos, sean jóvenes, hace que la interacción de los medios de comunicación a través de las redes sociales, se esté llevando a cabo con este tipo de audiencias.

Esto no sorprende en tanto que siempre que irrumpe una tecnología son los jóvenes los que la pueden incorporar a sus vidas, y durante un tiempo, y mientras no cambien sustancialmente los soportes, medios y lógicas de uso, las seguirán empleando en su adultez. Los jóvenes en uso de los canales digitales y con dispositivos móviles generan información que puede ser noticia con videos, fotos o textos en tiempo real. Durante un tiempo se notó cómo los medios de comunicación en prensa o televisión pedían a sus audiencias la participación con estos productos; hoy las audiencias ya motivadas, envían sus "colaboraciones" a los medios (Edo, 2007) de manera "espontánea". 


\section{Efectos de los entornos digitales en las relaciones jerárquicas. Los de la web piden autonomía y más trabajo colaborativo}

Los entornos digitales han afectado con diferente intensidad las jerarquías en las salas de redacción de los diarios y de los medios de comunicación que se investigaron. Estos cambios se presentan por dos causas: primera, impuestas por decisiones administrativas; y segunda, emanadas directamente del mismo contexto tecnológico condicionando las relaciones comunicativas. Además, los efectos se presentan tanto en los medios de comunicación que han modificado los diseños de sus salas de redacción, como en los que no lo han hecho aún, veamos algunos casos:

En medios como Portafolio y El Tiempo, que no han modificado físicamente sus salas de redacción desde una lógica colaborativa de las llamadas redacciones abiertas, los periodistas afirman que los entornos digitales no han hecho cambios significativos, "pues cada actor representa a un jefe o subalterno y eso no cambia" (Torres, 20 de diciembre de 2012, comunicación personal). En otros, los periodistas, al reflexionar sobre esta pregunta, encuentran que si hay cambios ocurren en medios de tamaño más reducido como en El Heraldo, El Universal o Radio Nacional de Colombia. Una periodista de El Universal sostiene que las relaciones, si se han modificado, nos hacen más próximos. El gerente tiene un grupo en el que dice:

“¡Hey, está pasando esto!”. Él se ha vuelto también una fuente. También con el director; todos nos comunicamos a través de un grupo de BlackBerry. Estamos superpendientes de la información que nos dan, él se ha convertido en un ciudadano más, enviándonos fotos; es un compañero más (Clavijo, octubre de 2012, comunicación personal).

\section{Horizontalidades vs. Verticalidades.}

En medios donde se ha rediseñado el espacio de trabajo (véase el capítulo referido a la descripción de las salas de redacción) y donde la convergencia abarca más niveles de relaciones, como en La República, los periodistas encuentran que hay cambios, constituyéndose estos en primera instancia en una decisión administrativa "pues se rotan en las funciones de editor. Eso hace que una vez al mes cada uno de nosotros sea jefe editor de los demás, esto genera horizontalidad, trabajo colaborativo. Comprensión de las funciones de jefe subalterno" (Abrew, 11 de abril de 2013, comunicación per- 
sonal). Pero no solo depende de los administrativos, lo tecnológico también motiva cambios en este diario.

Nuestra comunicación con los directores es directa, ellos saben qué le pasa a uno en cuanto a problemas de cubrimiento y técnicos, toda esta comunicación se hace por WhatsApp, la comunicación entre jefes y empleados tiende a ser más horizontal. La percepción es que se siente a los jefes más cercanos, casi como un compañero más, aunque no se desconoce el don de mando que tienen (Cubillos, 11 de abril de 2013, comunicación personal).

La indagación en este sentido también arrojó otras variantes y nichos a observar, como son las redes internas de los medios de comunicación, y los conflictos entre la parte tradicional del medio y la web. En el caso de El Pais, se cuenta con una plataforma interna para dialogar y compartir información pero está desaprovechada, los periodistas prefieren desplazarse hasta el escritorio de un compañero, del editor para hacer preguntas o comentarios. "Estamos digitalizados en la web, pero no a nivel interno" (Cardona, $17 \mathrm{de}$ mayo de 2013, comunicación personal).

En el Noticiero 90 Minutos la red interna funciona bien, y ella es lugar central para la corrección de los textos de las notas y para comunicarse entre todos los trabajadores del medio. El protagonismo entonces de las mediaciones tecnológicas al interior de los medios varía notablemente, haciendo mudar también las relaciones de comunicación entre los periodistas.

Con independencia de las necesidades particulares de cada medio, lo cierto es que en algunos casos faltan organización y decisiones que normalmente deben partir de la administración y que finalmente no son tan difíciles de aplicar, pero que tampoco deberían convertirse en obligaciones. Sin duda, la tecnología aparece desde la antigüedad como una mediadora en todo tipo de relaciones humanas, creando nuevos contextos de interacción en las relaciones jerárquicas.

\section{De nuevo las generaciones.}

En las observaciones a las salas de redacción notamos que la generación que se vincula en particular a los entornos digitales y web, es la de los periodistas más jóvenes, recién egresados o practicantes. Desde esta premisa se entiende que son los que cuentan con menos experiencia periodística, pero que tienen ya incorporadas en sus actividades cotidianas el uso y aplicación 
de las posibilidades de Internet. Esta situación ocasiona una mutua dependencia, donde los periodistas de la web quedan supeditados a los periodistas o directivas de la parte tradicional o análoga del medio. Intentar generalizar en este sentido es complejo, pues cada medio ha hallado la mejor manera de solucionar los problemas de las relaciones entre el medio tradicional y la web.

Este es un debate intenso al interior de los medios tradicionales y que alimentan los periodistas adscritos a la web. Cuando este hecho lleva a generar falta de coordinación entre el impreso y la web, parece constituirse en un problema de jerarquías entre las partes, como lo expresaron tanto los periodistas del medio tradicional, como los de la web en El Tiempo y El País, por ejemplo. En otros casos, cada una de las partes, impreso y digital, trabaja de forma autónoma, sin ignorar la interdependencia, como en El Colombiano. "No hay subordinación entre las áreas de la web y del impreso" (Jaramillo, 16 de abril de 2013, comunicación personal).

En otros medios, como El País, ha ocurrido que un mismo tema se trabaja de modo independiente, duplicando los esfuerzos del diario o en otras ocasiones una de las partes hace una nota y no la comparte. Así es como se verifica que, en las actuales condiciones, la labor del periodista tradicional tiende a sentirse más independiente que el de la web, pues le basta con hacer su nota y colocarla en las redes internas del medio, para que la sección la suba a la red, así lo asegura la periodista Jaqueline Guevara (19 de diciembre de 2012, comunicación personal) de la revista Semana.

El periodista de la web, tal como se presentan las estructuras de los medios que no han desarrollado en profundidad el tema de la convergencia en el ámbito administrativo, necesita más del trabajo colaborativo. Esta circunstancia es inherente a los medios escritos. Muy al contrario ocurre en radio o televisión, donde no hay aún ningún tipo de producción exclusiva para la web y donde los periodistas que laboran allí, se ocupan más de administrar los contenidos en los portales y en las redes sociales y que son prácticamente idénticos a los medio tradicionales. Parece que el uso de la tecnología queda demostrado ya en las esencias mismas de la televisión y la radio.

Además encontramos que las audiencias pueden estar mediando las relaciones jerarquías: "antes estaba solamente el criterio de uno y el del jefe para determinar qué era relevante o no, ahora también se tiene en cuenta la opinión de los lectores" (Abrew, 11 de abril de 2013, comunicación personal). 
Por último, surge una inquietud en este tema. Si los medios consideran tan importante su trabajo en la web y están buscando la forma de monetizarlo y conquistar científicamente a nuevas audiencias, ¿por qué están allí los periodistas menos experimentados? La naturaleza instrumental del uso de las herramientas o la creatividad no son categóricas.

\section{¿Qué hay sobre las relaciones con las fuentes?}

Aquí hay un cambio significativo en cuanto a la incidencia de lo digital en las rutinas periodísticas. En sus rutinas diarias los periodistas políticos y económicos consultan constantemente el celular o sus cuentas en los computadores para mirar si algún personaje o entidad ha dado alguna declaración o anuncio de último momento. El acceso a las declaraciones de los personajes de la vida pública y política se ha facilitado, este acceso es principalmente mediado por las redes sociales como Twitter y aplicaciones como el PIN del BlackBerry o WhatsApp.

Muchas de las fuentes colocan sus declaraciones en Twitter o Facebook, lo cual ocurre así porque algunas personalidades del mundo político, que también se encuentran en competencia ideológica o económica, están más interesadas en hacerse prominentes en el escenario público y ahora lo pueden lograr con o sin la mediación del periodista. "Otra manera de estar cerca de las fuentes es hacerles solo seguimiento a través de Twitter, lo cual lo puede hacer cualquier persona. Así mismo es posible tener conversaciones a través de esta red social" (Calvas, 5 de octubre de 2012, comunicación personal). "Con los trinos, los periodistas pueden irse ubicando en el tema, pero finalmente es necesario encontrarse con un documento, alguna declaración precisa" (Abrew, 11 de abril de 2013, comunicación personal).

Si nos remitimos a la teoría del periodismo, esto corresponde a lo que se conoce como apariciones, que son "declaraciones elocuentes de personajes. Se consideran periodismo barato y gratuito" (Gomis, 1991) se utilizan para aumentar efectos y amortiguar situaciones, y se consideran seudoeventos. La aparición de Twitter y su uso por parte de las personalidades han llevado a los periodistas a plegarse a esta tendencia que les evita tener que salir a buscar la nota, pero que también estandariza la información, de allí la importancia del valor agregado, del periodismo de datos, cuando se trabaja desde la web. 


\section{Dejarse ver o no dejarse ver.}

Otras fuentes se ocultan, lo que implica que muchas veces el periodista debe esperar a ver qué se declara en Twitter, con lo que la exclusiva de los temas se pierde. También ocurre que la llamada telefónica para conseguir a un personaje es remplazada por la insistencia ante una "arroba" esperando que responda (Calvas, 5 de octubre de 2012, comunicación personal).

Hablando de temas puramente políticos en declaraciones, ruedas de prensa, largos discursos, a las fuentes les sigue gustando el desplazamiento de periodistas, cámaras y micrófonos. Estos políticos aún confían en la televisión y no tanto en la pantalla del computador o móvil. Otros prefieren tener un perfil bajo: no dar declaraciones que salgan en la web, pues saben que allí podrán ser fuertemente confrontados.

La televisión en principio no genera, por lo menos en nuestro país, tanta retroalimentación como la web, o al menos eso cree este gremio. La gente quiere ver las noticias de la web en el impreso, pero curiosamente no quiere salir en ellas. Que salgan todas las empresas, menos la mía (Gómez, febrero de 2013, comunicación personal).

En ese mismo sentido las fuentes deben ser más cuidadosas y responsables, saben que sus declaraciones imprecisas al salir a la red, van a ser criticadas. Lo digital ha ayudado a contrastar mejor las fuentes, así la premura del directo lo dificulte. Reforzar la verificabilidad de la noticia es relevante para mantener la credibilidad de un medio.

\section{Buscando la chiva.}

Las exclusivas y las chivas también se han visto perjudicadas: antaño el acceso a las fuentes era más por cercanía o amistad. "Antes un periodista accedía a la fuente, ya sea porque era muy amigo del ministro, de la fuente. Pongo un ejemplo: un funcionario cualquiera o un muy amigo del funcionario le contaba a ese periodista sus chivas" (Montes, 17 de noviembre de 2012, comunicación personal). Así se adquiría la información exclusiva que posicionara al medio frente a la competencia. Era mucho más complejo si no se tenían los contactos.

Ahora la información es mucho más divulgativa; se la concibe como un derecho que tiene el público de conocer los movimientos de una empresa o de ciertas actuaciones políticas. "Ahora el concepto de que esa noticia es 
mía, y solo mía, ya no existe, ahora el concepto de exclusiva está es ligado al concepto del valor agregado de la información" (Gómez, mayo de 2013, comunicación personal). Por otra parte, hay un alejamiento físico entre el periodista y la fuente, pues el primero no requiere desplazarse hasta donde está la segunda. Numerosos reporteros, sobre todo en Bogotá, manifestaron no conocer personalmente a algunas de las fuentes con las que tienen contacto frecuente en la red.

\section{Más efectos.}

Otros mecanismos más tradicionales como el correo electrónico o el teléfono siguen siendo fundamentales en los medios de comunicación. Y a pesar de que el aparato como tal ha desaparecido de las salas de algunos medios como La República, eso no impide que puedan hacer llamadas a teléfonos fijos desde el computador.

Otro efecto, inesperado, es que las fuentes tradicionales han perdido relevancia, pues en el periodismo de datos, por ejemplo, se prescinde del informante; todo está en la red, ya con fuentes confiables, no es menester la persona. Aunque para algunos temas sí es necesaria, para tener entrecomillados o en el caso de la radio o la televisión, donde es evidente.

\section{Especificidades en lo económico.}

En económicas manejar chivas, a mi modo de ver, es difícil. Es precisamente por la puja de intereses que pueden aparecer y donde las fuentes son quienes manejan el poder económico, por eso la primicia es rara, tienen la facilidad de manejar cuerpos de comunicaciones, así mismo no son los medios quienes ponen la agenda, las mismas compañías le ponen la agenda a los medios (Peña, 19 de noviembre de 2012, comunicación personal).

\section{Sobre la creatividad en los formatos o narrativas.}

Acá debemos distinguir entre las decisiones y posibilidades que las empresas pueden ofrecer a sus periodistas, editores web o personal que maneja la información en las redes; y el trabajo y las posibilidades de los periodistas desde su propia iniciativa. Para este último caso, nos encontramos con que las oportunidades digitales han sido muy poco aprovechadas por los periodistas especializados en política y economía, y paradójicamente es donde más se cree que han influido. Uno de los argumentos que más emplean los 
reporteros para justificar la no utilización de formatos o aplicaciones nuevas es que "el registro y el día a día no dan mucho tiempo para usar o aprender a usar las aplicaciones" (Guevara, 19 de diciembre de 2012, comunicación personal). La mayoría de los periodistas manifiesta ser bastante pobre en la innovación, a pesar de las herramientas gratuitas que la red ofrece. Estas herramientas pueden variar de medio a medio.

\section{Innovar sí, pero en temas de alto consumo.}

En los medios nacionales en la red, sí se ven innovaciones y productos más elaborados, pero están referidos a contenidos de más alto consumo como cultura, deportes o entretenimiento (El Tiempo y El País). Estas posibilidades se deben a determinaciones administrativas, pues están creadas en soportes más robustos que requieren de más tiempo y más personal. ¿Son los temas de política y economía más difíciles de llevar a nuevos formatos? ¿Hay menos motivación para traducirlos a otras formas de presentación? ¿La posibilidad de generar productos mediáticos más interesantes para estas fuentes depende de decisiones administrativas?

Las respuestas a estas cuestiones, según lo expresan los periodistas, es afirmativa. Los medios apuntan a producir contenidos más acabados para temas de alto consumo: entretenimiento, cultura, deportes y, en general, temas de largo aliento. Recordemos lo que dice Kapuściński (2003):

Nuestra profesión siempre se basó en la búsqueda de la verdad: el valor de la noticia o del texto era dar cuenta de la verdad. Muchas veces la información funcionó como un arma en la lucha política, por la influencia y por el poder. Pero hoy, tras el ingreso del gran capital a los medios comerciales, ese valor fue remplazado por la búsqueda de lo interesante o lo que se puede vender (p. 26).

\section{"Lo hemos planteado".}

La presente investigación parece hacerse en un momento de significativos cambios para un alto porcentaje de los medios. Luego del desarrollo e implantación de sistemas digitales, ambientes colaborativos, uso de herramientas y aplicaciones en los más importantes medios de comunicación, los demás de mediano y pequeño tamaño comienzan a tener la posibilidad de hacer estos cambios, bien por condiciones financieras o por decisiones administrativas. "Se está trabajando en el tema", "lo hemos planteado", "estamos 
mirando la viabilidad y ya hemos experimentado con cosas en ese sentido". Son las frases recurrentes.

Todas estas expresiones son muestra de un estado aún primigenio del trabajo creativo de los periodistas, empleando las numerosas herramientas para la investigación, edición de contenidos en la red, en los portales de los medios o incluso sobre las mismas redes sociales, para ir más allá de Storify, Telly, Instagram, Pinterest y acercarse al periodismo de datos, por ejemplo, $\mathrm{y}$ a las decenas de aplicaciones y recursos digitales que no requieren diseños complejos. Algunos periodistas como Juan Carlos Leyton (15 de mayo de 2013, comunicación personal) de La Patria, afirman

[...] haberse contentado con ser muy planos, escribir la nota y quizá subir una fotografía, sabemos que debemos trabajar con más gráficas, menos texto, desarrollar formas creativas de presentar la información [...] nos han dado talleres sobre eso. En el medio no se ha escatimado para informarnos sobre esos temas $[\ldots]$ lo que falta es la determinación final.

El nuevo soporte digital parece propiciar algunas libertades a los periodistas en cuanto a la producción de la noticia. "Libertades de tipo estilístico o estético, jugando con las narrativas, para ser más atractivos y a la vez más masivos, con narrativas a la vez más sencillas yendo directamente al dato" (Abrew, 11 de abril de 2013, comunicación personal). Así lo asegura Nicolás Abrew, periodista económico del diario La República, y concluye diciendo -hablando siempre de las fuentes económicas- "que no se requiere hacer redacciones complicadas para hacer grandes análisis de temas, enfoques y niveles de profundidad o análisis indicados" (Abrew, 11 de abril de 2013, comunicación personal).

\section{En la experimentación.}

En el periodismo existen bastantes recursos para realizar ejercicios experimentales en la red. El País lo hace a través del portal Reportaje 360, con informaciones muy completas multimedia interactivas de temas de largo aliento, referidos a la cultura y sociedad de Cali. Esta llamativa y costosa producción es uno de los mejores ejemplos de empleo de herramientas y aplicaciones digitales que la investigación encontró. Si bien casi todos sus creadores pertenecen a una sección independiente de redacción para el manejo de herramientas con diseñadores, videógrafos, equipos de edición, todo 
el componente técnico; el contenido, la conceptualización, es tarea de los periodistas de la redacción. Sin embargo no se evidenció un uso semejante para los temas de política o economía.

Los periodistas declaran que estas fuentes resultan menos fáciles de tratar visualmente, además requieren de una inversión de tiempo y dinero que el medio no está siempre dispuesto otorgar dado que, entre otros motivos, como se ha demostrado, estos temas no son de gran consumo. "Por otra parte el tiempo requerido para su elaboración es de varias semanas, por lo que claramente resulta impráctico para la noticia del día a día, incluso para un resumen semanal" (Escobar, 28 de febrero de 2013, comunicación personal).

\section{Periodistas polivalientes o polivalentes.}

El esperado periodista polivalente aún no es una realidad y no hay una tendencia clara al respecto. Al preguntárseles a los reporteros sobre esta situación afirman sentirse motivados para desarrollar sus contenidos de manera más creativa. Nos manifestaron que requieren de la ayuda del medio de comunicación en una real capacitación y la disposición del tiempo necesario. Un argumento que escuchamos a un directivo de un medio impreso, fue que si a los periodistas ahora se les facilitaba la consecución de información por medio de la web y ya no tenían que disponer tanto de su tiempo para salir a la calle a contactar las fuentes, este tiempo podía invertirse en la producción de contenidos más elaborados, lo que incluye el manejo de herramientas para la web, siguiendo la línea propuesta por Carlos Scolari (2008) cuando asevera que el periodista de hoy debe ser polivalente para trabajar en multiformato, multiplataforma. No obstante, en las rutinas esto no ha dado resultados y existen periodistas especializados en la edición de imágenes, audios, en el montaje de video y galerías en la red, lo que implica conocer más a fondo las aplicaciones, usos de códigos htlm y ftp. Por el momento lo que puede hacer el periodista es

[...] pensar que su trabajo va a salir en la web, en la .com, en las redes, entonces tiene que imaginar en el momento de la producción cómo podría salir publicado o emitido y proveer (a la web) los posibles contenidos para este trabajo (Gómez, mayo de 2013, comunicación personal).

Los periodistas editores web exponen que una nota periodística se elabora hoy de muchos fragmentos que pueden estar dispersos en la red. Sonidos, 
antiguas declaraciones, informaciones enciclopédicas y documentales. El relativo esfuerzo de creatividad para combinar los fragmentos de las informaciones en una nota, se contrasta con el facilismo temático en Internet, donde hay poca creatividad, pues casi todo es inspirado allí mismo.

Pero un reportero no puede hacerlo todo, tomar la foto, editarla, subirla, colocarle pie de foto. Son periodistas que trabajan con un concepto de lo multimedial. Sin embargo, la mayoría de periodistas es diestra solamente para trabajos muy específicos, como la investigación, la crónica, el reportaje, la redacción propiamente noticiosa, así lo afirma Alejandro Santos (2013), director de Semana.

Las posibilidades también dependen de la empresa. "La empresa ya tiene más conciencia de la importancia de esta plataforma ya que significa un modelo de negocio y los clientes están pautando"; así lo manifiesta Evelyn Rosero (28 de febrero de 2013, comunicación personal) de El País. Esta situación también se evidencia con el comentario de la editora web del Noticiero 90 Minutos: "con lo que tenemos nos toca desarrollar y mostrar a quienes manejan el dinero para que vean e inviertan el dinero" (Figueroa, 1 de marzo de 2012, comunicación personal).

Otra dificultad que se observa es que no se sabe ahora quiénes son los públicos. Pueden ser de muchos tipos, y estar en lugares remotos o cercanos, y pensar en la creatividad sin conocer los públicos, puede ser arriesgado. Por eso se ve tanta experimentación y quizá cada medio deba seguir experimentando para encontrar los gustos temáticos, narrativos y estéticos de su audiencia.

Por último se plantea un riesgo que tiene que ver con la percepción del tipo de información llevada a otros formatos; consideramos que temas de política y economía colocados en un formato de informaciones de entretenimiento, deportes o cultura, podrían confundir, por lo menos en principio, a los públicos más tradicionales.

\section{Más allá de las herramientas.}

Kapuściński (2003) se refería a la creatividad en términos de nuevas narrativas, en el llamado nuevo periodismo, rescatando formas literarias llevadas al periodismo. Más allá de todas las críticas que se le puedan hacer 
a convertir parte del periodismo, en algo muy narrativo, cuando entrecruzamos esa propuesta con las posibilidades que da la red, tampoco evidenciamos que se esté trabajando en ese sentido, en política o economía, en los medios tradicionales, más allá de algunas experimentaciones del portal nativo digital La Silla Vacía. Y como lo mencionábamos antes, en temas de largo aliento.

\section{Efecto e interacciones de los nativos digitales como competencia.}

Está ocurriendo un fenómeno interesante: medios nativos digitales especializados en política, no solo se han convertido en punto de referencia para medios tradicionales, sino que incluso jalonan las agendas de estos. "El medio sí tiene gran incidencia en sectores, quizás intelectuales y políticos de la opinión pública" (León, abril de 2013, comunicación personal). La Silla Vacía no solo tiene influencia en Bogotá, sino también en las regiones para tener otro punto de vista, como sostienen algunos periodistas de las regiones.

Lo mismo acontece con El Blog del Ministro de Octavio Cardona, en Pereira, que según los periodistas del diario $\mathrm{La}$ Tarde es fuente de consulta cotidiana y muchas veces se encuentran allí noticias que el medio tradicional puede ampliar. Esta situación también se presenta en Medellín donde Punto de Vista de Rubén Darío Benjumea es consultado por los periodistas de El Colombiano. La revista digital Cali Escribe, también es referencia para otros medios como Noticiero 90 Minutos y El País. Todos estos pequeños medios digitales pueden adelantarse en temas y primicias que los medios tradicionales, a veces por su misma gran estructura, no alcanzan a captar.

\section{Eje ético: periodista político y económico en la red}

$\mathrm{Al}$ responder por este ítem, los periodistas afirman que la ética no tiene por qué cambiar en los ambientes digitales. Ese aspecto depende de quién hace periodismo. La ética no cambia, por ser un principio básico del periodismo al igual que la responsabilidad, la veracidad y el respeto por las audiencias, todo continúa. Sin embargo la web es más exigente, pues se está más expuesto a los comentarios y al error (León, abril de 2013, comunicación personal). Independiente del soporte, el periodista se enfrenta a los mismos debates éticos. Estas son algunas de las observaciones de los periodistas 
a este respecto, y que por protección de la fuente hemos omitido su autoría: "Sí, siempre ha estado influenciada por lo político y económico, la información siempre es influenciada porque el periodista, de alguna manera, tiene una especie de autocensura".

Siempre hay intereses de todo tipo y el tema político y económico como estructuras de una sociedad tienen mucha fortaleza y así uno como periodista no quisiera a veces involucrarse, dejarse manosear, a veces es inevitable porque la misma circunstancia a veces termina por envolverlo a uno el interés político o económico, para la muestra un botón: ¿quién está detrás, por ejemplo, de El Tiempo ahora? Uno quisiera poder marginarse de eso, pero a veces uno termina envuelto en esa misma esfera.

"Lo impreso es lo mismo que en lo digital, antes había mucha injerencia, con la nueva dirección solo hay sugerencias sobre profundizaciones, pero no sobre enfoques o contenidos. Antes la página era muy manoseada". "Yo ya no me doy tanto rejo con eso, y quisiera que ese discurso tonto de las facultades de Comunicación desapareciera de las aulas". "No me pregunte sobre eso". "Todo depende del tipo de medios, si el medio -digital- está respaldado por otro gran medio de comunicación puede que la independencia sea la misma”. Manuel Castells (1997) describe así el problema:

Los medios necesitan mostrar su independencia como un ingrediente clave de su credibilidad, no solo frente a la opinión pública, sino con respecto a la pluralidad de ostentadores del poder y anunciantes, ya que el sector de la publicidad es el cimiento económico de las empresas de medios de comunicación. Si un medio determinado se liga demasiado a una opción política explícita o reprime de forma sistemática cierto tipo de información, restringirá su audiencia a un segmento relativamente pequeño, apenas será capaz de obtener beneficios en el mercado y no atraerá el interés de la mayoría del público. Por otra parte, cuanto más independiente, abierto y creíble es un medio, más atrae información, vendedores y compradores de un amplio espectro. La independencia y profesionalidad no solo son ideologías gratificantes para los medios de comunicación: también se traducen en buenos negocios, incluida a veces la posibilidad de vender su independencia a un precio más elevado cuando surge la ocasión (p. 268).

Algunas de las nociones de ética en periodismo tienen que ver con informar con la "verdad" con la responsabilidad. Siguiendo el manual de Javier Darío Restrepo (2004) podemos agregar: 
La ética es una utopía, la ética dignifica porque impulsa a la excelencia, la ética de una profesión se conoce si hay una conciencia de identidad profesional, los dilemas éticos no se mueven entre lo correcto y lo incorrecto sino entre lo bueno y lo mejor, para ser un periodista ético se requiere una etapa previa: la de ser buenas personas (p. 30).

Pero ante estos preceptos el periodista, como ya se dijo, se enfrenta a poderes, miedos, presiones de colegas, de la competencia, de los jefes, malos salarios, inmediatez y viralidad de las informaciones.

Nuestra inquietud investigativa se apoya en la idea de que el acceso y la distribución de información a través de nuevas tecnologías puede "liberar", de alguna manera, los flujos por nuevos canales que podrían escapar al control central de un medio o de un poder gubernamental o de moldeamiento de pensamiento.

La capacidad de las redes para introducir nuevos actores y nuevos contenidos en el proceso de organización social, con relativa independencia de los centros de poder, se incrementó a lo largo del tiempo con el cambio tecnológico y más concretamente con la evolución de las tecnologías de la comunicación (Castells, 2009, p. 42).

Esto desde la Revolución Industrial a la Internet, pero en cada caso parece que el apoderamiento de las redes por parte del poder se ha dado en mayor o menor medida transformando a las redes de comunicación de sistemas más horizontales, en otros más verticales. Paradójicamente los periodistas y los públicos en Colombia son más bien sumisos respecto a esta situación. La independencia periodística de los medios no representa un gran valor para la sociedad nacional, muy a diferencia de lo que puede ocurrir en Inglaterra con The Guardian, por ejemplo ya no tanto con la $B B C$ de Londres. Hay amplia complacencia de los grandes públicos con los grandes medios que se saben cercanos al poder, muy a pesar de las constantes denuncias de las ciudadanías en las redes sociales, en muy pocas oportunidades alcanzan las agendas y los poderes detrás de los medios.

El ideal de libertad otorgado por la red y que podría haber sido ventajoso para los periodistas en cuanto a difusión de informaciones y a veces en cuanto a investigación, se ve opacado por el poder de las directivas y decisiones del medio, en una mayor o menor medida según la rigidez de la línea editorial. El periodista sabe para qué medio trabaja y en ese sentido acepta de manera implícita las restricciones que se le imponen. 


\section{Los poderes llegan por igual a la web.}

Podemos interpretar que los entornos digitales al interior del medio no parecen haber modificado mucho las influencias de poderes sobre los periodistas que podrían incidir sobre su trabajo periodístico. Los periodistas han expresado cuestiones que van desde la mitología ampliamente extendida, de que absolutamente todo está dedicado a replicar los intereses políticos y económicos, a la evidencia aceptada por ellos de que jamás, al menos en los medios comerciales, podrán estar ajenos a este tipo de influencias, o hasta que nunca les han indicado qué decir o qué escribir. La verdad, la responsabilidad, preceptos clásicos defendidos por el periodismo en función de la ciudadanía, la verificabilidad y, en últimas, la ética periodística, quedan muy en entredicho. En la red no parece haber cambios de fondo. No obstante, como lo consigna Castells (2009):

Allí, el principal activo en la capacidad para programar cada red es el control de las redes de comunicación, o la influencia ejercida sobre ellas, y la capacidad para crear un proceso de comunicación y persuasión efectivo que favorezca los proyectos de los supuestos programadores (p. 71).

Hay una ética, sí, pero solo hasta donde la independencia se los permita, igual pasa con la responsabilidad social, solo hasta donde las fuerzas políticas o económicas les permitan, en caso de que quieran hacerlo. Están en juego su trabajo, su salario, su carrera.

Lo interesante radica en la posibilidad de las audiencias de complementar o debatir las informaciones, pero en el mar revuelto que se convierten los espacios de debate, el hacer públicos los datos y su verificación resulta prácticamente improbable para la opinión pública.

\section{La independencia informativa: una cuestión de estructuras.}

La independencia informativa también varía de acuerdo con el gobierno de turno y con el estado de la economía, la política y la democracia. Elementos que forman parte de la macroestructura ${ }^{3}$, en la cual, para un análisis,

Javier Fernández Del Moral (1993). En Periodismo especializado, asegura que un verdadero periodismo especializado debe significar un trabajo sobre la estructura de la información que depende de tres niveles: macroestructura, mesoestructura y microestructura. A la macroestructura le corresponde la observancia del sistema político y judicial en el que operan determinados medios de comunicación. La 
se debe tener en cuenta el contexto y el sistema político y judicial en el que participa el medio de comunicación.

En momentos como el que atraviesa Colombia durante la presente investigación 2012 y 2014, en apariencia no hay mayor injerencia, pero gracias a un consenso tácito en los medios, las políticas del Estado tienden a no cuestionarse y los mensajes llegan ya filtrados, según manifestaron algunos periodistas (Benjumea, 16 de abril de 2013, comunicación personal; Calvas, 5 de octubre de 2012, comunicación personal; Peña, 19 de noviembre de 2012, comunicación personal) en el mismo sistema macroestructural,

[...] hoy hay más partidos y más gamas ideológicas, esto impide en la mayoría de los casos la polarización de las audiencias a partir de la información y del origen mediático de la misma. El papel del editor está ahora también en mirar las tendencias de la audiencia, para generar nuevos tópicos y enfoques (Cárdenas, 28 de febrero de 2013, comunicación personal).

Estos enfoques entran a negociar con el poder. Así mismo, el medio y el periodista tienen acceso a más fuentes, a redes y a bases de datos nacionales e internacionales y las exigencias de la información y del mercado les obligan a ponerse en contacto con ellas. Así la injerencia del poder también entra a negociar con ellas. Existe una libertad dentro de unos parámetros, pero prácticamente todos los periodistas expresan la imposición de agendas y enfoques, y el periodismo en la red no da más libertad, más allá de una estilística en las "nuevas narrativas" que no liberaría al periodista de la posible intromisión en su oficio. El subdirector de Noticiero 90 Minutos afirma que la red no tiene ninguna incidencia particular y que el noticiero, por ser parte de una universidad, la Autónoma de Occidente, trabajó con estudiantes en la web y que

[...] se los blinda, en la mayoría de las veces, frente a intereses políticos, pues su contacto con la fuente ha sido poca. Y en cuanto a lo económico, la información que aparece es tan básica y de bolsillo que no desencadena tampoco dilemas (Correa, 1 de marzo de 2013, comunicación personal).

De lo anterior podemos inferir que a los otros periodistas, a los profesionales, algún ente con poder, en algún momento, sí les han hecho ofrecimientos

mesoestructura atañe a la propiedad de los medios de comunicación, de oligopolios a monopolios y a las relaciones que establece con los periodistas adscritos a estos medios, y la microestructura corresponde a la construcción del mensaje. 
o insinuaciones sobre cómo llevar a cabo su trabajo y que los periodistas jóvenes no están teniendo la oportunidad de salir a la calle a hacer ese tipo de reportajes que los expondría con esos poderes. Lo que demuestra finalmente la existencia de esos poderes y el protegerse de ellos, muchas veces no informando sobre los mismos.

Los medios que son solo digitales manifiestan ser más independientes, sin embargo por ser medios pequeños, las respuestas obtenidas para esta investigación provienen de sus dueños o directores. Algo que sí es claro es que una menor inversión en el medio por parte de empresas o grupos influyentes, es el ambiente que propicia una mayor libertad informativa.

La reflexión que nos dejó la observación de las rutinas de los periodistas, es que su trabajo parece ser profundo y complejo. Se llenan los espacios de la prensa con información y datos de todo tipo. Tener algo que decir, algo que mostrar, es a veces lo importante en un medio comercial.

La complacencia con el poder, el decir solo hasta un límite para no incomodar, es el estado del periodismo que se ha detectado. El compromiso con los ciudadanos se desvanece, incluso al punto de referirse a ellos como "la gente", un término que nos recuerda el de "la masa" de los años sesenta.

En los foros, en los blogs, en la red en general, aparecen más informaciones de las que los medios tradicionales quisieran decir, aunque en tal cantidad y puntos de vista que es difícil para la audiencia estándar discernir sobre lo que es cierto y lo que no, además de que la información allí aparecida, publicada muchas veces por los mismos internautas, carece de elementos básicos del periodismo como la verificabilidad y el contraste de fuentes. La proliferación de autocomunicación (comunicación producida por la audiencia, como la califica Castells, (2009) se constituye en una cantidad de datos, textos, fotos, de un autismo comunicativo. Los blogs que están al interior del mismo medio tienen más oportunidad de ser leídos, pero más posibilidades de ser coartados. Siguiendo a Castells (2009), la posibilidad de resistencia

[...] se efectúa mediante los dos mecanismos que constituyen el poder de la sociedad en la red: los programas de las redes y la conexión entre ellas. De este modo, la acción colectiva de los movimientos sociales, en sus diferentes formas, pretende introducir nuevas instrucciones y códigos en los programas de las redes (p. 79). 


\section{El balance lo pueden lograr las audiencias activas.}

El balance de la información está provisto por las audiencias en las redes. La mayoría de los periodistas nos comentó que hacer crítica al financiador sigue siendo complicado (Peña, 19 de noviembre de 2012; Rotavista, 16 de mayo de 2013; Tovar, 5 de diciembre de 2012). Los periodistas sienten que las presiones sobre la libertad de información vienen más de la pauta comercial que de las políticas de partido o ideológicas. De todas formas, cuando la información aparece en la red, esta puede hallar su balance gracias a los comentarios que dejan los lectores (Cárdenas, 17 de mayo de 2013, comunicación personal).

En los medios nativos digitales que se autodenominan independientes (Benjumea, 16 de abril de 2013; Dada, 19 de abril de 2013, comunicación personal; León, abril de 2013, comunicación personal; Paz, 20 de abril de 2013, comunicación personal; Varela, 28 de febrero de 2013, comunicación personal), se encontraron argumentos como no pertenecer a los partidos tradicionales de abolengos, ni estar, en principio, apoyados o fundados por grandes emporios económicos. No les interesa hacerse con alguna causa política de partido determinada. En estos medios, más que lograr un balance en las redes con informaciones por parte de los lectores, lo que se obtiene son complementos que sirven a los periodistas para seguir profundizando sobre los temas.

\section{Papel del periodismo político y económico frente a los ciudada- nos en los entornos digitales. Entre la interactividad y las líneas editoriales.}

Los periodistas de los grandes medios son conscientes de la doble responsabilidad que tienen: una, frente a los conglomerados económicos o políticos dueños de los medios y allí mismo ante los contextos políticos, y la otra frente a las audiencias, en el sentido de informar con veracidad lo que la sociedad quiere y necesita.

Los entornos digitales han hecho posible que los periodistas especializados en política y economía se interesen más en los ciudadanos y tengan las herramientas para lograrlo. Así lo revela, por ejemplo, el periodista de política Fernando González Pacheco (5 de diciembre de 2012) de El Tiempo. Pero al mismo tiempo existe un "desfase entre la opinión que se expresa por parte de los ciudadanos y el lenguaje utilizado por los periodistas" (Tovar, 
5 de diciembre de 2012, comunicación personal). Estos últimos alegan una dificultad para apropiar las inquietudes e intereses de la ciudadanía.

Los periodistas confiesan que es difícil para ellos concretar y llevar a las publicaciones las opiniones y los sentimientos de la audiencia. Por otra parte, algunos de los argumentos que expresan los ciudadanos están elaborados más con el corazón que con la razón. Así las cosas, la interactividad puede verse disminuida por la misma dificultad que declaran los reporteros.

Por otro lado, los periodistas económicos señalan que han encontrado dificultades para explicar temas complejos para la ciudadanía (Leyton, 15 de mayo de 2013, comunicación personal; Peña, 19 de noviembre de 2012, comunicación personal; Tovar, 5 de diciembre de 2012, comunicación personal). Este inconveniente lo podemos resumir así: existe una brecha entre el lenguaje periodístico político y económico y el lenguaje de los ciudadanos, lo que complica la interacción directa por los canales digitales y la redacción de las notas. Bajar la complejidad de los temas a lo cotidiano, sin que pierda importancia la noticia o acontecimiento, es el reto que ha aparecido luego de que los periodistas pudieron conocer mejor las inquietudes de las audiencias.

Este papel se define como "más interactivo, más especializado y más útil para 'la gente', en cuanto a fuente de información. En esa interactividad está el poder responder de manera más rápida y acertada" (Leyton, 15 de mayo de 2013, comunicación personal).

Sin duda, luego de los entornos digitales y particularmente de las redes sociales, se puede responder con mayor facilidad y de modo más oportuno a las audiencias; empero, se reconoce a su vez que existen otros intereses. Como lo indica Juan Pablo Calvas (5 de octubre de 2012, comunicación personal) director, en ese entonces, de información y noticias de Radio Nacional de Colombia (hoy Señal Radio Colombia):

Buena parte del periodismo que se hace es para los mismos políticos, para los empresarios, para el medio o para el mismo periodista que se convierte en estrella en las redes sociales; la inclusión de los ciudadanos se da en los grandes medios en el momento que le convenga al medio.

Así, parte de las malas prácticas asociadas al periodismo tradicional se traslada al digital, que a su vez da tanto la posibilidad de mejorar el periodismo, como de desarrollar nuevas malas prácticas. 
El director de revista Semana, advierte que un medio debe tener una línea editorial clara y que esto no debe confundirse con una mala práctica (Santos, 2013). La información es una sola y al momento de llegar a la web se la empaca en diferentes formatos. Unas buenas prácticas son las referidas por Cardoso (2011) citando a García de Torres, et al. (2011):

Calidad y gestión de los contenidos generados por los usuarios; legitimidad del enmascaramiento de los flujos alocutorios (es decir, utilizar mensajes en un contexto conversacional para generar tráfico); convivencia del periodismo profesional y amateur al mismo nivel; emergencia de autocomunicadores profesionales en el marco de las organizaciones periodísticas; transgresión, en la práctica, de principios periodísticos consolidados (p. 3).

Todas estas buenas prácticas las podemos convertir en preguntas: ¿ise está dando correcta gestión a los contenidos? ¿La forma como se hace la interacción con ellos es ética, comunicativamente hablando? ¿Y a las informaciones que lo merecen se les está dando su reconocido lugar, se acepta la innovación?

Las maneras de darse a la ciudadanía, considerar sus demandas o inquietudes, varían sustancialmente de medio a medio y dependen de las líneas editoriales de estos, así como de la apreciación diferenciada entre directivas del medio y los periodistas que están en contacto con la red. Las directivas, según sus intereses, tienden a ver la relación con las audiencias de forma más distante.

\section{Sobre el activismo.}

En general, tanto los periodistas de los medios tradicionales como de los medios nativos digitales, exceptuando a El Turbión y en cierta medida a Punto de Vista, manifiestan no hacer "activismo" con la ciudadanía. Así por ejemplo lo expresó claramente Juanita León, del portal La Silla Vacía.

El ser conscientes de su papel frente a los ciudadanos, no significa sentirse obligados a hacer activismo. Sin embargo, cuando el medio tiene una línea editorial marcada como El Colombiano y se genera así opinión pública, surge un tipo de "activismo pasivo". De igual manera, la posibilidad de influir sobre el ciudadano de modo más racional y no por pura retórica o persuasión, requiere de un ciudadano con cierto nivel cultural e intelectual que pueda intervenir en la toma de posiciones que tengan algún grado 
de incidencia en la sociedad. Las directivas de los grandes medios parecen evadir la toma de una posición en tanto que activistas, sea en la web o en el impreso, colaborando así con un consenso. Los periodistas lo saben y así lo mencionan en las entrevistas.

Por otra parte, los medios también le están apuntando a cautivar a las audiencias mediante la inclusión de temas o contenidos cercanos y con capacidad de reacción. Se crea con ello una relación más directa y más frecuente del medio con las audiencias, lo cual se nota particularmente en los medios de prensa y televisión consultados. Los periodistas manifiestan que las redes y el periodismo en la web lo que ha hecho es masificar la información; otros afirman que más que una masificación es una democratización propiciada por los ambientes digitales y el uso adecuado que le da el medio. A la vez que se democratiza la información, el medio se legitima gracias al otorgamiento de espacios de participación de la ciudadanía.

\section{Generando actitud crítica en la web.}

Regresar a interrogantes tan fundamentales para el periodismo en un país como Colombia puede sonar inoficioso, más si los planteamos desde los medios de comunicación comerciales y tradicionales. Con todo, la pregunta sobre este punto se la proponemos a periodistas que tienen una formación humanista, que se han enfrentado a sus propios principios y que también son ciudadanos del común, subsidiarios de un sistema político y cultural.

Somos conscientes de la necesidad de generar una actitud crítica frente a la sociedad, a las políticas de los gobiernos y a los medios de comunicación. Pero incluso esos espacios del defensor del televidente, por ejemplo, se desvanecen en programas de poco interés, de media noche, donde solo los ven aquel que demandó y unos cuantos más, lo que de alguna forma demuestra el interés del medio por la crítica y de la propia audiencia.

¿Cómo percibir la actitud crítica de las audiencias? Para los periodistas no basta con que estén informadas o incluso bien informadas. "La retroalimentación de lectores bien informados no es muestra de actitud crítica" (Leyton, 15 de mayo de 2013, comunicación personal). Cuando la gente exige explicaciones mejor elaboradas por parte de los periodistas para dar respuesta a situaciones que la afectan, tampoco puede considerarse una actitud crítica de peso, más allá de un interés individual de la audiencia. 


\section{La audiencia también es responsable.}

Luego de escuchar las respuestas de los periodistas y de muchas veces encontrar en ellos cierta fatiga con relación a este principio, nuestra conclusión es que la actitud crítica no es una responsabilidad solo del medio. El ciudadano debe tener la responsabilidad de verificar y contrastar la información que le llega o a la que tiene acceso, y a partir de allí animar debates inteligentes en la red. Pero lo que ocurre es que buena parte de estos debates se realizan desde subjetividades extremas y no con los mejores argumentos ni expresiones. "En las redes sociales lo que ocurre es un libertinaje crítico" (Cárdenas, 28 de febrero de 2013, comunicación personal). Otros "se quedan en la inmediatez de la red, no les da información y no muestran actitud crítica" (Arias, 16 de abril de 2013, comunicación personal). La responsabilidad del periodista puede estar solamente en dar a conocer una noticia: "informar". El complemento de un ciudadano también riguroso como el periodista, es lo que podría estar haciendo falta al otro lado de la balanza.

Los periodistas entrevistados, en general, sostienen que la discusión que se hace en los foros de las noticias en las .com o de las noticias que se publican en Facebook, dan cuenta de una naciente actitud crítica frente al estado de las cosas, lo cual es favorable para la construcción de la democracia, de una sociedad y de una formación política.

La actitud crítica se presenta incluso de cara a los tratamientos periodísticos y no solo de cara a la noticia: falta de profundidad, enfoques perversos, desinformación, carencia de contrastación de fuentes, sesgo, escasez de equilibrio y hasta cuestiones de forma en la elaboración de titulares, redacción y ortografía. A menudo los periodistas deben modificar sus informaciones por llamados de atención de los lectores en la web.

La gran cantidad de información que indiscriminadamente circula en la red hace del periodismo especializado en política y economía un rubro más entre la gran oferta (Cifuentes, 15 de abril de 2013, comunicación personal). Para el ciudadano común que no tiene un interés particular, estas noticias se quedan estandarizadas frente a las demás informaciones, haciendo más difícil la tarea de los periodistas de política y economía para lograr destacar su trabajo y para la ciudadanía muy arduo concentrarse en la avalancha de datos en la red. A este fenómeno, Ramonet (2011) lo llama "censura democrática" y lo define así: "En las sociedades democráticas, la información ha 
llegado a ser tan abundante y a estar tan infectada de parásitos (soft newes, infotainment, trans news), que literalmente nos asfixia y nos impide conocer qué 'otra información' se nos oculta” (p. 46). Ello, junto con el contexto del mundo "afuera" de la red, conlleva una virtual apatía y fatiga por parte del ciudadano crítico.

\section{Respondemos a las necesidades de la audiencialno hacemos periodismo para la gente.}

El movimiento que tenga una noticia en la red da cuenta del interés que hay por el tema y de la retroalimentación entre los comentarios y la misma información. Algunos periodistas, como Karen Rotavista (16 de mayo de 2013, comunicación personal) de $L a$ Tarde, al evaluar lo que dicen las audiencias en los foros o en las redes en Internet, afirman que "sí la hay (actitud crítica), pero hay que saberla manejar, (desde el medio) hay que saberla propiciar; jugar con la participación para que se interesen en los temas políticos. La gente puede participar y generar debate". En términos similares se refiere Diego Sánchez (15 de abril de 2013, comunicación personal), subdirector del noticiero Hora 13, al decir que ahora "hay más medios para construir la actitud crítica".

Creemos en esta investigación que estas posturas respecto a la formación de la actitud crítica presentan algunas fisuras y parecen encaminarse más a la formación o direccionamiento de la opinión pública. Una investigación ulterior podría ahondar sobre este aspecto. Sin embargo, estas respuestas nos dan un marco para comprender qué se está entendiendo por actitud crítica. Citemos a Castells para encauzar nuestra pregunta. ¿Qué podrían hacer los periodistas en ese sentido?

Los valores que plantean los actores sociales para reprogramar la sociedad también deben pasar por las redes de comunicación a fin de transformar la conciencia y las opiniones de la gente para desafiar a los poderes existentes. Y solo actuando sobre los discursos globales a través de las redes de comunicación globales pueden influir en las relaciones de poder en las redes globales que estructuran todas las sociedades (Castells, 2009, p. 85).

Un alto porcentaje del periodismo que se hace en la red, lo señalan algunos periodistas y editores web, se hace para llamar la atención, consolidar una marca o estimular una opinión, antes que para responder a las necesidades de los ciudadanos, corroborando de esta manera lo que dice Ramonet (2011): 
[...] hoy los medios de comunicación acorralados, tienden a responder únicamente en términos de audiencia. Una "buena" noticia es aquella que puede interesar al mayor número de gente. No aquella que, por ejemplo, es más útil para la población, más decisiva o más esclarecedora en materia de economía, ecología, de política (p. 16).

Así dándoles a las audiencias contenidos que quieren y no los que necesitan para esclarecer asuntos fundamentales, la actitud crítica se desvanece.

\section{Actitud crítica hasta para abrir una publicación en papel.}

Esta actitud crítica podría manifestarse según Castells (2009) en temas como "la conciencia de un destino común del planeta que habitamos, ya sea en cuanto a medioambiente, derechos humanos, principios morales, interdependencia económica global o seguridad geopolítica" (p. 167)

La actitud crítica local, a nuestro modo de ver, también debe pasar por una actitud crítica global más allá de la Internet. En lo que pudimos observar, en los medios nacionales, incluso en los grandes medios, los comentarios de los periodistas sobre estos temas aludían a cuestiones nacionales o muy locales. Fueron escasas en las entrevistas las citas o referencias a un sentimiento universalmente compartido, más allá de las paradigmáticas al estilo de las de la plaza Tiananmén o las Torres Gemelas.

Las secciones internacionales son pequeñas, anecdóticas, de poca profundidad o esporádicas, aparecen en situaciones de guerra y como gancho para incrementar el prestigio del medio, sin mayor análisis, reduciendo así la posibilidad de crear una actitud crítica más global. "La conciencia opera sobre los procesos mentales. La integración de las emociones, sentimientos y razonamiento que en última instancia llevan a la toma de decisiones determina estos procesos" (Castells, 2009, p. 186).

\section{“Ahora mis críticas o pataletas están en la red".}

Una actitud crítica, nos dice Fernando Cifuentes (15 de abril de 2013, comunicación personal) del noticiero Hora 13, se puede lograr a través de "contenidos menos denotativos y más connotativos. Profundizando más en el deber ser y en las razones, también en las posibilidades de participación". Esto está más cerca de los objetivos, ideales de todas maneras. Lo que sí es una realidad que puede potenciarse es lo que dice Hugo Mario Cárdenas, 
periodista político de El País, casi al unísono con Andrés Mejía, ingeniero de sistemas y editor web de Cali Escribe: en el caso de la prensa escrita, si el lector que no está de acuerdo con la publicación, puedo romper, quemar la edición y nadie se va a enterar. Con los medios digitales, el lector puede escribir su comentario y todos pueden leer y opinar (Cárdenas, 28 de febrero de 2012, comunicación personal).

Para los periodistas sí se percibe una actitud crítica en los entornos digitales que antes no tenía por dónde darse a conocer. El periodista puede endilgarle a la ciudadanía lo que ella misma quisiera decir. Esta actitud crítica parece incrementarse con la profundidad que tiene la nota, su nivel de responsabilidad demostrado y la cantidad de herramientas que enriquecen esta (Mejía, 28 de febrero de 2013, comunicación personal). Cambios también de concepto, en el contenido. "Creo que también el lenguaje debe ser diferente, debe ser un lenguaje más fresco, que la gente en serio se interese y que la gente pueda participar y poderle responder" (Cifuentes, 15 de abril de 2013, comunicación personal).

Los periodistas manifiestan que esa actitud crítica a veces se distorsiona en expresiones beligerantes. No obstante ya es una ganancia que las personas pueden involucrarse en los temas del acontecer local o nacional. Buscar la información y comentar es una forma de participar.

Se desprende de los comentarios que hacen los periodistas, que finalmente la gente siempre quiso participar y ser escuchada en los medios y fuera de ellos. Es la reclamación de reconocimiento tras décadas de olvidado. Las participaciones de las audiencias en los medios comerciales, empero, hablan de cierta confianza y legitimidad que tienen estos dentro de la población. Paradójicamente cuando comienza a ser escuchada por estos medios, aparecen los espacios para que la ciudadanía funde sus propios medios. También se infiere que los periodistas pocas veces invierten en esa actitud crítica y que "descansan" cuando los ciudadanos la complementan.

En la anhelada situación de posconflicto, este será otro de los derroteros a seguir por parte de ese nuevo periodismo que podrá comenzarse a practicar; la aparición de nuevos medios desde la misma ciudadanía y sin el estigma de filiaciones políticas. 


\section{Independencia informativa frente a los intereses políticos y económicos.}

La independencia se sujeta al medio, a los intereses que este tenga, no al periodista. Para Nicolás Abrew (11 de abril de 2013, comunicación personal), de La República, es muy difícil sostenerla, pues las informaciones de una u otra manera golpean los intereses de alguien. Siempre puede ocurrir que una empresa amenace con quitar la pauta. Muchas veces la pelea de los periodistas al interior de los medios es por mantener esa independencia.

En la actualidad se percibe menos mediada la información por esos intereses. De todas formas hacer críticas al financiador sigue siendo complicado. Hoy es la gente la que equilibra la información. Hoy, al haber más gamas de partidos, hay más libertades y puntos de vista. En los medios tradicionales no se puede tener una mínima independencia (Varela, 28 de febrero de 2013, comunicación personal).

La independencia informativa de los medios es un tema sobre el cual falta hacer más debate y sacar a la luz. Los medios asociados a grandes conglomerados económicos, a oligopolios, con frecuencia se convierten en añadidos a estos. "La credibilidad no es el negocio, el negocio va por otra parte", afirma uno de los periodistas de uno de los grandes medios que prefirió el anonimato para este comentario. Sin embargo, los reporteros son conscientes de que viven de la credibilidad de su trabajo y del medio. Para el caso de La Silla Vacía, medio independiente, este aspecto es mucho más fácil de conciliar.

El grado de independencia está determinado entonces por los dueños de los medios. "Los periodistas pueden recibir una cantidad de mensajes subliminales sobre lo que se puede y no se puede hacer en el medio y eso ocurre desde un primer momento" (León, abril de 2013, comunicación personal).

Existe en este tema una diferencia entre lo que dicen los periodistas de un medio y lo que dicen sus directivas. En el caso de El Colombiano, las directivas pueden llegar a afirmar que no tienen ninguna filiación u orientación política, no estar casadas con ninguna ideología, mientras que otros periodistas de la misma ciudad califican al diario como de un "azul intenso".

Hoy (nuestro periódico) tiene una tendencia completamente periodística, no está casado con ninguna política, está casado con ideas, con argumentos, con 
noticias que sean positivas para el país pero no hay ninguna orientación política en este momento y es completamente independiente del poder y simplemente es línea periodística (Jaramillo, 16 de abril de 2013, comunicación personal).

Las directivas soportan su aseveración sobre el hecho de que "a ningún periodista se le dice qué hacer, o se le llama la atención por un enfoque, o que una fuente llame para quejarse o pedir tal o cual información" (Jaramillo, 16 de abril de 2013, comunicación personal). Una libertad circunscrita a la línea editorial del medio.

Se publica entonces teniendo en cuenta el compromiso específico del periódico, por ejemplo en el caso de El Colombiano, y este compromiso no lo determina el periodista. El periodista tiene que ajustarse a estos espacios, trabajar con más cautela ciertos temas pero sin omitir nada. "Que los lectores queden bien informados" (Jaramillo, 16 de abril de 2013, comunicación personal).

Los periodistas declaran tener libertad para proponer temas, aunque se comparan con otros medios como La Silla Vacía, que ha demostrado cómo se puede hacer periodismo independiente. En los medios regionales se ve cómo los intereses políticos y económicos caen sobre ciertos nichos económicos y grupos locales. Por ejemplo, en el Eje Cafetero el café y las licoreras forman parte de esos temas que ejercen poder sobre los medios. Esto, según los reporteros de la región que fueron entrevistados.

\section{${ }_{¿}$ Y en la web?}

En cuanto al manejo de la información en la web y la injerencia de los poderes políticos o económicos, los periodistas manifiestan que son los mismos, a pesar de que en la red, cuando hay la posibilidad de tener información exclusiva para este sector, se tiende a ser más cercano a la ciudadanía. Las .com si bien pueden ejecutar un periodismo sin "tantas mañas" por estar en manos de periodistas más jóvenes, como se afirma en El Pais, de todos modos deben responder a una línea editorial, que fue definida por el periodista político para ese medio como "azul discreto", haciendo referencia al color tradicionalmente utilizado por una línea conservadora.

En otros medios más pequeños, y cuya sección de periodismo web no está desarrollada, podemos encontrar afirmaciones como esta: lo que se publica en el impreso, es igual que en el portal; es igual pero 
[...] puede dar la sensación de más independencia, por la participación ciudadana. Se podría llegar a escribir de otra manera, para llegarle a la gente de manera diferente. Pero acá todo es igual a como aparece en el impreso. (Rotavista, 16 de mayo de 2013, comunicación personal)

Karen Rotavista (16 de mayo de 2013, comunicación personal) del diario La Tarde, considera que de todos modos ahora, con la nueva administración del periódico, el medio es mucho más independiente y los periodistas tienen más libertades propositivas. Cuando se vierten directamente los contenidos del medio tradicional sobre la web, y cuando esta función la hace un ingeniero, esta discusión no tiene lugar.

En el sistema global de la red aparecen más voces, lo que en términos generales puede significar una mayor independencia que recae finalmente en el aprovechamiento que le pueda dar la audiencia.

\section{Eje de autopercepción: ¿más prominencia?}

\section{Entornos digitales y la prominencia del periodista político o económico.}

La cómoda situación de los medios y de los periodistas, que detentan el monopolio de la información en la sociedad, se acaba. Una parte de los periodistas profesionales se consideraban a sí mismos como una élite con poder exclusivo para imponer el control de los debates. [...] La época en la que solo ellos podían escoger y publicar información ha concluido. La red les está despojando de su estatus de curas seculares (Ramonet, 2011, p. 15).

Con estas duras palabras conceptuaba hace poco Ignacio Ramonet el estado de los periodistas enfrentados a la web. Si bien esta apreciación tiene su grado de verdad, solo opera para las grandes figuras del periodismo en cada nación, y Colombia no es la excepción; sin embargo, para el periodista que trabaja para una sección de un periódico la situación es diferente, aunque los embates que vienen desde arriba de la mesoestructura de los medios lo impactan también.

Los periodistas políticos y económicos no se perciben como agentes prominentes ni ante sus colegas ni ante la ciudadanía. Esto es distinto respecto a los sectores de la sociedad que toman las decisiones del país. Un periodista, quiéralo o no, puede convertirse en prominente para el poder de acuerdo 
con el nivel de cercanía que tenga con él. El mundo digital parece solo haber confirmado el hecho, pues las comunicaciones internas entre periodistas y el poder, se dan ahora por medio del BlackBerry o el WhatsApp. Lo que sí consideran relevante los reporteros son los temas que cubren, más que su propia figura, a pesar del bajo interés que demuestran las audiencias.

\section{La imagen del periodista político se ha modificado con la llegada de la tecnología, y la tecnología llegó con los más jóvenes periodistas.}

El ambiente en las salas de redacción muestra a los periodistas tradicionales y veteranos con más importancia frente a los periodistas más jóvenes de la web; esto se da tanto por la experiencia como por el soporte desde donde se trabaja. Aún falta reconocer más el trabajo que se hace en la web (Cárdenas, 28 de febrero de 2013, comunicación personal).

Existen divergencias muy claras en cuanto a la impresión que se tiene sobre las transformaciones que causan los entornos digitales en la prominencia del periodista político y económico; por un lado, los periodistas tradicionales dicen que esta sigue siendo como en los medios análogos y que los entornos digitales no han cambiado mucho esta percepción que se tiene sobre la prominencia del periodista.

Los reporteros aseguran que con las características a las que son convocados en el ejercicio periodístico, las virtudes de los entornos digitales como la del tiempo real de la información, modifican la concepción de la labor del periodista político y económico que no ha sido muy atractiva. La posibilidad de innovar con otros diseños y con contenido especializado, como un producto especial para las audiencias, hace que la imagen que se tiene del periodista se amplíe y cambie a la par de las transformaciones de los medios y soportes.

Entre los periodistas encontramos coincidencias cuando aseveran que con los nuevos escenarios, el acceso a las fuentes y el abordar los temas desde más facetas, es lo que les da mayor visibilidad y relevancia. A pesar de la importancia que tiene el periodista para la opinión pública, en general no se tiene una imagen muy precisa de este; se ha pensado desde siempre al periodista político como un personaje cercano al poder y condescendiente con el poder; las redes han cambiado un poco esa idea, en la medida en que la ciudadanía siente al periodista más cercano. 


\section{Efectos de los entornos digitales sobre el trabajo investigativo.}

Gran parte de la información que le llega al periodista ocurre a través de Internet, es información de todo tipo: procesada, de primeras fuentes, exclusiva, pública, datos en bruto, etc. Esto ha tenido como efecto ya conocido que el periodista salga menos a la calle, o que incluso no tenga que ir al medio a hacer presencia física. Basta con que él cumpla con su trabajo de manera remota.

Mucho se ha escrito sobre las inmensas posibilidades que los periodistas tienen para la investigación, principalmente en temas de política y economía. Pero el sondeo que se hizo sobre este punto, demostró que aún hay vacíos.

En cuanto al trabajo investigativo y propiamente periodístico, el periodismo especializado en política y en economía se ha visto beneficiado. "Con los ambientes digitales se puede tener más acceso a las informaciones, a documentos, a contratos con el Estado y al pasado judicial de casi todas las personas. Es una información que es prácticamente pública” (Cárdenas, 28 de febrero de 2013, comunicación personal). De este modo se pueden contrastar fuentes, tener acceso a documentos oficiales y completos vía Internet y profundizar más en la materia, por cuestiones de espacios ilimitados de lo digital. Así el periodista ya no se lamenta, como antes, de que no pudo decir todo lo que quería porque el tiempo de emisión o los centímetros sobre el papel se lo impedían. Por otro lado, el hecho de que pueda tener un espacio ilimitado, no puede constituirse en excusa para acallar una información.

Pero salvo en muy pocos casos, los periodistas políticos y económicos no estaban haciendo uso de las herramientas del periodismo de base de datos. Incluso algunos no tenían conocimiento de estas bases.

Numerosa información le llega al periodista por correo electrónico (proveniente de personas, instituciones u organismos), tal información puede ser personal, pública, exclusiva o ya procesada. Los entornos digitales han simplificado mucho el trabajo de los periodistas, incluso hasta llevarlos al pleno facilismo, casi todo se puede conseguir en los entornos digitales, paradójicamente a pesar de tener más tiempo, pues se sale menos a la calle, las notas no han adquirido necesariamente más profundidad o más compromiso. "Existe más disponibilidad de las informaciones, pero se debe ser más cuidadoso para su verificación" (Cárdenas, 28 de febrero de 2013, comunicación personal). 
La retroalimentación presente en las redes sociales provee a los periodistas contenidos, enfoques y datos que pueden convertirse en notas. Esto es en particular evidente en los temas locales. No obstante, frente a estas nuevas dinámicas en la red, los periodistas revelan que son ellos mismos quienes toman las últimas decisiones sobre lo que es o no noticia (Clavijo, octubre de 2012, comunicación personal). Aquí los periodistas observados confiesan una tensión con los preceptos de un periodismo: la solución se va por dar curso a las tendencias de la red y evaluar verdaderamente la importancia de la información. En el caso, por ejemplo, de noticias en desarrollo, el periodista tiene que estar muy atento a lo que va apareciendo en la red, sobre todo en las redes sociales, pues ocurre que puede estar enfocado en un aspecto de la noticia, pero la red puede estar por otra vía a la que hay que prestarle atención (Clavijo, octubre de 2012, comunicación personal).

En los medios visitados, y que son únicamente digitales, la consulta de fuentes primarias es el pilar de las informaciones y de allí se decanta a otras informaciones que pueden estar en la red. Como lo declaran los periodistas de estos medios -todos-, el reporterismo y el periodismo de primera mano son su valor agregado.

Así el periodista se siente más responsable de dar a conocer una información específica a la opinión pública y que puede afectar los intereses de un individuo o colectividad. Gracias al acceso a numerosas fuentes, personas que con rapidez se pueden contactar en las redes sociales, por medio del PIN del BlackBerry o el WhatsApp, se puede llegar a la verdad con mayor celeridad.

Buena parte del periodismo que se practica, sobre todo en la región, se estaba haciendo hasta mediados y finales de 2013 de la manera tradicional, sin consultas sobre la web profunda; a base de correos, de las páginas oficiales de los entes sobre los que se investiga, entrevistas y ruedas de prensa. A pesar de este estado precario, también cabe señalar que en la mayoría de los medios se aseguró "estar trabajando sobre el tema".

\section{¿Movilizan los medios a las redes y estas a los ciudadanos?}

Los temas periodísticos de coyuntura política y económica tienen bastante movimiento en la red. Si una noticia llega a tener 500 comentarios y 
1.000 visitas $^{4}$, es una noticia muy prominente (para un medio como El Tiempo), aunque esto se refleja de modo muy incipiente en la calle. Se desarrollan en la red, pero aún no tienen fuerza de movilización en la calle como se esperaría (Cifuentes, 15 de abril de 2013, comunicación personal; Guevara, 19 de diciembre de 2012, comunicación personal).

Así la movilización social resulta ser efervescente y poco efectiva en términos de transformaciones y revocatorias de políticas económicas o sociales. Los movimientos en la red no pueden equipararse con la esencia de las plataformas sociales que los convocan; en este contexto los periodistas solo identifican su labor en cuanto a la incidencia de movilización social que su trabajo periodístico pueda suscitar directamente y que responde por lo general a coyunturas. Los casos de movilización de miles de ciudadanos que se vuelcan a las calles, han sido propiciados por organizaciones sociales convocantes que van desde colectivos de derechos humanos, magisterios, sindicatos y estudiantes, hasta grupos que tienen como parte de la plataforma organizativa la red social.

Los periodistas recuerdan movilizaciones como las de "No más Farc", que llegó con fuerza a la calle, impulsada por la red, o lo ocurrido en la Primavera Árabe o el $15 \mathrm{M}$ : "Si acaso una noticia llegara a tener 500 comentarios, lo que sería un número importante, esto se reflejaría de manera muy incipiente en la calle" (Guevara, 19 de diciembre de 2012, comunicación personal).

En los medios regionales los periodistas indican que los efectos del periodismo en la movilización ciudadana son más evidentes. Denuncias de casos que implican directamente al ciudadano y un trabajo investigativo lo han logrado.

Los medios digitales tienden a ocuparse de ciertas fuentes concretas, de ciertos formatos que no manejan los medios tradicionales masivos. Es así también como consiguen independencia y estar más cerca de intereses específicos de sociedad o de la ciudad. Por ejemplo, Cali Escribe dice ocuparse de temas como aguas, megaobras, planificación urbana de la ciudad, desarrollo vial, transporte masivo y el aeropuerto de Cali.

Durante el mundial de fútbol 2014, una noticia sobre el jugador colombiano James Rodríguez alcanzó la cifra de poco más de 33 mil likes y varios miles de comentarios. 
Los otros medios, Noticiero 90 Minutos y El País, rescataron el hecho de haber tumbado a un alcalde, a punta de investigación periodística, entrevistas, etc. Y a que estos contenidos se movieron mucho en la red. Algo que resulta interesante manifestado y evidenciado por el director de Noticiero 90 Minutos es que, según sus apreciaciones, "la web, si bien llega más a los estratos altos, la que más se mueve es la base, en algún momento la penetración de la web va a ser mayor y va a mover más la base, la masa" (Correa, 1 de marzo de 2013, comunicación personal). Si esta apreciación resulta cierta, el trabajo de los medios sobre las clases populares será de primer orden en términos políticos, queda por resolver el asunto del consumo.

Un análisis ulterior que se escapa a esta investigación podría dar luces sobre estos aspectos y sobre la sostenibilidad en el futuro de los medios tradicionales. "Y cada vez los medios tradicionales van a perder la influencia arriba y la influencia de la red va a aumentar. Y haciendo movilización que es lo más complicado y la movilización genera políticas" (Correa, 1 de marzo de 2013, comunicación personal).

Algunos temas generan movilización en la red, pero los periodistas aclaran que no es función de ellos suscitar o motivar movilizaciones ciudadanas, así estas se presenten. Los periodistas son conscientes de las posibilidades de la red, y dan ejemplos locales o globales, incluso en noticias de los propios medios o que ellos mismos han redactado. Muchas de estas movilizaciones son virtuales, van paralelas por la red y tienen impactos en lo real. Como el caso que se presentó en Pereira cuando se quisieron llevar la escultura del Bolívar Desnudo para que lo arreglaran. La ciudadanía se opuso a la iniciativa de la alcaldía, la movilización se dio en el espacio de la red, los medios de comunicación le prestaron atención y finalmente no se llevaron la pieza a reparar.

\section{Apuntes sobre la verdad y la responsabilidad.}

El no salir a la calle a cubrir y verificar los datos de la nota con fuentes primarias, que se suponía parte de los elementos de ética y responsabilidad del periodista, se remplaza ahora por una búsqueda en Internet.

En el caso del periodismo económico esta situación se acentúa. Este periodismo tiende a ser más informativo, así es menos cuestionador, menos incisivo. En los medios solo digitales, los periodistas nos manifiestan que a 
pesar -o quizá por la misma situación- de no tener periodistas especializados en las áreas prefieren salir a buscar fuentes primarias.

En el medio digital se lanza la noticia en caliente, en el impreso se puede profundizar, se puede hacer más análisis. Por la rapidez en la web se tiende a perder esmero, aunque eso mismo ha forzado a que se sea más cuidadoso.

Los del impreso toman datos de lo que aparece en las .com para hacer las notas. El periodista enfrentado a lo que aparece en la red y que proviene de fuente poco reconocida puede perder de centro las fuentes serias. El periodista político de El País afirma que "todos se creen redactores políticos" (Cárdenas, 28 de febrero de 2013, comunicación personal). Aludiendo con esto a algunos personajes de la audiencia. A veces los periodistas políticos entran en conflicto con una cantidad de seudoperiodistas que no han salido a buscar la fuente, como sí lo hace un medio de comunicación responsable. Personajes, anónimos que andan en la red lanzando informaciones, hacen entrar en duda la información que posee el periodista.

El olfato del periodista ha tenido que incursionar y saber manejar estos nuevos espacios donde circula la información y desarrollar las estrategias para el contraste de fuentes que pueden estar en la misma red. Esta es una circunstancia "nueva" en la que trabajan los periodistas, pero la manera de solucionarlo - confirmando, contrastando o triangulando- no dista mucho del periodismo clásico.

También se reconoce que muchas veces las redes terminan cambiando la agenda del día, los titulares y demás. Esto se afirmó tanto en el diario $E l$ País como en el Noticiero 90 Minutos. Por su parte, en el portal Cali Escribe, tal vez por estar en contacto más cercano con la red, los conflictos parecen ser menos frecuentes. Se dice allí:

En los medios digitales, la verdad comienza a tener mayor cercanía con la realidad fáctica. Una cosa es la verdad procesal, otra la verdad real y otra la verdad parcial. La realidad de los hechos, gracias al periodismo digital, se está abriendo paso (Varela, 28 de febrero de 2013, comunicación personal).

Por los medios digitales, "los políticos de la mano del periodismo tradicional están perdiendo terreno. Ellos solo tienen gran poder en los medios de los conglomerados económicos" (Varela, 28 de febrero de 2013, comunicación personal). Estas aseveraciones por parte de la revista digital Cali Escribe 
muestra, por lo menos en la autopercepción, que los medios digitales trabajan a otro nivel y que ven cómo los medios tradicionales, se debilitan junto con los directivos y políticos que los acompañan. Así, los medios digitales se consideran la opción de los medios futuros y presentes. La manera de seguir atrayendo más audiencia es trabajando con la verdad, esa es la forma de ser competitivos, aseguran.

Existe por tanto una idealización de la transparencia en los medios nativos digitales, eso es claro, por lo menos en los medios visitados hasta el momento, según lo manifiestan sus creadores y directores. El valor de la moral está en la independencia que los bajos costos de la red otorgan a sus creadores.

\section{Implicaciones del uso de los entornos digitales en la imagen del periodismo político y económico.}

El aura de prestigio del periodismo político y económico se ha visto afectada en los entornos digitales, pues al tiempo que se democratizan los contenidos, las fuentes también se homogeneizan y la información tiende a estandarizarse en medio de otras. La política como centro de interés regente en las sociedades del papel, ya había sido desplazada por la pantalla de la televisión con sus propias lógicas de recorte, registro y almacenamiento y que ubicó en su lugar a las estrellas del mundo del entretenimiento ${ }^{5}$. Fue un proceso en el cual la política, mediante el marketing televisivo, quiso equilibrarse. Con el régimen del papel, cada vez más lejos, la representatividad del Estado y sus gobernantes desean seguir vigentes en las nuevas pantallas y en la Internet, compitiendo con el caos del protagonismo, prescindible, banal y efímero.

La mediología argumenta que desde la entrada del régimen de la imagen al final de los años 60, el interés de los medios de comunicación y los públicos se centra en el espectáculo e incluso en el posespectáculo, donde se percibe un viraje de los espectadores que se convierten en productores. Así el interés por convertirse en un líder de opinión, o una figura política se ve desplazado por el deseo de querer convertirse en una figura del mundo de la imagen,

La grafósfera ubicaba al presidente de una nación y a las figuras de la vida pública como los principales regentes de esta mediásfera. Con la llegada de la televisión a color, la situación cambia y son las stars las que se sitúan en esta categoría (Debray, 2000). 
una star, o en su defecto el querer ser participes del mundo por medio de apariciones efímeras, espontáneas y pasajeras. ¿Tal es el rol del ciudadano en el universo de interacción de la web 3.0 gracias al uso aparatos de registro y distribución de la información, sustituyendo, y superando las posibilidades de los medios en cuanto a la inmediatez y a la innovación en la presentación de contenidos, u además, que tan en serio se toman los medios de comunicación esta participación de los ciudadanos?

Los medios de comunicación tradicionales también han alimentado la idea del prestigio de las figuras de la vida pública, en su propósito de congraciarse muchas veces con el poder. Otras veces se alían con figuras del espectáculo. En las esferas de la grafósfera y videósfera, los medios tradicionales controlaban los flujos de información alrededor de sus emisiones, pero en la red estas posibilidades se desbordan llegando a desviar los objetivos de verdad, realidad y responsabilidad.

Por eso es que ahora más que nunca, el periodismo y el periodismo especializado; no debe dejar que sean las tendencias de los usos comerciales de la técnica de la red las que tomen el rumbo de su trabajo, sino por el contrario que sea el periodismo el que las maneje para su beneficio. Pero también es imperioso un periodismo compartido con una audiencia educada y crítica; que la audiencia tenga la capacidad de crear sus propias agendas, para que produzca, busque y manifieste a los demás y a los medios lo que quiere y lo que necesita.

Aunque el ciudadano tecnologizado ahora es el protagonista en "diálogo", es evidente que no está en igualdad de condiciones; pues muchas de las propuestas y de los nodos del flujo de información siguen proviniendo de los grandes medios. En esta lucha, un grupo más reducido de los periodistas entrevistados considera que su labor se ha vuelto más útil en cuanto a suministro de información; por otra parte también afirman que tienen mayor presencia y dinamismo haciendo de las fuentes unos temas igualmente más dinámicos. Internet, aseguran, ha hecho posible que informen con más análisis y profundidad, haciendo que la gente se interese más, y con este mismo optimismo ven un muy buen futuro de la mano de la participación. Con todo, este entusiasmo proviene en efecto de un trabajo que se está ejecutando en ese sentido, pero la respuesta que están dando los medios tradicionales es tardía e insuficiente. 


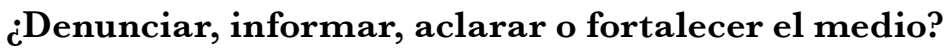

La respuesta clásica a este interrogante es: informar. La pregunta se realizó con el objetivo de tentar la respuesta de "educar" o "aclarar" a la opinión pública o a la ciudadanía. En los medios nativos digitales se encontraron las respuestas más cercanas a educar o explicar, lo cual es un valor agregado de estos medios. Es claro que el periodismo no está hecho necesariamente para educar, función de la escuela o la familia, sin embargo, dadas sus condiciones de persuasión masiva y frente a los contextos sociales que requieren aclaración, una función explicativa o educativa podría considerarse más allá de la seducción mediática, o de la intención de movilizar la opinión pública.

Si el periodismo se ocupó de informar durante su época dorada de segunda mitad del siglo XX, ¿qué función cercana a la explicación o educación podrían ejecutar o construir los nuevos medios? El generar conciencia es una de las vías. Nos sumamos a Javier Esteinou (2002) cuando afirma que el grado de información veraz y oportuna que recibimos y procesamos influye de manera importante en nuestros sentidos y la construcción de la realidad.

Los medios de comunicación son los mayores transmisores de esa información que se supone veraz. Así según Esteinou (2002) tanto nuestro celebro, como nuestro cuerpo reciben y asimilan del medio sensaciones, datos, signos, símbolos, informaciones. En ese sentido, el papel de los medios de comunicación es fundamental en la sedimentación de informaciones para un despertar de conciencia. ¿Hasta dónde los medios de comunicación hoy en las redes, colaboran con este fin?

$\mathrm{Al}$ indagar sobre este aspecto y como lo evidenciaremos más adelante, hallamos una divergencia entre los medios tradicionales y los medios nativos digitales. Mientras que los segundos aceptan la posibilidad de educar, construir, generar cambios, los primeros enfatizan en el informar. 



\section{Capítulo 2}

\section{GONVERGENGIAS Y DIVERGENGIAS. EDITORES WEB DE LOS MEDIOS TRADICIONALES}

Tos periodistas a los cuales les hicimos entrevista $u$

Lobservamos sus rutinas de trabajo son los siguientes:

- Evelyn Rosero. El País. Editora web, Cali.

- Javier Escobar. El País. Community manager. Cali.

- Diana Marcela Figueroa. Noticiero 90 Minutos. Editora web. Cali.

- Andrés Felipe Ossa. Noticiero 90 Minutos. Community manager. Cali.

- Leopoldo Díaz Granados. El Heraldo. Editor web. Barranquilla.

- Alejandra Sánchez. La República. Editora web. Bogotá.

- Ana María Bedoya. La República. Comunity Manager. Bogotá.

- Perla Toro. El Colombiano. Social Media Manager Medellín.

- Juliana Torres Aguirre. Hora 13. Comunity Manager. Medellín.

- Alejandro Arias. La Tarde. Comunity Manger/ editor web. Pereira.

- Jhon Jairo Martínez. La Patria. Editor web. Manizales. 
- Iván Ricardo Torres. Portafolio. Redes. Bogotá.

- Andrés Guevara. El Tiempo. Subeditor de redes sociales. Bogotá.

- Germán Espejo. El Espectador. Periodista político web. Bogotá.

- Yuranis Cristina Caballero. NTN24. Editora web. Bogotá.

Las funciones que cumplen estos periodistas son diversas, se encuentran en diferentes niveles de responsabilidad y relación con el medio tradicional y las audiencias. A pesar de que la especialización de CM ya está desarrollada y de que las tareas de los editores web en el mundo tienden a ser relativamente uniformes, lo que constatamos tanto en el trabajo de observación etnográfica como en las respuestas de los periodistas, es que existen distintas lógicas en torno al papel y función de los CM y de los EW al interior de los medios de comunicación, sean estos escritos, televisivos o totalmente digitales. Estas variaciones en las funciones tienen que ver con el grado de inserción en el entorno digital, el tamaño de la empresa y el interés o las decisiones de la firma periodística. Entre las múltiples definiciones para CM que circulan por la red, nos topamos con esta:

Es aquella persona encargada o responsable de sostener, acrecentar y, en cierta forma, defender las relaciones de la empresa con sus clientes en el ámbito digital, gracias al conocimiento de las necesidades y los planteamientos estratégicos de la organización y los intereses de los clientes. Una persona que conoce los objetivos y actúa en consecuencia para conseguirlos (AERCO, 2009, párr. 1).

También debe:

Monitorear el contenido de la organización y ver qué está haciendo la competencia.

Alertar sobre noticias de última hora y hacer curaduría de información en tiempo real.

Crear contenidos para redes sociales: desde la portada de Facebook hasta un pequeño clip de menos de un minuto con la finalidad de ir conquistando a la audiencia. El área de diseño no comprende el tiempo real como los redactores de la web y del área de social media lo entienden (Vargas, 2013).

Lo que pudimos evidenciar en las redacciones de los diarios colombianos es que las funciones de los CM varían. Esta variación depende principalmente de la cantidad de periodistas asignados a esta actividad. En algunos 
casos uno solo, en otros un grupo de diez y en otros todos los periodistas pueden llegar a cumplir esa función al publicar sus propias notas en las redes sociales. Son tareas relativamente nuevas que aún se están ajustando.

En medios como El Heraldo, el editor web cumple con labores administrativas y por cuestiones de tiempo, manifiesta no alcanzar a hacer curaduría de las informaciones, lo que lleva a ampliar de manera cooperativa la participación de los periodistas del .com y el impreso, quienes tienen criterios más sólidos de publicación.

En el caso de la edición web del Noticiero 90 Minutos, Diana Marcela Figueroa tiene diversidad de funciones que van desde hacer la lista de contenidos, como webmaster, a salirse de su sección para colaborar en temas de agenda del momento en Cali; Andrés Felipe Ossa, CM de este noticiero, no solo tiene una relación con las audiencias, sino que también monta los contenidos de la página. Es decir, que las múltiples necesidades del medio en la red se suplen por estos dos jóvenes periodistas asignándoles trabajos y funciones no totalmente caracterizados, lo que según revela el director del noticiero, podría subsanarse con más personal, pues se es consciente de las deficiencias a las que se enfrenta, con todo el noticiero logra hacer su presencia en la red y tener actualizados los contenidos.

Lo que se nota en muchos casos es la improvisación y la falta de especialización y autonomía estratégica de lo que debe hacer el medio en la web. Un principio de la comunicación montada sobre la técnica con miras a la interacción con las audiencias por medio de los contenidos.

\section{Intraacciones e interlocuciones}

De acuerdo con lo anterior, sigue siendo predominante el hecho de que los contenidos publicados en la web del medio están en su gran parte apoyados por la labor que efectúan los periodistas del medio tradicional y en algunos casos por las decisiones de entes superiores sobre las estrategias. Así, el editor web es quien esencialmente debe encargarse de "complementar" para la web la noticia elaborada por el periodista del impreso, teniendo la posibilidad de dar un giro de forma en cuanto a las maneras tradicionales de elaborar una nota. Sin embargo, estas posibilidades se ven disminuidas en el trabajo cotidiano, sobre todo por la presión del tiempo, la falta de direcciones más claras por parte del medio y la ausencia de especialización 
para lograr más autonomía. En lo que pudimos observar, existen grandes diferencias entre los medios visitados.

En El Colombiano, el ritmo al que se trabaja en la web es mucho más acelerado que en otros medios regionales, como por ejemplo en El Heraldo, y esto se debe a la cantidad de funciones y cargos que existen en la sección de este diario. Según datos proporcionados por la sección web del diario de Medellín, el porcentaje que del impreso se pasa a la .com es solo del $40 \%$ y lo demás lo constituyen notas propias que se realizan en el menor tiempo posible. Por ejemplo en economía, ya que en su mayoría son cifras de desempleo o inflación. Allí la información es rápidamente tratada. En cuanto a lo político, en la web el tratamiento no es menos cuidadoso, pues las directrices de las publicaciones las dicta el medio con miras a "no politizar ninguna noticia", sobre todo en el marco actual de las negociaciones de paz en La Habana, por ejemplo.

Con relación al trabajo en la calle del periodista de la web, se debe decir que el $60 \%$ de este se realiza en la sala de redacción, en ocasiones se sale a hacer reporterismo desde la calle misma. Las salidas se dan también por causa del desarrollo de temas propios de la web.

A pesar de la relevancia del reporterismo, el salir a la calle - un atributo que hace más independientes las redacciones del impreso que las de la web- no es frecuente, por causa de las funciones a las que están sujetos en el medio. Tal como lo menciona Diana Marcela Figueroa (1 de marzo de 2012, comunicación personal):

[...] hay cosas que la mayoría la hacemos por teléfono. Por ejemplo, si yo me voy, ¿quién monta? y si Andrés, que es el community manager sale, ¿quién hace el contacto en las redes? Como tenemos varias funciones asignadas, no podemos hacer mucho trabajo en la calle.

Esta situación descrita por Figueroa es común a todos los medios y es un impedimento al gusto innato de los periodistas por salir a la calle a hacer reporterismo, sobre todo en los primeros años del ejercicio profesional.

En El País, la subeditora web, Evelyn Rosero Ramírez, tiene como labor determinar los contenidos que se suben al portal; para ello debe también asumir la tarea de interlocutora entre el consejo de redacción y su equipo de periodistas, lo cual es una característica común a los editores web independientemente del medio; este procedimiento se presenta para poder 
cumplir con la política editorial del medio y posicionarlo; algunos temas hay que tratarlos "con pinzas". Se debe revisar que la información tenga la jerarquización adecuada, el enfoque preciso y que no falte ninguna noticia. Para el caso de los medios escritos que tienen su portal web, es muy importante que el subeditor se convierta en el mediador entre los periodistas del impreso y los periodistas de su equipo en el .com, pues lo esencial es buscar la convergencia y garantizar que las noticias más significativas, en las que el periodista del impreso realiza un cubrimiento, se desarrollen de forma pertinente en la red.

Existe una complementariedad entre el periodista que sale a hacer el cubrimiento y quien recibe la información para emitir un avance (si es un hecho de última hora) en la web.

Cabe resaltar que no todo el tratamiento multimedia que debe dársele a los contenidos lo hace el editor web; la mayor parte es ejecutada por los periodistas del equipo, mucho más especializados en el manejo de las herramientas digitales, o incluso diseñadores como en El País, o editores técnicos, como ocurre en La Tarde.

En resumen, podríamos decir que el editor web es un comunicador técnico y administrador de las informaciones, interlocutor con las audiencias y a veces mediador entre las plataformas. Así, a veces puede ser una especie de defensor no explícito de los lectores y una figura con funciones de diplomacia entre la web y el medio tradicional.

\section{¿Qué contenidos visitan más los internautas?}

La importancia de la información política y económica se mide a partir de su demanda por parte de las audiencias, que aún está por debajo del nivel esperado en un régimen democrático. Los temas políticos son efervescentes y los económicos ganan en relevancia cuando tocan los intereses individuales o cuando la economía familiar se ve afectada. También los grandes desfalcos financieros que perjudican a personas dentro del nicho y revisten un interés público. Un ejemplo de ello es la caída de Interbolsa en Colombia, que adquirió protagonismo durante semanas.

Los contenidos más visitados dentro de un medio pueden estar fijados por la situación política que se viva en algún momento en el contexto na- 
cional o regional y por el carácter del medio; nadie dudaría de que en portales como La Silla Vacia, Revista Gobierno, blog Punto de Vista o El Turbión, por nombrar algunos de índole política, o medios de carácter económico como Portafolio, La República y NTN24, los temas que más se consultan allí sean justamente estos. Sin embargo, en revistas y medios con una agenda más amplia en cuanto al manejo de cuestiones políticas, como Semana, o en asuntos económicos como La República, los temas más consultados no son de naturaleza política ni económica propiamente dichos.

En la revista Semana los temas más visitados van desde Gente, Vida Moderna, artículos científicos o curiosos hasta eventuales contenidos políticos y económicos coyunturales. Cada medio tiene una audiencia consolidada que posee rasgos comunes; su punto de encuentro son los temas que se convierten en los más visitados, o para el caso de la difusión por redes sociales en virales, como lo explica Andrés Guevara (19 de diciembre de 2012, comunicación personal) subeditor de redes sociales de El Tiempo:

Las polémicas, y los temas que indignan, son temas que se vuelven virales, hay casos que siempre están de colchón: el caso Colmenares', o de la indignación hacia el Congreso. Cuando hay logros deportivos, eventos o hazañas de escala nacional o mundial hay un pico para nosotros, siempre van a estar entre los temas más tocados en Internet.

En materia económica, el CM de Portafolio comenta:

[...] en el portal se ven los picos a final de mes, cuando se dan los informes de alza a la gasolina, precios al consumidor, en lo que tiene que ver con finanzas personales tocan a la gente con los informes sobre el aumento de la gasolina, la canasta familiar, los temas de economía de bolsillo, a las personas les gustan mucho los informes especiales y los gráficos sobre el comportamiento de la inflación (Torres, 20 de diciembre de 2012, comunicación personal).

En los medios de comunicación regionales -entre estos El Heraldo, El País, La Patria, El Colombiano, Noticiero 90 Minutos y La Tarde- el público comparte intereses similares al momento de seleccionar el contenido que prefiere. Allí los temas que más se mueven van en orden de importancia aunque con algunas variaciones: deportes, tendencias (gente, farándula, espectáculo)

El "Caso Colmenares" estuvo en la agenda de los medios comerciales desde 2011 a 2013 , con puntos altos en 2012 y principios de 2013. Se trató al parecer de un asesinato de un estudiante de una prestante universidad de Bogotá, caso no completamente resuelto por la justicia colombiana. 
y judiciales. En cuanto a temas de política, estos adquieren una prominencia mayor sobre las demás fuentes cuando son altamente controversiales o forman parte de la agenda cultural del momento. Por ejemplo en el portal de El Colombiano no hay lugares estáticos para los contenidos aunque sí predominantes: lo regional (Antioquia), de fútbol, de astrología, cine y noticias internacionales.

Todo lo cual, como ya mencionamos, depende en gran medida de la agenda informativa. Por ejemplo: en el mes de abril de 2013 El Colombiano registró altos índices de visitas al tema internacional, por causa del estado de la política en Venezuela, la renuncia del papa y los atentados terroristas en Boston (Estados Unidos).

Tanto en medios regionales como nacionales hay una tendencia de la ciudadanía a interesarse por los asuntos transversales al desarrollo urbano y en general, por lo relacionado con el erario de la ciudad y el orden público, a partir de los cuales no solo se suscita un número de visitas que convergen con los mismos temas, sino también diversidad de opiniones y niveles de interacción que se reflejan en los espacios que proporciona el medio. Paradójicamente, aunque lo político y lo económico no están entre los intereses netamente informativos de los usuarios, según lo evidencia el lugar que ocupan dentro de los contenidos más visitados, sí parecen estarlo dentro de los espacios que desde los medios se abren para fomentar la expresión, participación e interacción, como son foros, comentarios o sugerencias.

En medios como El Colombiano, algunas noticias de política, no necesariamente están rotuladas como tal, pueden estar en la sección de Actualidad. En opinión de la periodista Diana Figueroa, del Noticiero 90 Minutos, esto se hace así puesto que "el tema político como tal no funciona, lo que sí funciona es la política y la economía inmersa dentro de temas que la gente no sabe que tiene que ver con ello" (Figueroa, 1 de marzo de 2012, comunicación personal).

Otro de los aspectos esenciales con respecto a las temáticas que más consultan las audiencias, reside en el papel que cumplen las redes sociales; aquí estas se presentan como canales de difusión que influyen en el posicionamiento de una noticia, Facebook o Twitter son los principales. En Hora 13 en las horas de la mañana el Twitter se convierte en el espacio para invitar a la lectura de las secciones del noticiero en la web, lo cual incentiva a las audiencias para que 
se conecten al canal de televisión. Sin embargo, no se utilizan las redes para promocionar otro tipo de eventos o trabajos.

En el ambiente de transición que vive hoy el periodismo, a la pregunta por los formatos en los que se montan noticias que se sabe no resultan tan atractivas paras las audiencias, Juliana Torres (15 de abril de 2013, comunicación personal), CM de Hora 13 responde:

La idea es que la gente tenga la información de la noticia que escribió el periodista, que tenga el video con los fulles y que podamos colocar una imagen de la noticia. Otras alternativas aún no, pues la página web es nueva, pero la nueva se está esperando que sea más interactiva, que tenga más contacto con el público.

Así las cosas, el interés de los lectores en la web va más por informaciones que los impacten -los públicos parecen querer ser impactados- a modo de crear pequeñas y volátiles comunidades en torno a diversas materias, lo que podría estar ayudando a construir identidades.

\section{El supuesto imperativo para los periodistas de ser creativos en Internet}

En relación con la exigencia de creatividad que implican los entornos digitales en tanto exploración y aprendizaje de sus posibilidades innovadoras, y frente a la autoexigencia por posicionar el periodismo político y económico encontramos ciertas reticencias, sobre todo en los periodistas que llevan más años cubriendo estas fuentes. No es solo la tecnología en sí misma, son los giros narrativos, culturales y sociales que ocurren con el entorno digital, lo que genera cierta distancia, además de que muchos de ellos no ven la necesidad de entrar a presentar los temas a través de las nuevas herramientas o plataformas de difusión.

En este sentido existen escenarios variables respecto a la creatividad, lo cual depende de las características particulares de cada medio. Por ejemplo, en El Colombiano el proceso de consolidación de los entornos digitales incentiva un giro en las narrativas tradicionales y rebautiza muchas prácticas periodísticas: las noticias se realizan en tiempo real y se llama Twittercrónica, a partir de la cual se construye lo que en este medio se denomina la "voz coral".

Se trata de "un artículo con la reportería que nosotros hicimos y las fuentes que hicimos pero que también tiene las opiniones de la gente", expresa 
Perla Toro, quien fungía como editora de la Unidad de Interacción y como macroeditora durante la semana que visitamos el medio. La información no se presenta solamente en texto, hay multiplicidad de posibilidades que son más limitadas en la narrativa del impreso y que para la narración en línea se pueden llevar a video, audio, galería o infografía: "hemos hecho experimentos con las herramientas tecnológicas. Con nubes de etiquetas con palabras" (Toro, 16 de abril 2013, comunicación personal), afirma la macroeditora.

A partir de estas experiencias, se demuestra que el formato más susceptible de ser visitado y difundido en la .com es el video, luego las fotos y por último los textos. Esta situación da muestra de una correlación entre los entornos digitales y la información, en apariencia sin muchos conflictos y con el propósito de ser creativa.

La elaboración de la noticia de índole política y económica muchas veces está no solo circunscrita a la dictadura del tiempo o inmediatez que aún hoy sigue siendo una exigencia casi categórica, sino también a la escasez de nuevas herramientas, dados el desconocimiento y la no adaptación ${ }^{2}$ de los comunicadores y las empresas periodísticas, pues no hay aún prácticas definidas que perfilen las características de cada actor dentro de un periodismo digital que aspira, al mismo tiempo, a ser especializado. Sin embargo, en el medio donde hay convergencia entre lo analógico y digital se puede dar continuidad a un nivel de mayor desarrollo de la noticia a través de la red. Aunque debemos resaltar que:

Ya es conocida la experiencia del grupo Tribune y su redacción multimedia donde los periodistas trabajan para todos los soportes a la vez. Pero es una solución con inconvenientes y que tendrá que sufrir algunos cambios para convertirse en definitiva: se trabaja más, hay menos tiempo para la investigación y para profundizar en los temas (Edo, 2002, p. 56).

Así describe el CM de El País la situación: "Quienes estamos inquietos por explorar nuevas herramientas, nuevas formas de narrar los hechos somos muy pocos, porque el ejercicio sigue muy anclado a esos vicios de antaño de la rigurosidad, del estilo en la escritura y del formato que siempre han manejado, y ha generado una zona de confort y no se quiere salir de eso, entonces ahora a pesar de que hay nuevas generaciones, en ellas he visto que se empieza a replicar ese modelo, te lo digo mirándolo desde este sector digital, la gente que recibimos en elpaís.com en buena parte viene del impreso, entonces vienen con esa mentalidad, es aprender a manejar esa plataforma que hay allí, como que la información y otra forma de narrar no les fluye, no hay chispa (Escobar, 28 de febrero de 2013, comunicación personal). 
Este panorama de retos que genera todo el entorno digital parece atiborrar de exigencias únicamente a los periodistas, lo cual origina el interrogante sobre el papel que corresponde a los demás implicados en este proceso, como lo constituye de manera clave la empresa, en tanto se deben garantizar unas condiciones adecuadas para la transición, que no impliquen una cantidad mayor de trabajo para los periodistas y en donde se renuncie a la práctica de menos personas haciendo más tareas. En deterioro de algunos principios fundamentales del periodismo como es la responsabilidad de informar con profundidad, consecuente con el compromiso con la ciudadanía.

Que se haya venido desdibujando la esencia del cuarto poder ha hecho que la creatividad en los formatos pueda convertirse en un medio para atraer al usuario, un dispositivo utilitarista más en la sociedad de consumo de la información para producir cierto impacto y demostrar ante los anunciantes la aceptabilidad de lo que se está haciendo. No es un misterio para ningún periodista la opinión de la subeditora web del diario El País: "la empresa ya tiene más conciencia de la importancia de esta plataforma ya que significa un modelo de negocio y los clientes están pautando" (Rosero, 28 de febrero de 2013, comunicación personal).

Tal situación también se evidencia con el comentario de la editora web del Noticiero 90 Minutos: "con lo que tenemos nos toca desarrollar y mostrar a quienes manejan el dinero para que vean e inviertan el dinero" (Figueroa, 1 de marzo de 2013, comunicación personal). Igualmente la editora del portal NTN24, Yuranis Caballero, reconoce que en las redes sociales lo que importa es incrementar el tráfico hacia el portal mediante publicaciones que siempre llamen la atención. Así pues, no se ve al ciudadano que se interesa por los temas públicos, puesto que por principio este ya no pone mayor acento en la información política y económica, ni al periodista que en algunos casos no interpela al poder cuando hace mal su gestión, ya que se ve abocado a producir dentro de un marco editorial que responde cada vez más a las demandas del momento. La categoría ciudadanía se desdibuja en este marco de la inmediatez/creativa, ahora se produce la noticia en función de un usuario o audiencia (¿de lo que está buscando?), de aumentar el tiraje, o de popularizar el portal.

En los entornos digitales y bajo la égida de la democratización y en un horizonte ideal, se piensa la creación de la noticia - ya no en perspectiva 
política, para dar prominencia a estos temas- desde la perspectiva de la industria cultural, que tendría como fin hacer del producto noticioso algo cada vez más digerible, cómodo, atractivo y, sobre todo, entretenido.

El periodista político y económico debe entonces lidiar con el propósito de informar, con la manera de sorprender y con el imperativo económico de impactar, maquillando la información como algo más entretenido.

\section{¿Cuáles son las herramientas o aplicaciones que están utilizando los periodistas?}

El periodista que trabaja para cabeceras digitales tiene que interactuar con los lectores y pensar en multimedia, informar con textos, imágenes y sonido, aunque eso hoy produce, en la práctica, unas dificultades operativas que la tecnología y, como consecuencia, los medios todavía no han podido resolver (Edo, 2002, p. 32).

El estado de la creatividad de los periodistas en la publicación y difusión de las informaciones en temas de política y economía, es consecuencia del escaso uso y conocimiento de las aplicaciones y en general de las herramientas digitales. En medios como Hora 13, Noticiero 90 Minutos y La Tarde es más evidente; uno de los factores que explican el rezago de estos medios se deriva de las decisiones de las empresas periodísticas que retardan la inversión en la formación o adaptabilidad de los recursos y espacios para enfrentarse a este nuevo panorama de la comunicación.

No obstante, también hay un lugar de comodidad en el que se instala toda tradición y del que cuesta migrar para enfrentar los nuevos retos. Los periodistas políticos y económicos, a pesar de presentar cierta disposición, afirman no tener el chip y que eso "es cuestión para los jóvenes". Los periodistas ubican la instalación de este chip, aproximadamente, en periodistas menores de cuarenta años. La resistencia de los reporteros mayores, en medios como Hora 13, Noticiero 90 Minutos y La Tarde, se evidencia en que aún se implementan las herramientas y aplicaciones digitales de base (en relación con el avance de los entornos digitales) de difusión como Facebook, Twitter o correo electrónico.

Nos encontramos con algunos periodistas de este grupo que desconocen las herramientas que implementa la edición web, más allá de enviar correos o tuits, o tomar fotos con los móviles. Estas son algunas de las aplicaciones 
sobresalientes que, según nos mencionan, utilizan o han utilizado algunos periodistas en sus rutinas:

En El Heraldo Storify, Pinterest y Dipity. En El País Storify y Drupal el cual permite subir videos en el canal propio que tiene YouTube; Final Cut editor de video, y para elaborar líneas de tiempo Time Life. Andrés Felipe Ossa (1 de marzo de 2013, comunicación personal) de Noticiero 90 Minutos, manifiesta que hay una plantilla multimedia a la que están sujetos y que aún no permite funciones para la preparación de galerías fotográficas más sólidas, ya que hasta el momento son montajes de foto a foto que simulan un video y que luego se suben a YouTube. Toda posibilidad de un listado actualizado resulta inútil ante la avalancha de innovaciones.

Se enuncian nuevos instrumentos o aplicaciones que empiezan a adquirir popularidad, pero hay una limitación que en principio determina el rezago de la creatividad a pesar de la diversificación de plataformas, aplicaciones, formatos y medios por los que se puede elaborar una noticia; esta consiste en la preparación de los periodistas para adoptar estos cambios al ritmo en el que emergen, sobre todo de periodistas que son del medio impreso y no encuentran una convergencia con el portal web.

Debemos resaltar que El Colombiano es uno de los medios que está a la vanguardia de los cambios; Perla Toro (16 de abril de 2013, comunicación personal) nos expone una gama importante de aplicaciones y herramientas de las cuales están haciendo uso:

Usamos Twitter, Facebook, Flickr, Delicious, YouTube, Livestream para montar videos. Tenemos algunas para infografía, algunas sencillas con plantillas, si no tenemos mucho tiempo. Y otras para edición de audio y de video. Street Journal también es una forma de nuevas narrativas. Hacemos reportería desde nuestro celular, en tiempo real. Allí no importa tanto la calidad.

Una creencia ampliamente extendida es la de que en medios comerciales, propiedad de grandes compañías de la comunicación, hay una mayor inserción del entorno digital debido a los recursos materiales que pueden facilitar estas empresas, suposición frente a la cual no hay que ceder tan rápidamente. Germán Espejo (julio de 2013, comunicación personal), periodista político web de El Espectador, a la pregunta por el desarrollo de la creatividad en el portal y la innovación del contenido político responde que: 
[...] hemos fallado en eso, fuera de la foto, lo que escribimos, tal vez un audio o un video que es lo básico, de ahí no pasamos. Pero creería yo que sí hay más espacios en la política para desarrollar en [la] Internet.

Observaciones que realizamos sobre el portal de este periódico dieron como resultado que sí se ha venido trabajando más el tema de la creatividad, con aplicaciones sencillas de imagen y con tratamientos en la redacción de titulares y entradas.

\section{Relación del periodista especializado en política y economía con los ciudadanos}

La credibilidad es consecuencia inmediata de la popularidad de un periodista en las redes sociales. La participación dentro de este nuevo espacio, donde se mueven cada vez más las grandes personalidades de la política y la economía, proporciona unos efectos en cuanto se puede generar opinión pública, se posiciona así al medio y eventualmente a la noticia.

El contacto permanente que se puede establecer con el ciudadano a través de estos canales, es una de las virtudes que trae el periodismo de los entornos digitales y a partir de los cuales los ciudadanos incentivan al comunicador a visibilizar temas que por supuesto serán producto del trabajo de verificación y en general de investigación del periodista. Por otra parte, ya en algunos medios se instaura una sección como la de reportero ciudadano; en Noticiero 90 Minutos hay un formulario que llenan los ciudadanos y a través del cual pueden tener contacto con los periodistas. El CM lo remite al reportero según la sección que maneje, para que dé curso a los contenidos.

De acuerdo con ello, y como lo indica Concha Edo (2002): "por la cantidad creciente de información que brinda la red, se hace imprescindible un trabajo de documentación, selección y tratamiento de la actualidad que nadie sabe hacer como un periodista" (p. 63). Es una relación periodista/ ciudadano en perspectiva colaborativa que antes de los entornos digitales no existía.

Aunque todavía se está consolidando, se presenta con una virtud interesante: la de constituirse en un canal que funge como mecanismo de control social al periodista y al medio. Podríamos hacer una suerte de paralelo para explicar el vínculo que la ciudadanía sostiene con los periodistas citando un 
caso que nos da un periodista: "por ejemplo la ola verde en el tema de la campaña presidencial de Mockus, hubo mucho movimiento en Internet de los usuarios que no se vio reflejado en votos" (Cifuentes, 15 de abril de 2013, comunicación personal).

Según esto, puede haber mucho movimiento ciudadano en las redes sociales suscitado por las noticias que están haciendo los periodistas, pero esto no significa una profundidad en la relación periodista/ciudadano; estas relaciones parecen más bien pasajeras, de la noticia del día a día, sin mucho arraigo y con un interés que parece más instrumental en términos de los requerimientos del medio. En suma, la participación y vínculo de los periodistas con la ciudadanía sí es real, pero aún no está afianzada en tanto no hay unos perfiles determinados de cada uno en el proceso interactivo, que además no dependen únicamente del periodista, sino de las condiciones del medio en general. La interacción es la virtud que emerge como una de las ventajas sobresalientes del nexo entre el periodista y el ciudadano y que ha ocurrido de manera gradual y a veces tardía.

La aparición de los entornos digitales trajo consigo el evento de una interacción en doble vía, donde las funciones de emisor-receptor se desmarcan; algunos periodistas de la web parecen no alcanzar a imaginar cómo se caracterizaba la relación del periodista y el ciudadano anterior a este soporte; igualmente este imaginar un periodismo antes del Twitter, resulta difícil para los periodistas inmersos en la web.

Lo que sí es cierto, según lo corroboraron muchos de los periodistas y los editores web, es que en la red se requiere de una estrategia para hacer que las informaciones sean más llamativas para las audiencias. La diferencia no está tanto en el modo como se redacta o se presenta la información entre la red y el medio análogo, sino en los temas "con los que se desea atrapar al público".

\section{Más audiencias activas}

En contraste con los medios tradicionales están los medios nativos digitales, donde los ciudadanos interactúan de forma significativa con los periodistas y llegan a aportar información que afecta la agenda del medio, aunque de manera relativa. En los medios tradicionales, la capacidad de volcarse hacia los intereses ciudadanos se evalúa con cuidado, pues deben mediar entre las visiones parcializadas y amañadas a los intereses con que 
las personas cargan la información, buscando incidir a veces en el medio, así el ciudadano entonces se convierte en el coautor, aunque todavía no alcance el nivel de producir con responsabilidad.

Para la periodista Perla Toro (16 de abril de 2013, comunicación personal) las audiencias se constituyen en el factor más relevante que el periodista tiene hoy, además de que los avances tecnológicos humanizan cada vez más al periodismo, con la posibilidad de confrontar públicamente y en el menor tiempo posible al reportero.

Algunos medios regionales son conscientes de la importancia de las noticias locales para conectarse con las audiencias, por lo que deciden abrir con estas temáticas. A menos que la coyuntura amerite empezar con otras notas. Mauricio Arias (16 de mayo de 2013, comunicación personal) de La Tarde menciona el caso de un periodista que es acusado de mandar a asesinar al exalcalde del municipio de Dosquebradas, noticia de orden judicial con la que este periodista no abriría nunca, pero que por la prominencia se hace y logra, de modo impresionante, más de quince mil visitas en un solo día.

Así mismo, el medio puede ir moldeando ciertos aspectos de la audiencia. Por ejemplo, en la forma como el medio publica la información en la web: con los niveles de jerarquía y prominencia que él establece, va educando a la gente en cuanto al formato en que el medio presenta la noticia. Esta actitud puede ir de la mano del esfuerzo porque la gente pueda interesarse por lo importante, por las decisiones políticas y económicas que pueden llegar a afectarle, cuidando de no hacer proselitismo, lo que evidencia una postura ética del periodista, ya que como nos lo relataron bastantes periodistas, sobre todo en algunas regiones: los políticos siempre están pidiendo un espacio para ser nombrados en el medio, o en Twitter o en Facebook.

Las audiencias participan de acuerdo con la cantidad de canales de participación que crea el medio. Así hay formularios de inscripción de contacto para monitorear a las audiencias, utilizados en El Heraldo, aunque en el momento de nuestra visita el espacio para comentarios en las noticias había sido eliminado; tal determinación se llevó a cabo porque quizá las personas no sabían hacer buen uso de estos espacios; nos afirmaron los periodistas de este medio que, por ser una sociedad relativamente cerrada o pequeña, el anonimato tendía a desaparecer. En cambio se instaló la herramienta Facebook comments, un módulo de comentarios enlazado tanto al medio de 
comunicación como a la red social. Esto también funciona como estrategia de difusión y posicionamiento del medio.

La participación en redes, propiciada por las noticias de los medios de comunicación, facilita los debates en línea y la organización virtual que puede desencadenar movilizaciones, lo cual no es consecuencia inmediata de acciones directas que se den desde el medio. El trabajo del periodista genera la inquietud, proporciona un marco general en cuanto a la información, algunos datos y es finalmente la propia ciudadanía la que debe tomar posiciones de acción. Esta es la opinión resumida de la mayoría de los periodistas entrevistados.

Todos los periodistas exponen que su trabajo es informar, proveer datos, y que a la ciudadanía le correspondería las acciones. Sin embargo a la ciudadanía, manifiestan los periodistas, le falta tomar acciones. Las revueltas que solo suceden en la red no suscitan transformaciones, aunque sí un ambiente de inquietud.

Si volvemos sobre la función de los editores web como mediadores entre el impreso o el soporte tradicional y la web, son ellos también a quienes competería posicionar las opiniones ciudadanas dentro del medio en el instante que las comunican. La repercusión que tienen los temas políticos o económicos es variable aunque el primer paso para incentivar la participación lo constituyen las preguntas que de un tema hace el medio a la ciudadanía; por ejemplo, Mauricio Arias, editor web y CM de $L a$ Tarde, revela que ha elaborado preguntas como "¿qué piensan los pereiranos del proceso de paz?, ¿qué piensan de la eutanasia?, ¿qué piensan del matrimonio gay?”. Andrés Guevara (19 de diciembre de 2012, comunicación personal), subeditor de redes sociales de El Tiempo, nos explica:

Muy pocos periodistas están capacitados en las nuevas aplicaciones, además del teléfono inteligente y del PIN no salen de la foto y del texto, todavía está muy crudo esto, tiene que ver con que no conocen la herramienta y cuestiones técnicas y del valor de un teléfono inteligente, de la misma red $3 \mathrm{G}$, muy precaria para llegar a que esos usos sean eficientes, desde la red de transmisión de datos hasta el acceso a los teléfonos inteligentes con aplicaciones, el mercado de aplicaciones y el conocimiento se le suma a eso. No me atrevo a dar tiempo pero por ahí en cinco años los periodistas tendrán la cultura digital inserta en su trabajo.

En este sentido, podemos afirmar que los periodistas están empleando los teléfonos inteligentes más para informarse que para informar. 


\section{De la movilización ciudadana y el lugar del periodismo político y económico allí}

"Lo que pase con la información que se difunda no es lo que nos concierne, debido a que lo que se hace es periodismo y no activismo" (León, abril de 2013). No obstante, los efectos que se desprenden de su difusión noticiosa, de alguna forma hacen que haya una suerte de movilización de subjetividades, que por supuesto desbordan las intencionalidades del periodista. Lo que más tarde puede desembocar en una movilización ciudadana. Pero como lo señala el reportero Francisco Arias (16 de abril de 2013, comunicación personal) para entonces vinculado a El Colombiano, la labor del periodista llega hasta el punto de informar con responsabilidad, aportándole al análisis y dándole elementos a la opinión pública, pero no más que eso.

\section{Independencia informativa, la mediación de los intereses políticos y económicos en la labor periodística}

Las ediciones web de los medios tradicionales en apariencia gozarían de más autonomía editorial, lo cual no se traduciría en libertad. Igual allí los poderes políticos y económicos tienden a ejercer una influencia sobre las publicaciones digitales, llegando a presionar, como nos lo comentaron en algunos medios, para que se modifiquen muchas de ellas; así el monitoreo de información, por parte de estos poderes en la web, va en contra de la oportunidad que estos idealmente ofrecen para la democratización y la libertad de prensa, que en teoría podría propiciar la web por su misma esencia.

Sobre este punto los periodistas reiteran, casi que a modo de consenso y haciendo una retrospectiva de los resultados que arrojó el mismo ítem, que sin importar el formato, los intereses políticos y económicos estarán presentes, en especial en los medios que son la extensión del formato tradicional, en lo que a la propiedad del medio se refiere y en donde los vicios relacionados con la injerencia de los poderes políticos y económicos simplemente cambian de plataforma.

Por otra parte, el imaginario de que los periodistas del digital tienen más independencia que los del impreso se da porque los primeros tienen más diversidad de temas que los segundos, por el hecho de usar la multimedia que permite dar más contexto, extensión, hipertextos o contenido a una noticia y por cierta libertad de agendas y jerarquía de las noticias. Pero la línea edito- 
rial debe llegar a todos, nos manifestaron los editores web. El medio es una empresa que tiene que salvaguardar sus intereses, como lo menciona Diana Marcela Figueroa (1 de marzo de 2012, comunicación personal) webmaster de Noticiero 90 Minutos: "no somos más independientes por ser de la web, empezando porque el director es el mismo, por tanto, el nivel de independencia es igual porque los dueños son los mismos". Quizá se hace eco de que son más flexibles en cuanto a la generación de agendas y escogencia de temáticas.

Hay temas en la agenda que resultan más sensibles y sobre los cuales se generan directrices acerca del manejo del lenguaje. Esta situación se presenta en El Colombiano donde la periodista Perla Toro (16 de abril de 2013, comunicación personal) afirma:

Los temas de política dependen de las directrices del periódico... Hay unas directrices a seguir y en algunos momentos unas órdenes. En este momento son diálogos de paz, paz y derechos humanos [...]. Se da la orden de qué contenidos se publican y cómo se publican, incluso en el .com. Los muchachos reciben unas instrucciones de ellos. Por ejemplo: a las víctimas las vamos a tratar con estos nombres, cosas muy de lenguaje, sobre todo para que no se politice el proceso dentro del periódico. Cuando hay elecciones pasa una cosa similar.

Lo anterior es muestra de la injerencia de los intereses, en este caso políticos, que se ejerce sobre los medios de comunicación y que estos a su vez ejercen sobre el periodista. Además la tradición política de un periódico obliga a tener un tratamiento particular con ciertos contenidos de la agenda, lo cual escapa a las posibilidades de autonomía que otorga el entorno digital.

\section{Efectos de los Entornos Digitales sobre la prominencia del periodista y el periodismo político y económico}

Existen divergencias muy claras en cuanto a la percepción que se tiene de las transformaciones que causan los entornos digitales sobre la prominencia del periodista político y económico. Por un lado se dice que esta sigue siendo como en los medios análogos, que los entornos digitales no han modificado mucho la visión que se tiene sobre la prominencia del periodista, aunque por otro lado las características a las que nos convocan en el ejercicio periodístico las virtudes de los entornos digitales como la del tiempo real, dan la posibilidad de acercarse al lector y estar siempre sintonizado con lo que pasa, propician un giro en cuanto al nivel de interactividad. Se transforma, 
entonces, la imagen del periodista frente al público, ya que este puede hacer cosas más innovadoras con otros diseños, y a su vez con contenido especializado, como un producto especial para las audiencias. Esta oportunidad y posibilidad hace que la imagen que se tiene del periodista se amplíe y cambie a la par de las evoluciones de los medios y soportes.

En cuanto a las consecuencias de la visibilidad que adquiere el periodista con los entornos digitales en la medida de la difusión de información, el periodista se ve abocado a mantener una imagen de transparencia, lo que a su vez refuerza la credibilidad del medio. En las redes sociales, con su esencia marcadamente pública, se busca que el reportero sea más cuidadoso y riguroso, aunque no siempre se consiga, expresan los periodistas. Los periodistas manifiestan un cierto relajamiento; se considera que es aún más fácil borrar la información de la web que la de un impreso, por todos los protocolos que conlleva. 



\section{Capítulo 3}

\section{LOS MEDIOS NATIVOS DIGITALES. GONVERGENGIAS Y DIVERGENGIAS}

ntendemos por medios nativos digitales aquellos
que tienen su representación inicial en la web y que al momento de la investigación se hallaban únicamente allí. Esta investigación quiso separar los resultados de los trabajos de los medios tradicionales de los medios nativos digitales, dado que desde un primer momento comenzamos a descubrir importantes diferencias. En estos casos no se realizaron visitas directas a las sedes de los medios, ni se hicieron observaciones a los consejos de redacción, bien sea por celebrarse estos solo una vez a la semana o bien porque los medios no poseen una infraestructura física desarrollada en este sentido.

Se incluye acá también las entrevistas que se efectuaron a periodistas de medios extranjeros que pudimos abordar en encuentros o reuniones en torno a las problemáticas actuales del periodismo. La mayoría de las entrevistas se hizo a los directores de los mismos medios. Para este grupo de periodistas, directores de medios nativos digitales, se añadieron algunas preguntas y se seleccionaron otras que ya se habían elaborado para los periodistas económicos y políticos. Los periodistas, y sus respectivos medios, a los cuales tuvimos acceso son:

- $\quad$ El Blog del Ministro. Octavio Cardona. Pereira.

- Revista Gobierno. Patricia Betancourt. Manizales.

- Poderopedia. Miguel Paz. Chile. 
- El Faro. Carlos Dada. El Salvador.

- The Guardian. Mariana Santos. Reino Unido.

- Blog Punto de Vista. Rubén Darío Benjumea. Medellín.

- El Turbión. Omar Vera. Bogotá.

- Cali Escribe. Andrés Mejía. Cali.

- Zonacero. Lauren Puerta. Barranquilla.

- La Silla Vacía. Juanita León. Bogotá.

\section{Eje digital}

\section{Los temas más visitados por las audiencias.}

En los medios nativos digitales que pueden autodefinirse como independientes o alternativos ${ }^{1}$, el lugar de lo político y lo económico, a pesar de su esencia independiente, se enfrenta, al igual que en los medios tradicionales impresos, a la exigua prominencia que esta información está teniendo y que debería ser de vital trascendencia en una democracia para los ciudadanos y para los flujos de la información ${ }^{2}$. Los periodistas de estos medios al definir el periodismo que se hace en los medios masivos comerciales aseguran en términos generales que las informaciones políticas y económicas se las trata como mercancía de consumo que es digerible, breve, llamativa y se caracteriza por ser coyuntural, y mientras más se explota en ella lo cultural o patriótico, por ejemplo, por medio de la exaltación, más se logra capturar a las audiencias.

Allí tenemos temas como los deportes, el folclor y la cultura nacional de las regiones, o lo judicial en tanto que sensacionalismo que se pueda extraer

Los medios llamados independientes se autodenominan así por la posición y lugar que tienen frente a los oligopolios económicos y políticos que, directa o indirectamente, financian los medios de comunicación, comprometiendo la verdad, responsabilidad y profundidad. Los medios independientes sientan una posición más política de su valor en la sociedad, mientras que los alternativos sientan su diferencia en cuanto a tratar otras temáticas de la vida social y cultural de un país, sin que necesariamente sean independientes de los sistemas o ejercicios del poder político o económico.

2 A este propósito, para Ramonet (1998) "la información no tiene valor en sí misma en relación, por ejemplo, con la verdad o en relación con su eficacia cívica; la información es, antes que nada, una mercancía. En tanto que mercancía está en esencia sometida a las leyes del mercado, de la oferta y la demanda, y no a otras reglas como podrían ser las derivadas de criterios cívicos o éticos. Lo que entra a jugar allí el medio de comunicación como negocio de producción de información” (p. 16). 
de esa fuente, atributos que en la mayoría de veces no poseen las noticias de carácter político y económico, a excepción de las que se vuelven farándula para presentar la vida íntima de los personajes públicos de la ciudad, el periodismo de figuras, como algunos lo denominan, ese periodismo que por medio de las historias convierte a los personajes de la vida pública en personajes de relato novelesco ${ }^{3}$ al igual que en los momentos en que la información política y económica se presenta como un referente marcadamente coyuntural. Este es el panorama que se vislumbra en mayor medida en los medios que no son especializados en temas de política y economía, según los periodistas de los medios independientes y nativos digitales.

En contraste, los medios que exclusivamente se dedican a producir noticias de nicho político, y que son independientes, afirman trabajar a partir del reporterismo y la investigación, lo cual evidencia un periodismo especializado. Declaran tener unas audiencias consolidadas que reconocen al medio y lo visitan de manera directa, siendo entonces los contenidos políticos o económicos los de mayor afluencia. Tal es el caso de La Silla Vacía, Revista Gobierno, El Turbión y blog Punto de Vista. Este último muy visitado por "paisas" (habitantes del departamento de Antioquia), principalmente, y por personas que se encuentran en la capital del país o incluso en el exterior. Este medio se caracteriza por la denuncia de temas políticos y administrativos de la región. De igual modo, El Blog del Ministro, un medio que según su director, representa a la región cafetera en temas de carácter político y económico, y genera información "donde está el grueso del poder".

Por otra parte están los medios como Cali Escribe o Zonacero que no poseen un carácter únicamente político. Allí los contenidos que más pueden presentar visitas, además de los que momentáneamente resultan prominentes, ya sean políticos, económicos, judiciales o culturales, son las secciones que el medio incorpora para marcar una tendencia o un valor agregado particular, como la de Estudios Urbanos en Cali, según afirma Andrés Mejía (28 de febrero de 2013, comunicación personal), editor web.

Lo que importa es la percepción que se tenga del personaje en el momento de la lectura (Jouve, 1995). En la novela, con diferentes niveles de ficción, los personajes tienden a convertirse en personajes del mundo real, mientras que en los relatos con personajes reales de la vida pública, se los pone a jugar dentro de estructuras narrativas periodísticas pertenecientes a los relatos novelescos: de esa forma se crean conflictos e intrigas narrativas que los desplaza de su estado real a un estado casi mítico. 
Otro de los aspectos, quizá de carácter sociológico, que no se pueden desconocer a la hora de identificar los temas por los cuales se están interesando los ciudadanos y explicar su causa, es el nivel cultural de una nación, como lo menciona Mariana Santos (19 de abril de 2013, comunicación personal) de The Guardian:

Allá es más importante lo político... Hay un sitio en Internet donde usted puede poner el URL de un sitio de una portada de un periódico y les da a todas las portadas por días y se pueden comparar las portadas de todos los días y se verá cómo no solo hay política nacional sino internacional, en el caso de Europa y la crisis europea, eso es tema central casi todos los días.

La referencia constante en las primeras páginas de los diarios europeos, es para Santos (19 de abril de 2013, comunicación personal) indicio del nivel de relevancia que tiene lo político para las audiencias europeas. Lo anterior se puede contrastar con lo dicho por Omar Vera (21 de junio de 2013, comunicación personal) del portal El Turbión:

Por el nivel sociocultural que existe en Colombia [...] este tipo de información tiene un público muy definido, la información económica no es una información que sea consultada por el señor de la tienda del barrio sino que generalmente es consultada por la intelectualidad, por gentes que vienen sobre todo de las capas medias de la sociedad.

Lo precedente nos convoca a una reflexión, más aún en el marco de una democracia, parafraseando a Edgar Morin (2011) en La vía: para el futuro de la humanidad: si no se propende por elevar el nivel cultural de una nación a partir de los cambios estructurales e integrales de los cuales formarían parte los medios de comunicación; la incidencia de los ciudadanos interactivos en la generación de la agenda informativa en los temas de real impacto social, sería superflua, carente de virtud, de valor cívico y ético, posicionando contenidos alejados de la realidad nacional e internacional en cuanto se muestran como los más divertidos, digeribles y coyunturales posibles.

\section{Ubicación del periodismo político y económico en los entornos digitales.}

En un horizonte donde la información es diversa y superabundante, es difícil que lo político y lo económico se posicionen y tomen un lugar importante, máxime cuando la respuesta a estos temas, como se dijo, es por coyunturas, escándalos o hechos individuales. Esta situación demuestra a los 
públicos, sin decirlo, que la información es una mercancía. En este sentido está menos impulsada por una función cívica. Paradójicamente, en un momento donde la preocupación ética de los periodistas aumenta por cuenta de la interactividad, la limitación, naturalmente en la era del capitalismo financiero, desborda las preocupaciones éticas y cívicas que tanto inquietaron en un primer momento al cuarto poder.

Los periodistas directores de estos medios coinciden en la apreciación de que si bien el tema político y económico no se presenta dentro del menú de contenidos que más atraen a los ciudadanos, la capacidad de influencia que tiene lo que dicen los comunicadores sobre estos temas a un nivel especializado es relevante en la formación de la opinión pública, sobre todo en esferas más instruidas y más altas del poder en la sociedad con capacidad de influencia o decisión.

Los portales web de los medios impresos, al igual que los medios nativos digitales que no se especializan en política y economía, tienen que competir con otro tipo de información menos especializada. La ubicación del periodismo político y económico aunque tal vez sea más copiosa en el soporte digital, con ayuda de los motores de búsqueda, no tiene aún el grado de prominencia y el alcance que se esperaría en las condiciones de las democracias actuales.

Si bien la fuente política y económica resulta muy atractiva para los periodistas, convirtiéndose en una oportunidad para desarrollarse en el campo profesional, la dificultad que enfrentan los reporteros es cómo abordar mejor estos temas desde su producción y tratamiento. Según la opinión de Carlos Dada (19 de abril de 2013, comunicación personal) de El Faro, "no creo que estas cosas (los nuevos espacios) vuelvan más atractivo al periodismo político. Simplemente permiten hacer periodismo político de una nueva manera".

La percepción de los medios nativos digitales es que el periodismo especializado en política y economía está más desarrollado en la web; su alcance es mayor y se lo encuentra de calidad, en comparación con las plataformas tradicionales. Por ejemplo, la directora de La Silla Vacía, Juanita León (abril de 2013, comunicación personal), considera que el periodismo político es una fracción muy pequeña del periodismo en Colombia, lo cual también se refleja en los entornos digitales, así mismo asegura que este medio es el único de nicho en temas políticos. 
Los medios de la región cafetera, como El Diario del Otún, La Tarde, La Esmeralda Hoy y El Blog del Ministro, se enfocan en la imagen de los políticos y su vida íntima, por lo cual esta información no puede categorizarse como un periodismo político o económico especializado, no hay investigación ni análisis profundo enfocado específicamente en esta fuente.

\section{Estado de la creatividad en los entornos digitales.}

En cuanto al estado de la creatividad del periodismo especializado en política y economía en los entornos digitales, es prematuro aseverar que el ritmo de las transformaciones en las plataformas sea equivalente al de la implementación de los cambios para adaptarse a él. Los periodistas sostienen que no hay modificaciones radicales en el modo de hacer periodismo, se vive un periodo de transición y experimentación, aun cuando el influjo de nuevas aplicaciones y herramientas satura las posibilidades creativas de la red, incluso para el periodismo, este contexto convoca la emergencia de erigir como atributos, en la manera de hacer periodismo, los retos que imponen los entornos digitales, sobre todo para aquellos que tienen un contacto directo con las aplicaciones, los portales y las redes, como los CM y los editores web. Ello quizá porque aún no hay una convergencia consolidada y una discusión y reflexión al interior de los medios sobre la importancia y los efectos de los entornos digitales en el quehacer periodístico.

En contraste, los medios nativos digitales son mucho más cercanos y por lo tanto más receptivos y sensibles a los cambios que propone al periodismo el entorno digital. Las nuevas formas de contar, el lenguaje, en tanto nuevas narrativas interesantes y atractivas, no sacrifican la profundidad de la información. Seducir, cautivar y atraer son exigencias para que el receptor se detenga a leer la noticia, son los principios que se imponen al periodista cuando difunde información.

Se evidencian unas narrativas digitales no lineales aunque, con sorpresa, se están aproximando más a una "creatividad/simplificadora", como lo explica Concha Edo (2002, p. 14), en tanto que los textos noticiosos de los titulares o los sumarios de Facebook, es lo primero que miran los usuarios. A estas conclusiones llegó un estudio que se hizo público en los primeros días de mayo de 2000, y que es el resultado de los trabajos llevados a cabo durante cuatro años en Estados Unidos por la Universidad Stanford y el Poynter Institute. 
Los investigadores emplearon microcámaras especiales que se acoplan a la cabeza y un software que registraba los movimientos oculares, el tiempo de fijación en los distintos puntos de la pantalla, los clics del ratón y la navegación de unas páginas a otras. Se concluyó que se leen tres veces más artículos cortos que largos, pero se profundiza en la lectura de temas que interesan más. Estos resultados del estudio se corroboran con las respuestas que dan periodistas como Yuranis Caballero (19 de agosto de 2013, comunicación personal) de $\mathcal{N} T \mathcal{N} 24$ de Colombia, cuando declara que lo importante es decir mucho con poco y de la manera más creativa en Twitter y Facebook, de modo que esos titulares arrastren con clics a los usuarios hasta el portal, con miras a incrementar el tráfico de la página como estrategia comercial del sitio web. Para el director de El Turbión:

Las narrativas han cambiado radicalmente, no se puede hablar tan extenso, los periodistas se enfrentan al reto de informar con rigor a la vez que de manera breve, en poca extensión se debe tener profundidad, hay una lucha por la creatividad (Vera, 21 de junio de 2013, comunicación personal).

Otro ejemplo que confirma el lugar común donde se sitúan las nuevas formas de hacer periodismo desde el aspecto del lenguaje en los entornos digitales, se refleja en revista Semana -según su editor web-, donde el titular ha de ser cautivante, concreto, corto y diciente (Gómez, mayo de 2013, comunicación personal).

Es así como el lenguaje es un campo donde los periodistas reconocen que han debido enfrentar el reto de instaurar un estatuto de creatividad, demanda que trata de conciliar entre la inmediatez y la profundidad, y además donde como ya lo menciona Edo "el estilo, la manera de presentar los hechos, va en el periodismo unido a la brevedad, a la exactitud, a la precisión y, más que a cualquier otra cosa, a la realidad" (2002, p. 16). Habría que hacer un profundo análisis de discurso periodístico y de la estructura de la noticia para ver hasta dónde lo cautivante, diciente, seductor, atractivo y vuelto interesante en el ámbito de la inmediatez armoniza con la verdad y la profundidad.

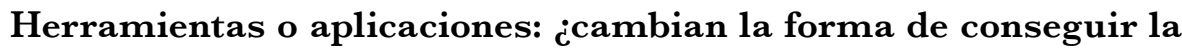 información?}

A partir de la indagación y acompañamiento a las rutinas de algunos de estos medios nativos digitales, se puede establecer que imperan las herra- 
mientas clásicas como la grabadora y el teléfono. De manera incipiente se introducen la búsqueda de datos a partir de las nuevas aplicaciones, los bancos de datos y las nuevas facilidades de los móviles con acceso a la web. En estos medios, todos los directores están familiarizados con los entornos digitales.

Una de las virtudes de las herramientas digitales para la elaboración de la información es que facilitan hacer el trabajo periodístico sin estar necesariamente en medios, como lo menciona Carlos Dada (19 de abril de 2013, comunicación personal). En ese sentido lo digital aporta visibilidad y opciones a los periodistas de los medios grandes y pequeños.

Ahora bien, es valioso resaltar la excesiva importancia que se otorga al soporte tecnológico, a partir de lo cual se puede correr el riesgo de desdeñar el contenido: "el contenido tiene que seguir siendo el rey" (Dada, 19 de abril de 2013, comunicación personal), o de emplear el soporte sin un fin claro: el para qué se lo quiere. De no ser así, termina vaciando de sentido la labor periodística y desplazando el contenido por la técnica. Lo uno no debe reemplazar a lo otro, son instancias complementarias, como lo indica Miguel Paz (20 de abril de 2013, comunicación personal): "si tienes que ocupar la herramienta para decir que estás ocupando la herramienta, entonces no estás haciendo periodismo. Eres solo un técnico experto en el uso de una herramienta".

En temas de política o economía que resultan de gran valor periodístico, como por ejemplo en Revista Gobierno, el uso multimedia fue importante para la presentación del caso de Agro Ingreso Seguro, plan frustrado del gobierno colombiano para el sector agrario.

La Silla Vacia también ha experimentado con nuevas narrativas creativas como simular el paso de las páginas de un libro para contar el trabajo de los dos primeros años del presidente Juan Manuel Santos, infografías interactivas para dar visiones de contexto de problemáticas nacionales. De todas formas se usan para informaciones de largo aliento y fruto de la investigación.

Los periodistas de la web no tienen así el límite del borde de la hoja que se presenta en el impreso, lo cual abre la posibilidad de hipervincular cientos de informaciones en un solo texto, lo que enriquece la nota. Aunque esto no se explota con todo el potencial, ni en todas las notas, ni tampoco de manera estandarizada. 


\section{Efectos de los entornos digitales en la búsqueda de la información y en la relación con las fuentes.}

Uno de los efectos que trae consigo el entorno digital, y con este las nuevas herramientas 2.0, tiene que ver con las maneras en cuanto a la búsqueda y elaboración de la información, sobre todo en lo que concierne a las fuentes.

En la redacción de la noticia, la investigación y el reporterismo se siguen implementando como una praxis tradicional en el periodismo, aunque hay una percepción por parte de quienes trabajan en estos medios nativos digitales, según la cual estas prácticas son cada vez menos recurrentes, más aún en medios grandes y tradicionales que preparan la noticia desde el imperativo de la inmediatez, y para quienes la disponibilidad de información al alcance inmediato en la web hace que acudan mucho más a este escenario.

Este panorama tiende a posicionar el uso de la investigación y del reporterismo como uno de los parangones del ejercicio periodístico, en mayor medida para aquellos de nicho político o económico que siguen conservando una relación directa con la fuente, como es el caso del portal La Silla Vacía y del medio alternativo El Turbión, para los cuales, a pesar de la entrada de nuevos recursos en cuanto a búsqueda de información en la web, no deja de ser imprescindible el recurso de la fuente directa. Sin embargo, para el primero no se muestra el reporterismo como un trabajo sobre el acontecimiento, sino sobre el contexto, mientras que el segundo sí registra hechos de ocurrencia cotidiana, lo que se deja ver, por ejemplo, en el registro fotográfico de los hechos del día, los cuales pudimos comprobar visitando su página.

Es en el campo de la relación con las fuentes donde se presentan variaciones determinantes, mientras la fuente se hace más asequible, paradójicamente es menos cercana para el periodista. Por otra parte, las redes sociales, los bancos de información y las páginas web de las instituciones o personajes de la vida pública, son un espacio propicio para el surgimiento y especialización del prosumidor.

La nueva tendencia de un acercamiento no directo a las fuentes en los medios tradicionales, puede verse como un retroceso o detrimento de la esencia de la labor periodística. En opiniones como la de Octavio Cardona (17 de mayo de 2013, comunicación personal) de El Blog del Ministro, "el desplazar el contacto con la fuente, es mortal y sería una estocada para el periodismo en 
general". El anterior panorama se convierte en muestra de las contradicciones que suscita el entorno digital; por una parte, se valora la disponibilidad de fuentes en tanto pululan multiplicidad de canales de comunicación, lo cual colabora con la inmediatez de la producción de información/mercancía; y por otra se considera como un menoscabo de la esencia del quehacer periodístico el que no haya un contacto directo con la fuente.

Uno de los aspectos que se pierde son los múltiples lenguajes que se pueden capturar a partir de este encuentro directo con la fuente, estandarizando los modos de expresión. Muchas variables hay acá, como las respuestas dadas solo en texto o en audio, pero en ausencia de las respuestas kinésicas que forman parte de las interpretaciones que puedan dar las fuentes.

\section{Papel y función del editor web/redes sociales frente a los perio- distas.}

En medio de la atmósfera de experimentación y transición en que se desarrolla el periodismo en los entornos digitales, parece haber una característica común a los medios nativos digitales, no hay roles muy delimitados allí, como sí ocurre en un medio tradicional: jerarquías más rígidas y fronteras espaciales y temporales. Esto tal vez debido a que el equipo de periodistas es muy grande, en contraste con el medio nativo digital que, por lo general, es de dimensiones más modestas y donde el ambiente laboral ayuda a desarrollar un trabajo en intensidad mucho más colaborativo, rasgo que se establece como uno de los atributos del periodista en los entornos digitales.

\section{Eje ético: ¿más compromiso?}

Relación del periodista especializado en política y economía con los ciudadanos en los Entornos Digitales.

Existen diversas percepciones con respecto a la relación del periodista especializado, ya sea político o económico, con el ciudadano. Una de ellas se instaura en el ejercicio de la denuncia, la información que podríamos llamar open info. Este tema de las denuncias es muy fuerte en los medios regionales, como el blog Punto de Vista, Zonacero o El Turbión, este último especializado en contenidos de derechos humanos. También es la base de espacios como Poderopedia, de Chile, y la reciente versión colombiana. La 
posibilidad de hacer este tipo de periodismo deriva directamente del momento tecnológico que se vive y de la independencia que se tiene, lo que a su vez define la línea editorial y posibilita un manejo menos discreto del lenguaje y la información.

De acuerdo con lo anterior, el vínculo de estos medios con los ciudadanos reside no solo en la capacidad que tienen los primeros de producir temas que no divulgan los medios tradicionales, sino también en la posibilidad que tienen las audiencias de participar activamente en cuanto pueden enviar información que luego retroalimenta o desencadena un tema de investigación para el mismo medio.

"Lo que exige cada vez más la ciudadanía es ser informada con transparencia sin confabulaciones de los periodistas con la política y la economía", dice Lauren Puerta (noviembre de 2012, comunicación personal) periodista de Zonacero. Otra de las particularidades de la relación del periodista especializado en los medios nativos digitales reside en que la ciudadanía se identifica más con el medio que con el periodista. "El medio es aquí quien define la relación, somos gente sin nombre y sin substancia, que generalmente no firma en los periódicos [...] en contraste con ese periodismo de opinión que posiciona al analista por sobre el medio" (Vera, 21 de junio de 2013, comunicación personal).

La relación que se da entre las audiencias y periodistas está más visibilizada y es por supuesto más interactiva en los medios tradicionales que tienen su versión digital, en tanto algunas cartas, preguntas o comentarios se dirigen en específico a ellos, de lo cual el medio como tal o el director no tiene el control.

Medios como el blog Punto de Vista, caracterizados por elaborar información "contrahegemónica", El Turbión, que por definición trata en mayor medida temas de derechos humanos, El Blog del Ministro y aquellos que parecen ser más moderados en la confección de la información como Cali Escribe, Zonacero y Revista Gobierno, se contrastan con medios como La Silla Vacía, que define a sus periodistas diciendo que "tienen una voz fuerte, producto de su trabajo de investigación, no de su ideología o activismo" (León, abril de 2013, comunicación personal). Así podemos evidenciar tres tipos de medios nativos digitales que se dedican a temas de ciudadanía y política: a) contrahegemónicos y activistas, de registro de acontecimientos y análisis de 
contexto; b) moderados y con información de profundidad de un periodismo más clásico y c) desideologizados, no activistas, de profundidad y contexto.

Se constatan también dos tipos de efectos de la información con respecto a la relación que se establece con el ciudadano: la direccionada y la no direccionada. La primera se produce cuando los medios divulgan información que tiene un carácter de denuncia, en tanto la mayor de las veces están informando sobre temas que otros medios callan, y la segunda ocurre en medios que poseen un enfoque investigativo desde el que se puede hacer un ejercicio de reflexión autónomo por parte de las ciudadanías. De Alzaga (2012) lo explica así:

Porque tal vez los males del periodismo hayan venido al asumir como válido el formar, informar y entretener que proponían algunos académicos. Pues un diario no debería formar a sus lectores, más allá de las conclusiones que estos puedan extraer tras leer sus páginas (p. 8).

Dentro de los aspectos más importantes encontramos la relación periodista/audiencia, y personaje político o económico/medios de comunicación. La primera alude a la demanda de veracidad de la información a la que llaman el amplio espacio casi infinito de difusión de Internet y que trae consigo la facilidad de contrastar la información, lo cual invita al periodista a ser más cuidadoso y a la vez lo expone al escarmiento público y a la censura inmediata. Como lo expresa Leopoldo Díaz Granados (17 de noviembre de 2012, comunicación personal) de El Heraldo, al considerar que hay una desventaja de los entornos digitales en términos de veracidad. El periodista comenta un caso de censura donde le solicitaron quitar de la web una información que habían publicado sobre un personaje político de la región; efectivamente se retiró el artículo ya que la tecnología lo permitía. Paradójicamente, la web como un espacio de alta y libre difusión, también hace posible un ocultamiento más sencillo de la información.

Por otra parte, hay quienes expresan un gran compromiso con lo social, como lo manifiesta el director de El Faro: "las sociedades se transforman cuando tenés la mayor parte de una sociedad mejor informada y mejor formada. Así se transforma una sociedad. Porque tienen mejor capacidad de decisión, incluso política" (Dada, 19 de abril de 2013, comunicación personal).

La segunda relación que se establece, personaje político o económico/ medios de comunicación, parte del hecho de la sensibilidad que las decla- 
raciones políticas o económicas adquieren en la red, como lo dice Andrés Mejía (28 de febrero de 2013, comunicación personal) de Cali Escribe: "el periodismo político debe tener mucho cuidado en lo que escribe y pone"; precisamente uno de los recursos de los entornos digitales que más colabora en hacer prominente la fuente política y económica son los videos que sobre las actuaciones de estos personajes salen a la luz pública, la mayoría de estos la proporciona la ciudadanía y se propaga de manera viral, como lo constituye el caso del senador Eduardo Merlano, que, pasados dos años, forma parte de los ejemplos citados por algunos de los periodistas.

Los ciudadanos producen acontecimientos y si estos son videograbados y de actualidad, mejor. La función de algunos medios, en compañía de las producciones de los ciudadanos, parece ir más allá de la seducción, como podría pensarse para un medio tradicional y se ubica en el regodeo con la audiencia productora y en su reconocimiento. Este tipo de relación es más distante para medios de investigación y contexto y no tanto de acontecimiento, como La Silla Vacía.

\section{De la independencia informativa en la mediación digital política y económica.}

Parece que hay una percepción clara sobre la incidencia de la mediación del soporte digital y de las plataformas: no hay un cambio esencial respecto a la independencia que podría traer consigo la plataforma digital. En palabras de Dada (19 de abril de 2013, comunicación personal): "la plataforma no te hace más ético, no te hace mejor periodista, más consecuente, menos consecuente. Sacar un periódico on line te hace simplemente... ¡más oportunista! No hay ningún vínculo entre la plataforma y los principios del oficio".

$\mathrm{Y}$ es que es indiscutible que una de las virtudes definitivas de esta plataforma, se halla en sus bajos costos y posibilidades mayores de difusión, como lo comenta Patricia Betancourt (15 de mayo de 2013, comunicación personal) de Revista Gobierno:

Creo que los entornos digitales han abierto mucho los espacios al periodismo en general, tienen mayor cobertura, hay menos miedo a que se sepan algunas cosas. Se explora más y se puede ir más allá, además de que es mucho más económico. 
Sin embargo, hay una utopía que ronda el periodismo en Internet; la misma planteada en la Revolución francesa: la libertad, como lo menciona Ramonet (1998, p. 27), "mientras la transmisión del saber siga las pautas impuestas por el poder político-económico, este ideal de una democracia de la información, seguirá residiendo en el terreno de la utopía". Aunque para algunos los entornos digitales se constituyen en la facultad de desarrollar pequeños medios, que no dependen de la pauta o de la inversión del capital privado que tiene intereses adjuntos.

La cuestión de la ética está hoy en el centro de las preocupaciones de los periodistas. La industrialización de la información ha traído como consecuencia una parcelación de las actividades y una dependencia de un sistema jerarquizado y de propiedad, que reclama su rentabilidad inmediata (Ramonet, 1998).

Los medios nativos digitales financiados por otras instancias, logran menor dependencia de oligopolios y con ello pueden conjugar ese espacio de alta difusión a bajos costos con calidad. Así lo creen Lauren Puerta (noviembre de 2012, comunicación personal) del portal Zonacero y Miguel Paz (20 de abril de 2013, comunicación personal) de Poderopedia. La Internet, afirman, es una de las mayores virtudes de la información política y económica en los entornos digitales: "lo bueno de la tecnología y de la Internet es que la gente tiene otros canales, ya no se puede tapar el Sol con un dedo" (Paz, 20 de abril de 2013, comunicación personal).

\section{De la autocensura.}

Quizá la expresión de "cómo le tiro a mi patrón" resulta muy diciente en cuanto al problema de la autocensura, algo que no es tan evidente en los medios nativos digitales, ya que su financiación no proviene de intereses políticos o económicos (nacionales o locales) más sensibles con el tratamiento que se le da a la información.

Este aspecto es recurrente y se naturaliza entre los periodistas que desde su experiencia pertenecieron a medios de comunicación tradicionales del país, que comúnmente han sido propiedad de familias vinculadas con intereses políticos y económicos. Los periodistas tienen muy claros los límites que traza la propiedad privada de los medios, (Cardona, 17 de mayo de 2013, comunicación personal). 
Se puede llegar a la conclusión de que la plataforma de difusión no es el imperativo para alcanzar una independencia informativa, los principios éticos dependerían más de la propiedad de los medios, no obstante, los entornos digitales contribuyen de manera determinante a la independencia por sus bajos costos. Las posibilidades de financiación son la puerta de entrada a muchos de los periodistas que quieren hacer otro tipo de información, menos mediada por los intereses políticos y económicos. Así mismo se accede a otros públicos más contemporáneos. La pelea por las audiencias está casada y es de largo aliento. Como lo menciona Pedro De Alzaga (2012)

El futuro parece mostrarnos un "ecosistema" informativo de pequeñas empresas capaces de hacer una información más especializada y más alejada de las antiguas redacciones en las que un periodista podía pasar por cinco secciones a lo largo de su carrera. Los agentes de este nuevo ecosistema serán más de "guerrilla", más independientes y menos atados por los intereses políticos y económicos (p. 7).

En aquellos medios más locales, casi unipersonales, que salen a buscar la pauta, el financiamiento y el objetivo de las agendas parecen más claros. Otros medios más estructurados con financiamientos internacionales, estarían por evaluarse y analizarse en el tema de la independencia.

\section{Del control social a los periodistas por los oligopolios económicos y políticos.}

El mecanismo de control social mejor implementado en el ejercicio periodístico es la subsistencia individual con la que se entra a negociar el tratamiento de la información. Debemos decir que hasta el momento no tenemos un estudio que pueda confirmar que efectivamente los medios nativos digitales están exentos de la censura y la autocensura, como lo expresa la opinión de un periodista: "qué tanto los recursos que provienen de ciertos sectores sociales definen la agenda mediática, informativa que tenemos" (Vera, 21 de junio de 2013, comunicación personal), refiriéndose a la financiación que proviene de cooperación internacional y demás instancias.

Hay tensiones manifiestas entre el poder y el ejercicio informativo de los periodistas nativos digitales y que los enfrenta a la autocensura. En el blog Punto de Vista, caracterizado por ir a contracorriente, hay muchos roces con personajes de la vida pública. El Turbión también es un medio que padece la presión de los poderes por la publicación de información que resulta sensible 
para estos. Un tema como el de derechos humanos en un país como Colombia causa ciertos conflictos. Esto también ocurre en La Silla Vacía.

\section{Eje de autopercepción: ¿mejor periodismo?}

\section{Adaptación de los periodistas a las transformaciones que propo- nen los entornos digitales.}

Howard Tyner, director del diario Chicago Tribune, decía en entrevista para el diario El País de España en el 2000 que "el periodista tiene que pensar siempre en multimedia. Necesitamos editores y reporteros que se sientan cómodos con textos, imágenes y sonido en el trabajo diario, en lugar de permanecer anclados en lo que han hecho siempre" (Howard, 2000).

Si bien hay una demanda que sería la de que el periodista pensara siempre en multimedia y esté presto a las transformaciones de su oficio, recordemos que la exigencia cada vez más reinante acerca del conocimiento que deberá tener el periodista sobre el entorno digital, se ha constituido en el motivo de los despidos masivos de los periodistas, por lo menos en España. La exigencia de un perfil digital con la intención de renovar la plantilla empresarial, demuestra el "olvido" de las empresas mediáticas de que el dominio del soporte no es el dominio del oficio.

La simplificación técnica y la aceleración del proceso de producción periodística fueron aprovechadas por las compañías para unir funciones: los fotógrafos, tal como los editores de sonido y de video, han visto desaparecer muchos puestos de trabajo porque las empresas cargaron esas ocupaciones a los periodistas. O como ocurrió a mediados de 2013, cuando el Chicago Sun-Times decidió prescindir de su planta de fotógrafos. La verdad es que cuanto más evolucionan los medios, mayor es la tendencia para que se establezca la polivalencia de los profesionales que van acumulando funciones anteriores con las nuevas, participando en la convergencia profesional (Canavilhas, 2012).

Los periodistas están empezando a mediar entre las virtudes con relación a la facilidad de contactar a las fuentes que ofrecen los entornos digitales y el riesgo que se corre al privilegiar a la web como el único canal de investigación de su labor periodística, frente al reporterismo o el salir a la calle. ¿Cómo complementar estas dos instancias? 
Algunos pocos periodistas entrevistados de los medios tradicionales parecen estar en el lugar cómodo que les otorgó la labor clásica del periodismo: periodistas maduros que tienen una resistencia a los entornos digitales. Temas como las aplicaciones o redes sociales, para algunos, parecen ser totalmente ajenos a su ejercicio periodístico. Pudimos observar en las salas de redacción que al no considerarse estas nuevas propuestas se va produciendo y abriendo una brecha entre los periodistas que pueden ser considerados clásicos y los jóvenes recién salidos de las facultades con una facilidad enorme para interactuar con el entorno digital, aunque corriendo el riesgo de sacrificar el contenido por el tratamiento técnico.

Es allí donde todavía no hay una convergencia muy clara entre este tipo de periodistas; pueden llegar a ser un complemento, pero lo que aún se requiere es que se logre conjugar las virtudes de uno y otro sin desvalorarse ninguno y antes de que se renueve totalmente la planta de periodistas. La tecnología, en este caso, en lugar de ser un elemento de la transmisión del "secreto de familia", se convierte en su muralla.

\section{¿Altera la corriente participativa la potente agenda mediática?}

Hay una evidencia contundente de que ha aumentado la participación. La pregunta fundamental sería: ¿qué tanta influencia tiene? Una vez que se publica la nota hay una participación que en palabras de Andrés Mejía (28 de febrero de 2013, comunicación personal) es una retroalimentación que los periodistas reciben a partir de los comentarios o de textos dirigidos directamente a ellos. Todo este tipo de interacción podemos definirla como asincrónica (comentarios, cartas de lectores, correos electrónicos a la redacción) (Rost, 2001). ¿Representan estos espacios una utopía de la libertad de expresión y de comunicación y qué tanto impacto tienen sobre las decisiones editoriales del medio? Si bien hay redes sociales embebidas en el sitio que podrían calificarse como un tipo de interactividad comunicativa sincrónica, estas privilegian la expresión individual más que la comunicación.

Uno de los periodistas más comentados en Cali Escribe es Ramiro Varela (28 de febrero de 2013, comunicación personal), por ser quien maneja el tema de las llamadas megaobras en la ciudad y alrededor de las cuales se tejen más polémicas. Buena parte de los contenidos son tomados o inspirados de la sección No te Calles, que da la oportunidad participativa en la web. 
A juicio de algunos periodistas como Dada (19 de abril de 2013, comunicación personal), director de El Faro:

Lo que ha hecho la red es que los individuos dejen de ser sujetos pasivos en todo el proceso. Porque antes eran simplemente receptores y si algo no te gustaba ibas y lo comentabas en la cantina o en tu casa. Ahora los ciudadanos [forman] parte de la esfera pública, parte activa.

No podemos asegurar que esta percepción se establece como un estado generalizado, ya que es una opinión parcial en cuanto al papel de los ciudadanos; sin embargo es solo una de las perspectivas del momento actual, que exige mucho más del ciudadano. Participar, comentar e incidir, es por norma general, la tendencia a la que nos está avocando el periodismo por Internet, como dice Rost (2004):

Estimamos que un periódico digital es más interactivo cuando presenta un repertorio de opciones que ofrezca mejores condiciones para la expresión y el debate público de ideas. $\mathrm{O}$, para decirlo de otra manera, cuando más favorezca la participación activa y crítica de los lectores en la construcción de la actualidad. (p.5)

Para La Silla Vacía los conflictos de interés, los vacíos en el reporterismo y la falta de respeto por los usuarios, se reflejan en los comentarios. La directora del portal afirma que en otros medios se desprecian los foros de comentarios; en los medios independientes se aprecian.

\section{¿Cómo marca la opinión pública las informaciones políticas a través de los entornos digitales de las noticias que aparecen en la web?}

$\mathrm{Al}$ interior de los medios especializados en política hay una dinámica en la cual los periodistas saben qué están investigando sus compañeros. Existe una agenda que es más abierta y más compartida. Esto hace que el propósito del medio sea más claro para las audiencias.

El aspecto del lenguaje también es importante. Para Patricia Betancourt (15 de mayo de 2013, comunicación personal) de Revista Gobierno, hay una tarea fundamental que ejerce el medio, y es la de bajar todo ese lenguaje político a la gente del común.

Los generadores de opinión en la sociedad colombiana, tienen como uno de sus referentes fundamentales a La Silla Vacía. El medio ha sido reconocido 
por sus buenas prácticas y es mencionado por los líderes de opinión y otros medios en general.

Una agenda más conjunta, un lenguaje más cercano a la audiencia y un trabajo diferenciado por su tratamiento de profundidad y contexto, son algunos de los elementos que detectamos y que de manera contextual ayudan a la cercanía y a influir en la opinión pública.

\section{¿En qué medida el periodismo político y económico que usa plata- formas digitales moviliza la participación ciudadana?}

1. ¿iSe puede responder mejor a los intereses de los ciudadanos?

2. ¿Los ciudadanos se sienten más incluidos gracias a los entornos digitales?

3. ¿Ayuda al círculo virtuoso?

A partir de las respuestas que dieron los periodistas a estas preguntas, no podemos asegurar que los medios promuevan directamente la movilización ciudadana, en el sentido en que hay un apoyo en tanto se pueden tratar temas que interesen y motiven a aquella, aunque desde la lógica del tratamiento de contenidos que están al orden del día, los medios no son el motor de las movilizaciones ciudadanas, pero sí colaboran o complementan de una manera indirecta el estado de cosas.

Las movilizaciones que se gestan en las redes sociales son registradas por los medios tradicionales y no tradicionales y su tratamiento es el mismo que se le da a otros temas coyunturales. En esta medida, los medios lo que consiguen hacer es un cubrimiento de los temas que resultan prominentes para la ciudadanía, como lo menciona Patricia Betancourt (15 de mayo de 2013, comunicación personal) de Revista Gobierno:

Hacemos seguimiento de lo que están hablando pero no necesariamente para responderles a los ciudadanos. Más que tomar una posición, decir que se está a favor o en contra sobre temas como el matrimonio igualitario o la eutanasia, es registrarlos y hablar de ellos.

Un ejemplo recurrente que los periodistas nos comparten cuando interrogamos por la incidencia del periodismo político y económico en la movilización, es el impacto que las redes sociales tuvieron en Medio Oriente, y las crisis europeas, como lo señala Andrés Mejía (28 de febrero de 2013, comunicación personal): 
De una convocatoria por la red, de pronto resultaron quince mil personas en la Puerta del Sol, a los acampados, al principio no les pararon bolas y por fuera se fue regando y aparecieron quince mil, y fueron llegando de todo el país, eso es un caso de convocatoria por redes y ocurre en sitios donde las redes tienen mucha fuerza móvil, aquí las redes todavía no tienen fuerza móvil, pero van para allá.

De acuerdo con lo anterior, encontramos que el fin del periodismo no es generar una movilización social, aunque de manera indirecta lo que puede pasar según el contexto, es que ayuda a que emerjan protestas sociales. 


\section{Gapítulo 4}

\section{GARACTERIZAGIÓN DE LOS COMMUNITY $M A N A G E R$ Y EDITORES WEB}

Tas redes sociales como Twitter o Facebook se han

Lconvertido en los últimos años en nuevos y significativos escenarios de trabajo para la difusión de la información noticiosa en Colombia; ello requirió la aparición de una nueva figura, el CM o social media, un periodista especializado en el manejo de las redes, para lo cual el conocimiento de la lógica, dinámicas y cultura de Internet era indispensable, pero con el tiempo, se necesitaron nuevas funciones en aras de las demandas y nuevos espacios y lógicas de los medios en la red.

En países europeos, particularmente en España y también en Estados Unidos, la situación del periodismo no es la mejor. El impacto a largo plazo de Internet, más la crisis económica, ha llevado a buscar inéditas formas de trabajo y organización, allí Twitter y Facebook son importantes sitios para el desarrollo y sostenimiento de los medios y de la profesión.

En Colombia la situación del periodismo no se caracteriza por estas tendencias, y los medios tienen aún gran fortaleza en lo impreso; la total determinación a trabajar en estos nuevos espacios se abre paso con la "complicidad" y la seducción de las nuevas generaciones. Igualmente el acceso a Internet, así como la cantidad de seguidores que tiene un medio en estas redes, es relativamente inferior. España y Colombia tienen una población 
similar que ronda los poco más de 47 millones; el diario El País de España tenía para mediados de 20132.800 .000 seguidores, mientras que El Tiempo de Colombia contaba con 1.600.000 seguidores. A mediados de 2014 el primero tenía poco más de tres millones y el segundo casi 2,9 millones. Esta rápida comparación nos da cuenta, sobre todo, de las posibilidades de acceso a la red y del gusto por las redes sociales, si bien las cifras aumentan día a día.

Entendiendo un medio de comunicación comercial y frecuentemente masivo como una cadena de producción de noticias y como un negocio, a los CM se les ha asignado el trabajo de postear las noticias, de atraer a las audiencias y de ser impulsadores del producto para generar el tan anhelado tráfico, para aumentar la cantidad de seguidores y fidelizar audiencias que en un futuro serán potenciales consumidores, no solo del medio sino también de lo publicitado por el medio. Así las cosas, este tipo de periodismo está más cercano del marketing de la información, de la publicidad y del manejo de las noticias en tanto que informaciones y datos.

El trabajo de los GM se encuentra en todo el proceso: captura de contenidos, subir notas de los periodistas, hasta el manejo de las redes. Durante las visitas y observaciones realizadas a los diferentes medios de comunicación se advirtió que el campo del CM adopta formas, roles, alcances y funciones diferentes en cada una de las estructuras organizativas de los medios y que también están en constante mutación.

A excepción de uno de los CM, todos son personas recién egresadas de sus carreras de comunicación social, publicidad o diseño. Y ello es entendible, ya que el manejo de las redes sociales requiere una gran empatía y entendimiento de algunas lógicas, que en principio, estaban escritas en ninguna parte, por lo que el manejo comenzó a ser intuitivo y requería que estos periodistas conocieran la cultura de la red, conceptos y praxis de la comunicación humana, buena redacción y las estructuras básicas de la noticia. Más recientemente este campo se ha visto fortalecido por cursos y especializaciones que han surgido.

Esta posición de periodistas recién egresados en las salas de redacción los ubica con los salarios más bajos, sobre la idea de la trayectoria y experiencia, pero también por no representar, en términos generales, al menos no todavía, una figura destacada o función importante para el medio. 
En la mayoría de los casos la creación del puesto como tal de CM es nuevo y no pasa de los cinco años, algunos medios lo tienen hace apenas un par de años. Con todo, las funciones y papeles, como dijimos, se diferencian de medio a medio, pero una generalidad de su trabajo es publicar noticias producidas por el medio, replicarlas en las redes sociales y a veces ocuparse de responder a los internautas o publicar informaciones o fotos que estos envían, "animar las redes" con preguntas o requerimientos como comentarios, fotos y publicar estas colaboraciones así como informaciones sobre eventos del mismo medio.

$\mathrm{Al}$ indagarse en los medios por las funciones, se encontró que muchas se mezclan con las del editor web, aunque la tendencia es a diferenciarlas. Mientras que el CM parece dedicado a la instrumentalización de las noticias en las redes, el editor web se encarga de analizar flujos de informaciones, tráfico de las noticias, priorizar y jerarquizar ciertas noticias por encima de otras en la red, mantener la línea editorial del medio y crear estrategias para el manejo de la información en la red de cara a las audiencias en un marco de interactividad.

Pero cuando la planta de periodistas es reducida o cuando el medio, siendo grande, tiene a pocos periodistas en el área web, son los mismos CM los que rinden informes y estadísticas sobre flujos, tráficos y tendencias y deciden junto con el editor general del medio las estrategias, jerarquías o tratamientos de las noticias de acuerdo con los principios o intereses del medio. Esto también cuenta cuando los internautas hacen críticas a los contenidos o tratamientos del medio. Por lo general, los CM están impedidos para responder directamente sin antes consultar con el editor.

En Twitter, en la mayoría de los casos, los periodistas que publican la información, no producen noticias y crean muy pocos contenidos originales; se limitan a redireccionar en las redes los titulares redactados por agencias o por los periodistas del periódico o medio tradicional; en el mejor de los casos buscan otras facetas de la noticia que también podrían convertirse en titulares o vuelven el titular pregunta para el lector o extraen lo llamativo de la noticia.

En las observaciones realizadas se notó cómo, eventualmente, hay cambios en la manera como se redactan los tuits; este es el caso de Portafolio, donde se le da un nuevo aliento a la noticia en Twitter, haciéndola más llamativa e intere- 
sante para la red, acercándose a los diferentes tipos de intereses de los consumidores. También generan enlaces externos, etiquetan una noticia sobre tendencia (\#) o con un personaje "arroba" (@), originando toda una nueva sintaxis con la cual nos hemos venido familiarizando a tal punto que un tuit puede ser una mezcla de textos de colores, signos, tendencias y nombres de los personajes, agentes, espacios, ciudades o países involucrados. Acá no hay normas de construcción y presentación del mensaje, cada medio las adopta como bien le parece.

A pesar de que en principio el campo de acción y trabajo del CM parece mucho más amplio, en la práctica aún se lo ve limitado. La Asociación Española de Responsables de Comunidad Online y Territorio Creativo definen así al CM:

[...] aquella persona encargada o responsable de sostener, acrecentar y, en cierta forma, defender las relaciones de la empresa con sus clientes en el ámbito digital, gracias al conocimiento de las necesidades y los planteamientos estratégicos de la organización y los intereses de los clientes. Una persona que conoce los objetivos y actúa en consecuencia para conseguirlos (AERCO, 2009, pp. 4-5).

Algunas de estas funciones en los medios nacionales visitados no están aún tan desarrolladas y las ejecutan los editores web e incluso los editores del medio o de las secciones del medio. No es posible una caracterización clara sobre estas tareas, ya que cada medio ha ido encontrando la mejor manera de adaptarse a estas necesidades. Por otra parte, en el transcurso de esta investigación reparamos en que medios como El Tiempo retomaron el tema, renovando algunas de las estrategias en las redes.

Lo que sí se puede apreciar es que en la mayoría de los casos el trabajo del CM es mecanizado; la red y el computador son los instrumentos del manejo serializado de la publicación de la noticia en las redes. "Nosotros también salimos a la calle a hacer cubrimientos que luego llevamos al portal" (Guevara, 19 de diciembre de 2012, comunicación personal).

La autonomía profesional del CM se ve disminuida a una réplica de noticias. Tampoco hay mayor autonomía en el poder responder a las inquietudes de los internautas, pues las respuestas deben pasar por un filtro editorial, a menos que sean datos de público conocimiento. En otros casos, como en el diario El Espectador, son los mismos periodistas que teniendo acceso a la cuenta oficial del periódico postean sus propias notas en Twitter, aquí las 
narrativas del Twitter y del portal convergen, no se piensa una narrativa exclusiva para los tuits y otra para el portal, esta se deja al criterio individual de los reporteros.

En Facebook el trabajo de los periodistas es menos claro, de hecho la mayoría prefiere Twitter sobre Facebook, pues este último parece más desordenado, más disperso y más mezclado con otro tipo de informaciones, mientras que en Twitter todos tienen el mismo espacio físico para la publicación, la misma jerarquía. El periodismo, sin duda, pudo adaptarse inicialmente más a Twitter, principalmente por su lógica de cantidad de caracteres.

Algunos medios usan Facebook simplemente como un canal más. Otros, como un espacio para generar aún más tráfico y como lugar de debate entre diferentes usuarios de la red. Sin embargo, tratándose de redes sociales, lo que se hace es experimentar fórmulas. La periodista de Interacción y Comunidades de El Colombiano asegura que estas experiencias en el diario incluyen también al ciudadano: "el ciudadano aporta una parte del proceso - de la producción de la noticia-. En las redes sociales se han explorado mucho las nuevas narrativas. Y están también los blogs como otros nuevos espacios” (Toro, 16 de abril de 2013, comunicación personal).

El CM se enfrenta también a la premura. Si lo que se quiere es informar primero que otros medios, no se deja tiempo para redacciones más creativas o de mayor profundidad. Parte de la creatividad y esfuerzo se va en las exigencias de posicionarse y generar muchos enlaces y entradas: redactar un tuit en el que se pueda enlazar más de una tendencia o personaje. Pero acá también hallamos diferencias. Mientras que algunos medios son más bien parcos en sus enlaces, otros saturan el tuit con estas herramientas.

Algunas de las secciones web se limitan a un solo periodista, como ocurre por ejemplo en el noticiero Hora 13 o en el diario La Tarde. En otros casos, la sección de nuevos medios cuenta con casi una decena de periodistas, como ocurre en El Colombiano. Estos periodistas sí hacen cubrimiento de calle.

\section{Sobre los espacios de trabajo}

En muchos de los medios visitados, los CM y las secciones web ocupan un espacio físico que no está integrado a la redacción del medio; por ejemplo en Hora 13 está en una de las salas de edición del medio; en Noticiero 90 
Minutos en una lugar aparte de las salas de redacción, igual ocurre en $L a$ Patria, en El Heraldo y de alguna manera en El País.

La lógica de organización de los espacios físicos cambia de medio a medio. En algunos, los periodistas web tuvieron que hacerse a un sitio dentro de las redacciones de los medios, en otros se los pensó como una sección aparte de la redacción central. En las salas de redacción renovadas recientemente como en La República o El Colombiano, los periodistas de los medios digitales o nuevos medios trabajan codo a codo con los periodistas de la redacción del periódico o, por lo menos, en un mismo espacio de trabajo con características claramente colaborativas.

La mayoría de los periodistas de los medios observados afirma que la situación se ha discutido al interior del medio y que estaría por cambiar, con más periodistas adscritos a la web. Estamos de acuerdo con Daniel Ponte Fernández (2010) cuando expresa que son muchas las funciones que debe desempeñar un CM, tantas que deberían ser gestionadas por un grupo de profesionales, abarca demasiados objetivos, y a esto deberíamos agregar que es una labor extremandamente importante. Muchas veces no se entiende como esta labor de la que tanto se habla en las empresas y que parece ser eje de sus relaciones en la red, está endilgada a un solo practicante, recién llegado a medio y sin experiencia. Esta es una contradicción que encontramos en gran parte de los medios visitados.

En esta disparidad de funciones en las que entran también en algunas ocasiones el editor web, el curador de contenidos para la web y el mismo editor de sección o editor general del medio tradicional, es difícil una caracterización general, lo que da cuenta del estado primigenio en el que se encuentra la profesión en Colombia en algunos medios de comunicación. La presente investigación no preveía perfilar de manera independiente a cada uno de estos actores y funciones en el proceso del tratamiento de la noticia. La observación se centró en lo que dimos a conocer como "periodistas adscritos a la web" y en dicha observación detectamos los rasgos arriba enunciados.

\section{Un evento casual}

En la mayoría de los casos, incluso en los medios más grandes y prestigiosos, la llegada del CM fue un evento casual y curioso, los periodistas llegados allí, eran chicos y chicas creativos e inquietos por las nuevas tecnologías y la 
Internet y conocían la cultura y lógicas de las redes sociales, lo cual les dio ventajas instrumentales sobre los periodistas más veteranos al interior de los medios. Contaban con poca o ninguna experiencia en reporterismo y no tenían una visión amplia y compleja de las rutinas de los periodistas tradicionales.

Para concluir este aparte, podemos decir que la rapidez con que se desarrollaron las redes -en particular con Twitter y después del triunfo de Barack Obama como presidente de los Estados Unidos-, hizo pensar que el manejo de la información noticiosa en ellas era de vital importancia, así nos lo hicieron saber numerosos periodistas:

Quizás impulsado por la campaña de Obama, se convencieron los políticos locales de que el uso de las herramientas informáticas de la web 2.0 podría servir para hacer política. Antes existía, pero era visto como elemento decorativo, pero no como elemento movilizador en las urnas (Cifuentes, 15 de abril de 2013, comunicación personal).

Si se desea desarrollar más esta profesión, y con miras a un trabajo en temas especializados en política y economía, aún habría mucho por hacer. Serían los medios especializados en estas fuentes y que hayan ejecutado una tarea comprometida en las redes, los que podrían dar pistas sobre su futuro. Así, el periodista CM también podría especializarse en fuentes. Ello con el fin de conocer mejor el mercado, las audiencias, el tiempo de interacción que se puede lograr y proponer con estas y evaluar formas y narrativas para tratar esta información; de lo contrario se continuará con una función difusa multitemática. El tiempo dirá si en el caso de medios comerciales y masivos de temas de gran espectro, esta figura especializada es necesaria.

Los periodistas CM, sobre la base de que su labor es la constante actualización, son a los que más inmediatez se les exige hoy en día. Por ello deben estar en la capacidad de incorporar o comunicar con rapidez los comentarios y contenidos de las audiencias a la redacción general del medio, previa verificación, como es natural, a través, por ejemplo, de alertas en las redes internas. Y así mismo hacer fluir las noticias en las redes sociales con claridad, exactitud y concisión.

La situación CM se presenta un tanto difusa y variable por lo que se demandaría una clara definición por parte de los medios, una mejor capacitación aumentando sus responsabilidades y un mejor reconocimiento dada la gran importancia que este tipo de figuras representa para un medio. 



\section{Capítulo 5}

\section{LOS GONSEJOS DE REDACGIÓN}

\section{Sobre las audiencias}

T as principales vías de interacción en la gran

Lmayoría de los medios, son el Twitter, el correo electrónico y Facebook, que han superado a la obsoleta correspondencia postal. Las vías de interacción provistas por los medios en los foros, espacios para comentarios o correos para enviar datos, acotaciones, fotos o videos, se han convertido no solo en una forma de interacción sino de participación ciudadana que los medios promueven constantemente, tanto para alimentar contenidos de las versiones digitales como de las tradicionales.

Son las audiencias en su interactividad y participación en los medios las que poco a poco irán abriendo lugar para un cambio social, como lo afirma Castells (2009). Sin embargo no se sabe para dónde va necesariamente ese cambio. Los cierto es, como sostiene el autor, que hemos pasado de "la comunicación de masas a la autocomunicación de masas" (Castells, 2009, p. 92), lo que implica una comunicación masiva donde todos participan.

Los medios de comunicación investigados utilizan con frecuencia, como mínimo, Twitter y Facebook. El 90 \% de los periodistas tiene cuenta en Twitter y la aprovecha continuamente. Mientras que el $70 \%$ usa Facebook. La cuenta de Twitter se emplea más para fines periodísticos, mientras que Facebook, casi para comunicación con 
amistades o familiares. Uno de los canales por los cuales las audiencias interactivas pueden comunicarse directamente con el medio o con el periodista es el Twitter. En el caso de comunicarse con las cuentas del medio, no hay seguridad de que un comentario o pregunta llegue al periodista que elaboró la información.

\section{Observaciones etnográficas de los consejos de redacción}

"Mi mejor amigo es el correo electrónico" (Vega, 5 de octubre 2012, comunicación personal). "Acá somos románticos, nos gusta el papel" (Tovar, 5 de diciembre de 2012, comunicación personal). Durante la investigación se tuvo la oportunidad de asistir a varios consejos de redacción. No se realizó un cubrimiento de todos los medios visitados, bien por logísticas o porque los medios no consideraban conveniente la presencia de investigadores en estos espacios donde se toman importantes decisiones.

El objetivo de estar presentes en los consejos de redacción surgió cuando se quiso observar la rutina de los periodistas y, a partir de este espacio, evidenciar cómo lo allí discutido podía reflejarse en su labor investigativa de reporterismo y trabajo final. Todo ello, desde luego, en el marco del estudio de los ambientes digitales. En los consejos de redacción también quisimos tomar nota del lugar jerárquico que ocupa el periodismo político y económico al interior del medio y del nivel y tipo de relación que tiene este con los ambientes digitales. Las categorías de observación que se tuvieron en cuenta fueron las siguientes:

1. Orden de presentación de los temas

- Nivel de participación del periodista

- Relación con el entorno tecnológico

2. Selección de los temas

- Tipos de temas aprobados

- Participación del entorno digital en la aprobación

3. Relación con las fuentes

- Tipos de fuentes

- Origen de la fuente

- Tipo de tratamiento con la fuente 
La tendencia actual es que los medios de comunicación impresos comiencen sus consejos de redacción entre las diez y las once de la mañana. Esto significa que los periodistas normalmente ya están agendados desde el día anterior para un cubrimiento e investigación a realizar en las primeras horas de la mañana, de tal manera que a las once ya se llega con un avance o con la nota cubierta. En medios como la televisión los consejos se realizan temprano en la mañana.

Pudimos así estar en los consejos de redacción de Radio Nacional de Colombia, El Heraldo, Portafolio, Semana, La República y La Patria. Por lo común los medios de comunicación cuentan con una sala especial para el desarrollo del consejo de redacción. Estas salas, en algunos casos, están provistas de dispositivos tecnológicos para la exposición de los temas de la agenda periodística, como televisores, computadores y proyectores de video. Otros consejos se realizan en los mismos espacios de las salas de redacción y finalmente otros, como en el caso de Portafolio, en la oficina del editor.

\section{Orden de presentación de los temas y nivel de participación de los periodistas especializados en política y economía}

Los temas de la agenda del día no tienen un orden temático específico en ningún medio. Lo más común es que se comience por el orden en que se sentaron los periodistas en la mesa de trabajo, por el tema más urgente o que se está moviendo en ese momento en la agenda, o por el orden en que fue consignado por los periodistas en un sistema y red interna del medio dispuesta para esta función. En el caso de los noticieros de televisión se empieza por los temas que más se están agitando y por el tema con el cual se va a abrir la emisión. Otro de los criterios es iniciar con los contenidos que los internautas más visitaron. Así ocurrió, por ejemplo, en El Heraldo, allí lo que más se había movido tenía que ver con partidos de fútbol de equipos extranjeros donde participaban jugadores colombianos.

Así las cosas, no hay una preponderancia, por defecto, en el orden de presentación de los temas de política o economía, por encima de las otras fuentes. El nivel de participación del periodista y la relevancia de sus aportes e interacciones pueden llegar a relacionarse con los contenidos que más visitan los internautas.

Gracias a este fenómeno evidenciamos cómo las audiencias logran colocar su agenda de manera indirecta en los consejos de redacción. En este 
punto también debemos decir que los consejos de redacción son aprovechados por los EW y algunos de los CM para informar sobre la actividad de los internautas en la web. Esto no ocurre todos los días. Los informes sobre los movimientos, tráficos y temas más visitados y comentados en la red son semanales, quincenales o mensuales.

La llegada de los CM a los consejos de redacción es relativamente nueva. Los CM nos dijeron cosas como: "yo también asisto a los consejos de redacción" (Guevara, 19 de diciembre de 2012, comunicación personal), como si se tratara de un hecho novedoso o poco usual.

La preeminencia de lo político o lo económico en los consejos de redacción, depende de que estos temas sean en verdad relevantes para el medio ese día. Con todo, se observaron en el diario El Heraldo, incluso temas coyunturales en política; no necesariamente se trataron con la relevancia hipotéticamente esperada, tal como ocurrió con la instalación de las mesas de conversaciones de paz entre el gobierno y las Farc-EP en La Habana.

En términos generales, los periodistas políticos y económicos tienen en el consejo de redacción un mismo nivel de participación que los demás periodistas. En la mayoría de los medios, los temas a los que se les dedica más tiempo y, sobre los que hay más comentarios casuales de parte y parte entre los periodistas y jefes de redacción, son los de deportes o farándula, coincidiendo con las preferencias cotidianas de las audiencias al momento de entrar a la red, según lo muestran las estadísticas de los medios consultados y que nos fueron dadas a conocer por los editores web entrevistados.

De los medios no especializados en economía o política, el que más atención prestó a estos temas fue La Patria, lo que no significa que los demás medios no traten en algún momento con más profundidad estas fuentes.

\section{Relación con el entorno digital}

Cuando se desarrollaron en las salas los consejos de redacción detectamos que el empleo de los entornos digitales con respecto a la participación del periodista es muy bajo. De un $40 \%$ de los periodistas que llegan al consejo con una tableta, solo la mitad de ellos la utiliza efectivamente para 
algo relacionado con la agenda que se está tratando. El uso de las libretas de papel es aún preponderante entre los periodistas. Pero se ha visto cómo poco a poco las tabletas o los celulares se van introduciendo para tomar notas o leer anotaciones o datos previamente registrados. En lo observado y socializado en el grupo de los consejos de redacción, el manejo de estos dispositivos para búsqueda de información o contactar fuentes durante los consejos fue de un solo caso.

En otros, como en Radio Nacional de Colombia, El Colombiano y La República, que celebran los consejos de redacción en las salas, los periodistas están cerca a sus computadores y desde luego con sus dispositivos móviles; con todo, la participación de lo digital sigue siendo muy baja, los reporteros usan de preferencia libretas de papel y en pocos casos tabletas para anotar sus asignaciones o fuentes.

En algunos medios, como La Patria, el uso de los entornos digitales está previsto en el desarrollo de los consejos de redacción. El procedimiento para ver las asignaciones, el avance de las mismas, el género en que se tratará la información o las fuentes a consultar pasan por un software al que tienen acceso todos los periodistas y que es visto en un televisor dispuesto sobre la pared al fondo de la sala de redacción.

En medios como Portafolio, el uso del teléfono tradicional y celular es destacado. El editor está recibiendo constantemente llamadas telefónicas y atendiéndolas; algo similar ocurre en Radio Nacional de Colombia, donde el jefe de información y el periodista político también utilizan mucho el teléfono fijo y celular. En estos casos se debe al tipo de fuentes que se cubren, un poco más tradicionales. En Radio Nacional de Colombia también se debe al tipo de audiencia, más tradicional y rural que aún emplea el teléfono fijo como principal mecanismo de comunicación con el medio.

\section{Selección de notas}

En la selección de los contenidos sí se evidencia una relevancia un poco mayor en cuanto a los temas de política. Los editores generales, luego de la exposición amplia de temas y cuando se trata de definir los contenidos aprobados y los que abrirán las páginas de los informativos, prestan más atención a los asuntos de política. 
En el caso de Radio Nacional de Colombia y de $\mathcal{N} T \mathcal{N} 24$, se advirtió la trascendencia del tema político. En $\mathcal{N} T$ N24 es entendible debido a la agenda del medio. En Radio Nacional de Colombia la importancia de los temas políticos y económicos está direccionada por el director de información que hace notar la relevancia del tratamiento de estos temas en la agenda de la emisora.

\section{Participación del entorno digital}

La participación allí de lo digital es similar para el caso del desarrollo de los consejos de redacción. La mayoría de los periodistas, más de un 70 $\%$, anota las asignaciones, enfoques, tratamientos y fuentes en sus libretas de papel, algunos en sus celulares, tabletas o el computador. Los editores, bien por facilidad de estar en sus oficinas o por dirigir las reuniones, utilizan softwa$r e \mathrm{y}$ formatos para consignar las asignaciones, avances y fuentes de las notas.

\section{Relación con las fuentes}

Durante los consejos no se apreció mayor relación de los periodistas o de los editores con las fuentes, o por lo menos algún tipo de relación que se pudiera constatar.

\section{Observaciones a las salas de redacción}

La disposición espacial de las salas de redacción se ha constituido en un valioso indicador de cómo los medios de comunicación están concibiendo el tema de las llamadas convergencias. La convergencia no solo tiene que ver con el uso de las tecnologías. En el caso de las salas de redacción implica un rediseño espacial que rompa con los espacios tradicionales de los medios de comunicación.

Los diseños espaciales lineales y en cuadrícula han sido cambiados en las nuevas redacciones por espacios pensados como ecosistemas, donde espacialmente pueden fluir de manera más integrada los periodistas y donde los límites espaciales jerarquizados son menos evidentes.

Redacciones circulares, algunas con espacios lúdicos y no estandarizados, son parte de las nuevas propuestas. El portal Clases de Periodismo, en su artículo "12 oficinas inspiradoras que las redacciones pueden imitar"(Calderón, 2013), muestra cómo es posible innovar el diseño espacial. La tendencia 
general son espacios abiertos, amplios, coloridos en algunos casos, ausencia de cubículos o divisiones. Pisos entapetados o de madera, o la combinación de dos colores para darle un aspecto moderno y serio a la vez.

De las salas de redacción visitadas solo dos de ellas presentan cambios significativos en el diseño de los espacios de trabajo. Estos diseños también apuntan a integrar la sección web del medio al resto de la sala de redacción.

A razón de que los entornos digitales fueron llegando poco a poco y eran un añadido o un plus a las salas de redacción, fueron acomodados en "alguna parte" de los medios o salas de redacción. Bien junto a las revistas, al lado de los clasificados, cerca de la publicidad, en el peor de los casos en otra ala o piso del medio. Esta situación aún se vive en casi todos los medios visitados. El cambio, se entiende, puede llegar a ser complejo, pues en algunos medios, como El Universal o La Patria, las divisiones entre secciones o periodistas están marcadas por pequeños muros de ladrillo; con todo y esta rígida estructura, un cambio podría ser posible al interior de las salas de redacción. En otros medios, a pesar de tener muy desarrollados sus sistemas de periodismo digital o de tener productos multimedia para Internet bien elaborados, las salas de redacción siguen siendo muy clásicas, como en $E l$ Tiempo y El País.

Cuando visitamos las salas renovadas, el cambio en el ambiente fue evidente y acorde con el ritmo de trabajo y con los procesos de convergencia, más allá del nivel tecnológico. Las divisiones solo son las estrictamente necesarias, como salas para entrevistas, videoentrevistas o reuniones privadas, o las oficinas de las más altas directivas.

En Colombia, entre las salas de redacción que presentan estas características, están las de La República y El Colombiano. Generadas desde concepciones y directrices semejantes por tradición familiar de los dueños de las dos empresas. Estos diarios comenzaron procesos de renovación similares, conservando marcadas señales de identidad.

El Colombiano poseía un piso amplio donde estaban los periodistas distribuidos en cubículos en filas; allí los periodistas podían apropiarse de sus espacios de trabajo con las típicas señales de identidad, que en el caso del periodismo, por lo menos en Colombia, están muy arraigadas: fotos de familia 
y de cubrimientos, regalos del último cumpleaños, adornos, fragmentos de textos, postales, muñecos y un largo etcétera.

Además, para los periodistas de la red estaba dispuesto un medio piso más arriba, a unos cuantos metros de la redacción principal. El nuevo espacio permitió a los periodistas de la web, de los nuevos medios, los que desarrollan aplicaciones para teléfonos o tabletas, trabajar junto con los demás periodistas del impreso. Todos organizados en semicírculos que cubren un área central donde se encuentran los macroeditores.

Los periodistas desarrollan su trabajo con la idea de panóptico, donde todos se pueden ver con todos, pero no para una vigilancia y control como lo mostraría Foucault (1975), sino para propiciar interactividad, es decir, para crear una metáfora de interconexión, como ocurre en la red, donde hay autopistas por donde fluye la información y donde hay nodos que la concentran; donde lo privado se minimiza en beneficio de aligerar e igualar los espacios. Francisco Jaramillo (16 de abril de 2013, comunicación personal), asesor de la dirección y de temas administrativos de la redacción de $\mathrm{El} \mathrm{Co^{- }}$ lombiano, en entrevista para esta investigación nos dijo que la idea es que el espacio no tenga obstáculos visuales:

El propósito es que en la sala de redacción haya una misma sinfonía... esto le permite a los periodistas sentir una misma vibración en la sala de redacción cuando sucede algo extraordinario o cuando realmente están enfocados al cubrimiento de algo especial.

Entre los escritorios de los periodistas no hay divisiones, lo que permite trabajar hombro a hombro. Los colores y ambientes también forman parte del cambio. En La República, los espacios de trabajo de los reporteros no están predeterminados, cada uno puede sentarse donde lo desee, no hay escritorios personalizados, en los mismos solo hay un computador portátil y el teléfono móvil de los periodistas y quizá una libreta de apuntes; no se aprecian teléfonos fijos, ni acumulación de ediciones impresas de días anteriores. Esta disposición administrativa da la sensación de mucho orden, limpieza y fluidez. Los colores son oscuros y sobrios.

Por lo demás es semejante al diario El Colombiano, sin muros, redacciones integradas entre los departamentos -incluso el comercial, de edictos, revistas y otras publicaciones-, con los periodistas de los nuevos medios y con una mesa central donde están los macroeditores. 


\section{Convergencias y nuevos espacios}

Las convergencias de nuevos y diferentes agentes interactuando en un mismo espacio, requieren de coordinación. Los flujos no van solo por la red, van también por los pasillos de desplazamiento y por las líneas circulares y visuales que puede generar el espacio. "Los regímenes circulatorios sustituyen la cohesión dada por un orden jerárquico y simbólico, por una cohesión basada en la contigüidad, en una sucesión continua y fluida del movimiento" (Sáenz, 2012, p. 88).

Los espacios fluidos para la circulación de personas, escritorios sin divisiones, escritorios sin "desorden", permiten desplazamientos libres, rápidos, físicos o visuales, o sea que no hay obstáculos visuales que interrumpan o distraigan la concentración o el trabajo de los periodistas. En ese sentido, estos espacios circulares y poco cargados de información, tienen también claras intenciones funcionales encaminadas a la mejor productividad de los periodistas, en un ambiente de aceleración, inmediatez e hiperconectividad propio del periodismo digital, en red.

\section{Observaciones etnográficas de algunas salas de redacción}

\section{El Heraldo.}

Foto 1. Sala de redacción $\boldsymbol{E l}$ Heraldo

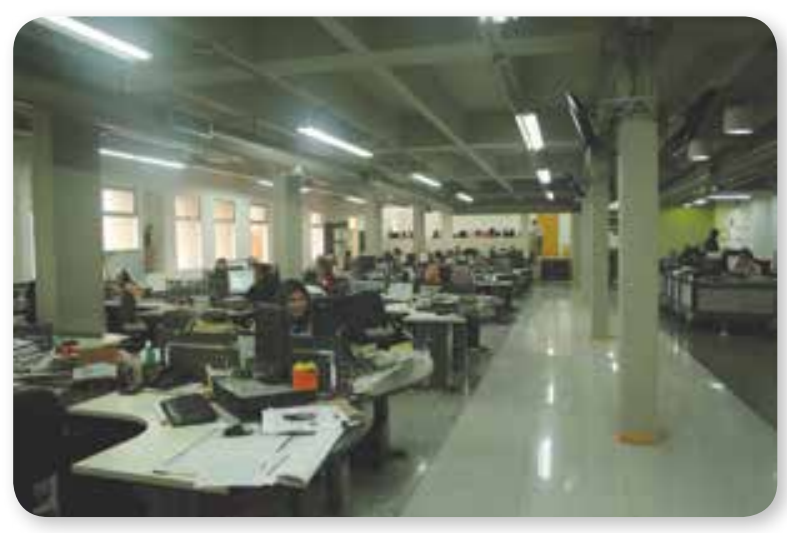

Fuente: Autor
Consejo de redacción de El Heraldo. Una amplia sala dividida tradicionalmente por fuentes. A la izquierda los puestos de trabajo de los periodistas, con su "tradicional" desorden. Papeles, anotaciones, teléfonos fijos y demás. A la derecha, el puesto del jefe de redacción y las salas de juntas y de consejos de redacción. Al fondo, sobre una entreplanta, la sala habilitada para los editores web y los periodistas asignados a la red. 
Foto 2. Momento del consejo de redacción

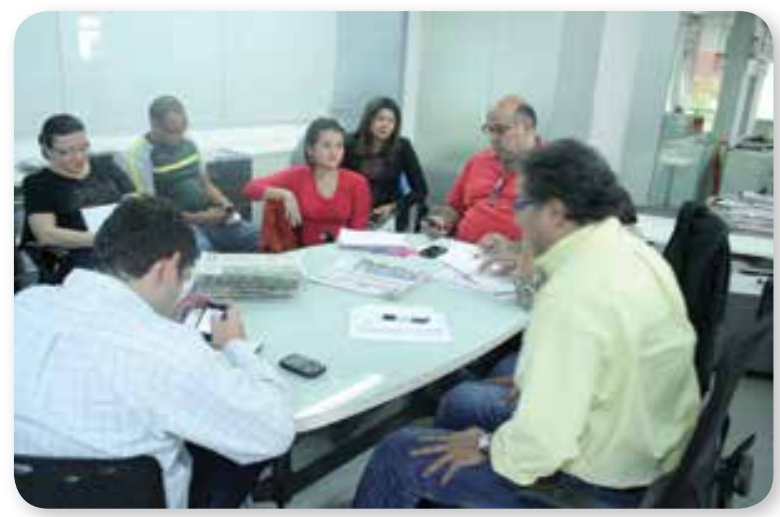

Momento del consejo de redacción. Los periodistas se ubican "como van llegando" y así mismo se desarrolla el orden de los temas y las notas propuestas o a tratar. La consulta de ediciones impresas se hace sobre el papel. La revisión del celular es constante. El jefe de redacción toma notas en papel.

Fuente: Autor

\section{Zonacero.com.}

Conjunto de cúbicos del portal Zona Cero de barranquilla. Allí se editan vídeos, se graban programas de radio y se montan las notas de prensa.

Foto 3. Conjunto de cúbicos del portal Zona Cero de barranquilla

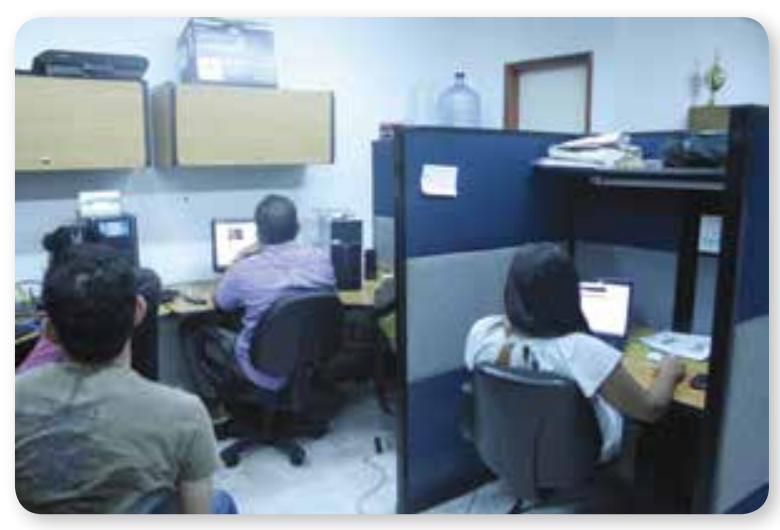

Fuente: Autor
En un espacio de unos 45 metros cuadrados se desarrolla este reconocido medio digital de la ciudad de Barranquilla, en la costa norte colombiana. Allí funciona tanto el portal como un programa de radio con un pequeño estudio. Los puestos de trabajo son tradicionales, con cubículos de paredes altas. Un grupo pequeño de reporteros recorre las calles trayendo notas. También se trabaja el video y todo ello se sube al portal. 


\section{El Universal.}

Foto 4. Sala de redacción del El Universal

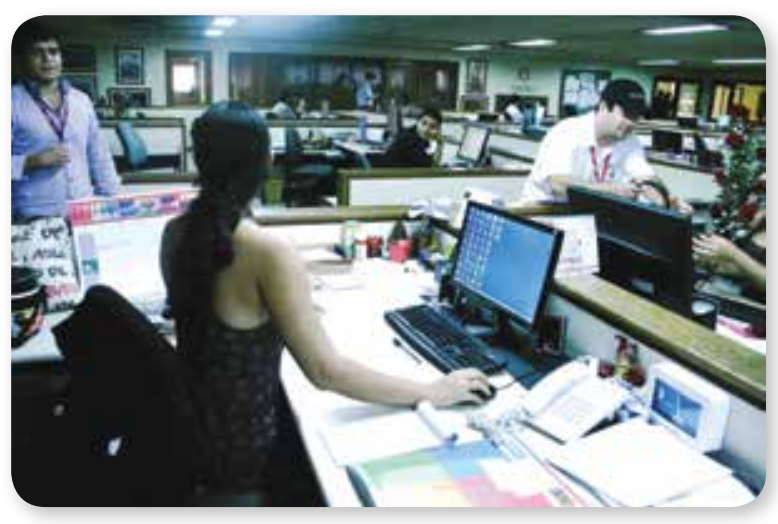

Este influyente periódico de Cartagena de Indias presenta una sala de redacción tradicional, con muros bajos que hacen de divisiones entre los puestos de trabajo. La personalización de los puestos es un índice de identidad del periodista en las salas de redacción.

Fuente: Autor

\section{Presidencia de la República.}

Foto 5. Sala de prensa Presidencia de la República

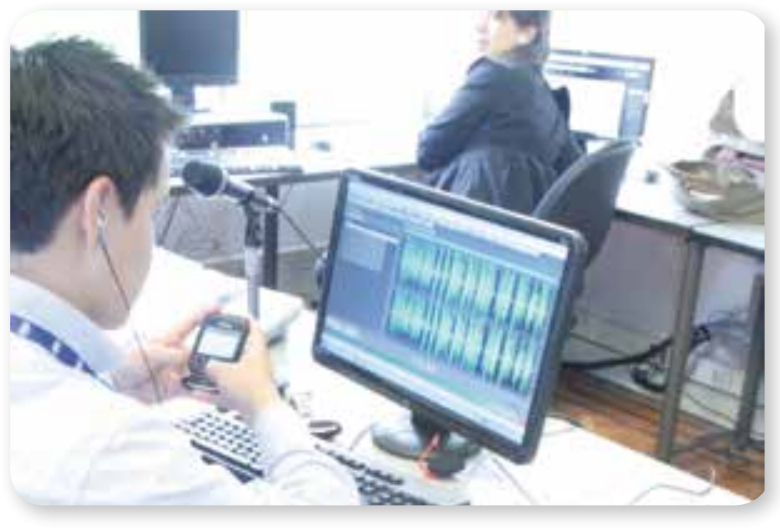

Fuente: Autor
Espacio meramente instrumental para locutar y editar noticias. Posee varios computadores $y$ servicios básicos y suficientes para que los periodistas envíen sus notas a los medios. Algunos de los puestos están marcados con el nombre del medio de comunicación. De igual manera, hay teléfonos, computadores con programas de edición, micrófonos, etc. 


\section{Radio Nacional de Colombia.}

Foto 6. Estudios Radio Nacional de Colombia

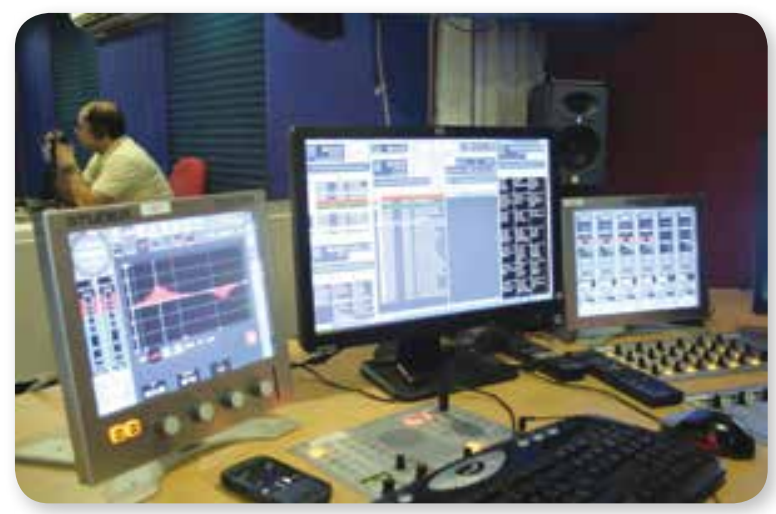

A la fecha de esta investigación, Radio Nacional de Colombia cuenta con recientes programas de edición y supervisión de emisión. Acá la cabina y estudio principal de la emisora estatal.

Fuente: Autor

\section{Noticiero 90 minutos.}

Foto 7. Sala de redacción del noticiero del mediodía: Cali.

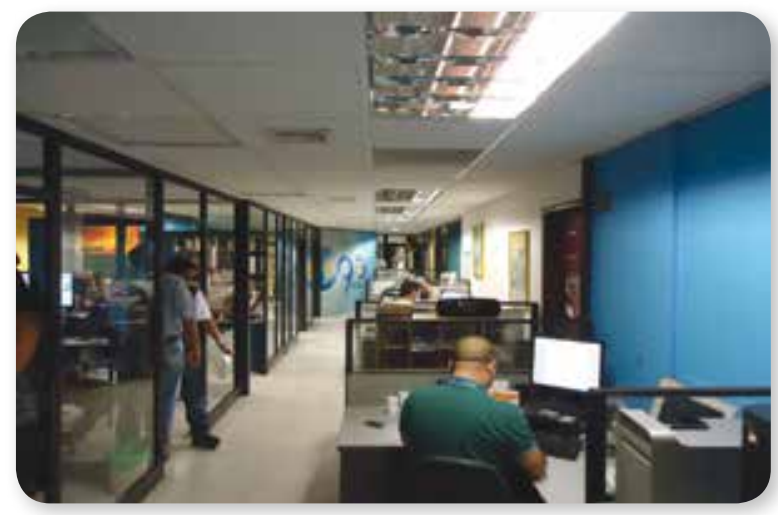

Máster emisión Noticiero 90 Minutos. Las oficinas se encuentran en un amplio espacio subterráneo en las instalaciones de la Universidad del Valle y cuentan con el apoyo logístico de la universidad y de su Escuela de Comunicación.

Fuente: Autor 
Foto 8. Máster emisión Noticiero 90 Minutos.

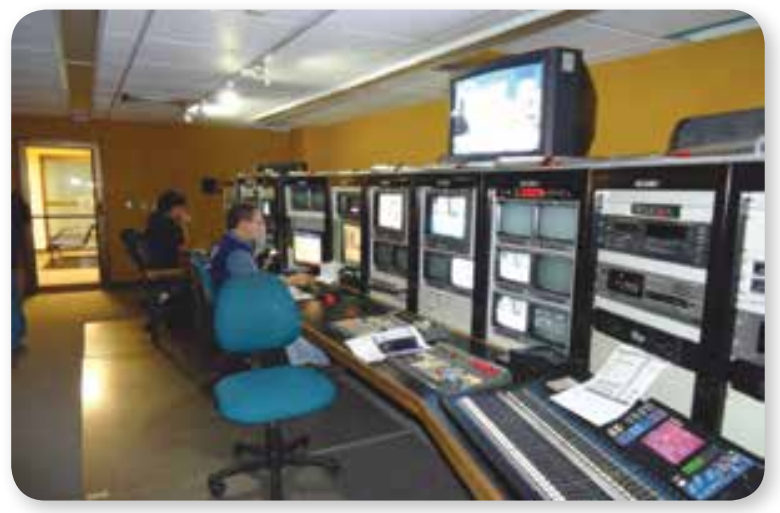

Fuente: Autor

\section{El Tiempo y Portafolio.}

Foto 9. Sección editores web y CM

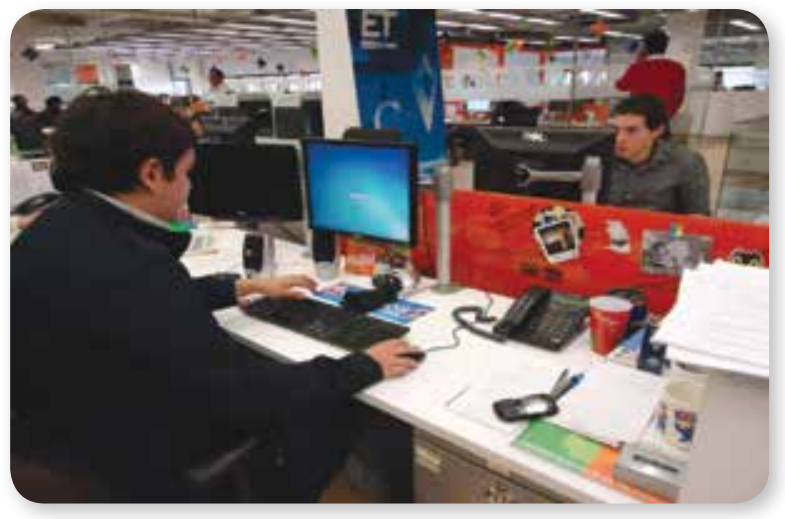

Puestos tradicionales, personalizados, con llamativos colores, con varias pantallas móviles y divisiones bajas para apreciar toda la sala. Alta densidad de periodistas

Fuente: Autor 


\section{Foto 10. Sala de redacción Portafolio y El Tiempo}

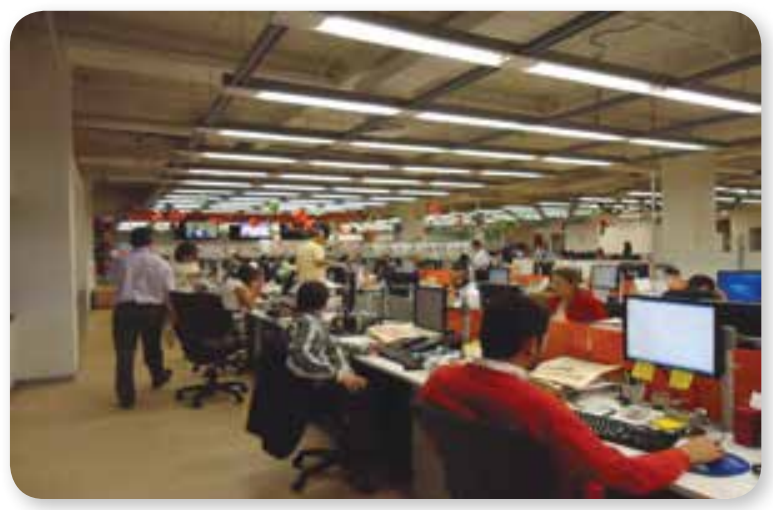

Amplios escritorios personalizados. División de fuentes por filas.

Fuente: Autor

Foto 11. Consejo de redacción Portafolio

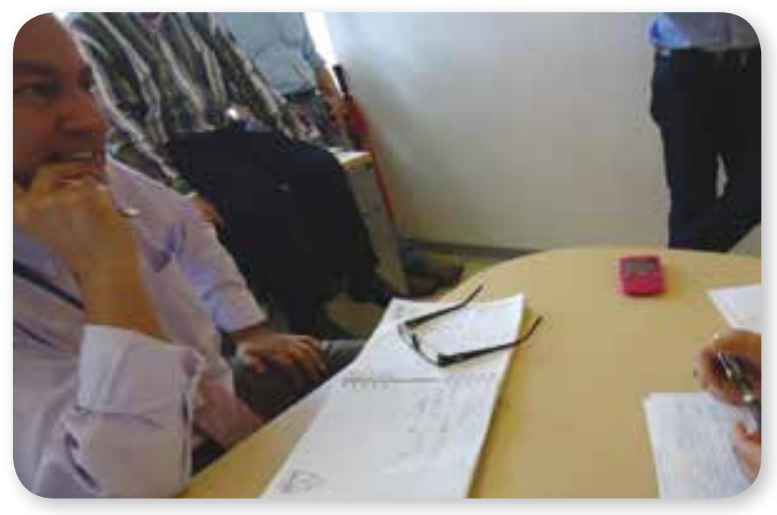

Oficina personal del editor del medio. Espacio casi íntimo para tratar los temas del día. Uso del papel por parte del editor y de los periodistas para tomar nota de las asignaciones del día.

Fuente: Autor 


\section{Hora 13.}

Foto 12. Salas de redacción

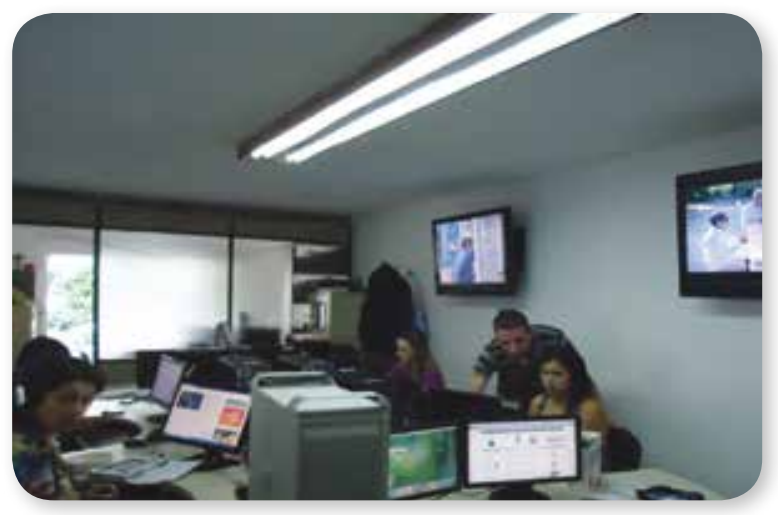

Fuente: Autor
Escritorios con diseños ergonómicos, uso de dos pantallas para redactar y previsualizar las filmaciones. Sintonización de canales de televisión para seguir paso a paso la actualidad informativa en términos de imágenes.
Foto 13. Sala de edición Hora 13

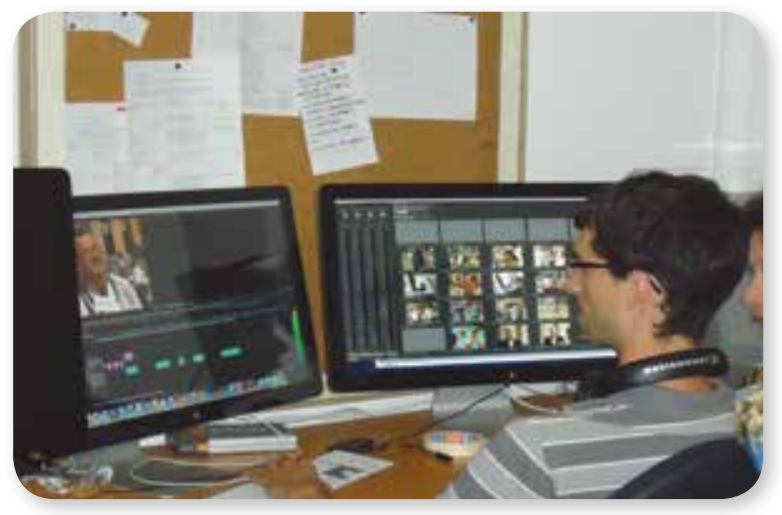

Fuente: Autor
El medio de comunicación se encuentra en una casa de un barrio residencial de la ciudad. Acá una periodista y un editor en pleno trabajo antes de la hora de emisión. 


\section{El Colombiano.}

Foto 14. Sala de redacción El Colombiano

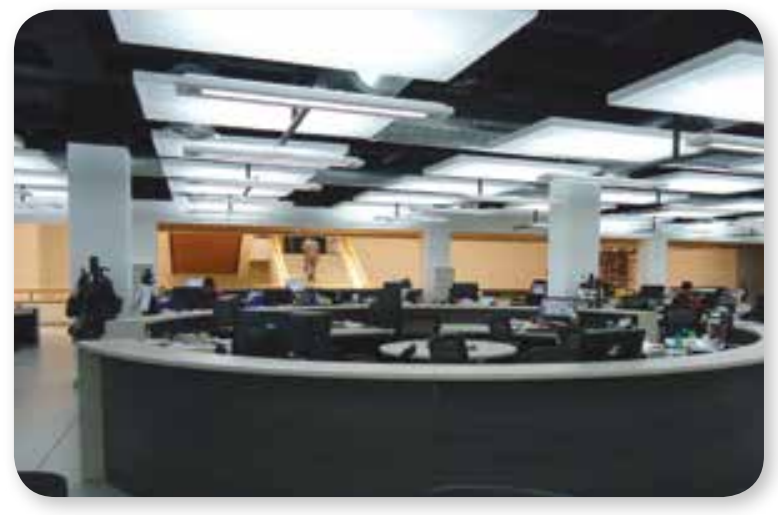

Espacios amplios, escritorios curvos que convergen en un centro donde se ubican los macroeditores. Escritorios sin divisiones y relativamente personalizados.

Fuente: Autor

Foto 15. Mesa central de los macroeditores, El Colombiano

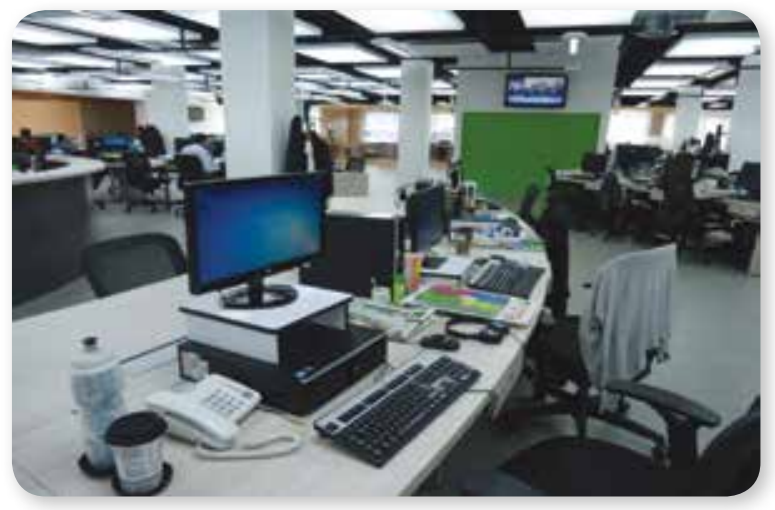

Mesa central circular para los macroeditores con dos accesos. Es un espacio de trabajo para unas cinco personas.

Fuente: Autor 
Foto 16. Realidad aumentada, El Colombiano

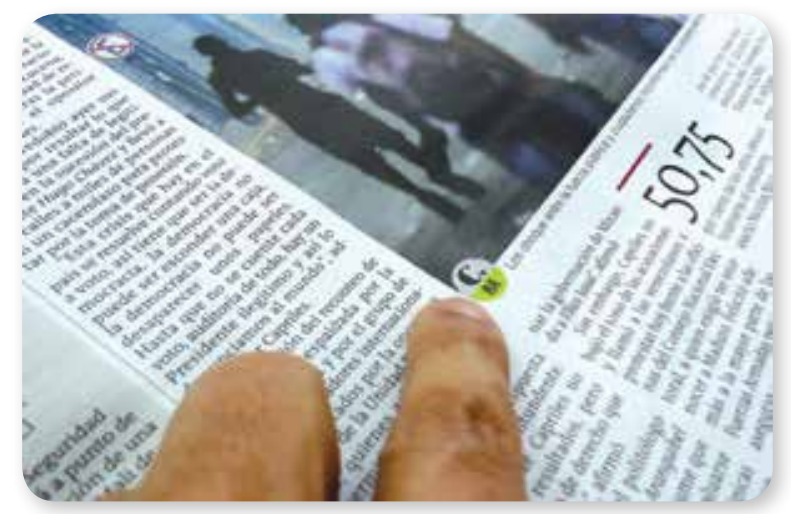

Fuente: Autor

\section{La Tarde.}

Foto 17. Sala de redacción $\boldsymbol{L a}$ Tarde

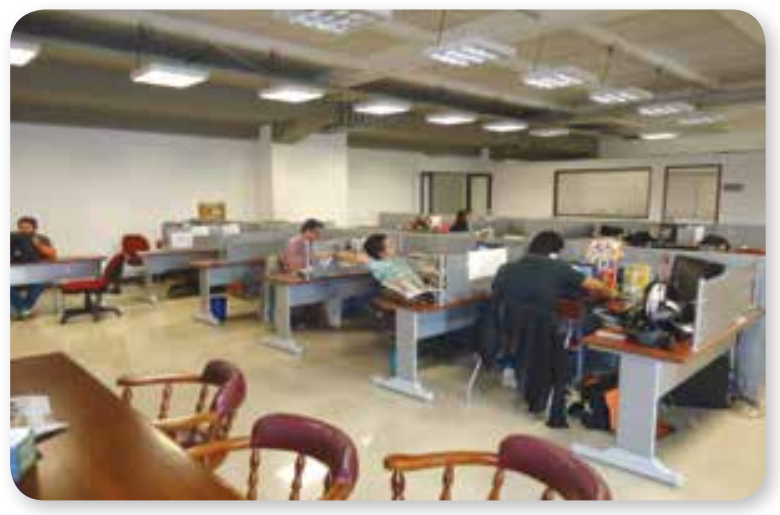

Fuente: Autor
Se señala el ícono de la realidad aumentada. Un recurso del impreso, para invitar a los lectores a visitar el portal web y allí profundizar sobre la nota. Se toma una foto con el celular y por medio de ella se enlaza a un video o a más fotos de la nota
Un grupo de periodistas jóvenes es el responsable de las informaciones para la ciudad de Pereira. 
Foto 18. Sala de redacción $\boldsymbol{L a}$ Tarde, parte posterior

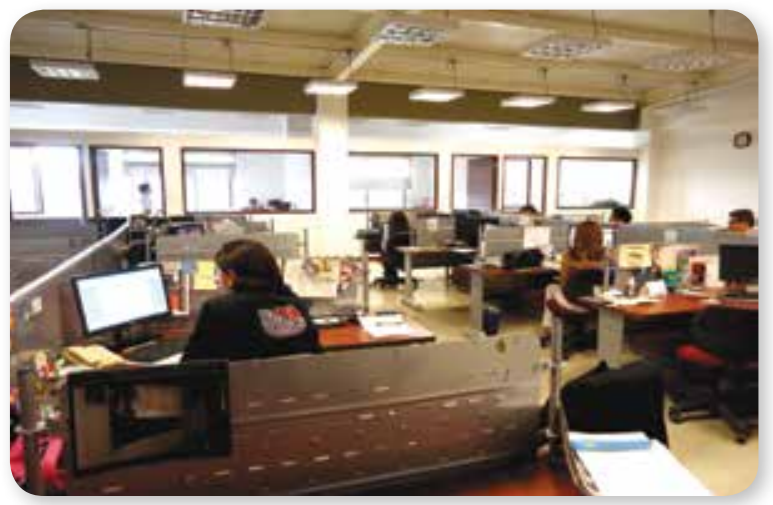

Sala de redacción tradicional. Espaciosa y con poca densidad de periodistas. El periodista de la web está integrado a esta sala.

Fuente: Autor

\section{La Patria.}

Foto 19. Sala de redacción La Patria

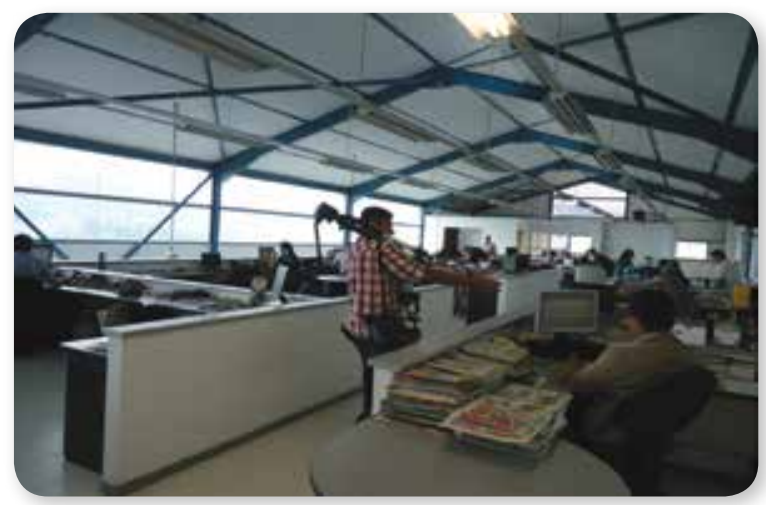

Sala de redacción tradicional. Amplios espacios. División por secciones donde trabajan unos cuatro periodistas. Los editores web y CM se encuentran en un pequeño espacio al fondo de la imagen, cerca de la puerta de acceso de este segundo piso. 
Foto 20. Consejo de redacción La Patria

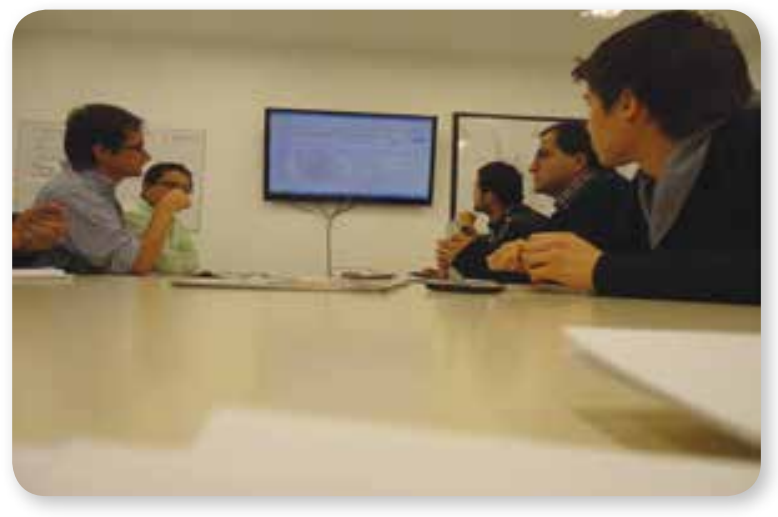

Uso de tecnologías: un software en pantalla para ver la asignación de las notas, el avance de las mismas, el tratamiento, las fuentes y los formatos.

Fuente: Autor

\section{La República.}

Foto 21. Sala de redacción La República

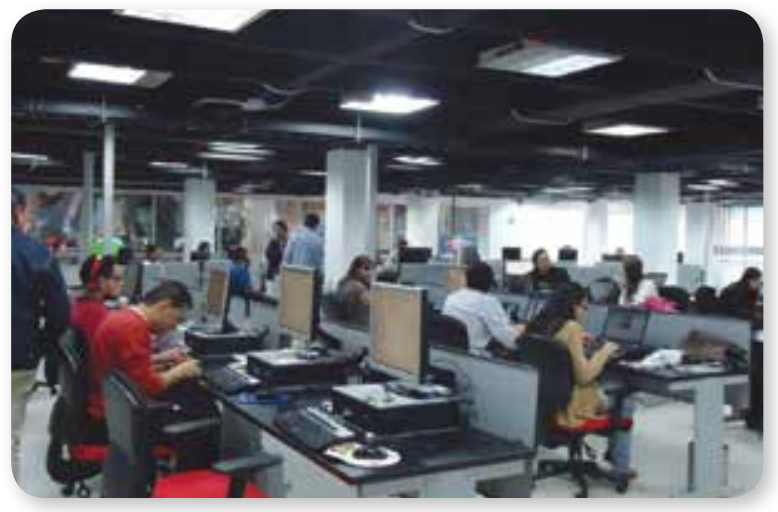

Diseños austeros y contemporáneos caracterizan la sala de redacción del diario capitalino La República.

Fuente: Autor 


\section{Foto 22. Sala de redacción, mesa central de editores La República}

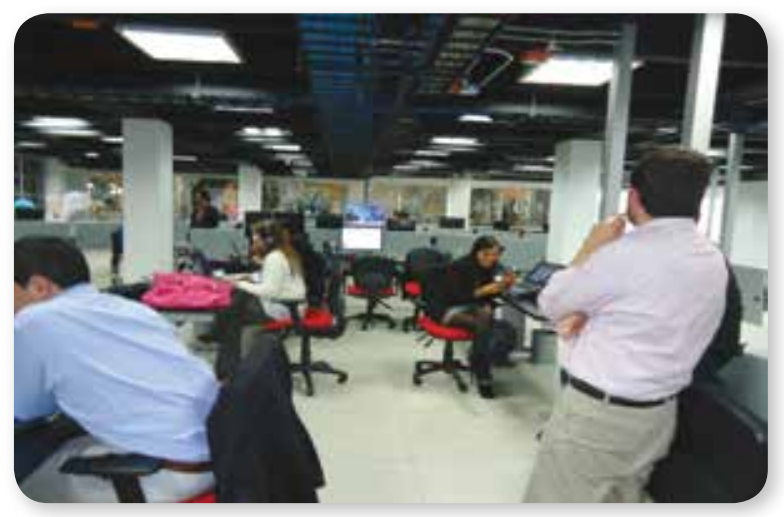

Sobre los escritorios de los periodistas solo se observan sus objetos personales del día. No hay teléfonos fijos. Las llamadas se hacen por medio del computador o de los teléfonos móviles de cada periodista. Se pueden comunicar entre ellos por redes internas.

Fuente: Autor 


\section{Capítulo 6}

\section{GARENCIAS DE LOS PERIODISTAS ESPEGIALIZADOS EN POLÍTIGA Y ECONOMÍA}

Se les demanda a los periodistas políticos y econó-

micos y a los editores suplir ciertas carencias que se detectan en ellos. Aquí un listado no jerarquizado:

- Conocer y entender en profundidad la estructura del Estado.

- Conocer las jerarquías, funciones y relaciones que existen entre el Congreso, las cámaras, la Corte Suprema, el Consejo de Estado y las asambleas departamentales.

- Entender y saber qué es una ley y cómo es su proceso de elaboración. Saber informar bien a las audiencias a este respecto.

- Comprender la historia política de Colombia, por lo menos desde la mitad del siglo XX.

- Conocer los términos y mecanismos del Estado.

- Saber cómo se estructuran políticamente las ciudades y los departamentos: su historia política y organización administrativa.

- Encontrar y experimentar formas para la redacción de temas políticos, sobre todo los llevados a la red.

- Dominar los conceptos básicos de la economía. 
- Conocer la historia del desarrollo de las sociedades capitalistas y socialistas. Hacer análisis comparativos.

- Saber de historia económica nacional.

- Hacer análisis más allá de lo que dicen las fuetes de poder.

- Conocer la Constitución, lo cual podría ser de gran ayuda a la hora de incrustar en los análisis al contexto, dada la interdependencia de lo social, económico y político.

- Conocer sobre tasas de interés, temas de crédito, bursátiles, del agro y de la minería.

- Saber sobre los TLC: funcionamiento e implicaciones reales en la población y en los productores; comercio exterior, inversión nacional y extranjera, infraestructura y finanzas.

- Tener en las salas de redacción al menos un economista y un politólogo de profesión de base en las salas de redacción.

- Los periodistas no deben confundir su labor de informar con la de convertirse en figuras faranduleras. El protagonista es la información, los actores de las noticias y no los periodistas.

- Manejar aplicaciones y herramientas de edición digital.

\section{A modo de cierre}

El periodismo político y económico en las salas de redacción en Colombia, no está verdaderamente especializado. Los periodistas que han cubierto y cubren estas fuentes han aprendido sobre la marcha, y aun en los grandes medios manifiestan tener o haber tenido grandes carencias. Solo un puñado de periodistas puede considerarse especializado, algunos pocos han tomado cursos, especializaciones o maestrías en política y economía, y se dedican más a ser editores que reporteros.

Las lógicas del fordismo que funcionaban al interior de las empresas de producción, incluidas las de los medios comerciales y masivos de comunicación y que tenían como características la división del trabajo, la producción serializada, la alta productividad a bajo costo y el intercambio de piezas, intentan renovarse en algunos medios con el mismo marco de producción al querer hacer -más en ideal que en realidad- del periodista un productor de informaciones polivalente, multiplataforma y multiformato, lo que rompería 
uno de los principios básicos del modelo original, relacionado con los roles rigurosamente delimitados. Así se dejan por fuera partes del modelo, pero emergen otras "ventajas" en pos del incremento de la producción de los trabajadores, al mismo costo.

En otros medios, la web se enlaza con una parte de la cadena de producción de noticias del medio tradicional, generando dentro de sí misma lógicas de división del trabajo: CM, produciendo tuits y publicando enlaces en Facebook o YouTube; editor y subeditor web, dirigiendo las publicaciones, productores y desarrolladores multimedia especiales para la web, haciendo diseños. En ese enlace entre el medio tradicional y la web se presentan conflictos por jerarquizaciones, por la esencia y el lugar de la sección digital.

La definición que se hace del periodismo político y económico desde los medios tradicionales tiene limitaciones al no situarlo más allá de la temática o de la fuente. Sin embargo, en algunos medios impresos, las secciones rompen con esta división tradicional de fuentes, abriendo posibilidades para lo político y lo económico. Los periodistas de los medios nativos digitales e independientes, por su misma posición de cuestionar a los poderes públicos, definen el periodismo político o económico más allá de las fuentes o temáticas, ubicándolo en condiciones de contextualización, descripción, explicación y trasfondo; y aquellos que hacen activismo, en términos de crítica directa y acción ciudadana.

En los medios de comunicación comerciales y tradicionales, la práctica cotidiana de un periodismo que pueda llegar a especializarse en lo político o económico, se circunscribe a la estructura organizativa del medio que ejerce su fuerza, tanto en la sección web como en el medio tradicional. Hay casos de periodistas que recurren a cuentas de Twitter o a blogs propios, algunos anónimos, para dar a conocer a la opinión pública sus propios análisis y puntos de vista.

El concepto de masa, grupo relativamente amorfo de receptores susceptible de ser influenciado, es rescatado por los medios de comunicación comerciales en su intención de persuadir a grandes públicos a través de la red. Los niveles bajos de capacidad crítica de los internautas en la web no ayudan a frenar el surgimiento de esta situación pese a la nutrida retroalimentación; es decir, con las nuevas posibilidades de interacción que transformarían el modelo tradicional emisor-receptor-retroalimentación, la comunicación 
sobre la "masa" sigue imperando, sobre todo en los soportes tradicionales, aunque ha buscado insertarse en Internet que paradójicamente se convierte en el mismo espacio de resistencia de dicha influencia mediática, entre otras causas porque las interacciones de los ciudadanos ya no pasan por el medio de comunicación: la ciudadanía se retroalimenta entre sí, y a expensas del medio, por soportes externos y ajenos en todo sentido al medio, lo que ayudaría enormemente a formar ciudadanía. Ahora es el medio el que debe estar atento a estas rutas. El control de los canales por parte de los grandes medios, por donde circula y se forma la opinión pública comienza a transformarse.

En ese sentido tenemos tres niveles de mediación: uno, a través de los periodistas con las notas que publican y encaminadas a las audiencias y que a la vez sustentan al medio. Otra mediación se da por los espacios de interacción del medio con la audiencia; y finalmente, una más entre los foristas o lectores en espacios como blogs, microblogs, redes, etc.

En general, el protagonismo del Periodismo Político y Económico en los Entornos Digitales dependerá mucho de las posibilidades que les dé el medio a los periodistas. Esto es, no se sujeta solo a la voluntad del reportero, en tanto hay una demanda de más creatividad y capacidad de adaptación a los entornos digitales, para hacer de estas fuentes temas prominentes.

Existen grandes contradicciones entre los periodistas sobre su apreciación de qué es la independencia informativa. Por un lado manifiestan ser relativamente autónomos y que nunca los han censurado, pero por otro reconocen la no independencia del medio frente a intereses políticos y económicos, lo cual pone en entredicho su hipotética autonomía.

"Experimentación" sigue siendo la palabra imperante, algunas veces con su dosis de improvisación, otras como parte de una agenda aplicada a las maneras como se desarrollan las metodologías para acercarse a las audiencias mediante los productos innovadores en los entornos digitales.

El periodismo digital, al hallarse en una nueva etapa tecnológica superaría no solo las posibilidades técnicas anteriores, sino que tiene la capacidad de hacer un periodismo distanciado de las características, en cuanto a sistema de producción de la era industrial, que lo vieron nacer y fortalecerse y que hoy le asiste en su temor a la decadencia. En otros términos, el pe- 
riodismo digital se está conformando hoy con herencias de un periodismo clásico de la sociedad industrial, respecto a producción y con elementos de la sociedad posindustrial en lo que tiene que ver con innovación y alienación. Hay una resignificación de lo masivo, lo local, lo serializado y las tradiciones de la división del trabajo.

Dado que la línea editorial y las formas de producción de la mayoría de los medios tradicionales llegan hasta los entornos digitales, el periodismo no podrá afinarse con el nuevo entorno digital. Las tensiones entre las herencias clásicas industriales y algunas posindustriales en cuanto a producción, distribución y autocomunicación no encajan con las de la sociedad de la Internet y la cibercultura. Estas tensiones retardan el paso del periodismo a una nueva etapa, de la cual aún desconocemos sus efectos en beneficio de lo que conocemos hoy como periodismo. Tal situación es particularmente importante en un momento donde la producción de un verdadero periodismo político y económico, parece estar disuelto entre el aumento de noticias y seudonoticias de todo tipo.

La libertad de la prensa hoy no solo está mediada por los intereses políticos y económicos clásicos, sino también por los intereses de subsistencia, buscando congraciarse de modo intencional con las audiencias a como dé lugar y a la espera de que un nuevo paradigma más rentable pueda rendir frutos. Si el modelo de fábrica inspiró a las salas de redacción y sus rutinas, la esencia del modelo de la web y todas sus implicaciones e interacciones podrá inspirar las nuevas formas de hacer periodismo.

Enfrentado a la nutrida y diversa participación que se le ha otorgado por parte de las audiencias en la producción de contenidos, el periodismo especializado deberá robustecerse cada vez más.

Nuevas funciones aparecen para los medios de comunicación, más allá del registro, vigilancia del entorno, correlación y transmisión del legado cultural y del entretenimiento, propuestas por Lasswell (1985) y luego completadas por Wrigth (1985) o las investigaciones posteriores de Katz, E., Blumler, J. G., \& Gurevitch, M. (1985), que han adicionado el escape a las rutinas diarias, desarrollar relaciones e identidades personales y la exploración de la realidad.

Encontramos que a estas funciones les sumamos algunas propias del Estado, como ser base de registro (y control) de la historia, dinamizar y crear 
vínculos de comunicación entre las ciudadanías mediante informaciones procesadas o en bruto sobre aspectos de la actualidad y de contexto, y que superen la expresión subjetiva; reanimar lo local, incentivar la creación de subgrupos sociales y democratizar la información. Funciones que incrementarían su grado de responsabilidad a corto, mediano y largo plazo, y que podrían fortalecer a los medios en cuanto a su legitimidad en la sociedad, hoy puesto en entredicho.

Las nuevas tecnologías en uso del periodismo están posibilitando, afirman algunos, lo que decenas de discursos sobre la función y papel del periodismo frente a los públicos no habían logrado: el rescate del interés por los requerimientos de los ciudadanos y de las audiencias. No obstante este "rescate" sigue mediado por intereses económicos y de posicionamiento de las empresas periodísticas tradicionales, lo cual influye en la tendencia de los medios a retomar sus intereses subjetivos, más que las necesidades reales ciudadanas. En ese sentido, el periodismo ha generado nuevas necesidades en las audiencias, como vías de escape y liberación de represión de la expresión.

En esa medida también le compete a la audiencia una nueva responsabilidad frente a los medios en la red, si es que quiere ser reconocida. Sería menester examinar hasta qué punto este tipo de interés por responder mejor a los ciudadanos, está en la agenda de los medios como una estrategia.

Las tecnologías aplicadas a las relaciones jerárquicas en las salas de redacción tienden a convertir estas en horizontales, hacen ver al otro usuario de la tecnología como uno más, pues al manipular una tecnología disponible para todos, se tiende a desmitificar la figura de los jefes que comparten un mismo espacio virtual.

Tradicionalmente existe un prejuicio en cuanto al grado de seriedad que debe tener el tratamiento de la política y economía, que debería ser más bien parco y formal en su presentación. El momento actual reclama otro tipo de estéticas y experiencias, más cercanas a las generaciones digitales, lo cual conlleva el reto de conjugar - al igual que pasa con la profundidad e inmediatez-la configuración estética de las informaciones políticas, sin que ello implique un sacrificio de la profundidad y análisis que estas fuentes requieren.

Internet ha creado un ecosistema alrededor del periodismo. Están los grandes medios con sus noticias y espacios para foros, y sus páginas en las 
redes sociales, Twitter y Facebook, principalmente. Están los medios nativos digitales que toman fuerza en el ámbito nacional y local y generan comunicación independiente y periodismo con primeras fuentes; están organizaciones y agrupaciones sociales que tienen también páginas y espacios en la red que interactúan con los medios y otros ciudadanos; y están los ciudadanos pasivos y menos pasivos produciendo contenidos en la web e interactuando con los grandes y pequeños medios.

En este sistema la imagen y el poder de los grandes medios tienden a relativizarse, los medios nativos digitales independientes pugnan por alcanzar los niveles de impacto que tienen los medios tradicionales en la red y fuera de ella, y la ciudadanía parece tener el privilegio de situarse en un espacio intersticial. Por un lado, acostumbrada a ser receptora pasiva de los medios tradicionales y que no inquietan a los poderes políticos o económicos, y por otro impulsada a utilizar su capacidad crítica gracias a la postura e incentivos de algunos medios digitales.

Las oleadas de las crisis en la periferia suelen ser menos intensas. En Colombia, la situación actual de los medios parece no evidenciar los niveles de la crisis social y económica mundial que afecta al periodismo, y aún los medios tradicionales tienen gran fortaleza en lo impreso, en la televisión y en la radio. De la misma forma siguen gozando de aceptación entre el grueso de las audiencias.

Algunos medios utilizan Facebook como un canal más, otros como un espacio para generar más tráfico y otros como lugar de debate entre diferentes usuarios de la red o para el uso combinado para posicionar la empresa. También se cambian con frecuencia las estrategias de acercarse a las audiencias en las redes sociales. La ausencia de una política de tratamiento de las redes, da cuenta del grado de experimentación en que se encuentran.

La lógica de organización de los espacios físicos de trabajo en los medios -salas de redacción- cambia de medio a medio. En algunos, los periodistas web tuvieron que hacerse a un espacio dentro de las redacciones, en otros se los pensó como una sección aparte de la redacción central. En otros los periodistas de los medios digitales o nuevos medios trabajan codo a codo con los periodistas de la redacción del periódico, o por lo menos en un mismo espacio de trabajo con características claramente colaborativas. 
Las audiencias saben distinguir con relativa claridad entre una información que proviene de fuentes no reconocidas y una emanada de un medio reconocido. Así las cosas, los medios tradicionales aún se constituyen en paradigmas y referentes de una información noticiosa verificada, al tiempo que los medios nativos digitales se posicionan lentamente al respecto.

Si los contenidos que primero se tratan en los consejos de redacción, a los que se les da más tiempo y retroalimentación y a los que se les presta más atención, son los temas que más consumen y retroalimentan las audiencias, esto se convierte en un indicador de cómo poco a poco las agendas de las audiencias van tomando protagonismo en los consejos y en las salas de redacción de los medios, pues los periodistas al recibir felicitaciones, promociones o premios de sus colegas o jefes y de las audiencias, podrían estar condicionando parte de su trabajo a las reacciones de los internautas.

La rutina del día a día de los periodistas puede llevar a que los grandes acontecimientos, de política, por ejemplo, queden ocultos tras convertirse en solo insumos de la elaboración de la noticia. Así los grandes temas y fuentes en política tienden también a situarse al mismo nivel que otros contenidos y fuentes.

La relativa libertad que tienen los editores y directores al construir las agendas y asignaciones de los periodistas, podría hacer posible que los temas y enfoques desde la política y economía tuvieran más relevancia en el desarrollo de los consejos de redacción.

Se demuestra cómo los consejos de redacción son los espacios ideales para motivar, encauzar a los periodistas, ventilar problemas en torno al manejo de la información y hacer propuestas de fondo y forma a los contenidos de los medios. Estos escenarios, como se vio en La Patria, El Heraldo, Portafolio y Semana, son espacios de discusión sobre la labor de los periodistas. Sin embargo, algunas de estas discusiones por fuera de una estrategia del medio, pueden ser inútiles en términos prácticos.

\section{Observaciones desde la mediología}

Para nuestras conclusiones no podemos ignorar el enfoque que decidimos escoger para estudiar el ejercicio del periodismo político y económico en los entornos digitales. Este enfoque es desde la mediología, disciplina en 
formación de origen francés que tiene por objetivo crear relaciones antes que teorizar. Las relaciones que desea construir se llevan a cabo entre la materia organizada y la organización materializada. Para el primer caso nos referimos a la techné dispuesta y estructurada para cumplir una función más bien instrumental pero con incidencias en lo social, en lo cultural y en la organización materializada.

Para observar mejor estas relaciones se construyen referentes espacio-temporales -mediásferas-. Ello, según el concepto propuesto por Régis Debray (2000) y que ya definimos en los primeros apartes de este texto, y en el cual se presta atención a la estabilidad de los elementos. Una mediásfera se determinará, entonces, por la estabilidad de esta temporalidad, "por las tendencias, los puntos de ruptura, las fronteras, los desequilibrios, las resistencias y los regresos" (Merzeau, 1998, p. 32).

Una mediásfera se estabiliza alrededor de una tecnología. Cuando la tecnología imperante y protagonista como agente transmisor de la cultura, cambia, cambia también la mediásfera. Así se generó el cambio de la grafósfera (cultura tipográfica) a la videósfera (cultura audiovisual) y más recientemente a la hiperósfera con la cibercultura e Internet. Nuestro punto de observación son las relaciones de los entornos digitales (materia organizada) con el sistema social (organización materializada), que en nuestro caso está representado por el periodismo político y económico.

El almacenamiento de saberes ya no está en los medios impresos, sino en los sistemas digitales. La manera, el lugar y las dinámicas como adquirimos conocimiento, se transforman; ejemplo, del impreso con letras de molde a los electrones sobre la pantalla de televisión, o a la conexión en línea. Según Merzeau (1998), creadora del concepto de hiperósfera, la mediásfera -espacio temporal donde se desarrolla la presente investigación- se entiende como:

[...] un reequilibrio de prácticas y herramientas alrededor del modelo hipertextual y de la red. Su régimen es el de la conexión, la interconexión y la diseminación. Ella introduce una tendencia a la indiferenciación de los actores de la transmisión, una distancia semiótica inédita (la del holograma) (Merzeau, 1998, p. 38).

Las mediásferas son sistemas de organizaciones espacio-temporales que consiguen definirse cuando un modelo de transmisión y almacenamiento se ha estabilizado, renovando el anterior sin destituirlo. Se trata más de una 
renovación, pues seguimos usando la cultura oral, el libro y viendo televisión, por ejemplo.

Se trata de una organización de elementos que muestra de manera resumida la tendencia singular y dominante de una época. Muestra la evolución temporal de una tendencia heredada de la anterior y dependiente del soporte de transmisión en relaciones horizontales. Evidencia verticalmente las características variadas y definitorias de una mediásfera. Verticalmente también se puede observar un proyecto social global de Occidente, un espíritu de época.

La forma de leer los ítems propuestos es a modo de "encadenamiento y negociación”, no de ruptura o de alineación. Además debe entenderse que la aceleración con la que se presentan los cambios tecnológicos hace y hará inestables a las más recientes mediásferas.

En el cuadro 1 que aparece más adelante, se pretende exponer a modo de resumen, vínculos por medio de conceptos extraídos o inferidos de las entrevistas y del trabajo de campo llevado a cabo con los periodistas políticos y económicos; también de las conclusiones precedentes. Esta propuesta de relaciones retoma algunos elementos ya planteados y descritos por Debray y Merzeau, (1998). Reubica, crea nuevas categorías y trata de resignificarlas, disponiéndolas más cerca de los nexos entre el periodismo, los periodistas, las audiencias y los medios de comunicación.

En tal sentido, se podrán encontrar elementos más genéricos referidos al mundo de las comunicaciones, al periodismo, y otros más específicos que atañen al periodismo político y económico. Si bien mucho del periodismo sigue siendo en el fondo "el mismo", también bastantes otras cosas se han modificado. Acá nos encaminaremos de preferencia hacia aquello que consideramos se ha transformado a modo de tendencia.

El periodismo tradicional impreso, tan hijo de la grafósfera ${ }^{2}$ y del papel, hace de su protagonista principal el producto periodístico, pero al inicio de la

Consultar en especial las obras Vida y muerte de la imagen: historia de la mirada en Occidente (1992) e Introducción a la mediología (2000).

2 La mediología distingue básicamente tres mediásferas, esferas espacio-temporales definidas por el principal soporte de transmisión de la cultura imperante en cada 
videósfera, el protagonista en la escena mediática es el mismo periodista político que gozaba de una importante aura de prestigio desprendida de las fuentes y medios en los que trabajaba, el autor de las piezas informativas. $\mathrm{Al}$ principio de la hiperósfera el agente más importante no es tanto el producto, ni el periodista que comienza a verse como un sujeto más, sino la búsqueda de la identidad del medio donde trabaja. Esto es particularmente evidente en los nuevos medios digitales. Por otra parte, el concepto de marca, llevado al manejo del marketing digital, es lo que se aprecia en los entornos digitales.

La propiedad de los medios de comunicación que durante la segunda mitad del siglo XX y los inicios del XXI se consolidó en general en Occidente en oligopolios de la información que se apoyaba sobre los ideales de veracidad y libertad en las sociedades democráticas, y de la utopía de la ética periodística, se traslada a medios más pequeños, de propiedades comunitarias o de accionistas, con funciones jerárquicas menos determinantes, grupos productores de noticias medianos, muchos de ellos como se ha visto en algunos países, desplazados por las crisis de los grandes medios.

La concepción de tiempo que parecen imponer los medios en la web y en las redes sociales, es una secuencia de puntos constituidos por la aparición de las noticias, emitidas desde la idea de competencia, figuración, oportunidad e inmediatez, del minuto a minuto. Se relega así la concepción de un tiempo presente a la aceleración de muchos puntos en secuencias ordenadas en una línea de tiempo que tiende al infinito.

Las ganancias de las audiencias, de las ciudadanías o de las gentes (difícil encauzar una definición estable) se alcanzan en un aparente y hasta tímido reconocimiento por parte de los medios de comunicación. La posibilidad de influencia del ciudadano, como ser político, sobre la sociedad y los medios, encuentra una luz a través de la participación y autocomunicación en los espacios de los medios como en el universo de la red. Ahora los individuos procuran ser parte, muchas veces momentáneamente, de causas virtuales, llamadas hoy

una. Logósfera, esfera del conocimiento, el habla y la escritura, va hasta la invención de la imprenta. Grafósfera, esfera determinada por los textos impresos, incluye a la fotografia, el cine y la radio, y va hasta la televisión, en particular la televisión a color. Videósfera, determinada por la sociedad de la televisión, va, según algunos mediólogos como Louise Merzeau, (1998) hasta la invención de la Internet. A partir de allí tendríamos la hiperósfera, esfera en la que podríamos estar ya viviendo. Para consultar sobre la hiperósfera véanse los Cahiers de médiologie, n 6, París, 1998, Gallimard. 
"tendencias" y manifestando adhesiones viscerales. Esta parece ser la nueva forma del rol del sujeto frente al soporte. Si antes se leía el medio para hacerse supuestamente una idea "propia", ideología, buscando una individualidad estable, hoy se pretende ser parte de una causa temporal inestable.

En la actualidad en la hiperósfera nos hemos encontrado con que, en palabras de los periodistas, un alto porcentaje del trabajo connotado que se hace es para que el medio logre y sea reconocido en diferentes frentes. Uno de estos trabajos es el de promover la discusión en las redes y el apoyar individualidades y neotribalismos.

Con independencia del tema o de las fuentes, los proyectos mediáticos parecen centrarse en motivar la creación de numerosos grupos para su participación en la red. Esta nos parece que es una peculiaridad de la hiperósfera que viene heredada por el objetivo que tenían los medios de reconocer la nación, crear nacionalidades y nacionalismos. Una tendencia que estaba dictada por el Estado y que con la llegada de la televisión se fue disipando para reconocer otras nacionalidades (en especial la norteamericana) y generar afectos de consumo masivo. El trabajo "político" de los periodistas tiene acá un inmenso espacio de práctica y reflexión.

Nuestra investigación encontró cómo los periodistas políticos y económicos deben hacer un mayor esfuerzo por traducir lo verdadero y lo real, paradigmas de la grafósfera y la videósfera, respectivamente, al mundo virtual, que es propio de la web, evitando un desbalance que aún no logra solución. Este desbalance se produce al crearse una tensión y un distanciamiento temporal entre los preceptos tradicionales del periodismo y las exigencias implícitas de la nueva época.

La llamada oferta simbólica de los medios tradicionales para las audiencias, pasa de la estrategia de hacer encuestas y medir las opiniones de "la gente" propia de la época predigital, a espacios donde la audiencia propone productos terminados o semiterminados en los plataformas interactivas. El mensaje del medio de comunicación ahora es "tenéis derecho a ser parte" de la emisión, de la edición.

Sin embargo, el ya poder "formar parte de" acarrea paradójicamente una pérdida de fiabilidades en las informaciones que circulan. Si antes para el consumo de noticias, la televisión era paradigma de fiabilidad -"si lo vi 
en televisión, es que debe ser cierto"-, ahora con los entornos digitales, principalmente en las redes sociales, tanto los periodistas como las audiencias, saben que verlo o leerlo en la web no es garantía de nada.

La pérdida de un espacio mediático que le dé al ciudadano un dictamen de autoridad, lo introduce en una incertidumbre que, entre otras cosas, se banaliza. Pero al mismo tiempo, las posibilidades y virtudes de la desacralización se van por otros canales. Se propicia la generación de múltiples verdades o la relativización de una única verdad. A esta situación deben estar atentos los periodistas políticos y económicos al pensar la efectividad de las informaciones puestas en circulación en la red.

El diario desprovisto de su materialización física y el noticiero de radio o televisión de su ritualización horaria de la emisión, llevan a debilitar el modo como se los había mitificado gracias al "todos en todas partes y a toda hora", por lo menos para las audiencias tradicionales. ¿Se posibilitaría entonces la configuración de un nuevo tipo de ritualización frente al medio? Internet desplaza la ritualización en virtud de la inmediatez y la singularidad. Lo que importa ahora es el tiempo propio del usuario en la red y no la tiranía del medio, "búscame cuanto tú quieras", es el mandato.

En este mismo juego de tensiones, el mundo del periodismo, incluido el de la política, parece ya no registrar el fundamento de las ideologías (tendencia más de la grafósfera) y tampoco el acontecimiento noticioso clásico, propio de la transmisión televisiva (en directo). Ahora en Internet, con toda y su convergencia, el elemento que se añade es el registro del evento, el que se diferencia del acontecimiento por su liquidez y a veces por la banalidad en la lógica de la inmediatez y su efímera presencia e impacto. Así, buena parte del "periodismo político" que reconoce la audiencia, se ha traducido en chismes, peleas de farándula de Palacio, en notas ligeras susceptibles de ser transmitidas con rapidez en la red, de ser consumidas con facilidad y descartadas por unas nuevas que vienen en la fila.

Conceptos clásicos siguen resistiendo al paso de los años, pero colonizando nuevos espacios de interacción. Uno de esos conceptos es el de la opinión pública. Mover, construir y medir opinión pública, está en todos los libros y manuales de periodismo. No se desconoce el hecho de manejarla e influir en ella con líderes de opinión e informaciones que aparezcan en medios de amplio reconocimiento. 
En la hiperósfera el periodismo halló un nuevo espacio, tanto para generar opinión pública como para medirla de manera inmediata y prácticamente gratis, sin pagar costosas encuestas. La medición combinada de visitas, likes, compartidos, la "viralidad" de una nota, los TT de Twitter y participación en foros, reúnen datos que les provee a los medios orientaciones claras, por lo menos de los participantes, sobre temas de coyuntura: le dice al periodista cómo irse orientando y al medio cómo ir impulsando o menospreciando un tema.

Así las cosas, el rol del medio frente al sujeto halla nuevas vías de acercamiento y hasta de control, sin desconocer algunas ganancias que han adquirido los individuos. El concepto de masa bien desarrollado por las escuelas norteamericanas en el siglo XX, apuntaba a generar tendencias de opinión favorables para elecciones presidenciales y sucesos políticos al interior de las naciones, mientras que el marxismo denunciaba ya desde sus inicios la manipulación de los trabajadores. Hoy parece que la forma de control ha cambiado, se controla masivamente mediante el fomento de la individualidad y la promoción y apoyo a grupos de todo tipo: social, sexual, cultural... impulsando la diversidad y la igualdad. Empero, en el campo de la diversidad ideológica y política las opciones siguen siendo más cerradas. Si aparecen grupos de diversidad sexual se los apoya, diferencias étnicas y culturales también encuentran su respaldo por los medios masivos.

La inmediatez, estar primero en la red, informar con el tuit, mantener todo el día a las audiencias conectadas e informadas, ha suscitado nuevas dinámicas tanto para el medio, a través de sus editores web y CM, como para los periodistas. La idea del medio es estar allí siempre presente en las redes sociales y renovando en los portales de Internet. Frente a la avalancha el medio debe diferenciarse y distinguirse de los demás. El medio debe impactar más que nunca. Este impacto se hereda del querer sorprender mediante la imagen televisiva y se encuentra ya un tanto lejos del querer informar "a secas".

Los periodistas consultados nos afirman que su principal propósito es informar, pero en la web el objetivo cardinal es posicionarse, tener más seguidores, generar discusión, etc. Llevada la argumentación por esta ruta, comprendemos que los medios en la grafósfera estimulaban a sus audiencias a que fueran ciudadanos participativos en la democracia, consumidores activos y hoy en la hiperósfera, finalmente sujetos, audiencias interactivas, autores y movilizadores de contenidos. 
Hoy la figura mítica del periodista polivalente y multiplataforma no es una realidad en los medios colombianos, salvo casos especiales, y esto a pesar de las predicciones y deseos de bastantes teóricos y de los medios de comunicación, a fin de bajar costos. Esta figura, de todos modos, es reemplazada por el trabajo conjunto del periodista y un desarrollador de contenidos o un diseñador para hacer "más atractivas" las informaciones. Este personaje movilizador de audiencias ya estaba presente en la cultura del audiovisual con el periodista estrella o la estrella fungiendo de periodista, incluso en los temas de política. El periodismo político se encuentra así en una encrucijada buscando cómo posicionarse, innovar e "impactar". Las vías de exploración siguen abiertas.

Guadro 1.

Mediásferas. Del periodismo político y económico

en los entornos digitales

\begin{tabular}{|c|c|c|c|}
\hline & Grafósfera & Videósfera & Hiperósfera \\
\hline Soporte & Lo impreso & Lo audiovisual & La red \\
\hline $\begin{array}{l}\text { A quién se hace } \\
\text { célebre }\end{array}$ & $\begin{array}{l}\text { Al medio y su noticia } \\
\text { (importa la noticia) }\end{array}$ & $\begin{array}{l}\text { Al medio y sus } \\
\text { reporteros } \\
\text { (importa quién hace } \\
\text { la nota) }\end{array}$ & $\begin{array}{l}\text { Al medio y su } \\
\text { "identidad" } \\
\text { (importa cómo se } \\
\text { impactó) }\end{array}$ \\
\hline $\begin{array}{l}\text { Concepción de } \\
\text { tiempo }\end{array}$ & $\begin{array}{l}\text { Diferido } \\
\text { (circunstancial) }\end{array}$ & $\begin{array}{l}\text { Presente } \\
\text { (posibilidad) }\end{array}$ & $\begin{array}{l}\text { Secuencia de puntos } \\
\text { acelerada } \\
\text { (oportunidad) }\end{array}$ \\
\hline $\begin{array}{l}\text { Rol del sujeto } \\
\text { frente al soporte }\end{array}$ & $\begin{array}{l}\text { Busca la individualidad } \\
\text { (estable) }\end{array}$ & $\begin{array}{l}\text { Busca ser parte por } \\
\text { medio del consumo } \\
\text { (variable) }\end{array}$ & $\begin{array}{l}\text { Busca ser parte por } \\
\text { medio de la adhesión } \\
\text { (temporal) }\end{array}$ \\
\hline $\begin{array}{l}\text { Experiencia del } \\
\text { sujeto frente al } \\
\text { medio }\end{array}$ & $\begin{array}{l}\text { Puedes leernos } \\
\text { (en la publicación) }\end{array}$ & $\begin{array}{l}\text { Puedes vernos } \\
\text { (en la emisión) }\end{array}$ & $\begin{array}{l}\text { Puedes formar parte } \\
\text { (de la publicación/ } \\
\text { emisión en línea) }\end{array}$ \\
\hline Proyecto mediático & $\begin{array}{l}\text { Hacer país } \\
\text { (generar nacionalidad) }\end{array}$ & $\begin{array}{l}\text { Formar parte de una } \\
\text { industria } \\
\text { (generar afectos) }\end{array}$ & $\begin{array}{l}\text { Formar parte de una } \\
\text { discusión } \\
\text { (generar grupos) }\end{array}$ \\
\hline $\begin{array}{c}\text { Ideal de } \\
\text { construcción social } \\
\text { y política }\end{array}$ & $\begin{array}{l}\text { Todos somos nación } \\
\text { (impulsa) }\end{array}$ & $\begin{array}{l}\text { Todos somos } \\
\text { consumidores } \\
\text { (motiva, persuade) }\end{array}$ & $\begin{array}{l}\text { Selecciona casos e } \\
\text { induce grupos }\end{array}$ \\
\hline
\end{tabular}




\begin{tabular}{|c|c|c|c|}
\hline $\begin{array}{l}\text { Paradigma de } \\
\text { atracción }\end{array}$ & $\begin{array}{l}\text { Lo verdadero } \\
\text { (se informa) }\end{array}$ & $\begin{array}{l}\text { Lo real } \\
\text { (se muestra) }\end{array}$ & $\begin{array}{l}\text { Lo virtual y lo viral } \\
\text { (simula lo verdadero y } \\
\text { lo real) }\end{array}$ \\
\hline $\begin{array}{l}\text { Régimen de } \\
\text { autoridad }\end{array}$ & $\begin{array}{l}\text { Yo lo leí en un libro y } \\
\text { en la prensa } \\
\text { (régimen solidificado) }\end{array}$ & $\begin{array}{l}\text { Yo lo vi en televisión } \\
\text { (régimen motivado) }\end{array}$ & $\begin{array}{l}\text { Yo lo encontré en } \\
\text { Internet (régimen } \\
\text { desforzado) }\end{array}$ \\
\hline $\begin{array}{l}\text { Peregrinación al } \\
\text { medio }\end{array}$ & $\begin{array}{l}\text { Ve al quiosco } \\
\text { (ritualizado, } \\
\text { publicación) }\end{array}$ & $\begin{array}{l}\text { Búscame a esta hora } \\
\text { (ritualizado, emisión) }\end{array}$ & $\begin{array}{l}\text { Búscame cuando quieras } \\
\text { (deritualizado, el "post") }\end{array}$ \\
\hline Ideal de registro & El fundamento & $\mathrm{El}$ acontecimiento & El evento \\
\hline $\begin{array}{l}\text { Generación de } \\
\text { opinión pública }\end{array}$ & $\begin{array}{l}\text { Se genera en columnas } \\
\text { de opinión }\end{array}$ & $\begin{array}{l}\text { Se la mide, anticipa y } \\
\text { se hacen sondeos }\end{array}$ & $\begin{array}{l}\text { Se la observa en foros y } \\
\text { se mide en línea }\end{array}$ \\
\hline $\begin{array}{l}\text { Rol del medio } \\
\text { frente al sujeto }\end{array}$ & Hacerlo masa & Hacerlo consumidor & $\begin{array}{l}\text { Hacer individuos y } \\
\text { grupos de todo tipo: } \\
\text { ideológico, cultural, } \\
\text { sexual, etc. }\end{array}$ \\
\hline $\begin{array}{l}\text { Propósito del } \\
\text { medio }\end{array}$ & $\begin{array}{l}\text { Yo te informo } \\
\text { (en diferido) }\end{array}$ & $\begin{array}{l}\text { Yo te sorprendo } \\
\text { (en el directo } \\
\text { televisivo) }\end{array}$ & $\begin{array}{l}\text { Yo te impacto } \\
\text { (en la inmediatez de la } \\
\text { red) }\end{array}$ \\
\hline $\begin{array}{l}\text { Expectativa frente } \\
\text { al individuo }\end{array}$ & Que sea ciudadano & $\begin{array}{l}\text { Que sea consumidor } \\
\text { de productos }\end{array}$ & $\begin{array}{l}\text { Que sea interactivo, } \\
\text { autor y movilizador de } \\
\text { contenidos }\end{array}$ \\
\hline $\begin{array}{l}\text { Figura idealizada } \\
\text { en el medio }\end{array}$ & $\begin{array}{l}\text { Tener un politólogo y } \\
\text { un economista en la } \\
\text { sala de redacción } \\
\text { (para consultar) }\end{array}$ & $\begin{array}{l}\text { Tener una figura } \\
\text { reconocida como } \\
\text { vedette } \\
\text { (para mostrar) }\end{array}$ & $\begin{array}{l}\text { Tener un desarrollador } \\
\text { de contenidos y } \\
\text { diseñador } \\
\text { (para atraer e impactar) }\end{array}$ \\
\hline $\begin{array}{l}\text { Figura de } \\
\text { dirección }\end{array}$ & $\begin{array}{l}\text { Líder ideológico } \\
\text { (sobre el ciudadano) }\end{array}$ & $\begin{array}{l}\text { Un representante } \\
\text { (sobre el consumidor) }\end{array}$ & $\begin{array}{l}\text { Un periodista polivalente } \\
\text { (sobre el prosumidor) }\end{array}$ \\
\hline $\begin{array}{l}\text { Contacto con las } \\
\text { audiencias }\end{array}$ & $\begin{array}{l}\text { Defensor del lector } \\
\text { (cartas a la redacción) }\end{array}$ & $\begin{array}{l}\text { Defensor del } \\
\text { televidente } \\
\text { (cartas a la dirección } \\
\text { de programación) }\end{array}$ & $\begin{array}{l}\text { Community manager } \\
\text { (mensajes a la redacción, } \\
\text { mediador entre } \\
\text { plataformas) }\end{array}$ \\
\hline $\begin{array}{l}\text { Modelo de } \\
\text { "producción" }\end{array}$ & Industrial & Posindustrial & --- \\
\hline
\end{tabular}

Fuente: Autor. 
Cuadro 2.

Observaciones mediológicas entre medios nativos digitales y medios tradicionales en tiempos de los entornos digitales

\begin{tabular}{|c|c|c|}
\hline & Medios tradicionales & Medios nativos digitales \\
\hline Lugar de influencia objetiva & Sobre grupos en "las masas" & Sobre líderes de opinión \\
\hline $\begin{array}{l}\text { Tipo de periodista } \\
\text { imperante }\end{array}$ & $\begin{array}{l}\text { Periodista clásico vs. } \\
\text { Diseñador y desarrollador }\end{array}$ & Periodista polivalente \\
\hline $\begin{array}{c}\text { Expectativa de } \\
\text { convergencia en los } \\
\text { periodistas }\end{array}$ & Poca exigencia y atributos & Toda la exigencia y atributos \\
\hline $\begin{array}{l}\text { Personal adscrito como } \\
\text { community manager }\end{array}$ & Practicante & $\begin{array}{l}\text { Periodista profesional, } \\
\text { multiplataforma }\end{array}$ \\
\hline $\begin{array}{l}\text { Función de las } \\
\text { informaciones en la red }\end{array}$ & $\begin{array}{l}\text { Seducir, cautivar, atraer, } \\
\text { posicionar al medio }\end{array}$ & $\begin{array}{l}\text { Profundizar, contextualizar, } \\
\text { posicionar al medio }\end{array}$ \\
\hline Por quiénes se sienten leídos & $\begin{array}{l}\text { Por audiencias locales y } \\
\text { nacionales }\end{array}$ & $\begin{array}{l}\text { Por audiencias nacionales e } \\
\text { internacionales }\end{array}$ \\
\hline $\begin{array}{l}\text { Proximidades del medio } \\
\text { con la fuente }\end{array}$ & $\begin{array}{l}\text { Se sienten menos cercanos a } \\
\text { la calle }\end{array}$ & $\begin{array}{l}\text { Se sienten más cercanos al } \\
\text { reporterismo }\end{array}$ \\
\hline $\begin{array}{c}\text { Estatus de la } \\
\text { metacomunicación respecto } \\
\text { a la fuente }\end{array}$ & $\begin{array}{l}\text { Pérdida de múltiples } \\
\text { lenguajes de contacto directo }\end{array}$ & $\begin{array}{l}\text { Recupera los lenguajes } \\
\text { directos con la fuente (salvo el } \\
\text { periodismo de datos) }\end{array}$ \\
\hline Relación espacio-temporal & $\begin{array}{l}\text { Espacios y tiempos más } \\
\text { regulados }\end{array}$ & $\begin{array}{l}\text { Espacios y tiempos menos } \\
\text { regulados }\end{array}$ \\
\hline $\begin{array}{c}\text { Tipo de procesamiento de } \\
\text { la información }\end{array}$ & $\begin{array}{l}\text { Procesamiento ideológico/ } \\
\text { económico }\end{array}$ & Procesamiento tecnológico \\
\hline
\end{tabular}

Fuente: Autor.

Estas son algunas preguntas de reflexión para los periodistas, directores de medios e investigadores necesarias para seguir adelante en la gran empresa que es el periodismo:

A quién se hace celebre:

¿Podrá ser la construcción y enaltecimiento de su propio ego la estrategia de algunos medios para sobrevivir tal y como lo hacen los youtubers. Esta es una vía para nueva mejorar su eficacia simbólica? Los medios también buscan su gratificación. 
Concepto de tiempo:

¿Este continuo fluir de la información será parte de una nueva sociología en el proceso de hominización, y el debilitamiento de la jerarquía de las noticias, hace parte de un proyecto mayor?

Papel del sujeto frente al medio:

¿Hasta dónde este "ser parte" significa una democratización real de los medios? A qué nuevos panoramas de participación mediática nos puede llevar?

Experiencia del sujeto frente al medio:

¿Qué tan en serio se toman los medios la participación de los ciudadanos, más allá de rinting, los públicos cumplen su gratificaciones?

Régimen de autoridad:

¿Cómo está impactando a los medios y a los periodistas compartir su propia eficacia simbólica con la ciudadanía común y corriente, qué estrategias se están planteando los medios a este respecto?

Peregrinación al medio:

¿Qué podrá significar el tamaño de la desritualización de nuestra experiencia frente a los medios?

Propósito del medio:

¿Tendrá este modelo una solución cuando el mismo modelo económico-publicitario de los medio supere la actual crisis, más aún cuando la publicidad también ha querido siempre impactar?

Expectativa frente al ciudadano:

¿Hasta cuándo o hasta dónde estarán dispuestas a asumir las audiencias tantas nuevas funciones?

\section{Recomendaciones}

Debido a los acelerados cambios en el mundo del periodismo digital, es necesario que los medios revisen constantemente el tema de las convergencias, las capacitaciones a los periodistas y las evaluaciones de las jornadas de trabajo en función del periodismo digital. 
En cuanto a factores en concreto periodísticos, los medios tradicionales tanto en sus secciones tradicionales, como en sus secciones web, deberán adoptar las lógicas de producción de noticias de los medios nativos digitales: recobrar la calle, el reporterismo y hacer periodismo de más profundidad y análisis, por lo menos para la parte impresa o tradicional. Medios como la televisión y la radio podrán pensar en productos exclusivos, si bien la migración digital es un imperativo más determinante en los diarios derivado de su factor tecnológico dependiente del papel, en los medios audiovisuales las plataformas en Internet también pueden aprovechar y potenciar el impulso innato tecnológico para que no se conviertan sus sitios en simples "colgaderos" de audios, videos o cables de noticias internacionales.

Se requieren estrategias no ya para recopilar las inquietudes de las audiencias, sino para poder interpretar sus necesidades y poderlas llevar a la práctica en productos periodísticos en la web.

Los medios deben evaluar la importancia de la calidad del periodismo, de la figura del periodista polivalente. Si bien este periodista es rentable, está visto que no podrá hacerlo todo. No solo por factores de tiempo, sino porque no puede asegurar siempre el manejo creativo de las aplicaciones.

Es apremiante que los medios tradicionales desarrollen investigaciones internas o con el acompañamiento de la academia que arrojen propuestas sobre cómo posicionar el periodismo especializado en política y economía en Colombia en los entornos digitales, a fin de suscitar interés, inquietud, impacto y cambio social, principalmente en las nuevas generaciones.

Los medios tradicionales deben examinar la posibilidad de hacer modificaciones estructurales a sus salas de redacción, en sintonía con los modelos más fluidos de comunicación propios de los medios nativos digitales. Un medio que ya esté innovando en la red y no lo haya hecho en los espacios físicos, tendrá su proceso de convergencia incompleto. Si bien no parece ser categórico, los espacios colaborativos son más que una metáfora de la circulación democratizada de las relaciones.

\section{Recomendaciones para la academia.}

Para un programa de especialización en periodismo político y económico se precisa de un currículo académico estructurado en un sistema de asignaturas que tenga como ejes centrales la producción periodística, los en- 
tornos digitales del periodismo y la formación humana y teórica en el contexto de la realidad nacional e internacional. De estos ejes se desprenderían cursos de economía y política.

Es menester una formación con énfasis en lo político y económico a partir de las carencias detectadas, haciendo hincapié en la estructura del Estado y en la historia política; y desde la economía, insistiendo en la micro y macroeconomía, en los sistemas económicos y en la historia económica nacional.

La academia debe formar al periodista como documentalista, con sentido histórico de la noticia, para que la inmediatez no se convierta en banalidad ni en informaciones efímeras. Este trabajo tiene tanto de práctica técnica como de formación humana. En este sentido, las notas periodísticas podrían elaborarse a dos o tres manos: un reportero en el lugar y momento del acontecimiento, un periodista que la retome, explique y coloque en contexto y un desarrollador de contenidos para que la lleve creativamente a la red.

El programa de especialización debe instruir a los periodistas para interactuar con las audiencias desde las funciones del CM al editor web. Esta interacción debe ir más allá de postear simples respuestas y realmente potenciar toda la participación difusa y dispersa de la ciudadanía, en la confección de proyectos conjuntos con miras a la producción especializada en política y economía y a seguir la línea de la ganancia que han dado los entornos digitales a la relación medios-periodismo-ciudadanía: darse a la comunidad, prestar un servicio a la comunidad.

Ello implica también para la academia, proveer las herramientas teóricas, metodológicas y humanas que puedan cuestionar al periodismo corporativo, a fin de aprovechar de él las prácticas que mejor se adapten a los ambientes digitales. La propuesta no es formar técnicos, tampoco "simples" periodistas o reporteros, sino periodistas con capacidad de editores y directores de sección de pequeños y medianos medios -tanto para los soportes tradicionales como para las variedades que propone Internet-. Periodistas que escudriñan nuevas posibilidades para el registro, difusión e interacción de las informaciones de tipo periodístico, especializado en política y economía.

Estos objetivos concretos y estructurados para la academia son propios para un trabajo de maestría en la cual se puedan examinar paradigmas de la comu- 
nicación periodística en la búsqueda, exploración, análisis y proposición de un periodismo digital especializado, fruto de los entrecruces siempre renovados entre periodismo y tecnología. En ese sentido, la academia debe mostrarse muy ágil en la implementación de los cambios tecnológicos, valorando la capacidad de los periodistas para acceder e intercambiar información, y seguir pautas críticas necesarias para un periodismo más de cara a la ciudadanía.

Los estudiantes de periodismo en posgrado pueden beneficiarse de la creación de laboratorios donde se recreen condiciones similares a las que los entornos de trabajo podrían temer y que los ponga en necesario contacto con aplicaciones para desarrollar la creatividad al momento de tratar temas de política y economía. Los periodistas demandan conocer mejores procedimientos y estrategias para la elaboración de productos periodísticos con nuevas narrativas, que sean de interés de las audiencias y que se ajusten a las necesidades y posibilidades de los medios; espacios donde se pueda desplegar la creatividad, partiendo de las condiciones reales de los hechos. Pero al interior de los medios no hay mucho tiempo para la experimentación.

La academia debe brindar espacios de simulación de la realidad a modo de laboratorios, en los cuales los estudiantes puedan enfrentarse a las condiciones de un trabajo cotidiano y que a la vez puedan estudiar cómo hacer del periodismo político y económico un tema vigente, de interés para toda la ciudadanía y donde los medios representen un lugar de participación potencialmente democrático.

El laboratorio que puede proveer la academia debe ser un escenario colaborativo y de convergencia, que desde el estudio haga los entrecruces necesarios entre tecnología y creatividad, el manejo de la realidad, la ética y responsabilidad, el posicionamiento de los temas de política y economía y la construcción de democracia. Un espacio que simule las relaciones jerárquicas y las condiciones de las rutinas de trabajo de los futuros periodistas especializados en política y economía. Un espacio que, desde su estructura organizativa (y con unas nuevas lógicas que inspire la web), simule modelos de convergencia que van desde las decisiones administrativas del medio, hasta usos transmedia y las nuevas posibles divisiones del trabajo.

En compañía de las facultades universitarias, los profesores deben estar diseñando nuevas estrategias pedagógicas que estén en la línea de saber ma- 
nejar la información especializada en política y economía, focalizándose en las carencias de los medios, de los periodistas y del contexto político y económico nacional e internacional. Estrategias que puedan estimular la interactividad con la ética.

El uso del laboratorio es un espacio académico de investigación tanto para estudiantes como para docentes, para sintonizar el trabajo con las nuevas lógicas de producción de la red; las lógicas de la economía y la sociedad actual y global; las lógicas de los contextos geopolíticos y, sobre todo, las lógicas de los soportes de la transmisión de la cultura como son el mundo virtual y sus desarrollos subsecuentes.

Como espacio de trabajo, el laboratorio se posiciona como un gran plus para un programa de especialización y para un programa de maestría, pues es un lugar para la investigación más contemporánea y sistémica del periodismo en los nuevos escenarios tecnológicos, políticos, económicos, globales y nacionales.

Lo anterior se justifica plenamente en los requerimientos actuales del periodismo tradicional y del periodismo de los medios nativos digitales. El primer grupo en la búsqueda de su modelo de negocio que debe incluir cambios estructurales en la organización interna, manejo de la información, garantías y libertades para los periodistas, acercamiento verdadero a la ciudadanía y exploración de herramientas y narrativas, todo con alta participación de los ambientes digitales. Para el segundo caso, ya inmersos en la cultura digital, para incidir de manera más adecuada en nichos y sectores sociopolíticos nacionales o internacionales, la ciudadanía también está demandando nuevos espacios, sus necesidades desde el punto de vista periodístico son apremiantes.

La investigación en laboratorio, además debe enfrentar al estudiante a la reflexión sobre la búsqueda de soluciones mediáticas para la transmisión, difusión e interactividad de las noticias políticas o económicas, a partir de la creación de medios de comunicación o plataformas periodísticas profesionales.

\section{Algunas paradojas para el cierre}

El periodismo, gracias a la llegada de los entornos digitales, ha podido hacer relucir parte de su propósito original como es darse a los ciudadanos, pudiendo responder de forma más fácil y oportuna a sus intereses y 
demandas. Aunque se reconoce que son pocos los periodistas los que logran realmente hacer un periodismo de cara al ciudadano, pues particularmente sobre este sector se ejercen intereses de sectores políticos y de grupos económicos. De todas maneras, la web no garantiza un periodismo más dado a las audiencias, pero sí deja el espacio abierto para que ese intercambio surja.

Los medios de comunicación tradicionales, al estimular a las audiencias a que demuestren su capacidad para hacer periodismo - o algún tipo de periodismo en los blogs o en las redes, utilizando sus mismas estrategias-, han debilitado su propio poder y el aire mítico que los envolvía.

Aunque las fuentes hayan facilitado la labor periodística en cuanto se hace menos dispendiosa la búsqueda y elaboración de la información, paradójicamente los periodistas dedican buena parte de su tiempo a seleccionar datos en un mar de información. La labor de curaduría está dejada a los más expertos.

Dada la contaminación de las plataformas, tanto informativas como sociales, con todo tipo de publicidad, anuncios y opiniones por doquier, sin un filtro que permita alcanzar un escenario menos atiborrado, los ciudadanos pueden perder de vista iniciativas periodísticas particulares o tendencias globales.

El relativo esfuerzo de creatividad para combinar los fragmentos de las informaciones en una nota, se contrasta con el facilismo temático, donde hay poca creatividad, pues casi todo está inspirado en la red.

Mientras que una fracción importante de los contenidos de los medios tradicionales se construye volcándose a la red, los medios más nuevos, nativos digitales, se vuelcan a las calles a recabar la información de primera mano.

Por una parte se valora la disponibilidad de fuentes en tanto pululan multiplicidad de canales de comunicación con las mismas, lo cual colabora con la inmediatez de la producción de información/mercancía. Por otra, se considera como un detrimento de la esencia del quehacer periodístico que no haya un contacto directo con la fuente.

Paradójicamente se presenta la web como un espacio de alta difusión que es proporcional a la posibilidad de ocultar la información. 



\section{ANEXO 1. \\ MATRIZ PARA PERIODISTAS POLÍTICOS Y EGONÓMICOS}

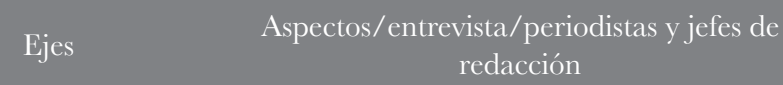

Ejes

Aspectos/entrevista/periodistas y jefes de redacción

El papel del Periodismo Político y Económico frente a los ciudadanos en los Entornos Digitales:

Ubicación del Periodismo Político y Económico en los Entornos Digitales:

Influencia del Periodismo Político y Económico en los Entornis Digitales sobre la opinión pública:

Efectos de los Entornos Digitales en los productos periodísticos:

Entorno Efectos de los Entornos Digitales en los canales de digital interacción que prefiere la audiencia:

Efectos de los Entornos Digitales en la dinámica frente a la competencia:

Efectos de los Entornos Digitales sobre las relaciones jerárquicas:

Efectos de los Entornos Digitales sobre las relaciones con las fuentes:

Efectos de los Entornos Digitales sobre la creatividad en los formatos:

Efectos de los Entornos Digitales en la ética y responsabilidad:

Ética Papel de los Entornos Digitales en la construcción de la actitud crítica:

Independencia informativa frente a los intereses políticos y económicos: 


\section{Aspectos/entrevista/periodistas y jefes de} redacción

Evidencia de la independencia informativa en los entornos digitales:

Ética

$$
\text { Independencia informativa en el medio: }
$$

Efectos de los Entornos Digitales sobre el trabajo investigativo:

Efectos de los Entornos Digitales en la prominencia del periodista y en el periodismo político y económico:

Efectos de los ED en la verdad y la responsabilidad:

Autopercepción

Considera que su papel como periodista es: denunciar, aclarar, influir, especializarse:

Eficiencia del periodismo político y económico en términos de movilización ciudadana:

Implicaciones del uso de los entornos digitales sobre la imagen en la opinión pública:

Influencia de las redes en la opinión pública:

\section{Carencias de los periodistas políticos:}

\section{Emergentes:}




\section{ANEXO 2. \\ GUÍA DE OBSERVACIÓN \\ ETNOGRÁFICA}

\section{Rutinas periodísticas, periodismo político y económico en entornos digitales}

Medio:

Periodista:

Fecha:

Hora de inicio:

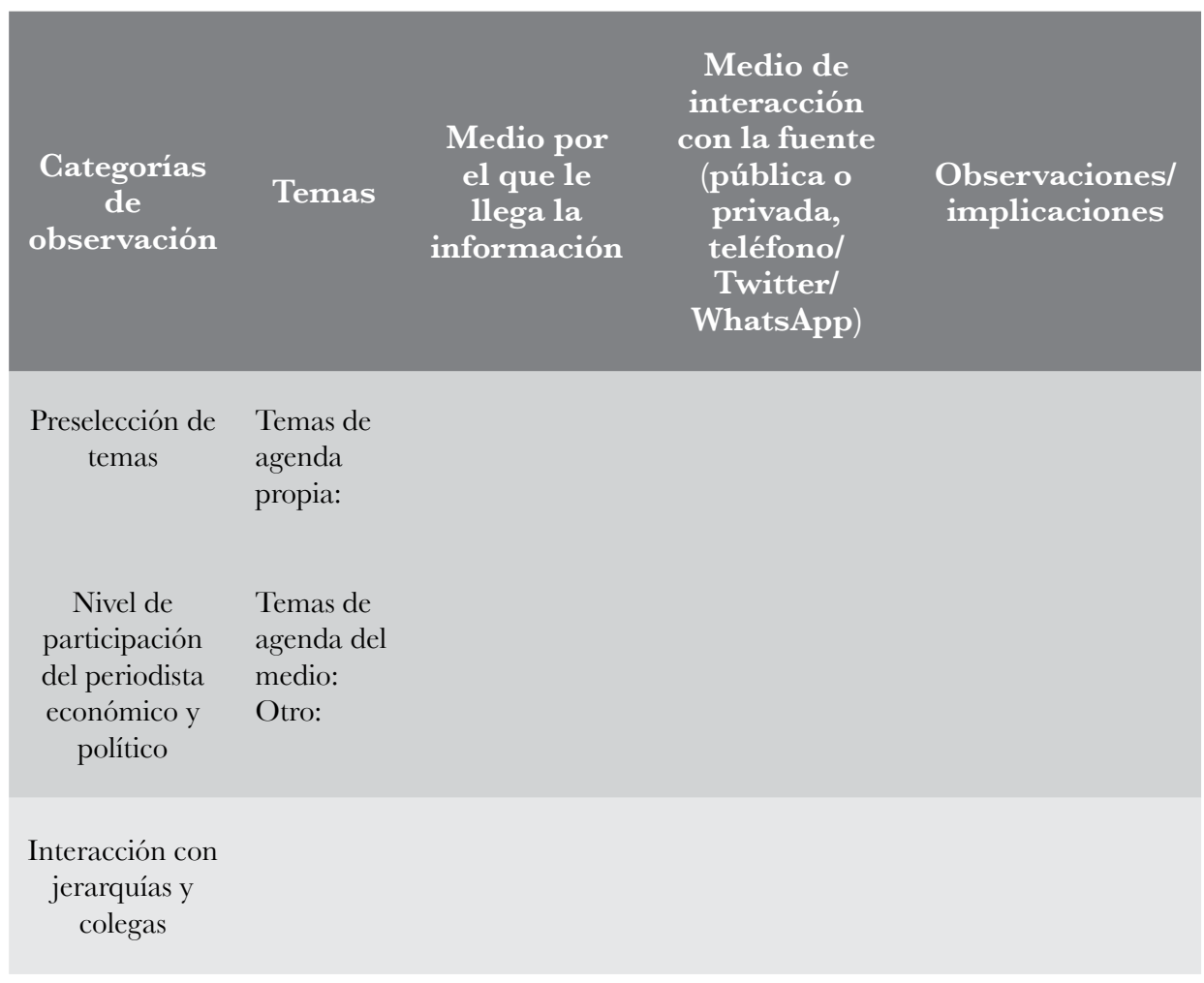




\section{Consejo de redacción}

\begin{tabular}{|c|c|c|c|c|}
\hline $\begin{array}{l}\text { Categorías } \\
\text { de } \\
\text { observación }\end{array}$ & Temas & $\begin{array}{c}\text { Nivel de } \\
\text { participación } \\
\text { de los } \\
\text { periodistas (de } \\
1 \text { a } 5)\end{array}$ & $\begin{array}{c}\text { Relación con } \\
\text { el entorno } \\
\text { tecnológico }\end{array}$ & \\
\hline \multicolumn{5}{|l|}{ Orden de los temas } \\
\hline $\begin{array}{l}\text { Categorías } \\
\text { de } \\
\text { observación }\end{array}$ & $\begin{array}{l}\text { Tipo de } \\
\text { temas } \\
\text { aprobados }\end{array}$ & $\begin{array}{l}\text { Participación del } \\
\text { entorno digital en la } \\
\text { aprobación del tema }\end{array}$ & & $\begin{array}{l}\text { Observaciones/ } \\
\text { implicaciones }\end{array}$ \\
\hline \multicolumn{5}{|l|}{ Selección de temas } \\
\hline $\begin{array}{l}\text { Categorías } \\
\text { de } \\
\text { observación }\end{array}$ & $\begin{array}{l}\text { Tipo de } \\
\text { fuente }\end{array}$ & Origen & $\begin{array}{l}\text { Tratamiento } \\
\text { cercano o } \\
\text { lejano, niveles de } \\
\text { confianza con la } \\
\text { fuente }\end{array}$ & $\begin{array}{l}\text { Papel del } \\
\text { entorno } \\
\text { tecnológico }\end{array}$ \\
\hline $\begin{array}{l}\text { Relación con las } \\
\text { fuentes }\end{array}$ & & & & \\
\hline
\end{tabular}

\section{Sala de redacción/Prensa}

\begin{tabular}{|c|c|c|c|}
\hline $\begin{array}{l}\text { Relaciones de } \\
\text { jerarquía y poder }\end{array}$ & $\begin{array}{l}\text { Relación } \\
\text { con actores } \\
\text { analógicos }\end{array}$ & $\begin{array}{l}\text { Relaciones } \\
\text { con actores } \\
\text { digitalmente }\end{array}$ & $\begin{array}{l}\text { Observaciones } \\
\text { sobre esta } \\
\text { diferencia }\end{array}$ \\
\hline \multicolumn{4}{|l|}{$\begin{array}{l}\text { Jefe de redacción } \\
\text { con sus subalternos }\end{array}$} \\
\hline \multicolumn{4}{|l|}{$\begin{array}{l}\text { Jefe de sección } \\
\text { con sus subalternos }\end{array}$} \\
\hline Entre colegas & & & \\
\hline Redacción de la nota & & & \\
\hline
\end{tabular}




\section{ANEXO 3. \\ GARACTERIZAGIÓN DE LOS MEDIOS TRADIGIONALES QUE FORMAN PARTE DE LA MUESTRA}

\section{Prensa:}

\section{Diario El Colombiano}

Diario regional colombiano, de la ciudad de Medellín, tiene algo más de cien años de circulación y su primer impreso fue el 6 de febrero de 1912 en Envigado; hoy se posiciona como el periódico líder de Medellín y Antioquia. Pertenece a Periódicos Asociados Latinoamericanos (PAL). Su posición política conservadora, apoya de manera abierta al expresidente de la República Álvaro Uribe Vélez.

El Colombiano.com es una página web noticiosa, reconocida por su constante actualización y sus contenidos multimedia que cuentan con videos, fotos y audios. La página fue finalista en el premio Círculo de Periodistas de Bogotá (CPB) en 2006.

\section{Diario El Espectador}

Su sede principal está en la ciudad de Bogotá. Lo fundó Fidel Cano Gutiérrez el 22 de marzo de 1887 en Medellín. Es el periódico más antiguo de Colombia y uno de los más antiguos de América; su nombre se debe a la admiración que su fundador le tenía al poeta Víctor Hugo, quien colaboraba en Francia en un periódico con el mismo nombre. En la actualidad la mayoría de sus acciones las posee Bavaria S. A., del empresario Julio Mario Santo Domingo.

En 1994, luego de hacer una encuesta, Le Monde Diplomatique lo consideró uno de los ocho mejores diarios del mundo. En 2010 fue el primero en imprimir completamente con tintas ecológicas, fabricadas con aceites derivados de la soya.

\section{Revista Fase 4}

Revista trimestral dirigida por Silverio Gómez Carmona. Este impreso está encaminado al sector de infraestructura colombiana, por lo tanto 
enfatiza en megaproyectos, nuevos negocios, legislación, economía y financiamiento. Basada en un pensamiento neoliberal, genera siempre nuevos proyectos que puedan interesar al gobierno.

\section{Diario El Heraldo}

Periódico colombiano con sede en Barranquilla, creado el 28 de octubre de 1933 por Alberto Pumarejo, Juan B. Fernández Ortega y Luis Eduardo Manotas; en la actualidad, es el diario más leído de la Costa Atlántica colombiana y se encuentra en tercer lugar en el ámbito nacional.

De ideología liberal, debe su nombre a un concurso popular que ganó Alicia Pacheco Hoyos. El diario El Heraldo tiene publicaciones de revistas con temas como cultura, espectáculos y variedad. Cuenta con un portal en Internet que funciona desde 2008.

\section{Diario El País}

Periódico creado en 1950 y publicado en Cali. Es propiedad de la familia Lloreda y es el medio más influyente del Cauca. Forma parte de Periódicos Asociados Latinoamericanos (PAL), entidad a la cual pertenecen otras editoriales latinas.

\section{Diario Portafolio}

Periódico líder en información de economía y negocios de Colombia. Pertenece a la casa editorial de El Tiempo y comparte sus mismas instalaciones, algunos de sus periodistas y la bolsa de noticias. Es el periódico "salmón" de Colombia en formato tabloide. En 2015 fue galardonado como el mejor diario económico de la región.

\section{Diario La Patria}

La Patria se edita en la capital del departamento de Caldas, Manizales, en donde fue fundado el 20 de julio de 1921. Es reconocido como el diario más leído de la zona. Defendió los ideales del partido nacionalista, desaparecido en la actualidad; en cuatro ocasiones fue incendiado y destruido por las violencias partidistas que azotaron a Colombia. 


\section{Diario La República}

Es un diario de economía y negocios colombiano, tiene su sede principal en Bogotá. Nació en 1954 con el expresidente conservador Mariano Ospina Pérez; en el presente, el 90 \% pertenece al periódico antioqueño El Colombiano y a Jorge Hernández Restrepo. Divulga una ideología neoliberal.

\section{Revista Semana}

Revista colombiana de actualidad. Fundada en 1946 por Alberto Lleras Camargo. La revista cerró en 1961; Felipe López Caballero reinició su publicación en 1982. En el presente su director es Alejandro Santos Rubino y su figura jurídica es Publicaciones Semana S. A.

Desde sus inicios la revista ha tenido una trayectoria liberal. Ha criticado la administración Uribe Vélez y a los grupos guerrilleros y paramilitares del país. En 2008 recibió el premio Rey de España por las investigaciones que aportaron al esclarecimiento de la parapolítica.

La revista es cada vez más influyente por sus polémicas en temas como los del extinto Departamento Administrativo de Seguridad (DAS), escuchas ilegales en 2009, y en la actualidad apoya al gobierno de Juan Manuel Santos y al proceso de paz en la Habana.

\section{Diario La Tarde}

Periódico fundado en Pereira el 9 de junio de 1975 y que dirigía Fabio Alfonso López Salazar y César Gaviria Trujillo. Con ideología liberal; ahora es dirigido por Alcides Arévalo.

\section{Diario El Tiempo}

Periódico colombiano creado el 30 de enero de 1911 por Alfonso Villegas Restrepo. Actualmente el empresario colombiano Luis Carlos Sarmiento es el propietario, después de comprar su parte al grupo Planeta de España, a la familia Santos y a Abdón Espinosa en 2012.

El Tiempo ha vivido los distintos momentos de la guerra en Colombia y ha formado parte de procesos como el "Frente Unido", que agrupó a distintos medios del país, después de que asesinaron al director del diario El Es- 
pectador, Guillermo Cano de; con el fin de redactar informes que dilucidaran los casos de corrupción política y narcotráfico de la década de los ochenta, además de mostrar los casos de violación a la libertad de expresión de los periodistas de la época.

Con una visión neoliberal, El Tiempo fue creando sus diferentes sucursales, como El Tiempo Cali, Tolima 7 Días, Llano 7 Días, Boyacá 7 Días, entre otras. Es uno de los periódicos más leídos, junto con El Espectador, su eterno rival.

En 2011 cumplió cien años y en su celebración, publicó 128 páginas junto al diario de ese día, y en su portal de Internet se divulgó una versión conmemorativa.

\section{Diario El Universal}

Con sede en Cartagena, fundado el 8 de marzo de 1948 por Domingo López Escauriaza (periodista) y Eduardo Ferrer Ferrer. Desde 1980 sus propietarios pertenecen a la Editora del Mar S. A. con el asocio creativo de la empresa periodística Vanguardia Liberal y con la participación de inversionistas locales. El diario en punto de referencia para el Caribe colombiano. Allí se formaron periodistas como el Premio Nobel Garcia Marquez.

\section{Radio:}

\section{Caracol Radio}

Es un sistema de estaciones de radio que cubre al territorio colombiano. Se consolidó en 1948 como lo que hoy conocemos como Cadena Radial Colombiana S.A.. A lo largo de los años, Caracol fue construyendo alianzas que la hacen ser ahora, una de las estaciones más escuchadas en el país. La Voz de Antioquia fue la primera emisora en unirse a esta grupo en 1945; le seguirían en el mismo año, Radio Cacique de Ibagué y en la década del cincuenta, se unieron las Emisoras Fuentes de Cartagena de Indias, Emisoras Unidas de Barranquilla y Radiodifusora del Occidente de Cali. Paulatinamente fue creciendo y en 2003 pasó a ser propiedad del grupo español Prisa, su director es Ricardo Alarcón Gaviria.

Con una posición ideológica liberal, donde los informes son noticiosos y de variedad; se caracteriza por sus programas de humor, como La Luciér- 
naga, dirigida por Gustavo Gómez; y por su programa 6 am Hoy por Hoy, informativo matutino que guía Darío Arizmendi.

Las emisoras que conforman esta cadena radial son: Radioacktiva, $\mathrm{La}$ Vallenata, Tropicana Estéreo, Radio Santa Fe, W Radio, Oxígeno y Los 40 Principales.

\section{Radio Nacional de Colombia}

Sistema radial de carácter estatal, operado por Señal Colombia Sistema de Medios Públicos. Esta es una entidad de Radio Televisión Nacional de Colombia (RTVG), antes conocida como Inravisión. Fundada en 1940 como Radiodifusora Nacional de Colombia y en 1954 con la llegada de la televisión al país se llamó Radiotelevisora Nacional de Colombia. Se dedica a la cultura y la educación.

Adscrita al Ministerio de Tecnologías de la Información y las Comunicaciones, generando un vínculo con los nuevos medios digitales, y mostrando una innovadora imagen como radiodifusor público; además tiene una nueva cara al pasar de ser Fonoteca RTVG a Señal Memoria, allí reposan los archivos audiovisuales de Señal Colombia.

\section{Televisión:}

\section{Noticiero Hora 13}

Noticiero de Medellín y Antioquia que se ocupa del acontecer regional. Cubre la información con sello propio en uno de los canales más vistos de la zona, Teleantioquia. Es dirigido por Luis Carlos Galeano. El canal es el más reconocido en su región, y su noticiero es lugar de referencia para todo el departamento de Antioquia.

\section{Noticiero 90 Minutos}

Tiene 22 años de existencia y es uno de los noticiarios más importantes del pacífico colombiano. Es líder en desarrollo tecnológico, emite desde su propia sede, y recibe apoyo de la Universidad Autónoma de Occidente. Cuenta con un portal que busca llegar a todos los rincones del mundo. Emite por Telepacífico y cubre toda la región. 


\section{ANEXO 4. \\ GARACTERIZAGIÓN DE LOS MEDIOS DIGITALES QUE FORMAN PARTE DE LA MUESTRA}

\section{El Blog del Ministro}

www.elblogdelministro.com

Según definición que suministró Octavio Cardona (17 de mayo de 2013), director del medio, El Blog del Ministro es un medio no comercial, independiente, referido a temas de la política local, tratados de manera creativa y acercándose a las fuentes de primera mano. Nació en 2009 y provee información que trata de ir más allá del acontecimiento mediático del día e intenta ser incisivo y generar movimiento de la opinión pública local.

Según comentaron otros periodistas de la región, El Blog del Ministro es punto de referencia para muchos periodistas y políticos, pues debido a las fuentes casi personales que maneja su director, puede tener acceso a otro tipo de informaciones que los medios más grandes no alcanzan a registrar. El medio no tiene sede propia y su centro de trabajo es la ciudad de Pereira.

\section{El Faro}

www.elfaro.net

Es un medio nativo digital independiente, financiado por cooperación internacional. Se le considera el primer periódico nativo digital de América Latina. Trabaja desde 1998. Su principal objetivo es defender un periodismo independiente y crítico de los gobiernos de turno de El Salvador. Es un medio digital que sirve de ejemplo de manejo administrativo, no tiene filiación ideológica.

\section{Revista Gobierno}

www.revistagobierno.com

Para Patricia Betancourt (15 de mayo de 2013) esta revista

Es un portal que nació hace cuatro años, desde la época en que surgió la idea (2009). Se quería tener un portal que mostrara los acontecimientos nacionales y la actividad del Congreso, ministerios y asambleas. Hemos visto que en muchos medios tradicionales reconocidos no hacen registro sobre los proyectos 
que tiene el Congreso, hay otros que quedan en el tintero [...] Finalmente son 257 congresistas. Hay mucho material para poderles mostrar a los colombianos y de otros países que se interesen por la política colombiana sobre lo que está pasando. También ofrecemos temas de economía, política mundial y cultura y salud.

Revista Gobierno no tiene sede física, sus miembros, unos quince, se reúnen de manera virtual para los consejos de redacción. La mayoría de estos periodistas se encuentra en la ciudad de Manizales. Al momento de realizar la visualización del portal para corroborar ciertas características, este estaba caído. Al momento de redactar este informe el portal del medio había sido eliminado o ya no estaba vigente.

\section{Poderopedia}

www.poderopedia.org

Portal independiente de información y formación en periodismo de investigación en bases de datos, principalmente. Tiene su base en Chile. Miguel Paz (2012) lo define en su la página web así:

Una plataforma colaborativa que ayuda a entender las relaciones entre las personas, empresas y organizaciones que se convierten en noticia e influyen en nuestra vida diaria. Usando visualizaciones de datos y tecnología semántica, muestra quién es quién en los negocios y la política.

También funciona como una base de datos de las relaciones y conexiones entre personas, empresas y organizaciones chilenas para hacer públicos todos los posibles conflictos de interés en la política y los negocios.

\section{Punto de Vista}

www.puntodevistardb.com

Medio que funciona desde 2008 en la web. Rubén Benjumea es quien hace las veces de director, periodista y administrador. El carácter del medio lo define como un difusor que cuenta lo que la prensa ortodoxa no registra:

Desde hace cinco años tomé la decisión de trabajar independiente, de no casarme con ninguna casa editorial, ni con ninguna casa periodística, debido a las limitantes que existen a la hora de escribir y de contar por lo menos una aproximación a la verdad verdadera, no lo puedo contar todo porque en esta tierra me pegan un tiro o porque me pueden amenazar o me pueden comercializar, fue 
como un aprender haciendo, me di cuenta de que hacer columnas de opinión para Internet no vende, a la audiencia no le importa lo que yo opine sino que me tocó empezar en la medida en que opinaba en esos artículos, incluyendo información inédita sobre el hacer periodístico. Cuando yo empecé a escribir en Internet sentí una anarquía, una libertad impresionante por escribir, que lo que radica es la exigencia que aplico como profesional para poder llegar a algo, no pretendo inventar nada novedoso, lo único que hice fue coger un blog y escribir lo que pasa en esta ciudad (Benjumea, 16 de abril de 2013).

\title{
La Silla Vacía
}

\author{
www.lasillavacia.com
}

Es un medio digital especializado en política colombiana y con sede en Bogotá. Fue fundado en abril de 2009. Su directora Juanita León lo entiende como un medio independiente que no se ocupa de las noticias del día a día, sino que cuenta la historia detrás de la noticia. Esto es, contexto, trasfondo y algo de análisis. Los que trabajan en este medio no son necesariamente periodistas, son politólogos. Así se definen en su portal:

La Silla Vacía es un medio informativo e interactivo para las personas interesadas en la actualidad política colombiana. Más que cubrir la noticia del día y acudir a ruedas de prensa, nos centramos en aquellas historias que realmente describen cómo se ejerce el poder en Colombia: en los personajes que mueven los hilos del poder, en las estrategias para alcanzarlo y mantenerlo, en las ideas e intereses que subyacen las grandes decisiones del país (León, s. f.).

\section{El Turbión}

www.elturbion.com

Su director Omar Vera (21 de junio de 2013) lo define como:

Un medio alternativo, independiente, que utiliza Internet como una plataforma de distribución de datos, de mensajes. El objetivo que tuvimos al construir nuestra línea editorial fue tratar de visibilizar y registrar la actualidad y la realidad de la situación de derechos humanos en Colombia, pero por el camino nos fuimos dando cuenta de que eso estaba muy ligado con la movilización social en general, con organizaciones sindicales, estudiantiles, indígenas, campesinas, de mujeres, y esos han sido como los dos pies fuertes del periódico, pero hay otras áreas que manejamos, una de esas es política, economía, cultura, ahora estamos trabajando el tema de tecnologías libres.

El Turbión se encuentra en Bogotá y cuenta con una red de colaboradores. 


\section{Zonacero}

www.zonacero.com

Es un reconocido medio digital de la ciudad de Barranquilla, que "pese al modesto espacio físico que ocupa en una oficina de un exclusivo barrio de la ciudad, logra movilizar la opinión pública y se ha convertido en punto de referencia informativo" (Puerta, 16 de noviembre de 2012).

Zonacero se fundó en 2009, es considerado uno de los portales más leídos de la ciudad. Cuenta con cinco periodistas multimedia y multiformato que se ocupan también de alimentar redes como Twitter y Facebook con información actualizada de las noticias que cubren. También tiene una emisora de radio que enlaza el noticiero de la mañana con una estación local. 



\section{REFERENCIAS}

Acosta, R. A. (2013). Producción y circulación de la noticia: el newsmaking. Chasqui, 123, 64-75.

Anderson, C. W., Bell, E. \& Shirky, C. (2013). Periodismo postindustrial, adaptación al presente. Huesca: eCícero. Recuperado de http://www.clasesdeperiodismo.com/2013/03/21/descarga-el-ebook-periodismo-postindustrial-adaptacion-al-presente

Asociación Española de Responsables de Comunidad Online y Territorio Creativo. [AERCO]. (2009). ¿Qué es un community manager? Recuperado de http://www.aercomunidad.org/ nuestros-socios/

Bezunartea, O., Canga, J., Coca, C., Diezhandino, M. P., Irirarte, I., Legarda, J. M. \& Urrutia, V. (1988). La prensa ante el cambio de siglo. Bilbao: Ediciones Deusto.

Borga, J. (2013). La WebTV como molalidad de Televisión 3.0: ¡El embrión de la verdadera televisión interactiva? III Congreso Internacional Comunicación 3.0, Salamanca, 10 y 11 octubre de 2012.

Borrat, H. (1993). Hacia una teoría de la especialización periodística. Anàlisi, 15, 79-84. Recuperado de http://ddd. uab.cat/pub/analisi/02112175n15p79.pdf

Calderón, L. (2013). 12 oficinas inspiradoras que las redacciones pueden imitar. Recuperado de http:// www.clasesdeperiodismo.com/2013/06/25/12-oficinasinspiradoras-que-las-redacciones-pueden-imitar

Canavilhas, J. (2012). Contenidos periodísticos en el ecosistema líquido: entre la convergencia y la divergencia. En: F. Irigaray, D. Ceballos \& M. Manna (Eds.). Webperiodismo en un ecosistema líquido. Rosario: Laborde Libros Editor. 
Cardeñoso, L. \& Ortega, F. (Eds.). (2012). Las media enterprises y las industrias culturales. Salamanca: Universidad de Salamanca.

Cardoso, G. (2011). El nacimiento de la comunicación en red. Más allá de Internet y de los medios de comunicación de masas. Telos: Revista de Pensamiento sobre Tecnología y Sociedad, 86, 14-22. Recuperado de http://dialnet.unirioja.es/servlet/ articulo?codigo $=3431182$

Castells, M. (1997). La era de la información. México, D. F.: Siglo Veintiuno Editores.

Castells, M. (2009). Comunicación y poder. Madrid: Alianza Editorial.

Collier, J. \& Collier, M. (1986). Visual anthropology, photography as a research method. Nuevo México: University of New Mexico Press.

Debray, R. (1991). Cours de médiologie général. París: Gallimard.

Debray, R. (1995). El Estado seductor, las revoluciones mediológicas del poder. Buenos Aires: Manantial.

Debray, R. (1998). Vida y muerte de la imagen. Historia de la mirada en Occidente. Barcelona: Paidós.

Debray, R. (2000). Introducción a la mediología. Barcelona: Paidós.

Déreze, G. (2009). Méthodes empiriques de recherché en communication. Bruselas: De Boeck.

De Alzaga, P. (2012). La prensa ante el riesgo de repetir su historia. Cuadernos de Comunicación Evoca, 8, pp. 5-10.

De Moragas, M. (1994). Sociología de la comunicación de masas II: estructura, funciones y efectos. México: Gustavo Gili.

Edo, C. (2002). Del papel a la pantalla, la prensa en Internet. Sevilla: Comunicación Social.

Edo, C. (2007). El lenguaje y los géneros periodísticos en la narrativa digital. IO formato da noticia, a linguagem e os gêneros 5, 7 .

Edo, C. (2009). Periodismo informativo e interpretativo. El impacto de Internet en la noticia, las fuentes y los géneros. Sevilla: Alfaomega.

Esteinou, J. (2002). Los medios de comunicación como instrumentos del desarrollo. Razón y Palabra, 29, Recuperado de http://www.razonypalabra.org.mx/ anteriores/n29/jesteinou.html

Fernández del Moral, J. \& Estévez, F. (1996). Fundamentos de la información Periodística especializada. Madrid: Editorial Síntesis.

Fernández, J., Llano, R., Losada, Á., Álvarez, L., Del Pozo, M., Blanco, E. \& Muñoz, A. (2004). Periodismo especializado. Barcelona: Ariel. 
Foucault, M. V. (1975). Vigilar y Castigar, México: Siglo XXI.

García, E. (2012). Cartografia del periodismo participativo. Estudio de las herramientas de participación en la prensa digital de Argentina, Colombia, España, Estados Unidos, Israel, México, Perú, Portugaly Venezuela. Valencia: Tirant Humanidades. Recuperado de http://periodismoyotrasyerbas.blogspot.com/2012/02/cartografia-del-periodismo.html

García Avilés, J. A. (2009). La comunicación ante la convergencia digital: algunas fortalezas y debilidades. Signo y pensamiento, 28(54), 102-113.

García, X. L. (Ed.). (2010). Convergencia digital: reconfiguración de los medios de comunicación en España. Santiago de Compostela: Universidad Santiago de Compostela. Recuperado de http://books.google.es/books?hl=es\&lr=\&id=tlQp5XTVcEk$\mathrm{C} \&$ oi $=$ fnd\&pg $=$ PA9\&dq

Gomis, L. (1991). Teoría del periodismo, cómo se forma el presente. Barcelona: Paidós.

Gordillo, M., Curiel, C. P., \& Rey, A. R. (2011). Periodismo de calidad y nuevas formas de periodismo en red. Hacia una definición de conceptos. En: La investigación en periodismo digital: algunos trabajos desde el ámbito universitario (pp. 319335). Aragón: Asociación de Periodistas de Aragón. Congreso de Periodismo Digital (12. 2011. Huesca)

Hernández, E. \& Espada, A. (Eds.). (2009). El fin de los periódicos. Barcelona: Duomo Ediciones.

Herrera, E. (2006). Rutinas de producción noticiosa del sistema informativo de Caracol Radio (Bogotá) bajo las dinámicas empresariales del grupo español Prisa. Tesis de maestría. Bogotá: Pontificia Universidad Javeriana.

Hora 13 Noticias. (s. f.). Recuperado de https://www.facebook.com/noticiashora13/ info

Horkheimer, M. \& Adorno, T. W. (1967). Dialéctica del iluminismo. Buenos Aires: Sur.

Howard, T. (2000) Entrevistado por Gómez, J. El Pais. Recuperado de: http://elpais. com/diario/2000/07/25/sociedad/964476017_850215.html

Jaimes, J. (1989). Historia del periodismo político en Colombia. Bogotá: Italgraf.

Jouve, V. (1992). L'effet-personnage dans le roman. Presses universitaires de France.

Kapuściński, R. (2003). Los cinco sentidos del periodista. (Estar, ver, oir, compartir y pensar). México D. F.: Fondo de Cultura Económica; Fundación para un Nuevo Periodismo Iberoamericano; Fundación Proa.

Katz, E., Blumler, J. G., \& Gurevitch, M. (1985). Usos y gratificaciones de la comunicación de masas. Sociología de la comunicación de masas. M. De 
Moragas. Sociología de la comunicación de masas II. Estructura, funciones y efectos, Barcelona: Gustavo Gili

Lasswell, H. (1985). Estructura y función de la comunicación de masas. M. de Moragas: Sociología de la comunicación de masas II. Estructura, funciones y efectos. Barcelona: Gustavo Gili.

Las tareas de un community manager en la redacción. (2013). Clasesdeperiodismo.com [sitio web]. Recuperado de http://www.clasesdeperiodismo.com/2013/09/08/lastareas-de-un-community-manager-en-la-redaccion/

Lévy, P. (2007). Cibercultura. México D. F.: Anthropos. Recuperado de http://api. ning.com/files/dR261CiX6Ej1UmSVtj1Qw9UvQlxgFXGXAUz9fUVclocygh1

WdsB9w8lbuWbUDbnD73S07wODeXavupVm5piQW20y8RQK2L7r/ LevyCibercultura.pdf

Lévy, P. (2009). Mutation inachevée de la sphére publique. Revista Signo y Pensamiento, $28(54), 36-43$.

Lipovetsky, G. (1994). El crepúsculo del deber. La ética inodora de los nuevos tiempos democráticos. Barcelona: Anagrama.

Lipovetsky, G. \& Serroy, J. (2009). La pantalla global. Cultura mediática y cine, en la era hipermoderna. Barcelona: Anagrama.

Lippmann, W. (2003). La opinión pública, Madrid: Langre.

Luhmann, N. (2000). La realidad de los medios de comunicación de masas.Barcelona, Antrhopos.

Marcuse, H. (1954). El hombre unidimensional, ensayo sobre la ideología de la sociedad industrial avanzada. Barcelona: Planeta DeAgostini.

Martini, S. \& Luchessi, L. (2004). Los que hacen la noticia, periodismo, información y poder. Buenos Aires: Biblos.

Mattelart, A., Delcourt, X. \& Mattelart, M. (1984). La culture contre la démocratie? París: La Découverte.

Merzeau, L. (1998). Ceci ne tuera pas cela. París: Gallimard. Recuperado de http:// mediologie.org/cahiers-de-ediologie/06_mediologues/merzeau.pdf

Morin, E. (2011). La vía para el futuro de la humanidad. Barcelona: Paidós.

Muñoz, J. (1997). Aproximación al concepto de Información Periodística Especializada. En Estudios sobre información periodística Especializada, Fundación San Pablo C.E.U. Valencia.

Noticiero 90 Minutos. (s. f.) Recuperado de http://www.telepacifico.com/noticiero90-minutos 
Ong, W.J. (1987). Oralidad y escritura. Bogotá: Fondo de Cultura Económica.

Orive, P., \& Fagoaga, G. (1974). La especialización en el periodismo. Madrid.

Ponte, D. (3 de noviembre de 2010). Community manager, ¿una profesión con fecha de caducidad? Recuperado de: http://www.marketingdirecto.com/punto-de-vista/ la-columna/community-manager-una-profesion-con-fecha-de-caducidad-3/

Quesada, M., (2001): "Periodismo Especializado", en Galdón, G. (coord) (2001): Introducción a la comunicación y a la información. Barcelona: Ariel.

Ramírez, F. E. \& Hernández, J. C. N. (Eds.). (2014). Nuevos retos del periodismo especializado (Vol. 1). Recuperado de http://books.google.com.co/books?id=roeaAwAAQBAJ\&pg=PT123\&lpg=PT123\&dq三

Ramonet, I. (1998). La tiranía de la comunicación. Madrid: Debate.

Ramonet, I. (2011). La explosión del periodismo. Internet pone en jaque a los medios tradicionales. Bogotá: Le Monde Diplomatique.

Renucci, F. \& Belin, O. (2010). Manuel infocom. Information, communication, médiologie. Recuperado de http://www.cafepedagogique.net/lemensuel/lenseignant/ documentation/Pages/2011/120_CDI_Lectures.aspx

Restrepo, J. D. (2004). El zumbido y el moscardón: taller y consultorio de ética periodística. México D. F.: Fondo de Cultura Económica.

Revista Fase 4. (s. f.). Quiénes somos. Disponible en: http://fase4.co/quienes-somos/, recuperado el 23 de agosto de 2013.

Reyes, A. (6 de agosto de 2013). La venta del Washington Post desde los ojos de sus célebres periodistas. Clasesdeperiodismo.com. Recuperado de http://www. clasesdeperiodismo.com/2013/08/06/la-venta-del-washington-post-desde-losojos-de-sus-celebres-periodistas

Romero, P. (2012). Los problemas de la inmediatez "hemos matado a Steve Jobs". Cuadernos de Comunicación Evoca, 8, 11-16.

Rost, A. (2001). Pero, ¿de qué hablamos cuando hablamos de interactividad?. Center for Civic Journalism, 2.

Rost, A. (2004). Pero, ¿de qué hablamos cuando hablamos de interactividad?. Congresos Alaic/Ibercom. La Plata 12 all 15 de octubre. Recuperado de: http://es.slideshare.net/catamora3/rost-alejandro-de-que-hablamos-cuandohablamos-de-interactividad

Sabésturno, F. \& Verón, J. (2013) Comunicación y la red. Nuevas formas de periodismo. Aragón: Asociación de Periodistas de Aragón. Recuperado de http:// decimocuarto.congresoperiodismo.com/pdf/libro2013.pdf 
Sáenz, J. (2012). Girculación, fluidez y libertad. Revista Análisis, 81, 87-115.

Salaverría, R. (2009). Los medios de comunicación ante la convergencia digital. Recuperado de http://dspace.unav.es/dspace/handle/10171/5099

Salaverría, R., \& García-Avilés, J. A. (2008). La convergencia tecnológica en los medios de comunicación: retos para el periodismo.

Santos, A. (2013). Cómo hacer buen periodismo en medio de la crisis económica, conflicto armado y era digital. Conferencia Inauguración Semana de la Comunicación. Bogotá: Universidad Sergio Arboleda.

Scolari, C. (2008). Hipermediaciones. Elementos para una teoría de la comunicación digital interactiva. Barcelona: Gedisa.

Soto, G. (1993). La nueva Edad Media. Ciencias Humanas, 18, 83-106.

Steinberg, C. \& Bluem, A. (1966). Los medios de comunicación social. México D. F.: Roble.

Tascón, M. (2012). ¿Sueñan los periodistas con algoritmos? Cuadernos de Comunicación Evoca, 8, 23-28.

Valle, S., Gomes, F., Fernández, D., García, J.M. (2012). Redacción digital en el aula. En: L. Cardeñoso \& F. Ortega (Eds.). Las media enterprises y las industrias culturales. Salamanca: Universidad de Salamanca.

Vargas, E. (2013). Las tareas de un Community Manager en la redacción. Recuperado de: http://www.clasesdeperiodismo.com/2013/09/08/las-tareasde-un-community-manager-en-la-redaccion/

Winkin, Y. (1967). La nouvelle communication. París: Seul.

Wright, C., (1985). Análisis funcional y comunicación de masas. M. de Moragas: Sociología de la comunicación de masas II. Estructura, funciones y efectos. Barcelona: Gustavo Gili. 


\section{Serie Investigación}

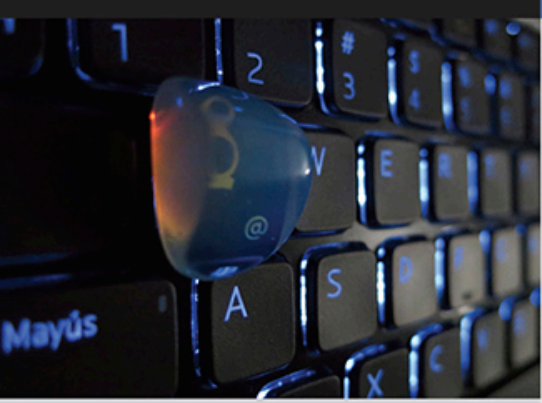

Periodismo ESPECIALIZAdo

EN POLÍTICA Y ECONOMÍA

Colombia

ENTRE CRUCES DIGITALES

En los últimos años el debate en torno al presente y futuro del periodismo ha estado en el centro de las reflexiones académicas, de las discusiones de pasillo y de las decisiones empresariales. La llegada de los entornos digitales ha incorporado una variable más que increpa al oficio desde su profesionalismo.

El texto presenta un conjunto nutrido de reflexiones sobre los efectos de la Internet sobre el periodismo, efectos que según el autor aún no están suficientemente configurados. Lo mejor está aún por verse.

La mediología fue la disciplina desde la cual se llevó a cabo la aproximación para este estudio. De origen francés, la mediología desea sacar a la luz los entrecruces entre tecnología y los amplios contextos sociales de cada momento histórico.

Entrevistando a casi 50 periodistas de diferentes medios de comunicación del país, el texto logra encontrar las tendencias del periodismo político y económico en lo que el autor denomina su "estado digital".

\section{UNIVERSIDAD SERGIO ARBOLEDA}

Calle 18 No. 14A-18. Tels: (575) 4203838 - 420 2651. Santa Marta Carrera 15 No. 74-40. Tels: (571) 3257500 ext. 2131 - 322 0538. Bogotá, D.C. 